\title{
Field Performance Assessment of Press-Brake-Formed Steel Tub Girder Superstructures
}

Cory L. Gibbs

Follow this and additional works at: https://researchrepository.wvu.edu/etd

\section{Recommended Citation}

Gibbs, Cory L., "Field Performance Assessment of Press-Brake-Formed Steel Tub Girder Superstructures" (2017). Graduate Theses, Dissertations, and Problem Reports. 5671.

https://researchrepository.wvu.edu/etd/5671

This Thesis is protected by copyright and/or related rights. It has been brought to you by the The Research Repository @ WVU with permission from the rights-holder(s). You are free to use this Thesis in any way that is permitted by the copyright and related rights legislation that applies to your use. For other uses you must obtain permission from the rights-holder(s) directly, unless additional rights are indicated by a Creative Commons license in the record and/ or on the work itself. This Thesis has been accepted for inclusion in WVU Graduate Theses, Dissertations, and Problem Reports collection by an authorized administrator of The Research Repository @ WVU. For more information, please contact researchrepository@mail.wvu.edu. 


\title{
Field Performance Assessment of Press-Brake-Formed STEEL TUB Girder SUPERSTRUCTURES
}

\author{
Cory L. Gibbs \\ Thesis submitted to the \\ Benjamin M. Statler College of Engineering and Mineral Resources \\ at West Virginia University \\ in partial fulfillment of the requirements \\ for the degree of
}

Master of Science

in

Civil and Environmental Engineering

Karl E. Barth, Ph.D., Chair

Gregory K. Michaelson, Ph.D.

Roger H. L. Chen, Ph.D

Department of Civil and Environmental Engineering

Morgantown, West Virginia

2017

Keywords: steel bridge, press-brake-formed steel tub girders, experimental testing, finite element analysis

Copyright 2017 Cory L. Gibbs 


\begin{abstract}
Field Performance AsSessment of

Press-Brake-Formed Steel Tub Girder Superstructures
\end{abstract}

\author{
Cory L. Gibbs
}

The Short Span Steel Bridge Alliance (SSSBA) is a group of bridge and culvert industry leaders (including steel manufacturers, fabricators, service centers, coaters, researchers, and representatives of related associations and government organizations) who have joined together to provide educational information on the design and construction of short span steel bridges in installations up to 140 feet in length. One concept developed by the SSSBA, shallow press-brakeformed steel tub girders, has emerged as a particularly advantageous solution for using steel in the short span bridge market.

After several years of lab testing at West Virginia University, members of the SSSBA collaborated with County Engineer Brian Keierleber, P.E., to arrange the construction of the Amish Sawmill Bridge in Buchanan County, Iowa. The Amish Sawmill Bridge is the first bridge designed, constructed, and opened to traffic using the press-brake-formed steel tub girder concept. Upon the completion of this bridge, researchers from West Virginia University and Marshall University traveled to Iowa to perform a live load field test.

This thesis presents the results and assessment from experimental and analytical testing of the Amish Sawmill Bridge. Furthermore, an overview of both the experimental and analytical testing programs is provided. This thesis also compares live load distribution factors (LLDFs) calculated using AASHTO specifications to the LLDFs calculated from experimental and analytical testing results. Based on testing results, shallow press-brake-formed steel tub girders are both a practical and economic solution for using steel in the short span bridge market. The tub girders not only exhibit excellent performance in the field, but can also be utilized with various deck designs to create a modular unit that greatly reduces construction time. With Accelerated Bridge Construction $(\mathrm{ABC})$ becoming more popular and necessary in the bridge construction industry, shallow press-brake-formed steel tub girders are a proven solution for short span bridge applications. 


\section{ACKNOWLEDGMENTS}

I would like to thank the American Iron and Steel Institute's Short Span Steel Bridge Alliance for providing funding necessary to perform the research that this thesis is based on. I would also like to thank the Buchanan County (Iowa) Secondary Roads Department for providing the necessary access and equipment needed to perform the live load field test on the Amish Sawmill Bridge. Additionally, I would like to thank my advisor Dr. Karl Barth for his unending guidance and encouragement throughout my time at West Virginia University. The support and advice that Dr. Barth provided through both professional and personal challenges will always be remembered.

I would also like to thank Dr. Gregory Michaelson for his guidance throughout my undergraduate and graduate career. If not for Dr. Michaelson and his exceptional ability to teach and relate, I never would have developed an interest in structural engineering. I would additionally like to thank Dr. Roger Chen for serving on this thesis' graduate advisory committee.

Next, I would like to thank my fellow graduate students and friends that I have made while at West Virginia University. I never would have made it through graduate school if not for the invaluable friendships that I have made, and the comradery that those individuals established in my daily life. Specifically, I would like to thank Bryan Gallion, for helping me become accustomed to graduate student life, and Robert Tennant, for being an outstanding co-worker and working together on homework, lab work, and everything in between.

Finally, I would like to thank my family. I cannot express how grateful I am to have such a supportive and loving family. My grandparents, parents, and siblings have all supported me every step of the way, and I am forever grateful for their love, guidance, encouragement, and patience. I would not be where, or who, I am today without my family. 


\section{TABLE OF CONTENTS}

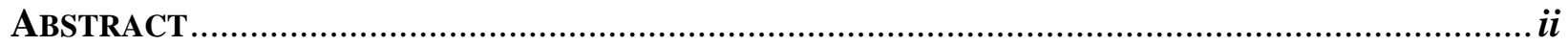

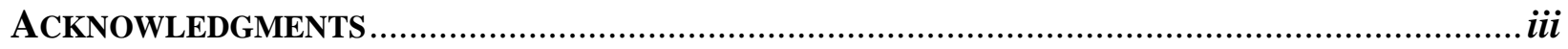

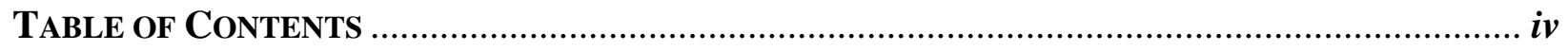

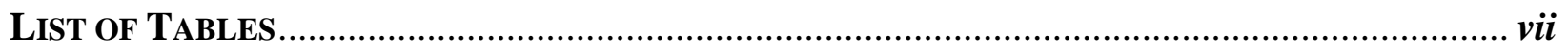

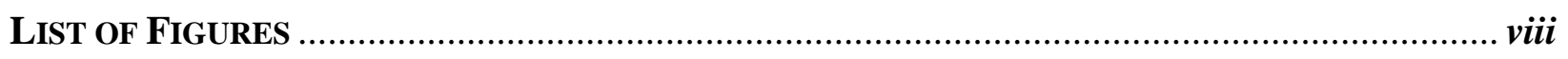

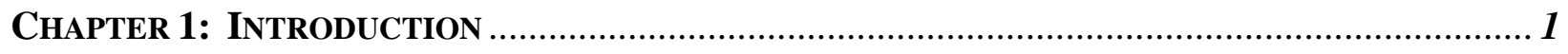

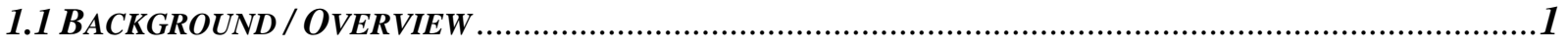

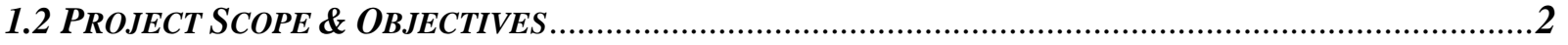

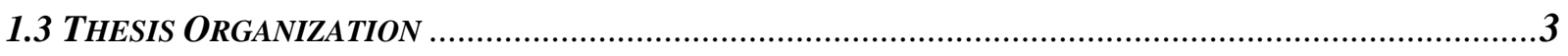

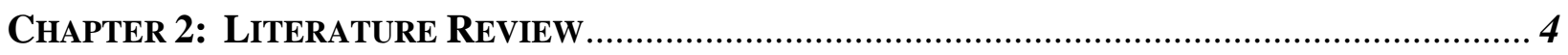

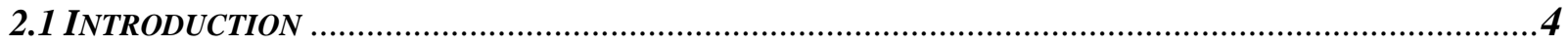

2.2 PREVIOUS APPLICATIONS OF COLD-BENT StEEL GIRDERS IN BRIDGE APPLICATIONS ...................4

2.2.1 Prefabricated Press-Formed Steel T-Box Girder Bridge System (Taly \& Gangarao, 1979) .....5

2.2.2 Composite Girders with Cold-Formed Steel U-sections (Nakamura, 2002) ...........................6

2.2.3 Folded Plate Girders (Developed at the University of Nebraska) ............................................7

2.2.4 Texas Department of Transportation Rapid Economical Bridge Replacement .........................7

2.3 PREVIOUS RESEARCH AT WVU ON PRESS-BRAKE-FoRMED STEEL TUB GIRDERS ........................8

2.3.1 Development and Feasibility Assessment (Michaelson, 2014) ..............................................9

2.3.2 Evaluation of Non-Composite Tub Girders (Kelly, 2014) ....................................................12

2.3.3 Evaluation of Modular Tub Girders with UHPC Joints (Kozhokin, 2016) ............................13

2.4 FHWA'S INNOVATIVE BRIDGE RESEARCH AND DEPLOYMENT PROGRAM ................................15

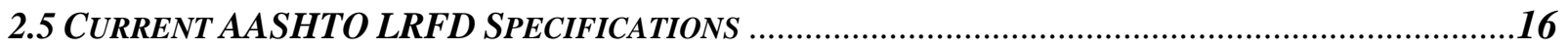

2.5.1 AASHTO Specifications for Box-Section Flexural Members (Tub Girders)...........................16

2.5.1.1 Cross-Section Proportion Limits...................................................................................

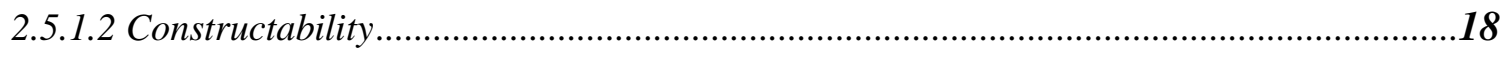

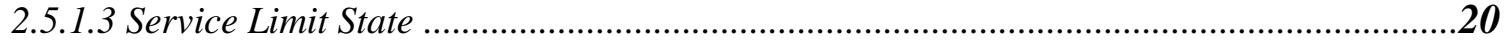




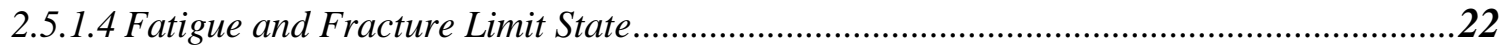

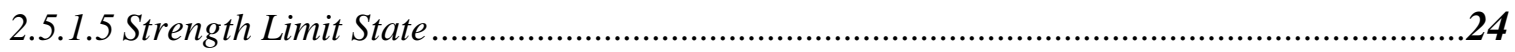

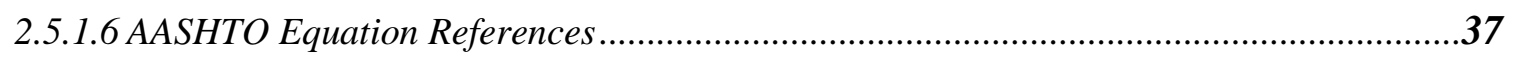

2.5.2 AASHTO Live Load Distribution Factors $(L L D F s)$...............................................................39

Chapter 3: Design And Construction of The Amish SAWmill Bridge ....................... 42

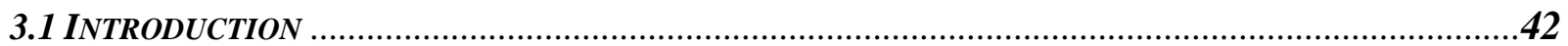

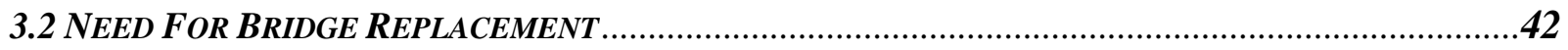

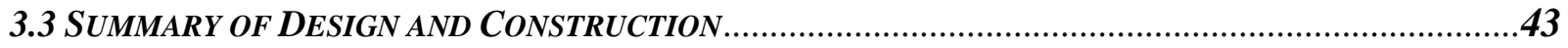

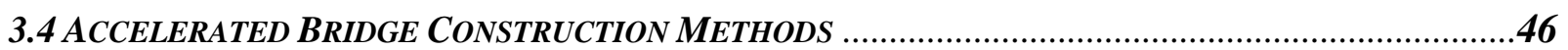

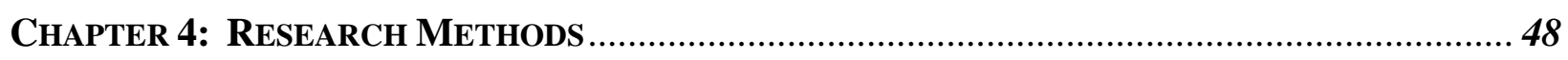

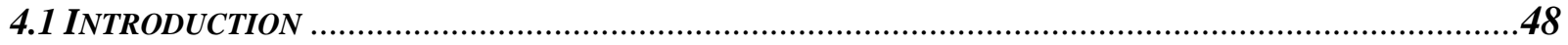

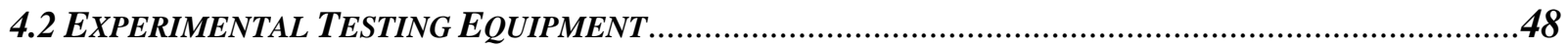

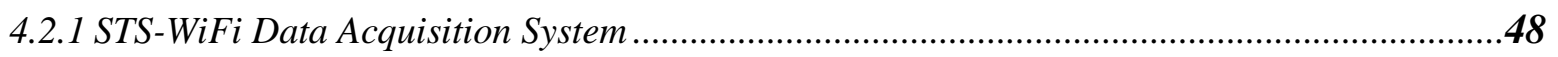

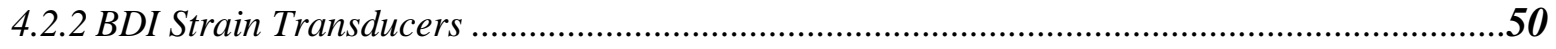

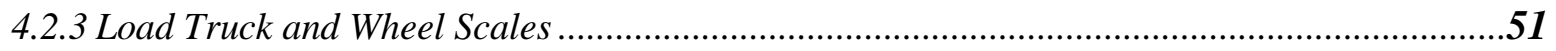

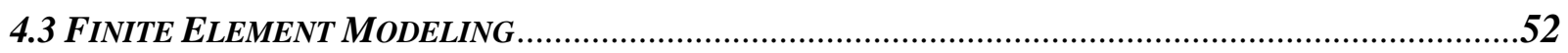

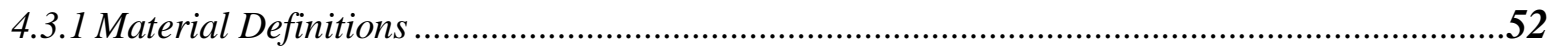

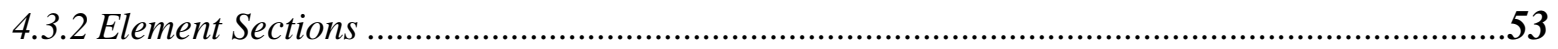

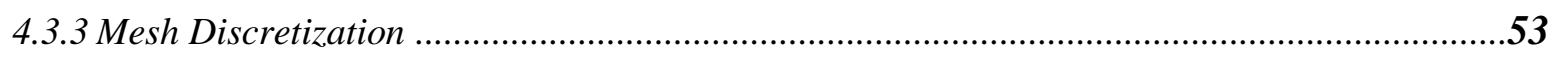

4.3.4 Boundary Conditions and Multiple-Point Constraints ..........................................................54

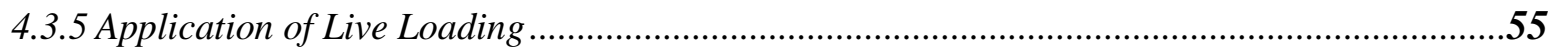

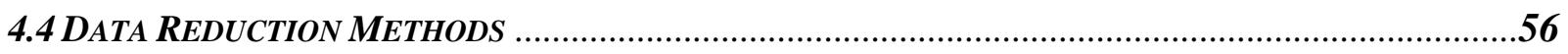

4.4.1 Computation of Midspan Bending Stresses...........................................................................57

4.4.2 Computation of Live Load Distribution Factors ...................................................................58

Chapter 5: Field Testing of The Amish SAWmill Bridge......................................... 62

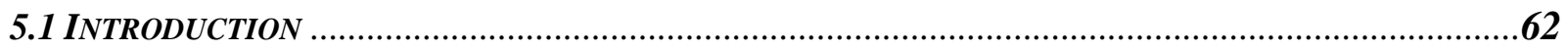

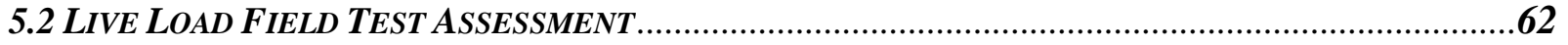

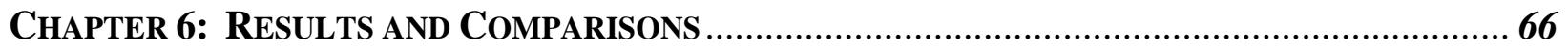

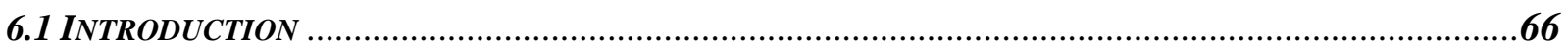

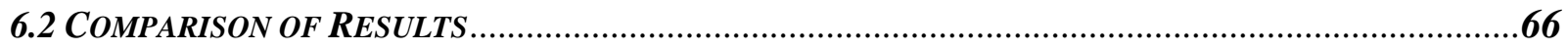




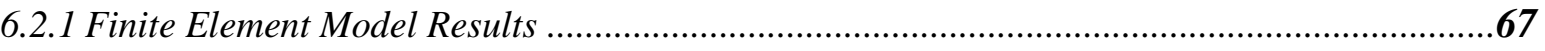

6.2.2 Live Load Field Test Results ...................................................................................................69

6.2.3 Comparison of Analytical vs. Experimental Results ...........................................................71

6.3 COMPARISON OF LLDFS TO AASHTO SPECIFICATIONS ............................................... 78

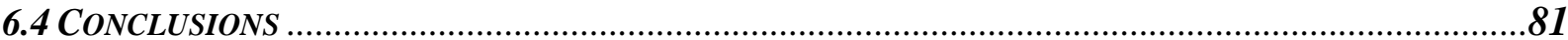

CHAPTER 7: SUMmary AND CONCLUDING REMARKS....................................................... 82

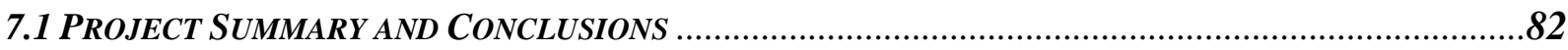

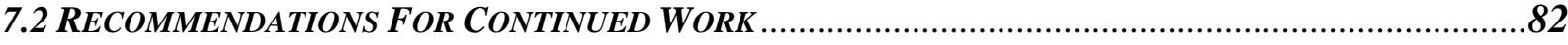

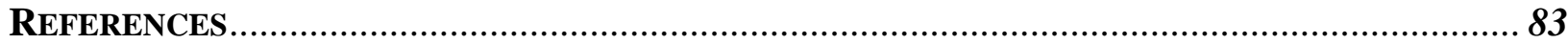

APPENDIX A: RESUlts FOR All Truck RUNS ........................................................... 85

Appendix B: Amish SAWmill Bridge Plans ......................................................... 112 


\section{LIST OF TABLES}

Table 2.1: Summary of Distribution Factors (Kozhokin, 2016) ............................................. 15

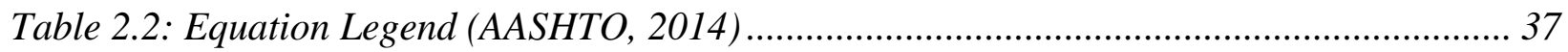

Table 2.3: Multiple Presence Factors (AASHTO, 2014)...................................................... 41

Table 6.1: Finite Element Model Bottom Flange Stress Results ........................................... 67

Table 6.2: Finite Element Model Distribution Factor Results ................................................ 68

Table 6.3: Live Load Field Test Bottom Flange Stress Results .............................................. 70

Table 6.4: Live Load Field Test Distribution Factor Results ............................................... 71

Table 6.5: Comparison of FEA vs. Experimental Bottom Flange Bending Stress ..................... 72

Table 6.6: Comparison of FEA vs. Experimental Distribution Factors.................................... 72

Table 6.7: FEA vs. Experimental vs. AASHTO LLDFs for Truck Run 2 ................................ 79

Table 6.8: FEA vs. Experimental vs. AASHTO LLDFs for Truck Runs 1 \& 4 ......................... 80 


\section{LIST OF FigURES}

Figure 2.1: Taly and Gangarao's Proposed Bridge System (Taly \& Gangarao, 1979) ............... 5

Figure 2.2: System Proposed at the University of Nebraska, Lincoln (Burner, 2010)................. 7

Figure 2.3: TxDOT Tub Girder for Rapid Bridge Replacement (Chandar et. al., 2010).............. 8

Figure 2.4: Press-Brake-Formed Steel Tub Girder System (Michaelson, 2014) ........................ 9

Figure 2.5: Typical Failure Mode for Non-composite Specimens (Michaelson, 2014) .............. 10

Figure 2.6: Typical Failure Mode for Composite Specimens (Michaelson, 2014) .................... 11

Figure 2.7: Load-Deflection Results at Midspan (Kelly, 2014) .............................................. 13

Figure 2.8: UHPC Joint Trapezoidal Shear-Key Detail (Kozhokin, 2016) ............................. 14

Figure 2.9: Center-to-Center Flange Distance (AASHTO, 2014)........................................... 40

Figure 3.1: Existing Amish Sawmill Bridge, Constructed in 1966........................................... 43

Figure 3.2: General Photo of the New Amish Sawmill Bridge ................................................ 44

Figure 3.3: Dimensional Cross-Section of Single Girder ...................................................... 45

Figure 3.4: General Cross-Section of Amish Sawmill Bridge ................................................. 45

Figure 3.5: Modular SPS Deck/Tub Girder System in Muskingum County, OH ..................... 47

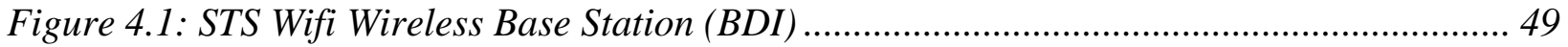

Figure 4.2: STS WiFi Wireless 4-Channel Node (BDI)...................................................... 50

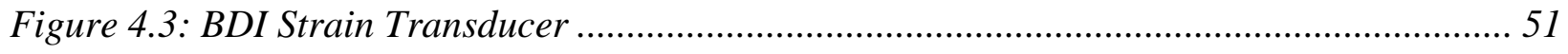

Figure 4.4: Tandem-Axle Dump Truck .................................................................................. 51

Figure 4.5: Standard Mesh Seeding for Each Tub Girder ................................................... 54

Figure 4.6: Schematic of Nodal Distribution of Point Loads (Michaelson, 2010)..................... 55

Figure 5.1: Gage Locations on Each Girder (Looking North) ............................................... 63

Figure 5.2: Tandem-Axle Dump Truck .......................................................................... 63

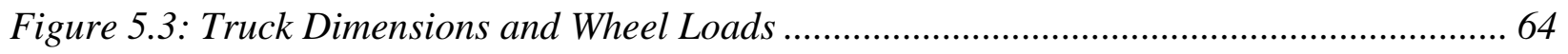

Figure 5.4: Live Load Truck Placements (Looking North) ................................................... 65

Figure 6.1: Deflected Shape of Abaqus Model - Truck Run 2, Panel Point 5.......................... 69

Figure 6.2: FEA vs. Experimental Bottom Flange Bending Stress for Girder 1, Truck Run 2 .... 73

Figure 6.3: FEA vs. Experimental Bottom Flange Bending Stress for Girder 3, Truck Run 2 .... 74

Figure 6.4: Comparison of FEA vs. Experimental Distribution Factors for Truck Run 2.......... 75 
Figure 6.5: FEA vs. Experimental Average Distribution Factors for Truck Run 2 ................... 75

Figure 6.6: FEA vs. Experimental Average Distribution Factors for Truck Run 3 .................. 76 Figure 6.7: Comparison of FEA vs. Experimental Bottom Flange Bending Stress for Combined Loading Scenario of Truck Runs 1 and 4 for (a): Girder 1 and (b): Girder 4 .......................... 77 Figure 6.8: Comparison of FEA vs. Experimental Average Distribution Factors for All Single and

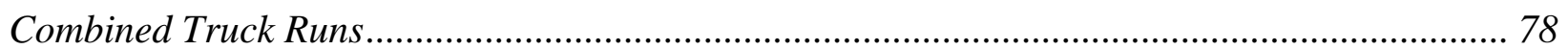

Figure 6.9: FEA vs. Experimental vs. AASHTO LLDFs for Truck Run 2 ............................... 79

Figure 6.10: FEA vs. Experimental vs. AASHTO LLDFs for Truck Runs 1 \& 4 ..................... 80 


\section{CHAPTER 1: INTRODUCTION}

\subsection{BACKGROUND / OVERVIEW}

The concept of shallow press-brake-formed steel tub girders was developed by members within the technical working group of the Short Span Steel Bridge Alliance (SSSBA). The SSSBA is a group of bridge and culvert industry leaders (including steel manufacturers, fabricators, service centers, coaters, researchers, and representatives of related associations and government organizations) who have joined together to provide educational information on the design and construction of short span steel bridges in installations up to 140 feet in length. Initial research on the topic of press-brake-formed steel tub girders began in October, 2011. After several years of lab testing at West Virginia University, members of the SSSBA collaborated with County Engineer Brian Keierleber, P.E., to arrange the construction of the first bridge that would utilize this technology in Buchanan County, Iowa. Upon the completion of this structure, the Amish Sawmill Bridge, researchers from West Virginia University and Marshall University traveled to Iowa to perform a live load field test.

Finite element modeling and analysis of the Amish Sawmill Bridge was completed so that analytical data could be compared to the experimental results obtained from the field test. Live load distribution factors (LLDFs) calculated from each of these two testing methods were also compared to LLDFs calculated using AASHTO specifications. The results from this research validate the performance of shallow press-brake-formed steel tub girders in short span bridge applications, and confirm that AASHTO specifications can safely be applied to the tub girders. 


\subsection{Project Scope \& OBJectives}

The scope of this thesis is to assess the performance of press-brake-formed steel tub girders in the field, and compare it to analytical testing completed through finite element modeling. Additionally, this thesis intends to show that AASHTO specifications may safely be applied to press-brake-formed steel tub girders. Specifically, this is accomplished in the following manner:

- A brief discussion of the AASHTO specifications for box section (tub girder) flexural members, as well as the computation of live load distribution factors (LLDFs).

- An overview of the design and construction of the Amish Sawmill Bridge, as well as various ways press-brake-formed steel tub girders may be used with accelerated bridge construction methods.

- An explanation of the research methods and field tests conducted on the Amish Sawmill Bridge. This includes a full description of the experimental investigation and testing procedures used in the field, as well as an in-depth look at the finite element modeling that was completed.

- Finally, a summary of results and conclusions comparing the experimental data to the analytical data, as well as a comparison of LLDFs calculated from the experimental and analytical data to LLDFs calculated using AASHTO specifications. 


\subsection{ThESIS ORganiZATION}

A brief overview of the organization of this thesis is as follows:

- Chapter 2:

- This chapter will provide a general overview of previous research on cold-bent tub girder applications at West Virginia University and elsewhere. Additionally, a summary of the Innovative Bridge Research and Deployment grant is provided, as well as a discussion of current AASHTO LRFD tub girder provisions.

- Chapter 3:

- This chapter briefly describes the design and construction of the Amish Sawmill Bridge. This includes a discussion of possible accelerated bridge construction methods that can be used to install press-brake-formed steel tub girders.

- Chapter 4:

- This chapter discusses the research methods which were employed during the testing procedures. The experimental testing equipment used in the field is described in detail, as well as methods used in the finite element analysis and data reduction.

- Chapter 5:

- This chapter describes the physical live load test performed on the Amish Sawmill Bridge.

- Chapter 6:

- This chapter discusses the results from both experimental and analytical testing, including a comparison of the two. Live load distribution factors (LLDFs) calculated using AASHTO specifications are also compared to the LLDFs obtained from both experimental and analytical results.

- Chapter 7:

- This chapter provides a summary of the scope of work conducted for this study and highlights the key findings. Lastly, this chapter provides suggestions for future efforts in this area. 


\section{CHAPTER 2: LITERATURE REVIEW}

\subsection{INTRODUCTION}

Presented in this chapter is a general overview of previous work conducted on cold-bent tub girders in bridge applications. All previous research performed at West Virginia University on this specific press-brake-formed steel tub girder design will be summarized, as well as a brief overview of research performed on cold-bent tub girder bridge applications elsewhere. Also, this chapter discusses the Federal Highway Administration's (FHWA) Innovative Bridge Research and Deployment (IBRD) program and its requirements which had to be met to receive the grant that helped fund the construction of the Amish Sawmill Bridge. Finally, a review of the current AASHTO LRFD Specifications applicable to steel tub girders and live load distribution factors (LLDFs) concludes this chapter.

\subsection{Previous Applications of Cold-Bent Steel Girders in Bridge Applications}

Although the increased efforts to discover a design solution to utilize steel in short-span bridge applications has increased the popularity of steel tub girders recently, the concept of using prefabricated steel tub girders is not brand new. Previous research has been conducted to try and utilize various tub and box girder designs in bridge applications. This section will provide a brief overview of several of these other designs and research efforts. 
Early development of similar systems was performed by Taly and Gangarao (1979). The design consists of a trapezoidal through section which is press-formed from 3/8-in. thick A36 steel. A prestressed concrete deck, embedded with a shear stud plate, is precast and then shop welded to the tub girder's flanges by way of the shear stud plate.

One major advantage of this design is the ability to be fabricated off-site in a shop, and then shipped to the bridge site due to its reduced size. The entire system, including the prestressed concrete deck, is only 6 feet wide, while the tub girder itself is only 3 feet wide. These modular units could then be placed alongside each other and joined with a longitudinal closure pour in order to construct bridges of varying width. The ends of each girder include bearing stiffeners and are closed off with a 3/8-in. thick steel diaphragm. The proposed design is shown below in Figure 2.1.

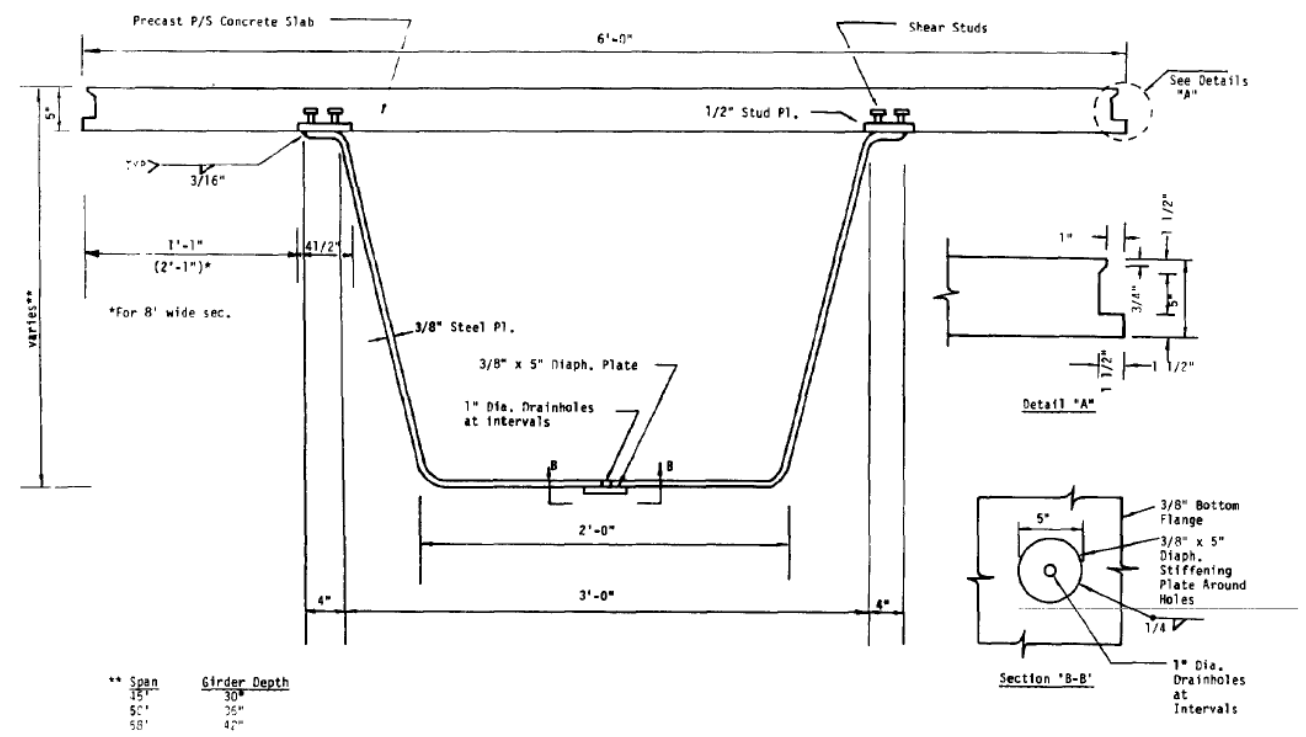

Figure 2.1: Taly and Gangarao's Proposed Bridge System (Taly \& Gangarao, 1979) 
The researchers ultimately found this design to be both economical and practical. The tub girder bridge system was conceived to be effective for spans of 40 to 100 feet. The most significant advantage of the system is that $95 \%$ of it can be fabricated off-site and then shipped to the bridge location. The bridge system is also very lightweight, enabling low capacity equipment to be used during the construction of the bridge. By using a press-brake to cold form the tub girders, fabrication costs are reduced significantly as compared to traditional fabrication processes for box girders.

\subsubsection{Composite Girders with Cold-Formed Steel U-sections (Nakamura, 2002)}

Nakamura (2002) also designed a bridge system that uses a press-brake to cold form steel tub girders. The primary difference between Nakamura's bridge system and other cold formed steel tub girder systems is that Nakamura intended for the system to be utilized in continuous, multiple span bridges. The system consists of twin tub girders supporting a prestressed concrete slab to form a composite modular unit. One issue with this system is the potential for buckling of the bottom flange at pier locations. Nakamura accounted for this in the design by filling the tub girders with concrete and using prestressed bars to generate increased strength against buckling at pier locations.

Testing performed on this bridge system included several experimental bending tests. The results from this testing demonstrated that the tub girder behaved as a composite beam at midspan and behaved as a prestressed beam at pier locations, with the prestressed concrete preventing local buckling of the bottom flange. While Nakamura's design lacks traditional practicality, it was determined to be a feasible option for various bridge applications. While the tub girders require more steel than traditional plate girders, the decreased fabrication costs offset the cost, resulting in a reasonably economical bridge system. 


\subsubsection{Folded Plate Girders (Developed at the University of Nebraska)}

Cold-bent steel tub girders have also been studied by researchers at the University of Nebraska, Lincoln. Researchers developed a composite steel girder system utilizing an inverted tub girder where the flanges are bent inwards (Burner, 2010; Glaser, 2010). The orientation of the girder in this system results in the top flange consisting of a much wider flange in the center of the girder, as opposed to two smaller exterior top flanges. Shear studs are welded to the top flange, and a reinforced concrete deck is cast directly on top. The proposed system is shown below in Figure 2.2. Advantages of this system include providing a safer work area during construction due to the wider flange, and allowing for easier maintenance and inspection as a result of the bottom being open.

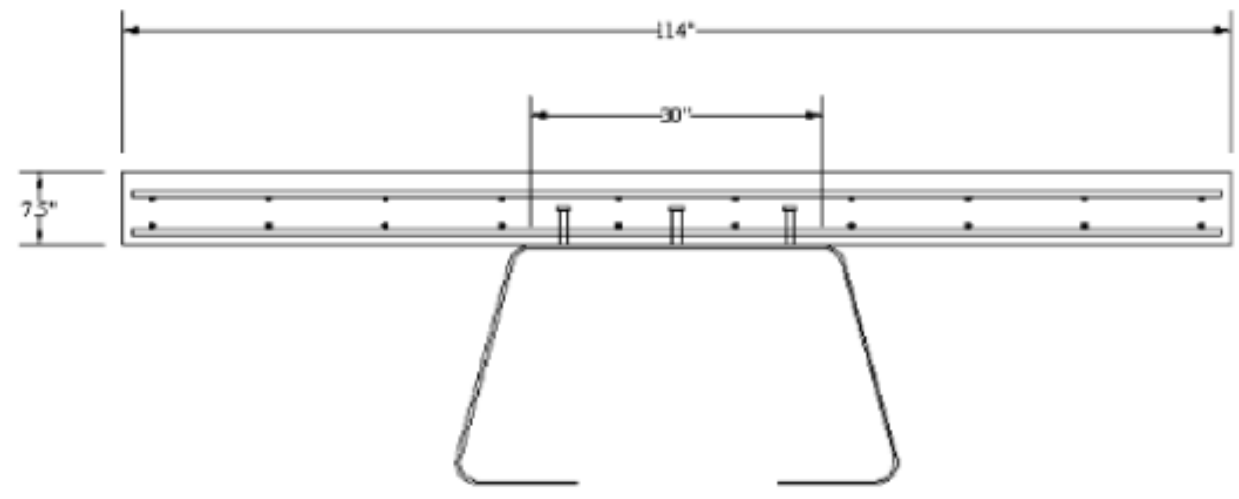

Figure 2.2: System Proposed at the University of Nebraska, Lincoln (Burner, 2010)

\subsubsection{Texas Department of Transportation Rapid Economical Bridge Replacement}

Texas Department of Transportation (TxDOT) developed a bridge system to create a shallower bridge superstructure utilizing shallow steel tub girders (Chandar et. al., 2010). The tub girder design consisted of a 5-foot-wide bottom flange width and a 3-foot-deep web as shown in Figure 2.3. Shear studs were welded to the top flanges, and a reinforced concrete deck 
was cast on top. This design was implemented in the construction of a bridge that was completed in August 2010. The bridge consisted of four simply supported spans of 45 feet, 100 feet, 100 feet, and 65 feet, respectively. Six tub girders were utilized since the total width of the bridge was 78 feet. Although this system was used in an actual bridge application, it should be noted that the bridge employed conventionally fabricated steel tub girders as opposed to coldbent tub girders.

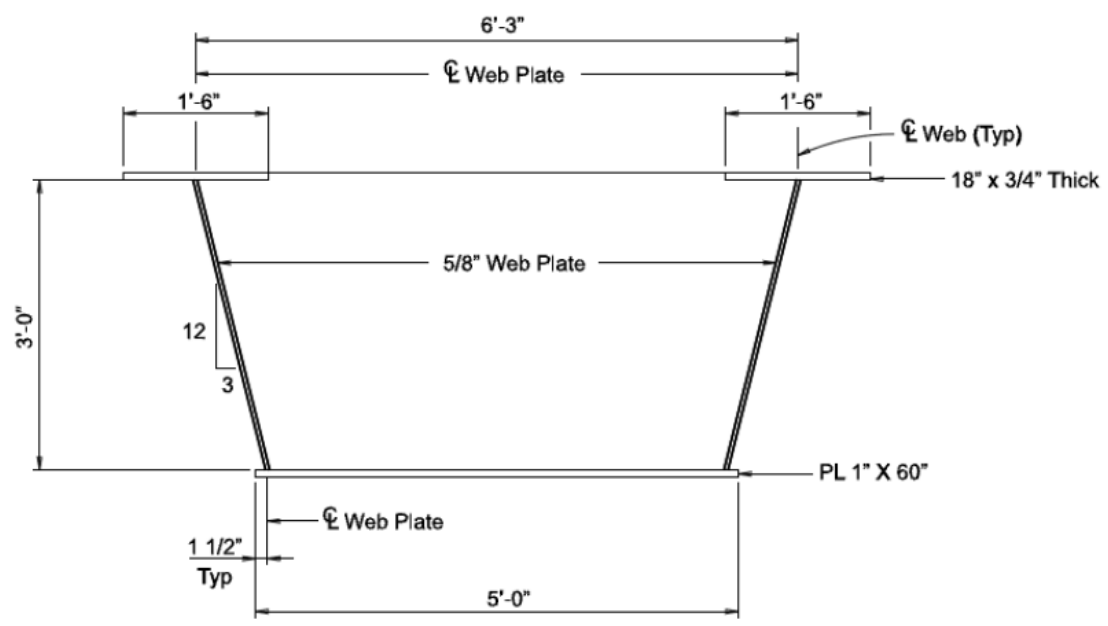

Figure 2.3: TxDOT Tub Girder for Rapid Bridge Replacement (Chandar et. al., 2010)

\subsection{Previous Research at WVU on Press-Brake-Formed Steel Tub Girders}

As mentioned previously, early research on press-brake-formed steel tub girders began at West Virginia University in October, 2011 when researchers worked with the Short Span Steel Bridge Alliance (SSSBA) to develop the closed, trapezoidal tub girder design shown below in Figure 2.4. This section will detail all previous research conducted at WVU on this specific tub girder design. 


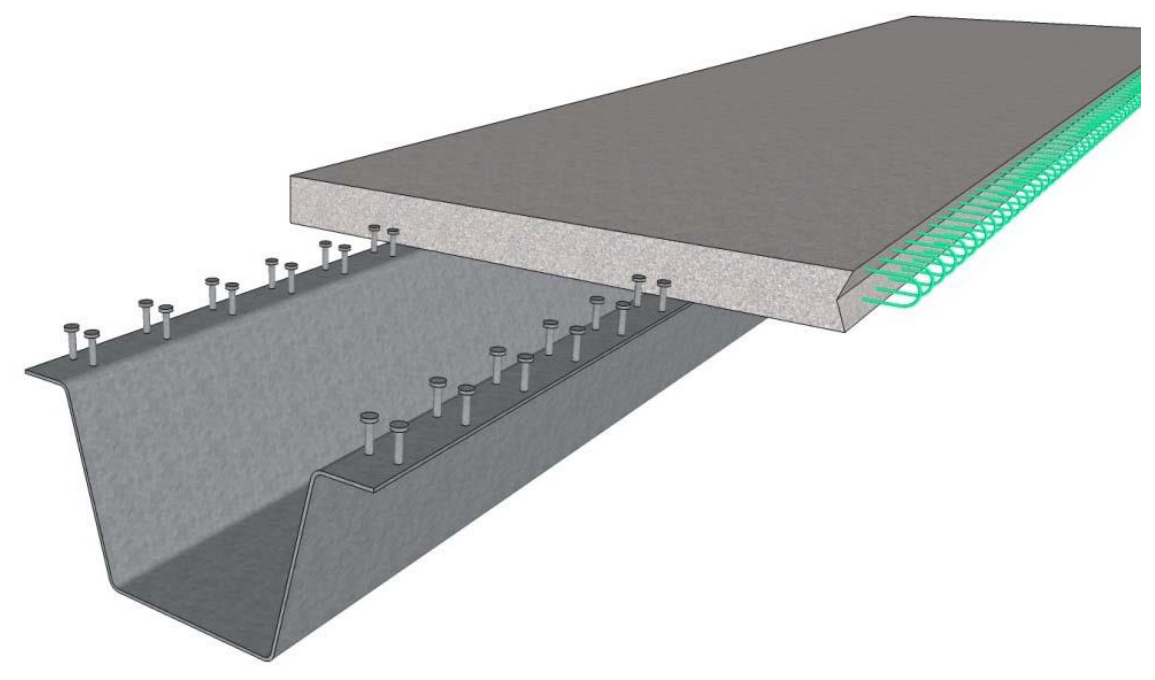

Figure 2.4: Press-Brake-Formed Steel Tub Girder System (Michaelson, 2014)

\subsubsection{Development and Feasibility Assessment (Michaelson, 2014)}

The first publication involving the press-brake-formed steel tub girders came in the form of a doctoral dissertation by Michaelson (2014). Michaelson worked with Barth and Barker (Barth et. al., 2015) to create a set of standardized press-brake-formed tub girder designs which would be fabricated from commonly sized steel plates that mills produce regularly. This was beneficial for multiple reasons. Not only are the girders more economically feasible, but availability is not an issue, as mills readily have these standard plate sizes available. Once research and design for these standardized girders was complete, researchers performed a series of laboratory experiments that tested the tub girders both compositely and non-compositely.

Several flexural tests were performed on a number of different configurations of pressbrake-formed tub girders. For the non-composite specimens, the failure modes were governed by the section's stability, with most tests being terminated due to excessive lateral deflection and twist as shown in Figure 2.5. Testing showed that the non-composite girders were susceptible to global system lateral-torsional buckling and torsional instability under relatively low applied loads. Michaelson concluded that this can be abated by installing stay-in-place formwork prior to girder erection, which would increase the torsional stiffness of the girder and provide bracing against 
lateral torsional buckling. Also, this was not considered to be a large concern since the ideal use of the tub girders is to be delivered to the bridge site with a pre-cast deck already in place to utilize accelerated bridge construction (ABC) methods.

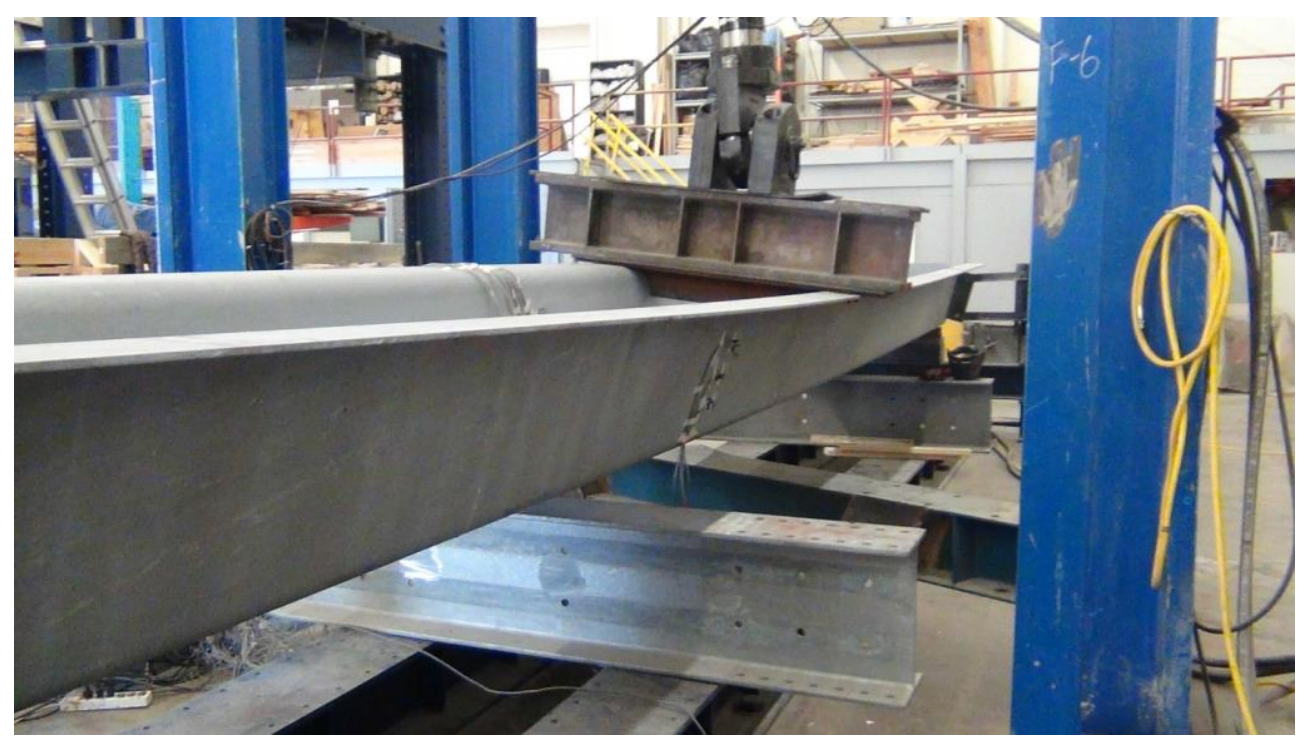

Figure 2.5: Typical Failure Mode for Non-composite Specimens (Michaelson, 2014)

In addition to testing non-composite specimens, a series of flexural tests were performed on composite specimens as well. For these tests, shear studs were welded to the top flanges, and a reinforced concrete deck was cast on top of the girders. The specimens were able to withstand much greater loads than the non-composite specimens, as the typical failure mode for the composite specimens were governed by the section's ductility, as shown in Figure 2.6. The composite specimens experienced an average maximum applied load of approximately 304 kips and a maximum deflection of approximately 3.1 inches at failure. 


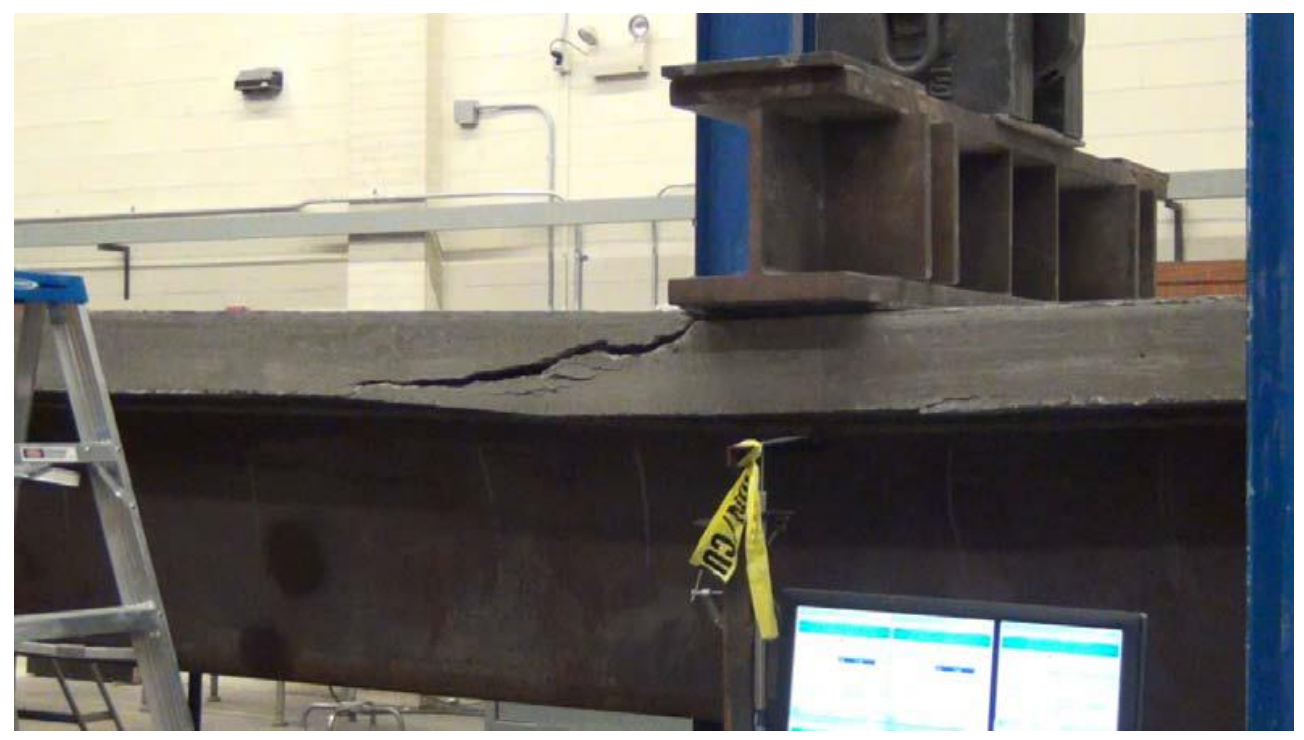

Figure 2.6: Typical Failure Mode for Composite Specimens (Michaelson, 2014)

After laboratory testing was complete, Michaelson performed several studies assessing the behavior of the composite systems. The goal of these studies was to compare the testing results to AASHTO LRFD Specifications, and determine if the specifications were reasonably applicable to this new design. It was discovered that the AASHTO LRFD Specifications were somewhat conservative in computing the nominal capacity of the modular composite specimens. Michaelson derived an improved, simplified expression to compute the nominal capacity of the proposed system which is shown below.

$$
M_{n}= \begin{cases}M_{p} & D_{p} \leq 0.1 D_{t} \\ M_{p}\left(1.025-0.25 \frac{D_{p}}{D_{t}}\right) & 0.1 D_{t}<D_{p} \leq 0.42 D_{t}\end{cases}
$$

After the performance of the system was fully evaluated, a feasibility and economic analysis was performed to determine if the tub girders could be a viable design solution to using steel in short span bridge applications. A number of different size tub girders were included in this analysis against traditional solutions for short span highway bridges. Although it was 
discovered that tub girder systems employing a 120" x 5/8" plate would work for spans up to 80 feet, the tub girders excelled in performance, and were most competitive with other solutions, in applications with span lengths 60 feet and less.

\subsubsection{Evaluation of Non-Composite Tub Girders (Kelly, 2014)}

In addition to Michaelson's body of work, further studies and testing were completed to develop a complete understanding of the stability and torsional behavior of the non-composite press-brake-formed steel tub girders (Kelly, 2014). This research included destructive flexural testing of two non-composite girders to physically verify their buckling capacity and behavior, as well developing finite element models to simulate the behavior of the specimens to compare with the experimental data. The ultimate goal was to use the experimental data along with the finite element analysis results to determine a need for bracing options and develop recommendations for future research.

Flexural testing of the specimens was completed using a servo-hydraulic actuator which applied loads to a spreader beam that was placed across the top flanges of the tub girders at midspan. The two specimens tested were each fabricated from 84" x 7/16" plate, and were 38 feet in length. The only difference between the two specimens was the first girder was fabricated from a HPS-50W weathering steel plate, and the second girder was fabricated from a HPS-50 steel plate that was hot-dipped galvanized. The second girder exhibited geometric imperfections in the form of an inconsistent initial twist without load present which resulted in varying results between the two tests. It should be noted that the geometric imperfections in the second girder were a result of fabrication processes and not galvanization.

The load-deflection results obtained from the two tests, along with the finite element analysis, are shown in Figure 2.7. The first specimen behaved linearly up to a critical load of approximately 94 kips before failing in a global lateral-torsional mode while the second specimen reached a critical load of 33 kips before testing was terminated due to excessive lateral deflection and twist from lateral-torsional buckling phenomena. This loss of capacity was a direct result of second order effects due to the girder's initial imperfections. 


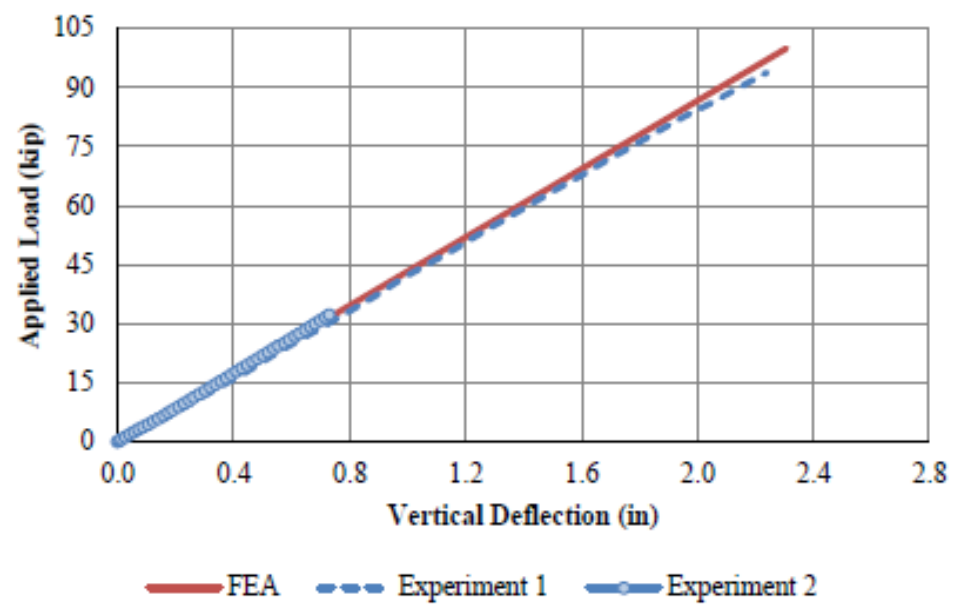

Figure 2.7: Load-Deflection Results at Midspan (Kelly, 2014)

Similar to Michaelson's (2014) findings, it was found that the girders were vulnerable to lateral-torsional buckling and torsional instability under relatively low loads. It was also concluded that initial imperfections and other second-order effects can greatly contribute to the loss of capacity for these specimens.

\subsubsection{Evaluation of Modular Tub Girders with UHPC Joints (Kozhokin, 2016)}

Further research was conducted at West Virginia University to evaluate the use of a modular system utilizing the press-brake-formed steel tub girders, specifically using an ultra-high performance concrete (UHPC) joint (Kozhokin, 2016). The primary goal of this work was to physically test a bridge model system consisting of two composite modular press-brake formed steel tub girders connected with a UHPC joint. This was intended to accomplish two things: demonstrate the tub girder's modular capability to be utilized in accelerated bridge construction $(A B C)$, and test the efficiency and capability of the UHPC joint - which has only recently emerged as a viable option for modular bridge joints.

In order to join the two modular components with UHPC, a shear-key detail had to be constructed on the edge of each concrete deck where the joint would be installed. Extensive 
research and testing was completed to determine the ideal design for the shear-key, and ultimately a trapezoidal shaped design with exposed aggregate and protruding reinforcing rebar, as shown in Figure 2.8, was chosen.

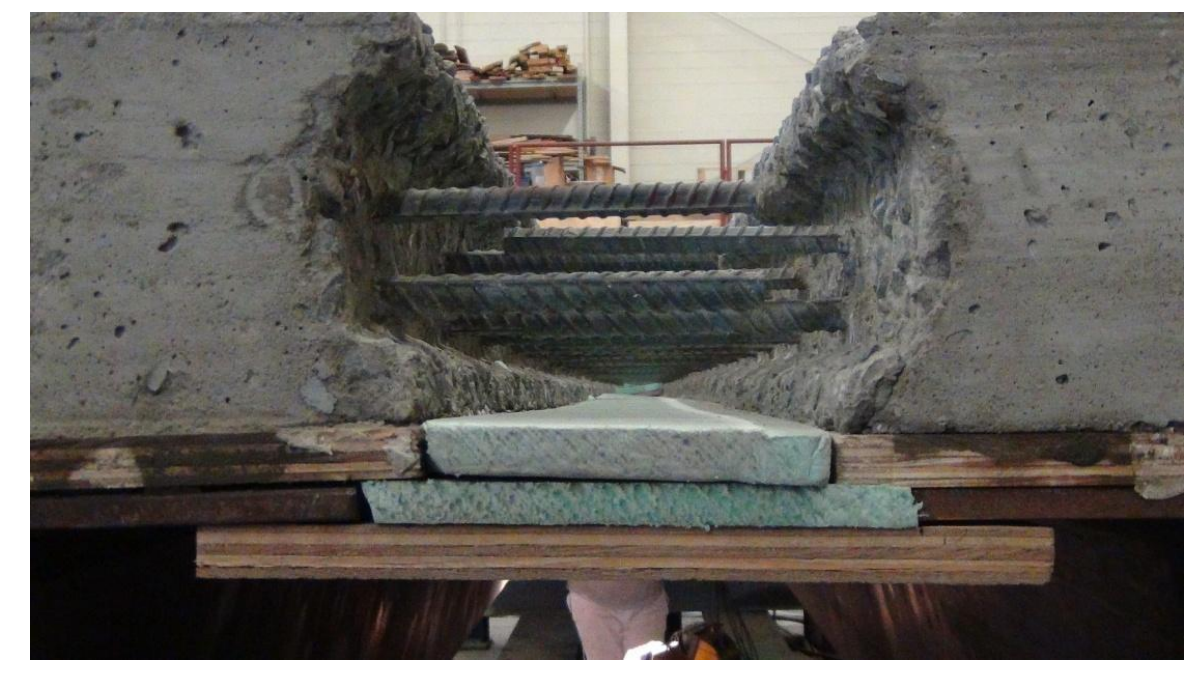

Figure 2.8: UHPC Joint Trapezoidal Shear-Key Detail (Kozhokin, 2016)

Testing was completed using a servo-hydraulic actuator to apply load which was placed directly above the center of one girder at midspan. The actuator was placed in this manner in order to study how the composite system transferred loads between the two girders through the UHPC joint. Utilizing AASHTO LRFD Specifications, the loads to induce the Fatigue I and Service II moments were calculated. The Fatigue I load of 67.93 kips was used simulate the load of the AASHTO HL-93 design truck and cyclically load the specimen up to 2,737,500 cycles, which was the calculated number of cycles to simulate the bridge model's 75-year design life. The Service II load of 90.78 kips was broken up into 10 intervals which were applied to the bridge model during static tests that were performed throughout the cyclic testing.

Table 2.1 shows the summary of distribution factors that were calculated throughout the entirety of the testing. The data suggests that the UHPC joint performed well through the simulated life of the bridge. In addition, no significant changes to the tub girders were observed throughout testing signifying that they performed effectively as modular units in the bridge model. 
Table 2.1: Summary of Distribution Factors (Kozhokin, 2016)

\begin{tabular}{|r|c|c|}
\hline \multicolumn{3}{|c|}{ Average Distribution Factor } \\
\hline Cycle Count & Directly Loaded Girder & Indirectly Loaded Girder \\
\hline 0 & 0.691 & 0.309 \\
\hline 100,000 & 0.631 & 0.369 \\
\hline 250,000 & 0.676 & 0.324 \\
\hline 500,000 & 0.678 & 0.322 \\
\hline $1,000,000$ & 0.690 & 0.310 \\
\hline $1,500,000$ & 0.717 & 0.283 \\
\hline $2,000,000$ & 0.707 & 0.293 \\
\hline $2,100,000$ & 0.708 & 0.292 \\
\hline $2,200,000$ & 0.707 & 0.293 \\
\hline $2,300,000$ & 0.706 & 0.294 \\
\hline $2,500,000$ & 0.711 & 0.289 \\
\hline $2,700,000$ & 0.712 & 0.288 \\
\hline $2,800,000$ & 0.743 & 0.257 \\
\hline
\end{tabular}

\subsection{FHWA's InNOVATIVE BRIDGE RESEARCH AND DEPLOYMENT PROGRAM}

The Federal Highway Administration (FHWA) created the Innovative Bridge Research and Deployment (IBRD) Program to provide funds to state DOT's willing to implement innovative designs, materials, and construction methods in the construction and rehabilitation of bridges and other highway structures. Buchanan County, Iowa Engineer Brian Keierleber, P.E. learned about this program through his involvement with the Short Span Steel Bridge Alliance (SSSBA). In 2014, members of the SSSBA worked with Buchanan County to apply a \$350,000 IBRD grant to replace the Amish Sawmill Bridge utilizing press-brake-formed steel tub girders (Short Span Steel Bridge Alliance, 2016). Keierleber was awarded the grant for the bridge replacement with an additional requirement of utilizing Geosynthetic Reinforced Soil (GRS) abutments.

The Geosynthetic Reinforced Soil-Integrated Bridge System (GRS-IBS) is an innovation developed to help reduce bridge construction time and cost (Federal Highway Administration, 2017). GRS-IBS consists of a reinforced soil foundation, an abutment, and the integrated approach to the bridge. For the Amish Sawmill Bridge, sheet piling was utilized to contain the reinforced soil foundation, creating the abutment. The FHWA states that GRS-IBS bridges can cost 25 to 60 
percent less than bridges constructed using conventional methods. Other advantages to GRS-IBS bridges include a number of positive environmental impacts, increased durability, and less maintenance.

\subsection{CURRENT AASHTO LRFD SPECIFICATIONS}

The American Association of State Highway and Transportation Officials (AASHTO) publishes the U.S. bridge specification titled, AASHTO LRFD Bridge Design Specifications (2014). In the current AASHTO LRFD specifications, live load distribution factors (LLDFs) are presented in Section 3.6, and box-section (tub girders) flexural members are presented in Section 6.11. This chapter will summarize the current AASHTO specifications for tub girders, and will also outline the specifications for computing LLDFs for tub girders.

\subsubsection{AASHTO Specifications for Box-Section Flexural Members (Tub Girders)}

This section will outline current AASHTO specifications for box section (tub girder) flexural members. These specifications are not directly applicable to cold-bent press-brakeformed tub girders, but a review of these provisions is necessary to assess the applicability of the specifications to this system and/or approach the production of specifications for this system in future research efforts.

\subsubsection{Cross-Section Proportion Limits}

This section will summarize AASHTO specifications specific to tub girders starting with cross-section proportion limits. These limits are used to prevent transportation and erection issues

and are based upon years of construction and fabrication experience in addition to research incorporated into the development of the specifications (Morgan, 2010). 
The webs must meet the following proportions:

Webs without longitudinal stiffeners:

$$
\frac{D}{t_{w}} \leq 150
$$

Eq. 2.1

Webs with longitudinal stiffeners:

$$
\frac{D}{t_{w}} \leq 300
$$

Eq. 2.2

$D=$ depth of the web plate measured along the slope

$t_{w}=$ web thickness

The top flange must meet the following proportions:

$$
\begin{aligned}
& \frac{b_{f}}{2 t_{f}} \leq 12.0 \\
& b_{f} \geq \frac{D}{6} \\
& t_{f} \geq 1.1 t_{w}
\end{aligned}
$$

Eq. 2.5

$b_{f}=\quad$ full width of the widest top flange width within the section under consideration

$t_{f}=$ flange thickness

$t_{w}=$ web thickness

$D=$ depth of the web plate measured along the slope 


\subsubsection{Constructability}

In order to provide adequate resistance by the tub girders during construction, Article 6.11.3 of ASHTO (2014) is employed. In addition to Article 6.11.3, Article 3.4.2 is used to determine the appropriate load factors for construction loads. Unlike plate girders where different plate thickness can be employed in different field sections, individual tub girder geometry must be maintained throughout the entire span length. Internal and external cross-frames and diaphragms, and top lateral bracing may be used to control deformations. Finally, the unbraced length is taken as the distance between interior cross-frames or diaphragms. For tub girders in flexure, the following criteria must be met:

Discretely braced top flanges in compression must meet the following criteria:

$$
\begin{array}{lc}
f_{b u}+f_{\ell} \leq \phi_{f} R_{h} F_{y c} & \text { Eq. } 2.6 \\
f_{b u}+\frac{1}{3} f_{\ell} \leq \phi_{f} F_{n c} & \text { Eq. } 2.7 \\
f_{b u} \leq \phi_{f} F_{c w w} & \text { Eq. } 2.8
\end{array}
$$

Discretely braced top flanges in tension must meet the following criteria:

$$
\begin{array}{ll}
f_{b u}+f_{t} \leq \phi_{f} R_{h} F_{y t} \quad \text { Eq. } 2.9 & \text { E }
\end{array}
$$

Continuously braced top flanges in tension or compression must meet the following criteria:

$$
f_{b u} \leq \phi_{f} R_{h} F_{\not f}
$$

For critical stages of construction, non-composite box flanges in compression shall satisfy the following requirements:

$$
\begin{aligned}
& f_{b u} \leq \phi_{f} F_{n c} \\
& f_{b u} \leq \phi_{f} F_{c n v}
\end{aligned}
$$


For critical stages of construction, non-composite box flanges in tension and continuously braced box flanges in tension or compression shall satisfy the following requirements:

$$
f_{b u} \leq \phi_{f} R_{h} F_{y j} \Delta
$$

$\phi_{f}=\quad$ resistance factor for flexure specified in Article 6.5.4.2

$f_{b u}=$ longitudinal flange stress due to the factored loads at the section under consideration calculated without consideration of longitudinal warping

$f_{\ell}=\quad$ flange lateral bending stress determined as specified in Article 6.10.1.6

$F_{c r w}=$ nominal bend-buckling resistance for webs specified in Article 6.10.1.9

$F_{n c}=$ nominal flexural resistance of box flanges in compression determined as specified in Article 6.11.8.2

$R_{h}=$ hybrid factor specified in Article 6.10.1.10.1

$F_{y c}=$ specified minimum yield strength of the compression flange

$F_{y t}=$ specified minimum yield strength of the tension flange

$F_{y f}=$ specified minimum yield strength of the flange under consideration

$\Delta=\sqrt{1-3\left(\frac{f_{v}}{F_{y f}}\right)^{2}}$

$f_{v}=$ St. Venant torsional shear stress in the flange due to the factored loads at the section under consideration $=\frac{T}{2 A_{o} t_{f}}$

$A_{0}=$ enclosed area within the box section

$T=$ internal torque due to the factored loads 
For shear requirements, webs shall satisfy the following requirement during critical stages of construction:

$$
\begin{aligned}
& V_{u} \leq \phi_{v} V_{\sigma} \\
& V_{u i}=\frac{V_{u}}{\cos (\theta)}
\end{aligned}
$$

$\phi_{v}=$ resistance factor for shear specified in Article 6.5.4.2

$V_{u}=$ vertical shear due the factored loads on one inclined web

$V_{c r}=$ shear buckling resistance determined from Eq. 6.10.9.3.3-1

$V_{u i}=$ shear due to the factored loads along one inclined web

$\theta=\quad$ the angle of inclination of the web plate to the vertical

\subsubsection{Service Limit State}

The function of the service limit state is to ensure the maintainability and durability of the structure. In doing so, it not only provides the user with a higher level of ride ability but also preserves the life of the structure throughout the bridge's service life (Morgan, 2010). The limits specified in this section are related to resisting both elastic and plastic deformations.

To control permanent deformations, several requirements are established. If the concrete deck is assumed to be fully effective in both the negative and positive bending regions, the Service II load combination is applied to both the short-term and long-term composite sections.

The flanges must satisfy the following requirements in order to prevent web yielding and bend-buckling from occurring prior to flange strength development: 
For the top steel flange of the composite section, the following requirement must be met:

$$
f_{f} \leq 0.95 R_{h} F_{x f}
$$

For the bottom steel flange of the composite section, the following requirement must be met:

$$
f_{f}+\frac{f_{t}}{2} \leq 0.95 R_{h} F_{x f}
$$

For both steel flanges of non-composite section, the following requirement must be met:

$$
f_{f}+\frac{f_{t}}{2} \leq 0.80 R_{h} F_{y f}
$$

\footnotetext{
$f_{f}=\quad$ flange stress at the section under consideration due to Service II loads calculated without consideration of lateral flange bending

$f_{\ell}=$ lateral flange bending stress at the section under consideration due to the Service II loads determined as specified in Article 6.10.1.6

$F_{y f}=$ specified minimum yield strength of the flange under consideration

$R_{h}=$ hybrid factor specified in Article 6.10.1.10.1
}

Article 2.5.2.6 in AASHTO (2014) lists suggested limits for elastic live load deflections. When checking live load deflection, the load to be used is the greater of the design truck plus impact or 25\% of the design truck with impact plus the design load lane. It is assumed that all components of the bridge deflect equally and that all design lanes are to be equally loaded. The short-term composite section is to be used as the stiffness of the structure when computing deflection. 
Web bending buckling can cause accelerated deck deteriorating and could possibly lead to rupture from plastic deformations. The following Service II requirements are established so the web has the capacity to resist web bend buckling:

All sections of the web must satisfy:

$$
f_{c} \leq F_{c r w}
$$

$$
\begin{aligned}
& f_{c}=\quad \text { compression flange stress at the section under consideration due to the Service II } \\
& \text { loads calculated without consideration of lateral flange bending } \\
& F_{c r w}=\text { nominal bend-buckling resistance for the web specified in Article 6.10.1.9 }
\end{aligned}
$$

\subsubsection{Fatigue and Fracture Limit State}

For the fatigue limit state, the design life of the bridge and limits for live load stress ranges are used to prevent fatigue crack growth. Fatigue is generally divided into two categories: loadinduced fatigue and distortion-induced fatigue and is outlined in Articles 6.6.1.2 and 6.6.1.3 in AASHTO (2014), respectively. Connections and fabrication details are arranged according to fatigue categories and are specified in AASHTO (2014) Table 6.6.1.2.3-1.

For load-induced fatigue, the stress range caused by live loads is computed for flexural members using the short-term composite section. Residual stresses are not considered and fatigue is only considered in regions where permanent loads produce compression if the compression stresses are less than twice the maximum tensile stresses. The maximum tensile stresses are caused by the live loads calculated using the fatigue limit state load combination (Morgan, 2010). 
Each detail must satisfy the following for load induced fatigue:

$$
\begin{array}{ll}
\gamma(\Delta f) \leq(\Delta F)_{n} & \text { Eq. } 2.20
\end{array}
$$

For the Fatigue I load combination and infinite life, the nominal fatigue resistance is computed as follows:

$$
\begin{array}{ll}
(\Delta F)_{n}=(\Delta F)_{T H} & \text { Eq. } 2.21
\end{array}
$$

For the Fatigue II load combination and finite life, the nominal fatigue resistance is computed as follows:

$$
\begin{array}{ll}
(\Delta F)_{n}=\left(\frac{A}{N}\right)^{\frac{1}{3}} & \text { Eq. } 2.22
\end{array}
$$

$N=$ number of fatigue cycles over the design life of the structure $\quad$ Eq. 2.23

$A=$ constant take from Table 6.6.1.2.5-1

$n=\quad$ number of stress range cycles per truck passage taken from Table 6.6.1.2.5-2

Distortion-induced fatigue is specified in AASHTO (2014) Article 6.6.1.3. Connection details are established to ensure sufficient load paths exist to properly transmit all intended and unintended forces. These forces could be transferred through transverse, lateral, and longitudinal members. To establish load paths, the girder compression and tension flanges are bolted or welded at connecting diaphragms, internal or external diaphragms, and floor beams or stringers. These diaphragms, floor beams, or stringers are attached to transverse connection plates or to transverse stiffeners acting as connection plates. If the load that will act on the welded or bolted connection is unknown, the connection should be able to resist a lateral load of at least 20 kips (Morgan, 2010).

Article 6.6.2 in AASHTO (2014) defines the requirements for fracture. All primary longitudinal superstructure components and connections sustaining stress due to the Strength I Load Combinations shall require Charpy V-notch testing. Finally, all structural members that are fracture critical must meet Charpy V-notch toughness requirements (Morgan, 2010). 


\subsubsection{Strength Limit State}

The strength limit state ensures that the bridge has sufficient capacity to safely resist the applied moments and shears that act over the entire life of the bridge. Article 6.11.6 in AASHTO (2014) describes the strength limit state for box girders and is broken down into four main sections.

\section{General Requirements}

For straight bridges the minimum yield strength of both flanges and the web cannot exceed 70 ksi. The web must satisfy AASHTO (2014) Article 6.11.2.1.2 which is cross-section proportion limits; webs without longitudinal stiffeners.

To check if the web slenderness limit is met, the following equation must be satisfied:

$$
\frac{2 D_{c p}}{t_{w}} \leq 3.76 \sqrt{\frac{E}{F_{y c}}}
$$

$D_{c p}=$ depth of the web in compression at the plastic moment determined as specified in Article D6.3.2

$F_{y c}=$ specified minimum yield strength of the compression flange

$E=$ modulus of elasticity of steel

$t_{w}=$ web thickness 
Compact sections shall satisfy AASHTO (2014) Article 6.11.7.1. If the section does not satisfy Article 6.11.7.1, the section is considered noncompact and shall meet the requirements of AASHTO Article 6.11.7.2.

Compact and noncompact sections shall meet the ductility requirement as follows:

$$
D_{p} \leq 0.42 D_{t}
$$

$D_{p}=$ distance from the top of the concrete deck to the neutral axis of the composite section at the plastic moment

$D_{t}=$ total depth of the composite section

\section{Flexural Capacity of Composite Sections}

The following provisions apply to compact sections:

At the strength limit state, the section shall satisfy:

$$
M_{u} \leq \phi_{f} M_{n}
$$

$\phi_{f}=$ resistance factor for flexure specified in Article 6.5.4.2

$M_{n}=$ nominal flexural resistance of the section determined as specified in Article 6.11.7.1.2

$M_{u}=$ bending moment about the major axis of the cross section due to the factored loads at the section under consideration 
The nominal flexural resistance of simply-supported beams is computed as follows:

$$
\text { If } D_{p} \leq 0.1 D_{t} \text { then: }
$$

$$
M_{n}=M_{p}
$$

Otherwise:

$$
M_{n}=M_{p}\left(1.07-0.7 \frac{D_{p}}{D_{t}}\right)
$$

$D_{p}=$ distance from the top of the concrete deck to the neutral axis of the composite section at the plastic moment

$D_{t}=$ total depth of the composite section

$M_{p}=$ plastic moment of the composite section determined as specified in Article D6.1

$M_{n}=$ nominal flexural resistance

The nominal flexural resistance of continuous-span beams is limited to:

$$
M_{n}=1.3 R_{h} M_{y}
$$

Eq. 2.29

$M_{n}=$ nominal flexural resistance

$M_{y}=$ yield moment as specified in Article D6.2

$R_{h}=$ hybrid factor specified in Article 6.10.1.10.1 
The following provisions apply to noncompact sections:

At the strength limit state, compression flanges shall satisfy the following:

$$
f_{b u} \leq \phi_{f} F_{n c}
$$

Eq. 2.30

$\phi_{f}=\quad$ resistance factor for flexure specified in Article 6.5.4.2

$f_{b u}=$ longitudinal flange stress at the section under consideration calculated without consideration of lateral flange bending or longitudinal warping

$F_{n c}=$ nominal flexural resistance of the compression flange as specified in Article 6.11 .7 .2 .2

The nominal resistance of compression flanges is computed as follows:

$$
F_{n c}=R_{b} R_{h} F_{y c}
$$

$F_{n c}=$ nominal flexural resistance of the compression flange as specified in Article 6.11.7.2.2

$R_{b}=$ web load shedding factor determined as specified in Article 6.10.1.10.2

$R_{h}=$ hybrid factor specified in Article 6.10.1.10.1

$F_{y c}=$ specified minimum yield strength of the compression flange 
The following provisions are applied to noncomposite sections:

At the strength limit state, the following requirement shall be satisfied for flanges in compression:

$$
f_{b u} \leq \phi_{f} F_{n c}
$$

$\phi_{f}=$ resistance factor for flexure specified in Article 6.5.4.2

$f_{b u}=$ longitudinal flange stress at the section due to the factored loads at the section under consideration calculated without consideration of longitudinal warping

$F_{n c}=$ nominal flexural resistance of the compression flange as specified in Article

\subsubsection{2}

At the strength limit state, the following requirement shall be satisfied for flanges in tension:

$$
f_{b u} \leq \phi_{f} F_{n t}
$$

$\phi_{f}=\quad$ resistance factor for flexure specified in Article 6.5.4.2

$f_{b u}=$ longitudinal flange stress at the section due to the factored loads at the section under consideration calculated without consideration of longitudinal warping

$F_{n t}=$ nominal flexural resistance of the flange determined as specified in Article 6.11.8.3 
The nominal flexural resistance of the compression flange, $F_{n c}$, shall be taken as:

$$
F_{n c}=F_{c b} \sqrt{1-\left(\frac{f_{v}}{\phi_{v} F_{c v}}\right)^{2}}
$$

$F_{c b}=$ nominal axial compression buckling resistance of the flange under compression alone calculated as follows:

- If $\lambda_{f} \leq \lambda_{p}$, then:

$$
F_{c b}=R_{b} R_{h} F_{y c} \Delta
$$

- If $\lambda_{p}<\lambda_{f} \leq \lambda_{r}$, then:

$$
F_{c b}=R_{b} R_{h} F_{y c}\left[\Delta-\left(\Delta-\frac{\Delta-0.3}{R_{h}}\right)\left(\frac{\lambda_{f}-\lambda_{p}}{\lambda_{r}-\lambda_{p}}\right)\right]
$$

- If $\lambda_{f}>\lambda_{r}$, then:

$$
F_{c b}=\frac{0.9 E R_{b} k}{\lambda_{f}^{2}}
$$

$F_{c}=$ nominal shear buckling resistance of the flange under shear alone calculated as follows:

- If $\lambda_{f} \leq 1.12 \sqrt{\frac{E k_{s}}{F_{y c}}}$, then:

$$
F_{c v}=0.58 F_{y c}
$$

- If $1.12 \sqrt{\frac{E k_{s}}{F_{y c}}}<\lambda_{f} \leq 1.40 \sqrt{\frac{E k_{s}}{F_{y c}}}$, then:

$$
F_{c v}=\frac{0.65 \sqrt{F_{y c} E k_{s}}}{\lambda_{f}}
$$


- If $\lambda_{f}>1.40 \sqrt{\frac{E k_{s}}{F_{y c}}}$, then:

$$
F_{c v}=\frac{0.9 E k_{s}}{\lambda_{f}^{2}}
$$

$\lambda_{f}=$ slenderness ratio for the compression flange

$$
=\frac{b_{f c}}{t_{f c}}
$$

$$
\lambda_{p}=0.57 \sqrt{\frac{E k}{F_{y c} \Delta}}
$$

$\lambda_{r}=0.95 \sqrt{\frac{E k}{F_{y r}}}$

$$
\Delta=\sqrt{1-3\left(\frac{f_{v}}{F_{y c}}\right)^{2}}
$$

$$
\begin{aligned}
& f_{v}=\text { St. Venant torsional shear stress in the flange due } \\
& \text { to the factored loads at the section under } \\
& \text { consideration (ksi) } \\
& =\frac{T}{2 A_{o} t_{f c}}
\end{aligned}
$$




$$
\begin{aligned}
& F_{y r}=\text { smaller of the compression-flange stress at the } \\
& =(\Delta-0.3) F_{y c} \\
& =4.0 \\
& k_{s}=\text { plate-buckling coefficient for shear stress } \\
& =5.34
\end{aligned}
$$

where:

$$
\begin{aligned}
\phi_{f}= & \text { resistance factor for flexure specified in } \\
& \text { Article 6.5.4.2 } \\
\phi_{v}= & \text { resistance factor for shear specified in } \\
& \text { Article 6.5.4.2 } \\
b_{f c}= & \text { compression-flange width between webs (in.) } \\
A_{o}= & \text { enclosed area within the box section (in. }{ }^{2} \text { ) } \\
R_{b}= & \text { web load-shedding factor determined as specified } \\
& \text { in Article 6.10.1.10.2 } \\
R_{h}= & \text { hybrid factor determined as specified in } \\
T= & \text { Article 6.10.1.10.1 } \\
T= & \text { internal torque due to the factored loads (kip-in.) }
\end{aligned}
$$


The flexural resistance of longitudinally stiffened flanges in compression is computed in the same fashion as for unstiffened flanges, with the following substitutions:

- $w$ shall be substituted for $b_{f c}$

- $k$ shall be taken as follows:

- If $n=1$, then:

$$
k=\left(\frac{8 I_{s}}{w t_{f t}^{3}}\right)^{\frac{1}{3}}
$$

- If $n=2$ then:

$$
k=\left(\frac{0.894 I_{s}}{w t_{f t}^{3}}\right)^{\frac{1}{3}}
$$

$$
1.0 \leq k \leq 4.0
$$

- $k_{s}=\frac{5.34+2.84\left(\frac{I_{s}}{w t_{f t}{ }^{3}}\right)^{\frac{1}{3}}}{(n+1)^{2}} \leq 5.34$

$I_{s}=$ moment of inertia of a single longitudinal flange stiffener about an axis parallel to the flange and taken at the base of the stiffener

$n=\quad$ number of equally spaced longitudinal flange stiffeners

$w=$ larger of the width of the flange between longitudinal flange stiffeners or the distance from a web to the nearest longitudinal flange stiffener

$t_{f c}=$ thickness of the compression flanges

The flexural resistance of flanges in tension is computed as follows:

$$
F_{n t}=R_{h} F_{y t}
$$

$R_{h}=$ hybrid factor specified in Article 6.10.1.10.1

$F_{y t}=$ specified minimum yield strength of the tension flanges

$F_{n t}=$ nominal flexural resistance of the tension flanges 


\section{$\underline{\text { Shear Capacity }}$}

The provisions for addressing shear concerns are as follows:

At the strength limit state, straight and curved web panels shall satisfy:

$$
V_{u} \leq \phi_{v} V_{n}
$$

where:

$$
\begin{aligned}
& \phi_{v}=\text { resistance factor for shear specified in } \\
& \text { Article 6.5.4.2 } \\
& V_{n}=\text { nominal shear resistance determined as specified } \\
& \text { in Articles 6.10.9.2 and 6.10.9.3 for unstiffened } \\
& \text { and stiffened webs, respectively (kip) } \\
& V_{u}=\text { shear in the web at the section under } \\
& \text { consideration due to the factored loads (kip) }
\end{aligned}
$$

The nominal shear resistance of unstiffened webs shall be taken as:

$$
V_{n}=V_{c r}=C V_{p}
$$

in which:

$$
V_{p}=0.58 F_{y w} D t_{w}
$$

where:

$$
\begin{aligned}
C= & \text { ratio of the shear-buckling resistance to the } \\
& \text { shear yield strength determined by Eqs. } \\
& 6.10 .9 .3 .2-4,6.10 .9 .3 .2-5 \text { or } 6.10 .9 .3 .2-6 \text { as } \\
& \text { applicable, with the shear-buckling coefficient, } k, \\
& \text { taken equal to } 5.0 \\
V_{c r}= & \text { shear-buckling resistance (kip) } \\
V_{n}= & \text { nominal shear resistance (kip) } \\
V_{p}= & \text { plastic shear force (kip) }
\end{aligned}
$$


The nominal shear resistance of an interior web panel complying with the provisions of Article 6.10.9.1, and with the section along the entire panel proportioned such that:

$$
\frac{2 D t_{w}}{\left(b_{f t} t_{f t}+b_{f t} t_{f t}\right)} \leq 2.5
$$

shall be taken as:

$$
V_{n}=V_{p}\left[C+\frac{0.87(1-C)}{\sqrt{1+\left(\frac{d_{o}}{D}\right)^{2}}}\right]
$$

in which:

$$
V_{p}=0.58 F_{y w} D t_{w}
$$

where:

$$
\begin{aligned}
d_{o}= & \text { transverse stiffener spacing (in.) } \\
V_{n}= & \text { nominal shear resistance of the web panel } \\
& \text { (kip) } \\
V_{p}= & \text { plastic shear force (kip) } \\
C= & \text { ratio of the shear-buckling resistance to the shear } \\
& \text { yield strength }
\end{aligned}
$$


The ratio, $C$, shall be determined as specified below:

- If $\frac{D}{t_{w}} \leq 1.12 \sqrt{\frac{E k}{F_{y w}}}$, then:

$$
C=1.0
$$

Eq. 2.56

- If $1.12 \sqrt{\frac{E k}{F_{y w}}}<\frac{D}{t_{w}} \leq 1.40 \sqrt{\frac{E k}{F_{y w}}}$, then:

$$
C=\frac{1.12}{\frac{D}{t_{w}}} \sqrt{\frac{E k}{F_{y w}}}
$$

- If $\frac{D}{t_{w}}>1.40 \sqrt{\frac{E k}{F_{y w}}}$, then:

$$
C=\frac{1.57}{\left(\frac{D}{t_{w}}\right)^{2}}\left(\frac{E k}{F_{y w}}\right)
$$

in which:

$$
\begin{aligned}
k & =\text { shear-buckling coefficient } \\
& =5+\frac{5}{\left(\frac{d_{0}}{D}\right)^{2}}
\end{aligned}
$$

Otherwise, the nominal shear resistance shall be taken as follows:

$$
V_{n}=V_{p}\left[C+\frac{0.87(1-C)}{\left(\sqrt{1+\left(\frac{d_{0}}{D}\right)^{2}}+\frac{d_{0}}{D}\right)}\right]
$$


The nominal shear resistance of a web end panel shall be taken as:

$$
V_{n}=V_{a}=C V_{p}
$$

in which:

$$
V_{p}=0.58 F_{y w} D t_{w}
$$

where:

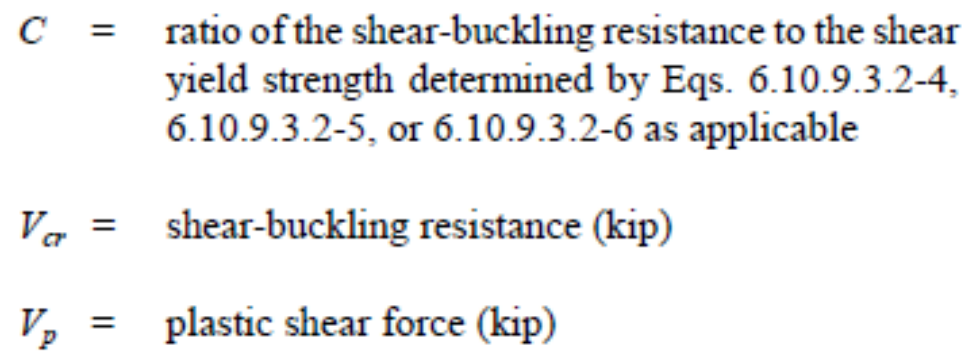

The transverse stiffener spacing for end panels with or without longitudinal stiffeners shall not exceed $1.5 \mathrm{D}$. 


\subsubsection{AASHTO Equation References}

Table 2.3 details a summary of the equations referenced in the previous section along with their respective AASHTO equation references.

Table 2.2: Equation Legend (AASHTO, 2014)

Chapter 2

Equation 2.1

Equation 2.2

Equation 2.3

Equation 2.4

Equation 2.5

Equation 2.6

Equation 2.7

Equation 2.8

Equation 2.9

Equation 2.10

Equation 2.11

Equation 2.12

Equation 2.13

Equation 2.14

Equation 2.15

Equation 2.16

Equation 2.17

Equation 2.18

Equation 2.19

Equation 2.20

Equation 2.21

Equation 2.22

Equation 2.23

Equation 2.24

Equation 2.25

Equation 2.26

Equation 2.27

Equation 2.28

\section{AASHTO 7th Edition}

Equation 6.11.2.1.2-1

Equation 6.11.2.1.3-1

Equation 6.11.2.2-1

Equation 6.11.2.2-2

Equation 6.11.2.2-3

Equation 6.10.3.2.1-1

Equation 6.10.3.2.1-2

Equation 6.10.3.2.1-3

Equation 6.10.3.2.2-1

Equation 6.10.3.2.3-1

Equation 6.11.3.2-1

Equation 6.11.3.2-2

Equation 6.11.3.2-3

Equation 6.10.3.3-1

Equation 6.11.9-1

Equation 6.10.4.2.2-1

Equation 6.10.4.2.2-2

Equation 6.10.4.2.2-3

Equation 6.10.4.2.2-4

Equation 6.6.1.2.2-1

Equation 6.6.1.2.5-1

Equation 6.6.1.2.5-2

Equation 6.6.1.2.5-3

Equation 6.11.6.2.2-1

Equation 6.10.7.3-1

Equation 6.11.7.1.1-1

Equation 6.10.7.1.2-1

Equation 6.10.7.1.2-2 
Chapter 2

Equation 2.29

Equation 2.30

Equation 2.31

Equation 2.32

Equation 2.33

Equation 2.34

Equation 2.35

Equation 2.36

Equation 2.37

Equation 2.38

Equation 2.39

Equation 2.40

Equation 2.41

Equation 2.42

Equation 2.43

Equation 2.44

Equation 2.45

Equation 2.46

Equation 2.47

Equation 2.48

Equation 2.49

Equation 2.50

Equation 2.51

Equation 2.52

Equation 2.53

Equation 2.54

Equation 2.55

Equation 2.56

Equation 2.57

Equation 2.58

Equation 2.59

Equation 2.60

Equation 2.61

Equation 2.62

\section{AASHTO 7th Edition}

Equation 6.10.7.1.2-3

Equation 6.11.7.2.1-1

Equation 6.11.7.2.2-1

Equation 6.11.8.1.1-1

Equation 6.11.8.1.2-1

Equation 6.11.8.2.2-1

Equation 6.11.8.2.2-2

Equation 6.11.8.2.2-3

Equation 6.11.8.2.2-4

Equation 6.11.8.2.2-5

Equation 6.11.8.2.2-6

Equation 6.11.8.2.2-7

Equation 6.11.8.2.2-8

Equation 6.11.8.2.2-9

Equation 6.11.8.2.2-10

Equation 6.11.8.2.2-11

Equation 6.11.8.2.2-12

Equation 6.11.8.2.3-1

Equation 6.11.8.2.3-2

Equation 6.11.8.2.3-3

Equation 6.11.8.3-1

Equation 6.10.9.1-1

Equation 6.10.9.2-1

Equation 6.10.9.2-2

Equation 6.10.9.3.2-1

Equation 6.10.9.3.2-2

Equation 6.10.9.3.2-3

Equation 6.10.9.3.2-4

Equation 6.10.9.3.2-5

Equation 6.10.9.3.2-6

Equation 6.10.9.3.2-7

Equation 6.10.9.3.2-8

Equation 6.10.9.3.3-1

Equation 6.10.9.3.3-2 


\subsubsection{AASHTO Live Load Distribution Factors (LLDFs)}

In lieu of a complex three-dimensional analysis, live load distribution factors are commonly employed by bridge engineers to simplify the analysis of a bridge system. Specifically, instead of analyzing the three-dimensional bridge system as a whole, these factors allow for a designer or analyst to consider bridge girders individually by determining the maximum number of lanes that may act on a given girder.

AASHTO Specifications include a number of geometric restrictions that tub girder crosssections must satisfy in order to utilize AASHTO methods for determining LLDFs for use in line girder analysis. The distance center-to-center of flanges of adjacent boxes, a, taken at midspan, shall neither be greater than 120 percent nor less than 80 percent of the distance center-to-center of the flanges of each adjacent box, w, as shown in Figure 2.9. Also, if nonparallel girders are used, the distance center-to-center of adjacent flanges at supports shall neither be greater than 135 percent nor less than 65 percent of the distance center-to-center of flanges of each adjacent girder. Additionally, bearing lines shall not be skewed, and the inclination of the web plates shall not exceed a 1 to 4 slope. In the case of bridges with support skew, additional torsional effects occur in the box sections and the lateral distribution of loads is also affected. For these cases, refined structural analysis is necessary to perform a more rigorous analysis of stresses. Finally, the cantilever overhang of the concrete deck, including curb and parapet, shall not be greater than either 60 percent of the average distance between the centers of the top steel flanges of adjacent box sections, a, or 6.0 feet. 


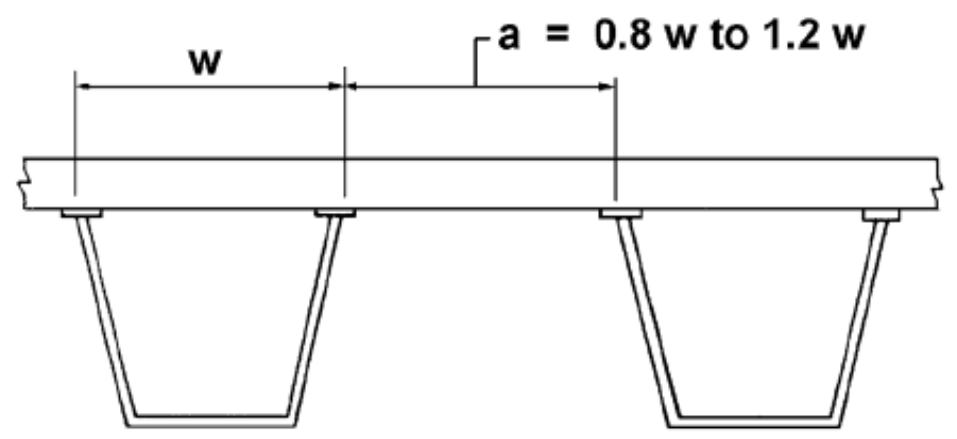

Figure 2.9: Center-to-Center Flange Distance (AASHTO, 2014)

For tub girders that meet the geometric restrictions listed above, AASHTO specifications reference Article 4.6.2.2.2b which provides LLDFs for moment in interior beams for various types of bridge superstructures. Article 4.6.2.2.2d, which provides LLDFs for moment in exterior beams, specifies that the methods used to calculate LLDFs in Article 4.6.2.2b shall be used for exterior girders as well. Therefore, LLDFs for a concrete deck on multiple steel box girders for both moment and shear are calculated as follows, regardless of the number of design lanes loaded:

$$
\begin{aligned}
& 0.05+0.85 \frac{N_{L}}{N_{b}}+\frac{0.425}{N_{L}} \\
& 0.5 \leq \frac{N_{L}}{N_{b}} \leq 1.5 \\
& N_{L}=\text { number of design lanes as specified in Article 3.6.1.1.1 } \\
& N_{b}=\text { number of girders }
\end{aligned}
$$


AASHTO specifications use multiple presence factors to account for the possibility of multiple bridge lanes being loaded simultaneously. The AASHTO multiple presence factors are shown below in Table 2.2. It should be noted that these factors are not to be used when considering the fatigue truck; when assessing fatigue, one design truck is used, regardless of the number of design lanes.

Table 2.3: Multiple Presence Factors (AASHTO, 2014)

\begin{tabular}{|c|c||}
\hline Number of Loaded Lanes & $\begin{array}{c}\text { Multiple Presence } \\
\text { Factors, } m\end{array}$ \\
\hline \hline 1 & 1.20 \\
\hline 2 & 1.00 \\
\hline 3 & 0.85 \\
\hline$>3$ & 0.65 \\
\hline \hline
\end{tabular}




\section{Chapter 3: DeSign AND Construction OF The AMiSh SAWMill BRIDGE}

\subsection{INTRODUCTION}

The following chapter discusses the design and construction of the Amish Sawmill Bridge in Buchanan County, Iowa. This chapter includes an explanation for why a bridge replacement was needed, a summary of the design and construction, and a discussion of various accelerated bridge construction methods that can be used to install press-brake-formed tub girders.

\subsection{NEED FOR BRIDGE REPLACEMENT}

The existing Amish Sawmill Bridge was a 24-foot by 30-foot timber structure with full concrete abutments and pier built in 1966 (See Figure 3.1). The bridge was constructed on the abutments from a previous bridge. Prior to the summer of 2015, the bridge was deemed structurally deficient and functionally obsolete by certified bridge inspectors, and it was one of several bridges slated for replacement by the Buchanan County engineer's office. Through his involvement in the SSSBA, Buchanan County engineer Brian Keierleber had learned about the development of press-brake-formed steel tub girders, which met the requirements for the Federal Highway Administration's (FHWA) Innovative Bridge Research and Deployment (IBRD) program. The IBRD program provides funds to promote innovative designs, materials, and construction methods in the construction, repair, and rehabilitation of bridges and other highway structures (Federal Highway Administration, 2012). Members of the SSSBA worked with the Buchanan County engineer's office to assist them in the development of an IBRD application in 2014. The grant was approved on the basis of using a trapezoidal bent steel girder section supported on Geosynthetic Reinforced Soil (GRS). 


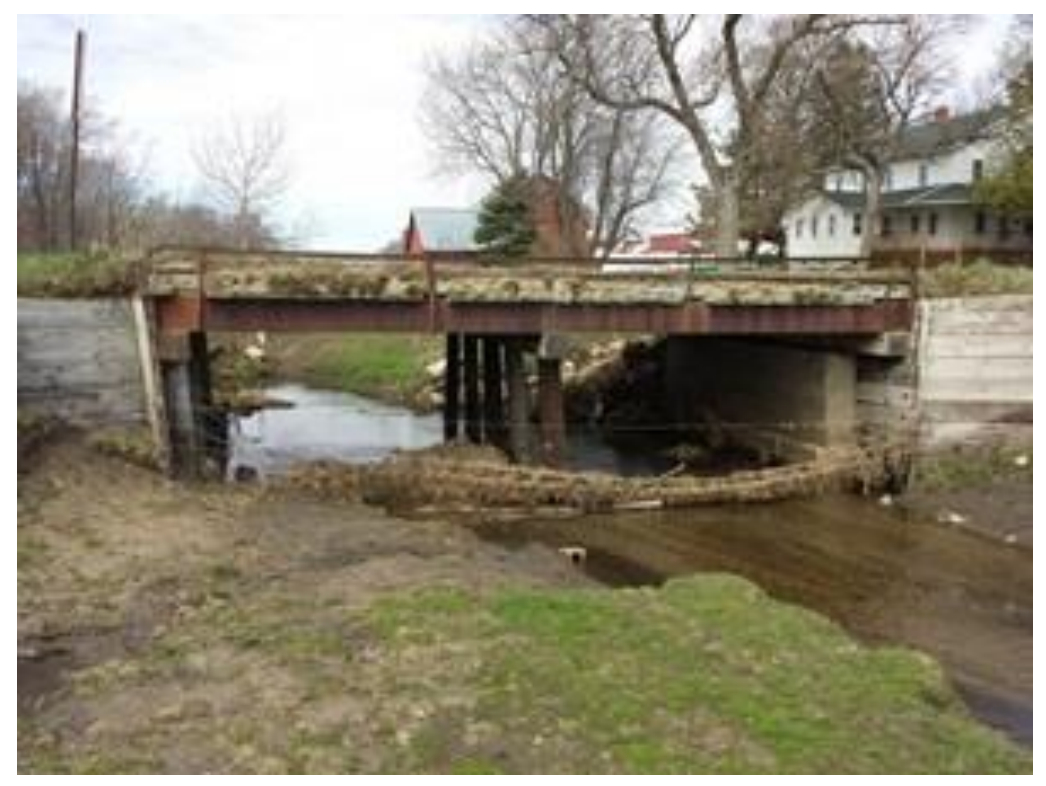

Figure 3.1: Existing Amish Sawmill Bridge, Constructed in 1966

\subsection{SUMMARY OF DESIGN AND CONSTRUCTION}

The Amish Sawmill Bridge, as shown in Figure 3.2, is a 52-foot long, single span pressbrake-formed steel tub girder bridge located in Fairbank, Iowa. As mentioned, this is the first bridge to utilize the press-brake-formed steel tub girder design that was formulated by members of the SSSBA. Construction on the bridge began late in the summer of 2015, and was completed in the following December 2015. The bridge carries local traffic on Dillon Avenue, and spans an unnamed creek that flows in to the Wapsipinicon River. 


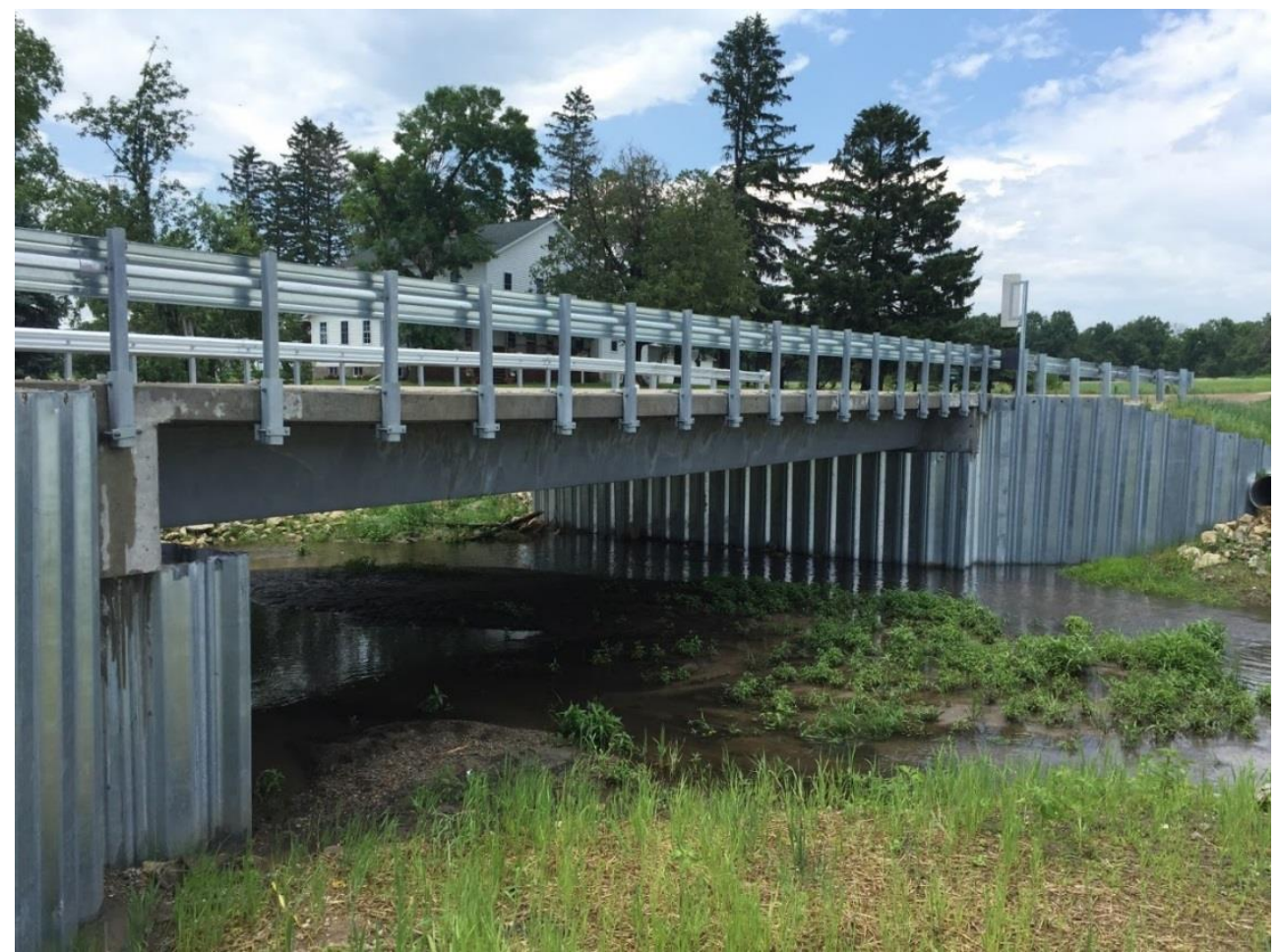

Figure 3.2: General Photo of the New Amish Sawmill Bridge

The four press-brake-formed tub girders that support the bridge were made from 96-inchwide by $1 / 2$-inch thick steel plates, and were galvanized before being taken to the bridge site. Figure 3.3 shows the cross-sectional dimensions of one of the girders. The girders are spaced $71 / 2$ feet apart. The bridge was constructed with a total of six steel diaphragms; two between each girder, $17 \frac{1}{2}$ feet from each end. The concrete deck is 31 feet-3 inches wide, with a thickness of $81 / 2$ inches. Although contractors chose to utilize a cast-in-place deck option for the Amish Sawmill Bridge, a number of pre-cast deck options are possible to be used with press-brake-formed tub girders, as is discussed in Section 3.4. A general cross-section of the bridge is illustrated in Figure 3.4 . 


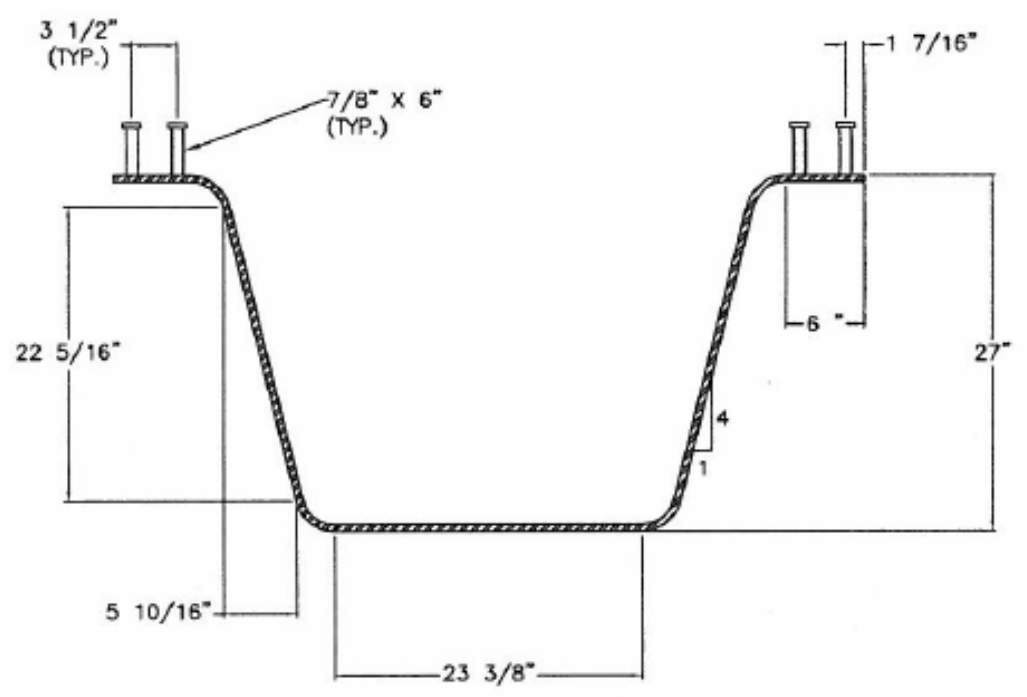

Figure 3.3: Dimensional Cross-Section of Single Girder

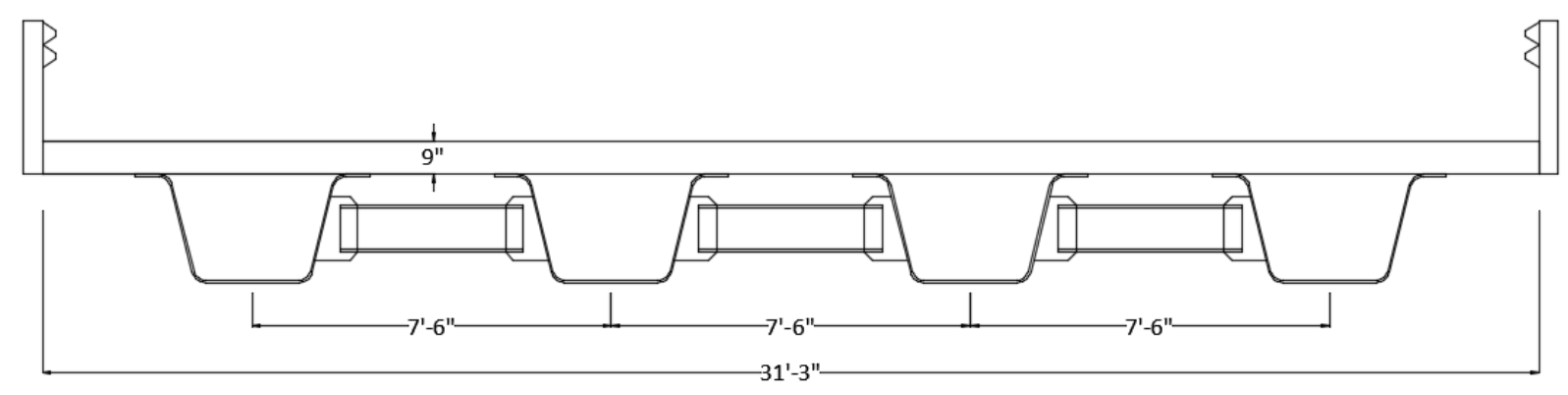

Figure 3.4: General Cross-Section of Amish Sawmill Bridge

In addition to using the tub girders, the FHWA provided another requirement for the Amish Sawmill Bridge when awarding the IBRD grant. The bridge would also need to utilize Geosynthetic Reinforced Soil (GRS). The project included the construction of GRS integral abutments with a sheet piling face, which helped reduce construction time. 


\subsection{ACCELERATEd BRIDGE CONSTRUCTION METHODS}

Accelerated Bridge Construction ( $\mathrm{ABC}$ ) is an extremely prevalent subject in the field of bridge construction and engineering. As the lifespans of an increasing number of bridges are coming to an end, a significant need has emerged to replace those bridges with newer designs that can both be constructed quickly, and ensure longevity. Press-brake-formed tub girders are extremely $\mathrm{ABC}$ compatible in a number of ways.

First, the tub girders themselves can be fabricated economically and quickly compared to other alternatives. All girders are made from standard plate width sizes (60", 72", 84", etc.) that are widely available from North American mills, as well as service centers. Sections are standardized for specific targeted span ranges. The fabrication process can be completed in 30 45 minutes, which is significantly shorter than the time it takes to produce more traditional bridge girders.

Another way the tub girders can be utilized to achieve rapid bridge replacement is by exploring a number of different modular deck options. Most commonly, shear studs are welded onto the top flanges of each girder, and then a reinforced concrete deck is pre-cast off site on top of either one or two girders. These modular units are then shipped to the bridge site where they can quickly be set in place with a crane. Once in place, a number of different joint options can be utilized to join the modular components including ultra-high-performance concrete, or a more traditional construction joint. Another deck option that has been utilized with the tub girders is the "Sandwich Plate System" (SPS) technology. The SPS deck consists of two metal plates bonded with a polyurethane elastomer core (Intelligent Engineering). Similar to the method described above, modular units are created by bolting a SPS deck to the top flanges of the girders off site, and are then shipped to the bridge site to be set in place. Once in place, the modular units are bolted together to produce a compositely acting system. This deck option was used with the pressbrake-formed steel tub girders for the first time on a bridge in Muskingum County, Ohio, where the entire superstructure was set in approximately 20 minutes. One of two modular units for the Muskingum County bridge is shown in Figure 3.5. 


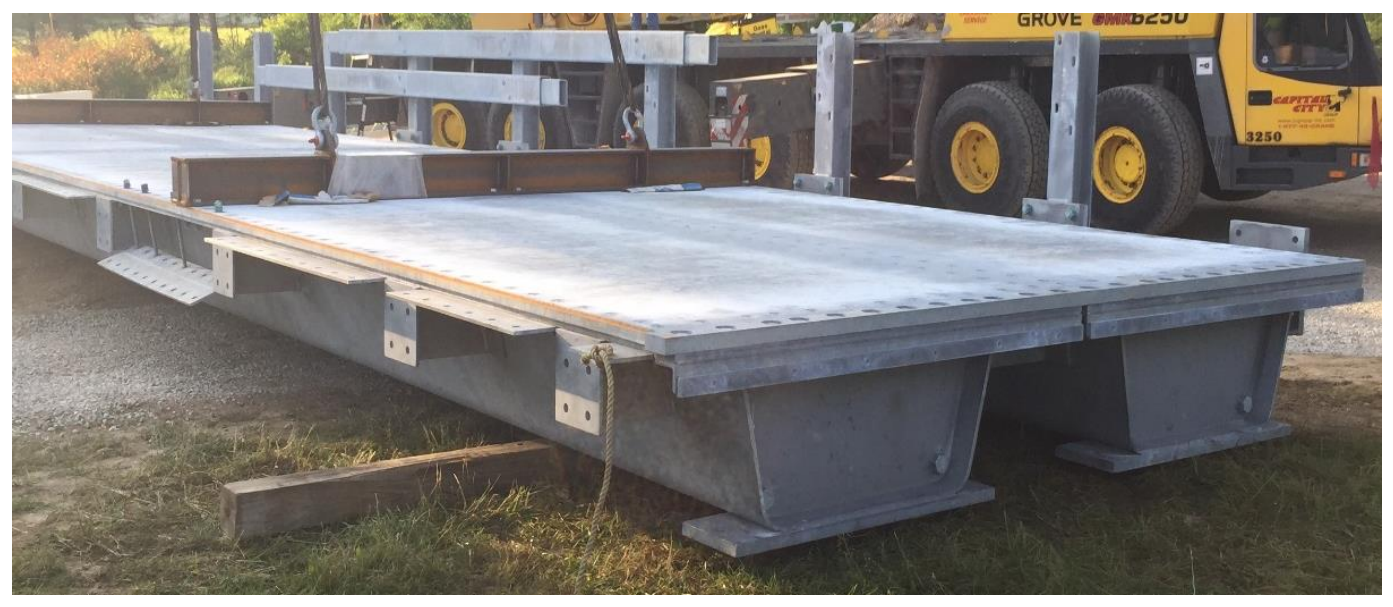

Figure 3.5: Modular SPS Deck/Tub Girder System in Muskingum County, OH 


\section{CHAPTER 4: RESEARCH METHODS}

\subsection{INTRODUCTION}

This chapter contains an overview of the research methods used to assess the Amish Sawmill Bridge. This includes a description of the experimental testing equipment used in the field, as well as an overview of finite element modeling and data reduction methods used.

\subsection{EXPerimental Testing EquipMent}

The following section provides a descriptive list of testing equipment that was used to perform the live load field test of the Amish Sawmill Bridge.

\subsubsection{STS-WiFi Data Acquisition System}

During the field test, data was collected using an assortment of wireless testing equipment and software from Bridge Diagnostics, Inc. (BDI). The BDI system used includes a series of wireless nodes, which can each accommodate up to four BDI strain transducers, a wireless base station, and a laptop to run the BDI software. The instruments used for this field test were BDI strain transducers which will be discussed in Section 4.2.2. Each instrument used was equipped with BDI's "Intelliducer" chip, which allows the equipment to identify itself in the software. This allows for much easier data collection and organization, especially during post-processing when trying to distinguish data collected from different gages. Although all of the equipment used in this field test is capable of running on batter power alone, a generator was provided by the Buchanan County Secondary Roads Department which was used to ensure there were no power losses during testing. 
The primary physical components of the system used consist of a wireless base station and multiple 4-channel nodes, which are shown in Figures 4.1 and 4.2, respectively. The base station receives information by monitoring real-time wireless broadband signals that are transmitted from the 4-channel nodes. The base station is capable of taking readings of up to 500 samples per second $(500 \mathrm{~Hz})$, and can monitor a wide number of instruments on 4 to 128 channels.

This test system provides a number of significant advantages to users in the field. First, both the base station and 4-channel nodes are capable of running on battery power alone. Each piece of equipment is powered by rechargeable $9.6 \mathrm{~V}$ Makita $\mathrm{Ni}-\mathrm{MH}$ batteries that can last up to six hours under continuous use. This allows users plenty of time to collect data during field testing without having to worry about providing a power source or recharging batteries. Additionally, having wireless equipment allows for much easier data acquisition, especially if the testing location is difficult to access. Another advantage of the BDI testing system is the quality and durability of each piece of equipment. Individual testing components could be strapped to the bridge and left in place overnight with no concern of being damaged.

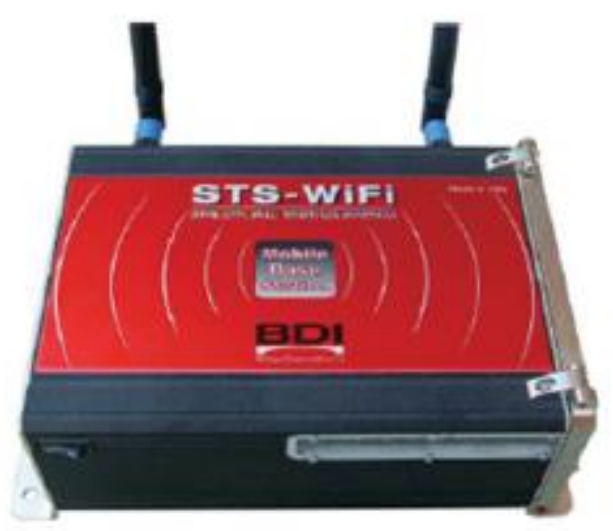

Figure 4.1: STS Wifi Wireless Base Station (BDI) 


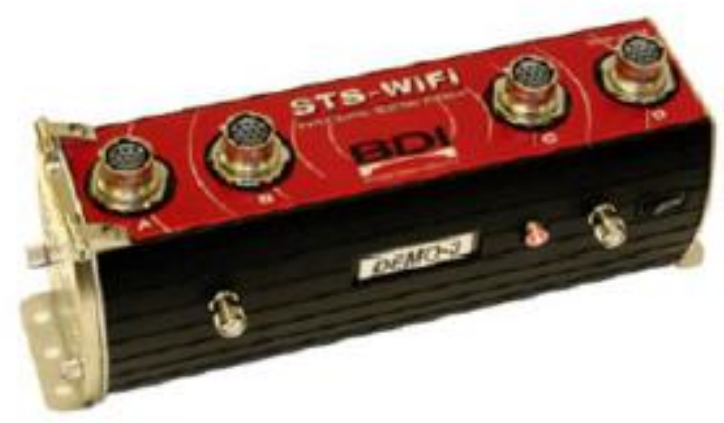

Figure 4.2: STS WiFi Wireless 4-Channel Node (BDI)

\subsubsection{BDI Strain Transducers}

BDI's re-usable strain transducers (Shown in Figure 4.3) were chosen as the strain gages to be utilized during this testing. These gages were used due to a number of benefits they provide, especially for an outdoor field test. Each strain gage has a range of $\pm 2,000 \mu \varepsilon$ with an accuracy of \pm 2 percent. Each gage also has a temperature range of $-60^{\circ} \mathrm{F}$ to $+250^{\circ} \mathrm{F}$, and requires minimal surface preparation and effort to install. The gages are attached to the girder by two re-usable mounting tabs. The mounting tabs fit through two holes on each end of the gage and the gage is tightened snug with two 7/16-in. nuts. Each tab is placed into a slotted BDI jig during this process to ensure proper alignment and spacing of the tabs. After proper measurements have been taken, the girder surface is prepared using a disk grinder to clean off the areas where the tabs will be mounted. Loctite 410 Black Toughened Adhesive is used to attach the tabs to the girder. Once the adhesive dries and the nuts are tightened down, the only remaining task is to plug the gages into the wireless nodes. 


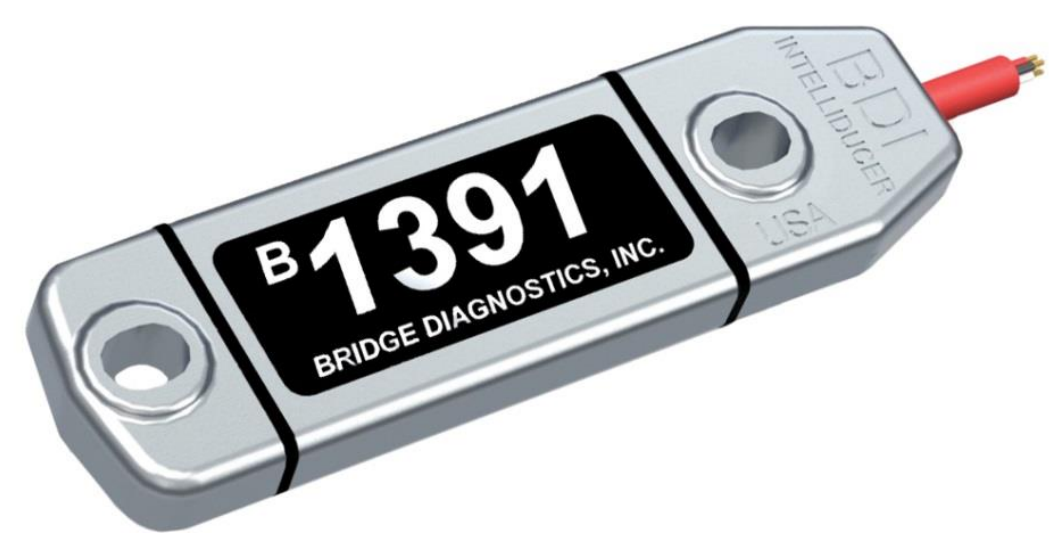

Figure 4.3: BDI Strain Transducer

\subsubsection{Load Truck and Wheel Scales}

The live load for the field test was produced by a fully loaded tandem-axle dump truck provided by the Buchanan County Secondary Roads Department which is shown in Figure 4.4. The weight of each axle was taken prior to the arrival of the truck at the bridge site.

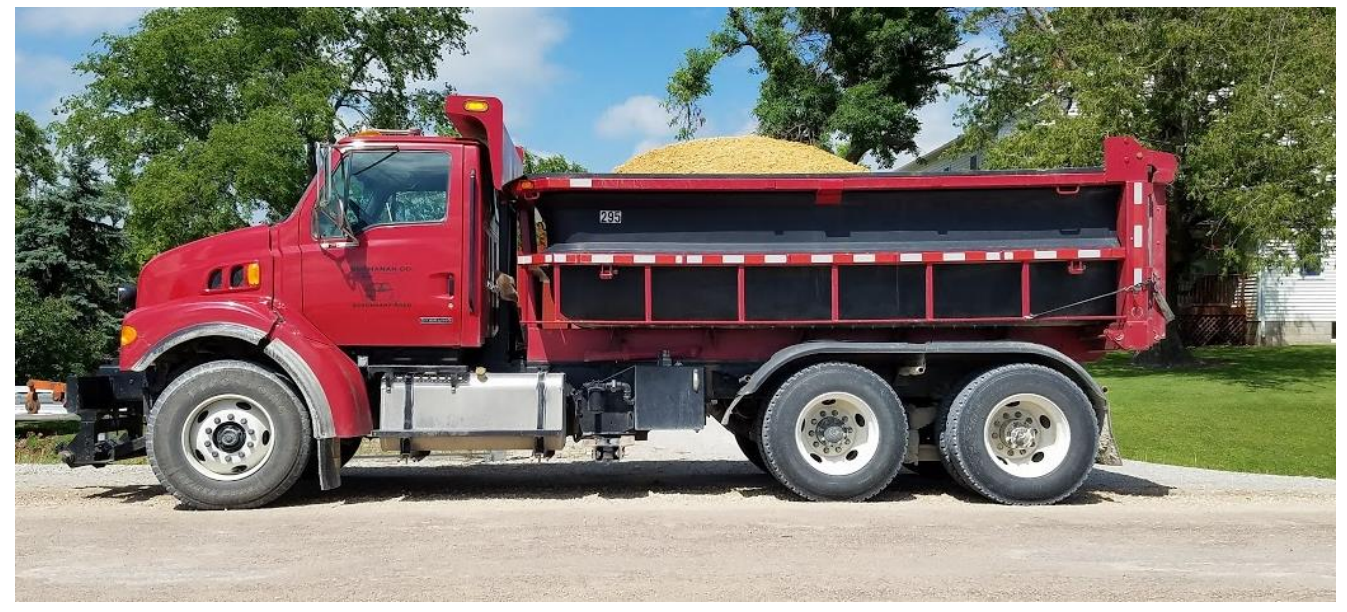

Figure 4.4: Tandem-Axle Dump Truck 


\subsection{Finite ELEMENT Modeling}

To compare the results obtained from the field test to an analytical model, Abaqus/CAE 6.12-1 (Dassault Systèmes, 2012) was utilized to create a finite element model of the Amish Sawmill Bridge. Upon completion of the model, loads were placed to simulate each wheel location of the tandem-axle dump truck during the field test. This will be further discussed in Section 4.3.5. The model was analyzed to compare strains, stresses, and live load distribution factors for each girder. The ensuing section will discuss the techniques and methods used to create the finite element model used in this research.

\subsubsection{Material Definitions}

The incorporation of nonlinear behavior would create difficulties in predicting the strain and live load distribution since strain values would be somewhat unpredictable once stresses exceeded the yield point. As a result, all materials were modeled as linear, elastic, isotropic mediums. It should also be noted that the maximum stress values for both the steel and concrete in the model were found to be well below the yield stress for steel or the compressive strength of concrete, respectively. This indicates that that the modeling of the materials as linear elastic mediums was appropriate. This conclusion has also been made by other researchers. Eom and Nowak (2001) concluded, after testing 17 steel I-girder bridges in Michigan, that the observed response of these bridges under the application of live load was linear throughout their study.

Specifically, the following material properties were employed:

- For reinforced concrete, which was taken to have a compressive strength of $4.0 \mathrm{ksi}$, according to the previsions of AASHTO LRFD Section 5.4.2.4, the modulus of elasticity was determined to be $3640 \mathrm{ksi}$. Also, according to AASHTO LRFD Section 5.4.2.5, Poisson's ratio was taken to be 0.2 . 
- For steel, which was taken to have a yield strength of $50 \mathrm{ksi}$, according to the provisions of AASHTO LRFD Section 6.4.1, the modulus of elasticity was taken to be $29,000 \mathrm{ksi}$. Also, Poisson's ratio was taken to be 0.3 .

\subsubsection{Element Sections}

The finite element model of the Amish Sawmill Bridge only includes one type of element; 4-node, doubly-curved, finite-membrane-strain, general-purpose shell elements with reduced integration. These are referred to in the Abaqus/Standard User's Manual as S4R elements. S4R elements made up each part of the model and produced accurate results upon completion of the model.

\subsubsection{Mesh Discretization}

AASHTO LRFD Section 4.6.3.3 (American Association of State Highway Transportation Officials, 2014) outlines certain specifications and guidelines that should be followed when modeling beam-slab bridges. For example, the code states that the aspect ratio of finite elements should not exceed 5.0 and abrupt changes in size and/or shape of elements should be avoided.

For the Amish Sawmill Bridge finite element model, the mesh discretization was designed to follow AASHTO LRFD specifications and also generate accurate results. For each tub girder, each of the following parts were independently "seeded" to make up the discretization; top flanges, webs, bends, and the bottom flange. The "seeding" for one of the girders is shown in Figure 4.5; there are two elements along each top flange, seven along the webs, three around each bend, and 7 along the bottom flange. Each element was approximately three inches long. 


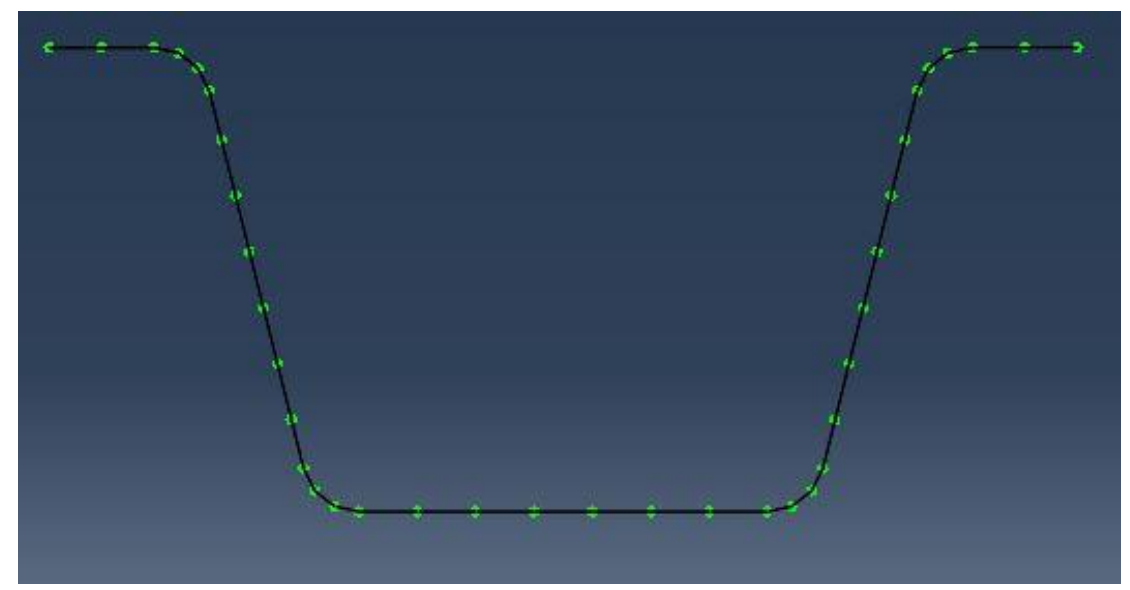

Figure 4.5: Standard Mesh Seeding for Each Tub Girder

The mesh discretization for the deck consisted of 210 elements along the length of the bridge and 116 elements along the width. Each deck element is approximately 3" x 3". The diaphragms at the end of each girder were modeled to match the mesh density along the webs and bottom flange of the girders to ensure consistent behavior. Finally, the steel channel diaphragms between the girders were discretized through a trial and error method until the desired mesh was achieved. The connection plates for the diaphragms were modeled to match the discretization along the webs of each girder. The element's shapes and sizes within the diaphragm vary slightly, but not extensively enough to have any effect on the outcome of the model.

\subsubsection{Boundary Conditions and Multiple-Point Constraints}

The boundary conditions applied to the Amish Sawmill Bridge model represented common simple span "hinge-roller" conditions. Also, as is common with bridge construction, the girder ends were restrained from lateral movement as well. These boundary conditions were placed on the nodes along the edges of the bottom flange of each girder. Additionally, Multiple-Point Constraints (MPC's) were used to ensure composite action within the model. MPC's are a general tool in Abaqus used to relate degrees of freedom to one another within the model. Without MPC's, Abaqus would not properly transfer the live load from the concrete deck to the steel girders. For 
the Amish Sawmill Bridge model, MPC's were placed on nodes between the concrete deck and top flanges of each girder. MPC's were also placed between the steel channel diaphragms and their corresponding connection plates.

\subsubsection{Application of Live Loading}

Once the truck placement positions were determined from experimental testing (See Section 5.2), the corresponding elements in the model that each wheel point load fell on were identified. Since most of the loads did not line up on exact nodes, wheel point loads were linearly distributed to the neighboring nodes of each of these elements. A schematic of this loading is shown in Figure 4.6. Also, Equation 4-1 through Equation 4-4 describe the nodal loads shown in Figure 4.6.

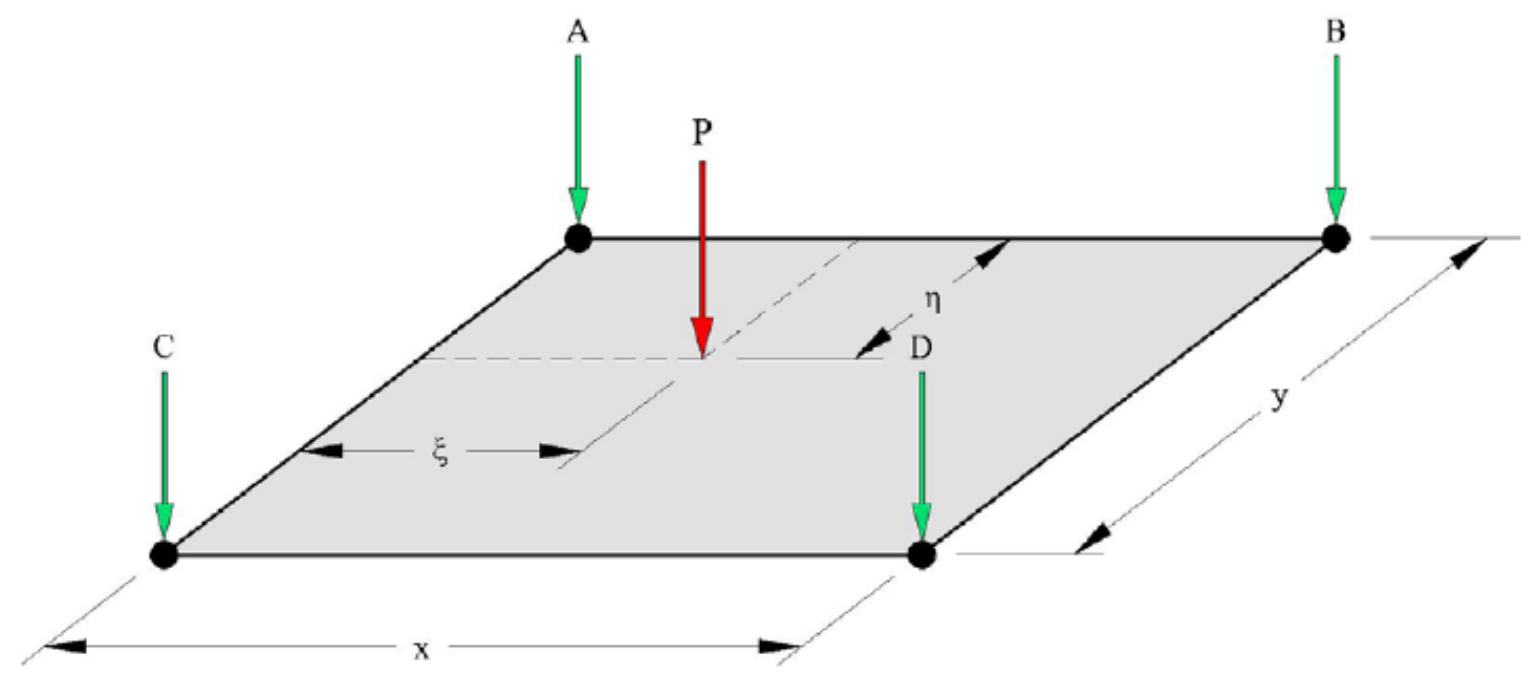

Figure 4.6: Schematic of Nodal Distribution of Point Loads (Michaelson, 2010) 


$$
\begin{aligned}
& A=P\left(1-\frac{\xi}{x}\right)\left(1-\frac{\eta}{y}\right) \\
& B=P\left(\frac{\xi}{x}\right)\left(1-\frac{\eta}{y}\right) \\
& C=P\left(1-\frac{\xi}{x}\right)\left(\frac{\eta}{y}\right) \\
& D=P\left(\frac{\xi}{x}\right)\left(\frac{\eta}{y}\right)
\end{aligned}
$$

Equation 4-3

Equation 4-4

According to AASHTO LRFD Section 4.6.3.3.1, nodal loads shall be statically equivalent to the actual loads being applied. As seen above, once summed, the equations corresponding to Figure 4.6 will equal the applied point load.

\subsection{DAta REduCtion Methods}

Three strain gages were placed at midspan on the bottom flange of each girder during testing. The raw data collected from both the physical live load test and the finite element model consisted of strain readings (measured in microstrain, $\mu \varepsilon$ ) at the locations of each of these gages. The strain values for each respective girder were isolated and averaged in order to obtain a midspan strain value at each panel point. This calculation was performed for each of the five truck runs completed during testing. The exact location of the load truck during each truck run, as well as strain gage locations, is discussed in Section 5.2. Further data for each truck run, including midspan bending stresses and live load distribution factors, was generated from these strain values in order to compare the experimental and analytical results. The methods used to calculate the data are outlined in the following section. This section will also discuss the computation of AASHTO live load distribution factors for steel bridge tub girders as discussed in Section 2.5. 


\subsubsection{Computation of Midspan Bending Stresses}

The strain data from the bottom flange gages, for each girder, was isolated and averaged to obtain a single midspan strain value at each panel point. This was completed for all five truck runs. These strain values were used to compute midspan bending stresses so the maximum stress in each girder could be evaluated. To obtain the midpan bending stresses, the strain values were first divided by $1,000,000$, since the values were measured in microstrain. After converting the data from microstrain to strain, the values were multiplied by the Young's Modulus of steel, 29,000 $\mathrm{ksi}$, yielding the midspan bending stress in units of kip/in ${ }^{2}$ (ksi). An example calculation showing the steps to calculate midspan bending stress from the raw data is shown below.

Midspan Strain Values for Girder 2, Truck Run 2, Panel Point 5:

\begin{tabular}{|c|c|c|c|}
\hline Gage Number & G07 & G08 & G09 \\
\hline Strain Reading $(\boldsymbol{\mu \varepsilon})$ & 101.62 & 97.17 & 93.11 \\
\hline
\end{tabular}

Average of Values:

$$
\varepsilon_{\text {avg }}=\frac{\sum \varepsilon}{3}=\frac{101.62+97.17+93.11}{3}=97.30 \mu \varepsilon
$$

Converting Strain to Bending Stress:

$$
\sigma=\frac{\varepsilon_{\text {avg }}}{1,000,000} \times E_{s}=\frac{97.30}{1,000,000} \times 29,000=\mathbf{2 . 8 2} \mathbf{k s i}
$$

where: $\sigma=$ bottom flange bending stress

$$
\begin{aligned}
& \varepsilon_{\mathrm{avg}}=\text { average bottom flange strain }(\mu \varepsilon) \\
& \mathrm{E}_{\mathrm{s}}=\text { Young's Modulus of steel }
\end{aligned}
$$




\subsubsection{Computation of Live Load Distribution Factors}

Live load distribution factors (LLDFs) were generated from the average strain values for each girder mentioned above in Section 4.4.1. The general equation (Equation 4-5) used to calculate LLDFs is shown below. In order to calculate LLDFs for each panel point, the strain in each respective girder was divided by the total strain in the system at that panel point. This calculation was completed for each panel point in a given truck run. Next, each girder's LLDF for each panel point was averaged to obtain one distribution factor for each girder per truck run. In order to effectively compare these values with AASHTO LLDFs, the experimental and analytical LLDFs were multiplied by a multiple presence factor of 1.2 as described in Section 2.5.2.

$$
g_{i}=\frac{n \varepsilon_{i}}{\sum_{j=1}^{k} \varepsilon_{j}} * m
$$

where: $g_{i}=$ distribution factor for the "i $i$ 'th" girder

$$
\begin{aligned}
& \varepsilon_{\mathrm{i}}=\text { bottom flange static strain at the " } \mathrm{i} \text { 'th" girder } \\
& \mathrm{n}=\text { number of applied design trucks } \\
& \mathrm{k}=\text { number of girders } \\
& \mathrm{m}=\text { AASHTO multiple presence factor }
\end{aligned}
$$

LLDFs were also calculated for simulated scenarios in which two lanes were loaded simultaneously (Truck Runs $1 \& 4$ and Truck Runs $2 \& 5$ ). In order to obtain results for these simulated scenarios, strain values from each single truck run were added together and LLDFs were calculated as described above. Example calculations showing the computation of LLDFs for both single and two-lane loading scenarios are presented below. 


\section{Single-Lane Loading:}

Average Midspan Strain Values for Truck Run 2, Panel Point 5:

\begin{tabular}{|c|c|c|c|c|}
\hline Girder Number & G1 & G2 & G3 & G4 \\
\hline Avg. Strain $(\boldsymbol{\mu} \varepsilon)$ & 118.54 & 97.30 & 50.54 & 23.22 \\
\hline
\end{tabular}

Calculating LLDF for Girder 1, Panel Point 5:

$$
L L D F_{G 1-5}=\frac{\varepsilon_{G 1}}{\sum_{j=1}^{k} \varepsilon_{j}}=\frac{118.54}{118.54+97.30+50.54+23.22}=0.409
$$

Note: This is the LLDF for Girder 1, Panel Point 5. LLDFs were calculated for all nine panel points and then averaged, which is shown in the next step. The sum of these LLDFs was 3.631 for this example.

Calculating Average LLDF in Girder 1, Truck Run 2:

$$
L L D F_{G 1}=\frac{\sum G 1 L L D F s}{9 \text { panel points }}=\frac{3.631}{9}=0.403
$$

Applying AASHTO Multiple Presence Factor to Girder 1, Truck Run 2 LLDF:

$$
L L D F_{G 1}=0.403 \times m=0.403 \times 1.2=\mathbf{0 . 4 8 4}
$$


Two-Lane Loading:

Average Midspan Strain Values for Truck Runs 1 \& 4, Panel Point 5:

\begin{tabular}{|c|c|c|c|c|}
\hline Girder Number & G1 & G2 & G3 & G4 \\
\hline $\begin{array}{c}\text { Avg. Strain for } \\
\text { Truck Run 1 }(\boldsymbol{\mu \varepsilon})\end{array}$ & 138.85 & 91.86 & 41.84 & 16.93 \\
\hline $\begin{array}{c}\text { Avg. Strain for } \\
\text { Truck Run 4 }(\boldsymbol{\mu \varepsilon})\end{array}$ & 41.94 & 75.31 & 97.17 & 76.52 \\
\hline
\end{tabular}

Summing Strain Values for Girder 1, Truck Runs 1 \& 4:

$$
\varepsilon_{G 1}=\varepsilon_{G 1,1}+\varepsilon_{G 1,4}=138.85+41.94=180.79 \mu \varepsilon
$$

Note: Strain values from the two truck runs were also summed for the other girders. The combined strain values for Girders 2, 3, and 4 were respectively 167.17, 139.01, and 93.45. These values were added to the strain for Girder 1, calculated above, to obtain the total strain in the system, which is used below.

Calculating LLDF for Girder 1, Panel Point 5:

$$
L L D F_{G 1-5}=\frac{n \varepsilon_{G 1}}{\sum_{j=1}^{k} \varepsilon_{j}}=\frac{2 \times 180.79}{180.79+167.17+139.01+93.45}=0.623
$$

Note: This is the LLDF for Girder 1, Panel Point 5. LLDFs were calculated for all nine panel points using the methods above and then averaged, which is shown in the next step. The sum of these LLDFs was 5.618 for this example. 
Calculating Average LLDF in Girder 1, Truck Runs 1 \& 4:

$$
L L D F_{G 1}=\frac{\sum G 1 L L D F s}{9 \text { panel points }}=\frac{5.618}{9}=\mathbf{0 . 6 2 4}
$$

Note: Since the AASHTO multiple presence factor for two-lane loading is equal to one, the LLDF for Girder 1 is 0.624 .

In order to compare the experimental and analytical data to AASHTO specifications, LLDFs were also calculated using the methodology discussed in Section 2.5.2. As stated in Section 2.5.2, the AASHTO methodology for calculating LLDFs for both interior and exterior tub girders is the same. The computation of AASHTO LLDFs for both single and two-lane loading is shown below. It should also be noted that multiple presence factors are already factored in to the AASHTO methodology. LLDFs for a concrete deck on multiple steel box girders for both moment and shear are calculated as follows, regardless of the number of design lanes loaded:

$$
\begin{aligned}
& 0.05+0.85 \frac{N_{L}}{N_{b}}+\frac{0.425}{N_{L}} \\
& 0.5 \leq \frac{N_{L}}{N_{b}} \leq 1.5 \\
& N_{L}=\text { number of design lanes as specified in Article 3.6.1.1.1 } \\
& N_{b}=\text { number of girders }
\end{aligned}
$$

\section{Single-Lane Loading:}

$$
0.05+0.85\left(\frac{1}{4}\right)+\frac{0.425}{1}=\mathbf{0 . 6 8 7 5}
$$

Two-Lane Loading:

$$
0.05+0.85\left(\frac{2}{4}\right)+\frac{0.425}{2}=\mathbf{0 . 6 8 7 5}
$$




\section{Chapter 5: Field TeSting OF The Amish SAWMILl BRIDGe}

\subsection{INTRODUCTION}

In June 2016, researchers from West Virginia University and Marshall University traveled to Fairbank, Iowa to perform a live load field test on the Amish Sawmill Bridge. The goal of the testing was to evaluate the performance of the bridge by comparing experimental results measured in the field to analytical results obtained from finite element modeling analysis. This section of the thesis outlines the instrumentation plan and testing procedure used for the live load field test that was completed.

\subsection{LiVE LOAD FIELD TEST ASSESSMENT}

The field test of the Amish Sawmill Bridge was completed in three days. On the first day of the field test, measurements were taken, locations for each strain gage were marked onto the girders, and the surface of each girder was prepared to apply the re-usable tabs which hold each gage in place. The surface roughness of the girders was treated using a disk grinder to ensure the tabs would properly adhere to the steel. During the second day of the field test, gages were tightened onto each set of tabs, and plugged in to one of four wireless nodes that were used. The

girders were labeled 1 through 4 from left to right, looking north, as shown in Figure 5.1. The last day of the field test consisted of verifying the equipment status, collecting data for each run during the live load test, and demobilizing the bridge site. 


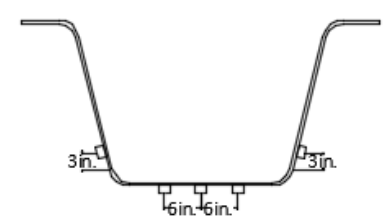

G1

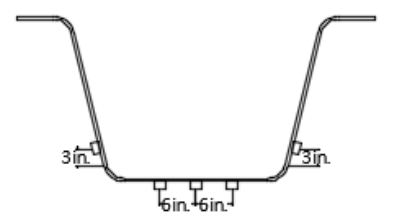

G2

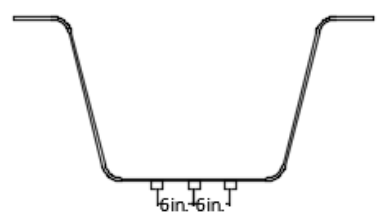

G3

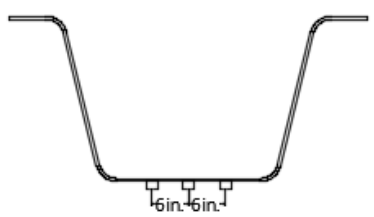

G4

Figure 5.1: Gage Locations on Each Girder (Looking North)

A total of 16 gage locations were prepared for this field test. Each girder was equipped with a minimum of three gages on the bottom flange at midspan. Girders 1 and 2 were equipped with two additional gages each at midspan; one on each web of each girder, three inches above the bend in the girders. The bottom flange gages were spaced six inches apart along quarter points across the width of the bottom flange. Exact gage locations on each girder are shown in Figure 5.1 .

On the day of testing, axle measurements of the tandem-axle dump truck were taken upon its arrival to the bridge site. The truck is shown in Figure 5.2, and the dimensions and wheel weights are shown in Figure 5.3. This truck was deemed appropriate for this test because of its similarity to the AASHTO HS-20 design load truck.

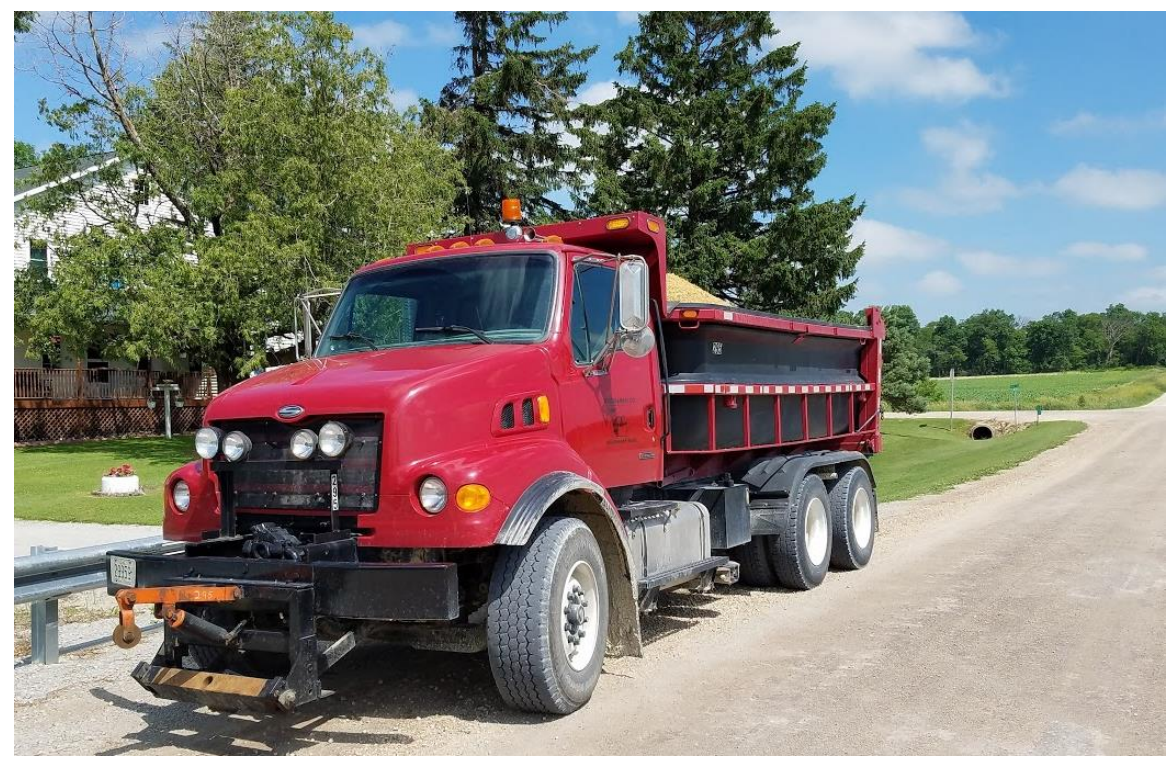

Figure 5.2: Tandem-Axle Dump Truck 


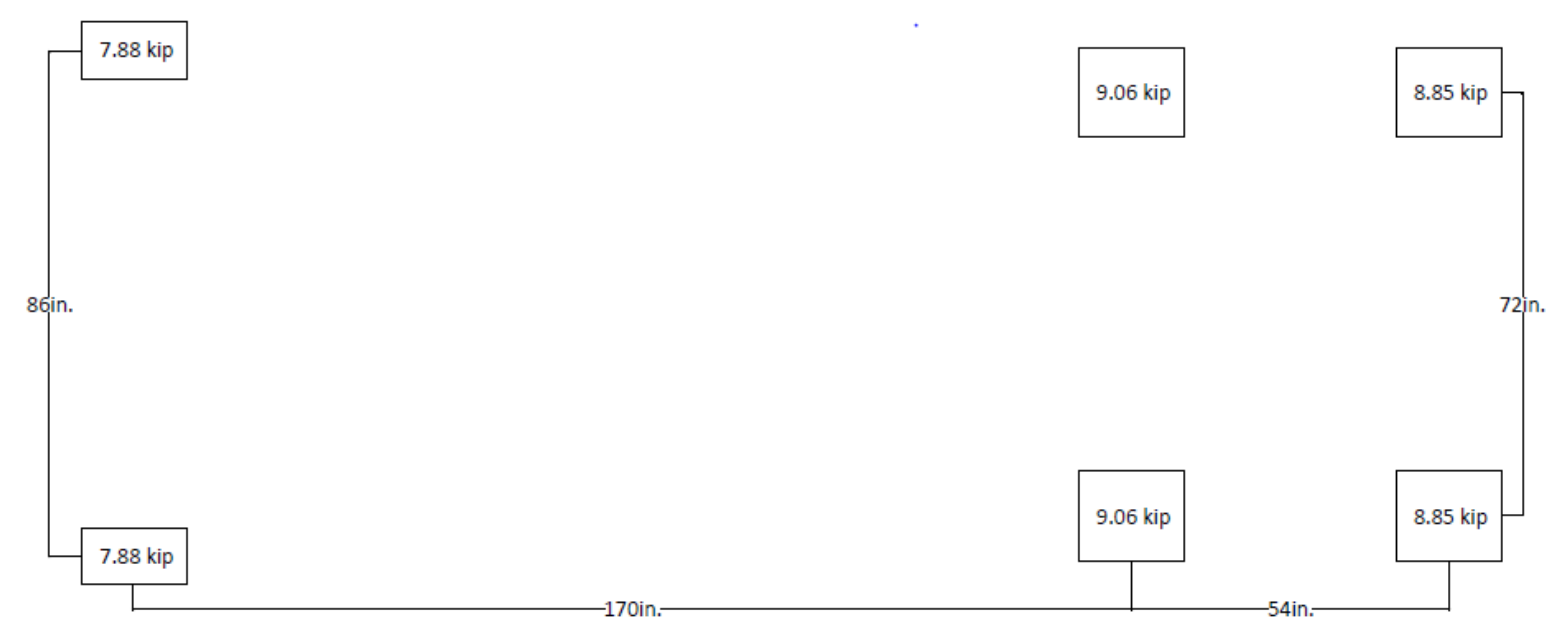

Figure 5.3: Truck Dimensions and Wheel Loads

Considering that the bridge is symmetric and not skewed, only five truck runs were needed to complete the field test. A total of five truck runs, shown below in Figure 5.4, were mapped out onto the bridge deck using chalk at each tenth point along the length of the bridge. For each run, the truck was directed to stop with the center axle resting at each tenth point on the previously marked spots. Upon moving to each new spot, time was taken to let any vibrations settle out in the girders so that the data taken was as static as possible. Measurements for each truck run were taken from the west guard rail to the center line of the front tire closest to the guard rail.

According to AASHTO (2014) Section 3.6 the worst-case loading scenario for an exterior girder places the load truck two feet from the guard rail. Therefore, Truck Run 1 was placed two feet from the guard rail. Truck Run 2 was placed so that one wheel line was directly above Girder 2 to maximize load effects on the interior girder. Truck Run 3 was placed in the center of the bridge to observe if symmetrical results were produced. Truck Run 4 was placed 12 feet from Truck Run 1, and Truck Run 5 was placed 12 feet from Truck Run 2. AASHTO Section 3.6 states that the standard lane width is equal to 12 feet. Therefore, Truck Runs 4 and 5 were placed 12 feet from Truck Runs 1 and 2, respectively, so that results for two-lane loading scenarios could be calculated. The combination of Truck Runs 1 and 4 maximizes load effects on the exterior girder, while the combination of Truck Runs 2 and 5 maximizes load effects on the interior girder. 


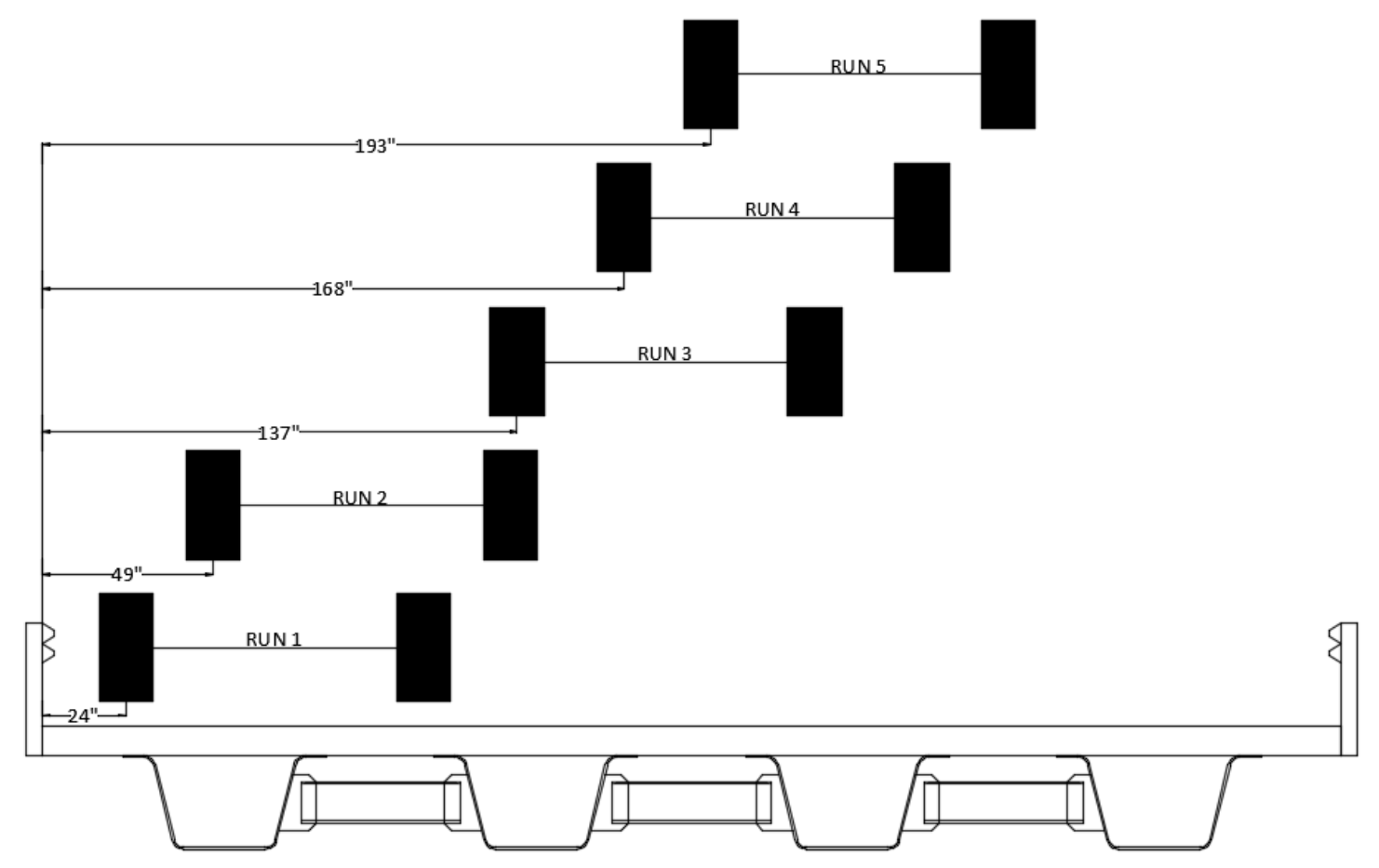

Figure 5.4: Live Load Truck Placements (Looking North) 


\section{CHAPTER 6: RESUlTS AND COMPARISONS}

\subsection{INTRODUCTION}

The following chapter will summarize the results of both the analytical and experimental tests performed on the Amish Sawmill Bridge. Data from the bridge's finite element model will be presented along with physical data obtained from the live load field test. In addition, the two sets of data will be compared and discussed in detail. Results detailed include bottom flange stresses at midspan, as well as calculated live load distribution factors (LLDFs) from each method of testing. LLDFs from each test will also be compared to LLDFs calculated using AASHTO (2014) specifications.

\subsection{COMPARISON OF RESUltS}

This section will discuss the results from the finite element model analysis and the live load field test. Comparisons between the two tests include discussion, raw data, tables, and charts to easily compare the results and draw conclusions from this testing. Appendix A includes all charts and data generated to compare the two tests, however Truck Run 2 (out of 5) will be the main test discussed in this chapter. Each truck run will not be discussed in depth because the behavior and results from each run were very similar, respective to each truck placement. The conclusions drawn from Truck Run 2 also apply to all other runs. Truck Run 2 was selected to be discussed due to the clear depiction of the distribution of loads among the girders while also having the truck placed clearly on one side of the bridge (as opposed to placement over an exterior girder or in the center of the bridge). The truck was placed over the first two girders for Truck Run 2, as shown in Figure 5.4. 


\subsubsection{Finite Element Model Results}

As mentioned in Section 4.3, Abaqus/CAE 6.12-1 (Dassault Systèmes, 2012) was utilized to create a detailed finite element model of the Amish Sawmill Bridge. The modeling methods and techniques are further discussed in that section. This section will highlight and discuss the results from running the Amish Sawmill Bridge model.

First, bottom flange stresses at midspan are compared. To remain consistent with the method used for the field test results, these stresses were calculated from strain values output by Abaqus, as opposed to taking the stress values directly from the program itself. As shown below in Table 6.1, the stresses in Girders 1 and 2 are higher due to the truck placement. Also, the stress in each girder proportionally increases as the truck approaches midspan, and then decreases as the truck passes midspan and approaches the end of the bridge. These are very simple observations, but prove that the model is running correctly.

Table 6.1: Finite Element Model Bottom Flange Stress Results

\begin{tabular}{|c|c|c|c|c|c|}
\hline \multicolumn{7}{|c|}{ Truck Run 2, Bending Stress } \\
\hline \multicolumn{5}{|c|}{ Panel Points } & \multicolumn{5}{c|}{ Average Stress (ksi) } \\
\hline $\mathrm{x}(\mathrm{ft})$ & $\mathrm{x} / \mathrm{L}$ & $\mathrm{G} 1$ & $\mathrm{G} 2$ & $\mathrm{G} 3$ & $\mathrm{G} 4$ \\
\hline 0 & 0 & 0 & 0 & 0 & 0 \\
\hline 5.2 & 0.1 & 1.41 & 1.11 & 0.67 & 0.31 \\
\hline 10.4 & 0.2 & 2.29 & 1.83 & 1.05 & 0.50 \\
\hline 15.6 & 0.3 & 2.82 & 2.24 & 1.29 & 0.61 \\
\hline 20.8 & 0.4 & 3.23 & 2.58 & 1.44 & 0.68 \\
\hline 26 & 0.5 & 3.44 & 2.82 & 1.47 & 0.67 \\
\hline 31.2 & 0.6 & 3.11 & 2.56 & 1.33 & 0.61 \\
\hline 36.4 & 0.7 & 2.27 & 1.82 & 1.04 & 0.48 \\
\hline 41.6 & 0.8 & 1.50 & 1.17 & 0.75 & 0.36 \\
\hline 46.8 & 0.9 & 0.86 & 0.66 & 0.47 & 0.23 \\
\hline 52 & 1 & 0 & 0 & 0 & 0 \\
\hline
\end{tabular}


Next, Table 6.2 shows the simplified distribution factors for each girder during Truck Run 2. The values displayed under the "Averages" columns in the table are average strain values (measured in $\mu \varepsilon$ ) calculated from the Abaqus output. The last three rows of the table display average distribution factors, average distribution factors with AASHTO multiple presence factors applied, and standard deviations, respectively, for each girder. For Truck Run 2, Girders 1 through 4 respectively carried $40.3 \%, 32.1 \%, 18.7 \%$, and $8.8 \%$ of the load before multiple presence factors were applied. Again, since the truck placement for Truck Run 2 was primarily over Girders 1 and 2 , the distribution factors calculated fit the expected results.

\section{Table 6.2: Finite Element Model Distribution Factor Results}

\begin{tabular}{|c|c|c|c|c|c|c|c|c|c|}
\hline \multicolumn{2}{|c|}{ Panel Points } & \multicolumn{4}{|c|}{ Averages ( $\mu \varepsilon)$} & \multicolumn{4}{|c|}{ Distribution Factors } \\
\hline$x(\mathrm{ft})$ & $x / L$ & G1 & G2 & G3 & G4 & G1 & G2 & G3 & G4 \\
\hline 0 & 0 & 0 & 0 & 0 & 0 & --- & --- & --- & --- \\
\hline 5.2 & 0.1 & 48.54 & 38.29 & 22.94 & 10.72 & 0.403 & 0.318 & 0.190 & 0.089 \\
\hline 10.4 & 0.2 & 78.93 & 63.17 & 36.22 & 17.18 & 0.404 & 0.323 & 0.185 & 0.088 \\
\hline 15.6 & 0.3 & 97.31 & 77.30 & 44.64 & 21.16 & 0.405 & 0.322 & 0.186 & 0.088 \\
\hline 20.8 & 0.4 & 111.31 & 89.04 & 49.78 & 23.32 & 0.407 & 0.326 & 0.182 & 0.085 \\
\hline 26 & 0.5 & 118.54 & 97.30 & 50.54 & 23.22 & 0.409 & 0.336 & 0.175 & 0.080 \\
\hline 31.2 & 0.6 & 107.36 & 88.23 & 45.69 & 20.87 & 0.410 & 0.337 & 0.174 & 0.080 \\
\hline 36.4 & 0.7 & 78.44 & 62.72 & 35.74 & 16.45 & 0.406 & 0.324 & 0.185 & 0.085 \\
\hline 41.6 & 0.8 & 51.89 & 40.36 & 25.95 & 12.51 & 0.397 & 0.309 & 0.199 & 0.096 \\
\hline 46.8 & 0.9 & 29.79 & 22.77 & 16.05 & 7.84 & 0.390 & 0.298 & 0.210 & 0.103 \\
\hline 52 & 1 & 0 & 0 & 0 & 0 & --- & --- & --- & --- \\
\hline & & & & \multicolumn{2}{|c|}{ Average } & 0.403 & 0.321 & 0.187 & 0.088 \\
\hline & & & & \multicolumn{2}{|c|}{ MPF Applied } & 0.484 & 0.386 & 0.225 & 0.106 \\
\hline & & & & \multicolumn{2}{|c|}{ St. Dev. } & 0.006 & 0.012 & 0.011 & 0.007 \\
\hline
\end{tabular}

Figure 6.1 shows an exaggerated deformed image of the bridge model during Truck Run 2, Panel Point 5. The model also shows the various strain distribution, which is exaggerated for visual purposes. Since the truck is placed over Girders 1 and 2 during this truck run, the strain is 
much higher in those girders, as shown. While Girders 1 and 2 carry most of the load, the model also depicts the distribution of the load into Girders 3 and 4 as discussed above.

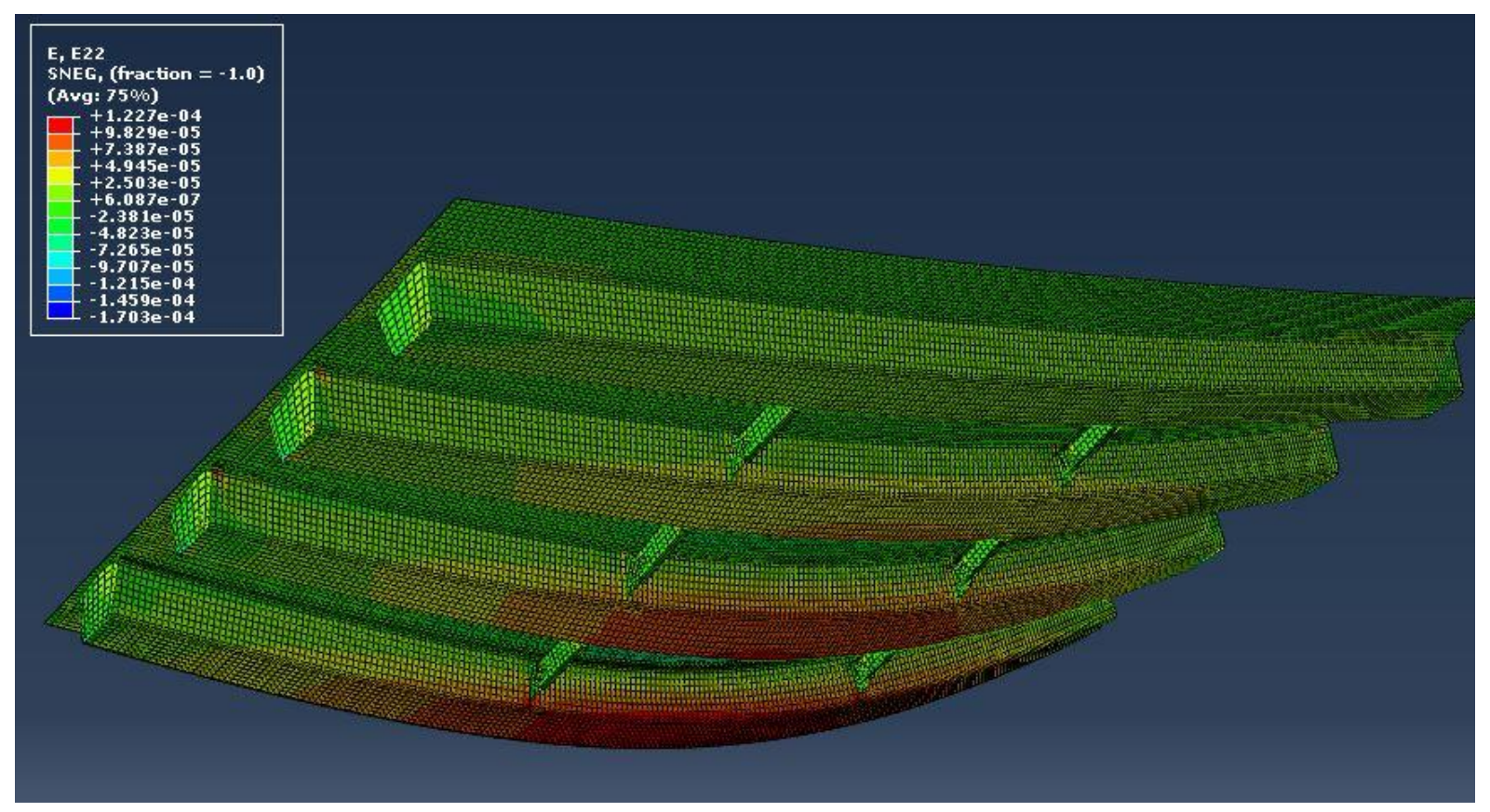

Figure 6.1: Deflected Shape of Abaqus Model - Truck Run 2, Panel Point 5

\subsubsection{Live Load Field Test Results}

This section will highlight results from the data collected during the live load field test of the Amish Sawmill Bridge. In addition, comparisons will start to be discussed with the analytical data from the finite element model.

Like the previous section, bottom flange stresses at midspan will be discussed first. Table 6.3 displays the stresses calculated at midspan for Truck Run 2. Stresses were calculated directly from the strain readings taken during the field test. Upon viewing the results, the field data follows the same trends as the analytical data in that the stresses are higher in Girders 1 and 2, and the stress increases/decreases as the truck moves toward/past midspan. The only difference between 
the two sets of data is the experimental results in the field are lower than the results obtained from the finite element model. The cause of this will be further discussed in Section 6.2.3.

Table 6.3: Live Load Field Test Bottom Flange Stress Results

\begin{tabular}{|c|c|c|c|c|c|}
\hline \multicolumn{7}{|c|}{ Truck Run 2, Bending Stress } \\
\hline \multicolumn{2}{|c|}{ Panel Points } & \multicolumn{5}{|c|}{ Average Stress (ksi) } \\
\hline $\mathrm{x}(\mathrm{ft})$ & $\mathrm{x} / \mathrm{L}$ & $\mathrm{G} 1$ & $\mathrm{G} 2$ & $\mathrm{G} 3$ & $\mathrm{G} 4$ \\
\hline 0 & 0 & 0 & 0 & 0 & 0 \\
\hline 5.2 & 0.1 & 0.48 & 0.38 & 0.27 & 0.21 \\
\hline 10.4 & 0.2 & 0.91 & 0.75 & 0.43 & 0.32 \\
\hline 15.6 & 0.3 & 1.08 & 0.84 & 0.53 & 0.35 \\
\hline 20.8 & 0.4 & 1.26 & 0.99 & 0.62 & 0.40 \\
\hline 26 & 0.5 & 1.64 & 1.32 & 0.61 & 0.40 \\
\hline 31.2 & 0.6 & 1.51 & 1.17 & 0.54 & 0.36 \\
\hline 36.4 & 0.7 & 0.89 & 0.67 & 0.40 & 0.25 \\
\hline 41.6 & 0.8 & 0.46 & 0.35 & 0.25 & 0.19 \\
\hline 46.8 & 0.9 & 0.20 & 0.17 & 0.14 & 0.13 \\
\hline 52 & 1 & 0 & 0 & 0 & 0 \\
\hline
\end{tabular}

The distribution factors obtained from the field test during Truck Run 2 are shown below in Table 6.4. The values under the "Averages" columns are average strain readings calculated from the raw data collected in the field. The last three rows of the table display average distribution factors, average distribution factors with AASHTO multiple presence factors applied, and standard deviations, respectively, for each girder. Comparing these results to the analytical distribution factors will show that both sets of data are very similar. The comparison of the results from the two methods will further be discussed in the next section. 
Table 6.4: Live Load Field Test Distribution Factor Results

\begin{tabular}{|c|c|c|c|c|c|c|c|c|c|}
\hline \multicolumn{10}{|c|}{ Truck Run 2, Simplified Distribution Factors } \\
\hline \multicolumn{2}{|c|}{ Panel Points } & \multicolumn{4}{|c|}{ Averages $(\mu \varepsilon)$} & \multicolumn{4}{|c|}{ Distribution Factors } \\
\hline$x(\mathrm{ft})$ & $\mathrm{x} / \mathrm{L}$ & G1 & $\mathrm{G} 2$ & G3 & G4 & G1 & $\mathrm{G} 2$ & G3 & G4 \\
\hline 0 & 0 & 0 & 0 & 0 & 0 & --- & --- & --- & --- \\
\hline 5.2 & 0.1 & 16.48 & 12.99 & 9.36 & 7.27 & 0.357 & 0.282 & 0.203 & 0.158 \\
\hline 10.4 & 0.2 & 31.44 & 25.97 & 14.85 & 11.02 & 0.378 & 0.312 & 0.178 & 0.132 \\
\hline 15.6 & 0.3 & 37.33 & 29.02 & 18.12 & 12.22 & 0.386 & 0.300 & 0.187 & 0.126 \\
\hline 20.8 & 0.4 & 43.56 & 34.07 & 21.25 & 13.86 & 0.386 & 0.302 & 0.188 & 0.123 \\
\hline 26 & 0.5 & 56.68 & 45.54 & 21.16 & 13.93 & 0.413 & 0.332 & 0.154 & 0.101 \\
\hline 31.2 & 0.6 & 52.10 & 40.47 & 18.52 & 12.39 & 0.422 & 0.328 & 0.150 & 0.100 \\
\hline 36.4 & 0.7 & 30.64 & 23.08 & 13.81 & 8.56 & 0.403 & 0.303 & 0.182 & 0.113 \\
\hline 41.6 & 0.8 & 15.95 & 11.90 & 8.68 & 6.69 & 0.369 & 0.275 & 0.201 & 0.155 \\
\hline 46.8 & 0.9 & 7.06 & 5.97 & 4.81 & 4.38 & 0.318 & 0.269 & 0.216 & 0.197 \\
\hline 52 & 1 & 0 & 0 & 0 & 0 & --- & --- & --- & --- \\
\hline & & & & \multicolumn{2}{|c|}{ Average } & 0.381 & 0.300 & 0.184 & 0.134 \\
\hline & & & & \multicolumn{2}{|c|}{ MPF Applied } & 0.458 & 0.360 & 0.221 & 0.161 \\
\hline & & & & \multicolumn{2}{|c|}{ St. Dev. } & 0.031 & 0.022 & 0.022 & 0.031 \\
\hline
\end{tabular}

\subsubsection{Comparison of Analytical vs. Experimental Results}

This section will further discuss the comparisons between the analytical and experimental results. Shown below in Tables 6.5 and 6.6 is a summary of the data listed in the previous sections from Truck Run 2 for each method, side by side. Table 6.5 shows the bottom flange stress results at midspan, while Table 6.6 displays the distribution factors (without AASHTO multiple presence factors applied) calculated for each girder. 
Table 6.5: Comparison of FEA vs. Experimental Bottom Flange Bending Stress

\begin{tabular}{|c|c|c|c|c|c|c|c|c|c|}
\hline \multicolumn{10}{|c|}{ Truck Run 2, Bending Stress (ksi) } \\
\hline$x(\mathrm{ft})$ & $\mathrm{x} / \mathrm{L}$ & G1 & G2 & G3 & G4 & G1 & G2 & G3 & G4 \\
\hline 0 & 0 & 0 & 0 & 0 & 0 & 0 & 0 & 0 & 0 \\
\hline 5.2 & 0.1 & 1.41 & 1.11 & 0.67 & 0.31 & 0.48 & 0.38 & 0.27 & 0.21 \\
\hline 10.4 & 0.2 & 2.29 & 1.83 & 1.05 & 0.50 & 0.91 & 0.75 & 0.43 & 0.32 \\
\hline 15.6 & 0.3 & 2.82 & 2.24 & 1.29 & 0.61 & 1.08 & 0.84 & 0.53 & 0.35 \\
\hline 20.8 & 0.4 & 3.23 & 2.58 & 1.44 & 0.68 & 1.26 & 0.99 & 0.62 & 0.40 \\
\hline 26 & 0.5 & 3.44 & 2.82 & 1.47 & 0.67 & 1.64 & 1.32 & 0.61 & 0.40 \\
\hline 31.2 & 0.6 & 3.11 & 2.56 & 1.33 & 0.61 & 1.51 & 1.17 & 0.54 & 0.36 \\
\hline 36.4 & 0.7 & 2.27 & 1.82 & 1.04 & 0.48 & 0.89 & 0.67 & 0.40 & 0.25 \\
\hline 41.6 & 0.8 & 1.50 & 1.17 & 0.75 & 0.36 & 0.46 & 0.35 & 0.25 & 0.19 \\
\hline 46.8 & 0.9 & 0.86 & 0.66 & 0.47 & 0.23 & 0.20 & 0.17 & 0.14 & 0.13 \\
\hline 52 & 1 & 0 & 0 & 0 & 0 & 0 & 0 & 0 & 0 \\
\hline
\end{tabular}

Table 6.6: Comparison of FEA vs. Experimental Distribution Factors

\begin{tabular}{|c|c|c|c|c|}
\hline \multicolumn{5}{|c|}{ Truck Run 2, Average Distribution Factors } \\
\hline Girder & G1 & G2 & G3 & G4 \\
\hline FEA & 0.484 & 0.386 & 0.225 & 0.106 \\
\hline Experimental & 0.458 & 0.360 & 0.221 & 0.161 \\
\hline
\end{tabular}

The main observation taken from this data is the distribution factors calculated for each method match very closely, but the bottom flange bending stresses differ between the two methods. As shown in Table 6.5, the bending stress calculated from the finite element model is much higher than the bending stress calculated from the field test. The reason for this difference is the varying boundary conditions between the two methods. As mentioned in Section 3.3, the Amish Sawmill Bridge is constructed with integral abutments. This means that the ends of each girder are completely encased by concrete, which makes the bridge much stiffer than if traditional simply supported "hinge-roller" conditions were utilized (as they were in the finite element model). Integral abutment boundary conditions were not used in the finite element model because there is 
not an exact "proper" method to replicate those conditions. Modeling integral abutments in finite element software is a very popular topic that is highly debated in the structural engineering community. While the use of "hinge-roller" conditions did affect the magnitude of the bottom flange stress values, Figure 6.2 and Figure 6.3 shows that the behavior exhibited in each method is proportionally the same. Figure 6.2 shows the bottom flange stress in Girder 1 for Truck Run 2 as the truck progressed across the bridge, and Figure 6.3 shows the same data for Girder 3 . The stresses are much higher in Girder 1 than they are in Girder 3 due to the truck being placed primarily over Girders 1 and 2 during Truck Run 2.

\section{Girder 1, Truck Run \#2}

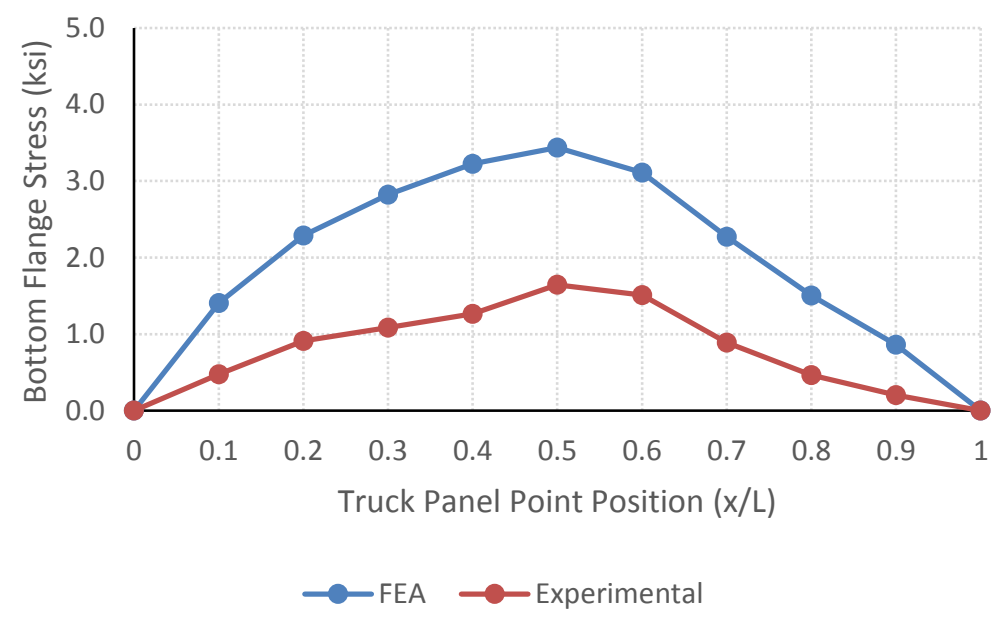

Figure 6.2: FEA vs. Experimental Bottom Flange Bending Stress for Girder 1, Truck Run 2 


\section{Girder 3, Truck Run \#2}

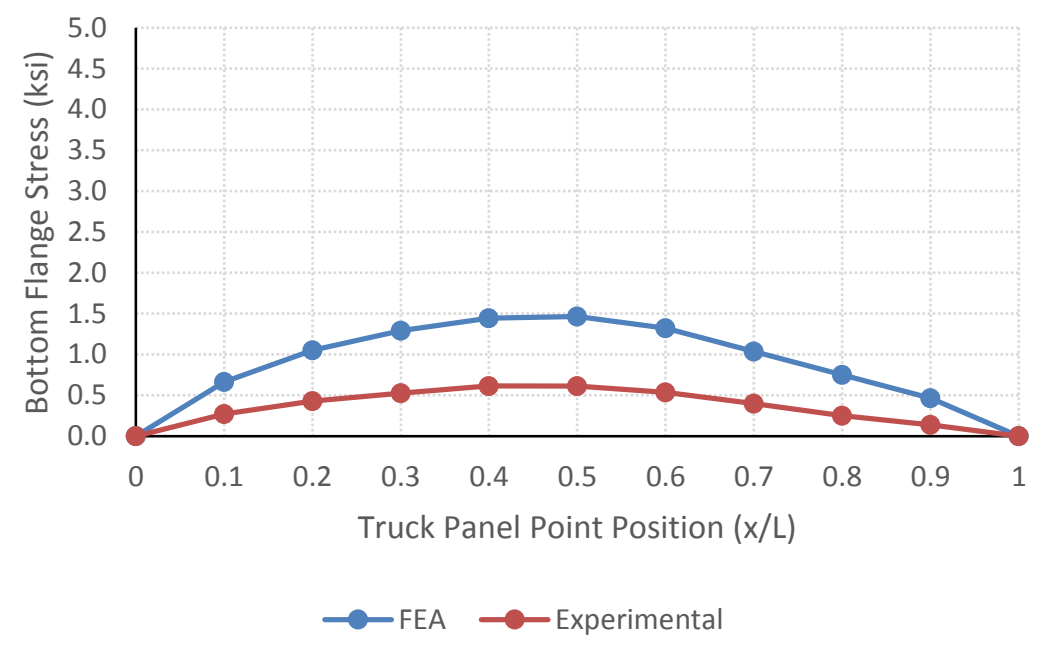

Figure 6.3: FEA vs. Experimental Bottom Flange Bending Stress for Girder 3, Truck Run 2

As mentioned previously, although the varying boundary conditions affected the magnitude of the bottom flange stresses on each girder, the distribution factors calculated for each method matched very closely. As shown in Figure 6.4 and Figure 6.5, the distribution factors (with multiple presence factors applied) for Truck Run 2 are around the same values for both the finite element model and the field test. For this specific truck run, each graph is showing that Girders 1 and 2 supported most of the truck load, while Girders 3 and 4 supported a lesser portion of the load. 


\section{Truck Run \#2 DFs}

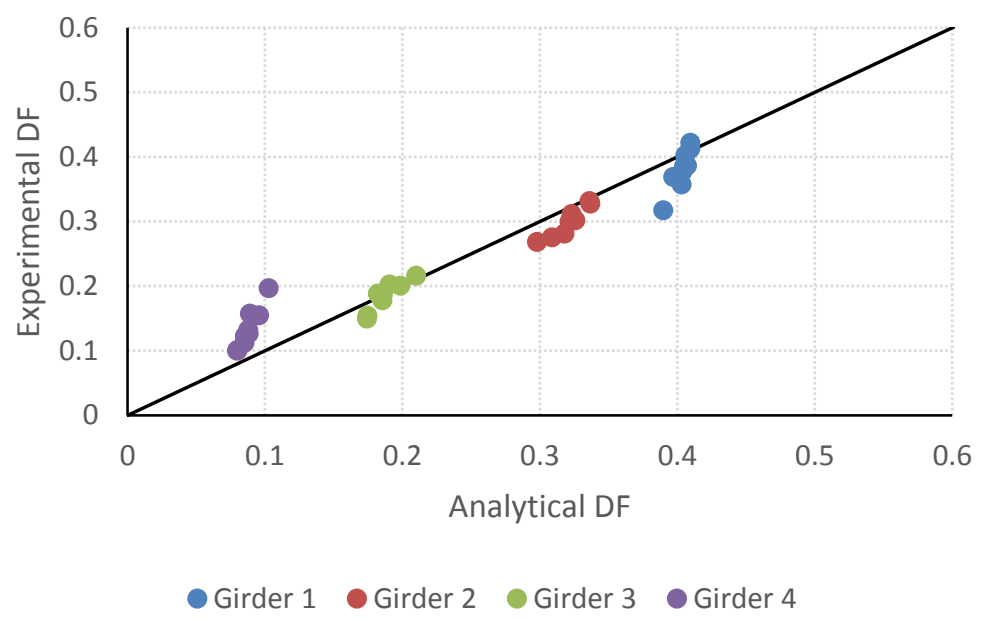

Figure 6.4: Comparison of FEA vs. Experimental Distribution Factors for Truck Run 2

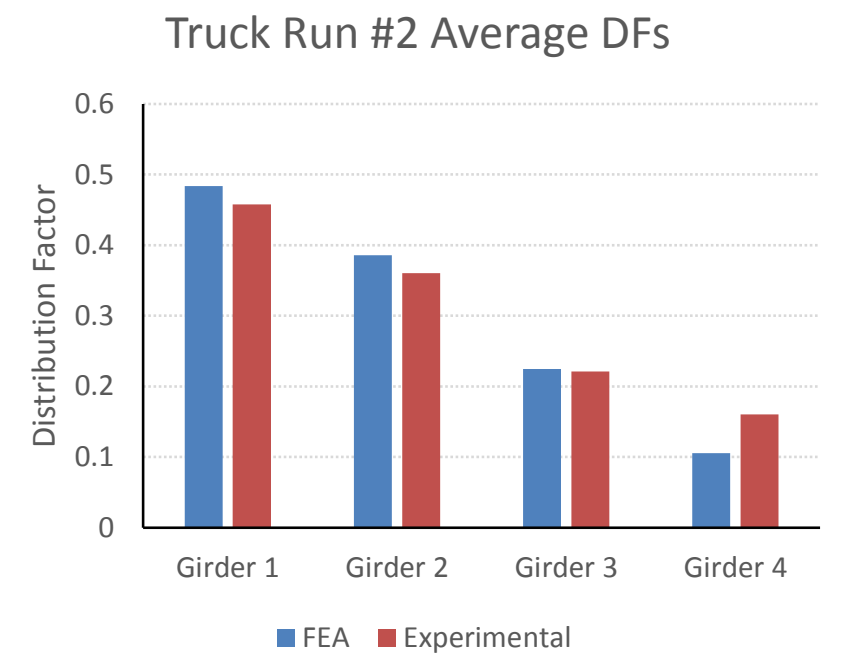

Figure 6.5: FEA vs. Experimental Average Distribution Factors for Truck Run 2 
For comparison, the average distribution factors (with multiple presence factors applied) calculated for each method for Truck Run 3 are shown in Figure 6.6. As seen in Figure 5.4, in Section 5.2, the load truck was placed in the middle of the bridge, over Girders 2 and 3, for Truck Run 3. The average distribution factors shown in the graph correlate to this truck placement, as the middle two girders are carrying more of the load (approximately $60 \%$ combined) than the outside girders.

\section{Truck Run \#3 Average DFs}

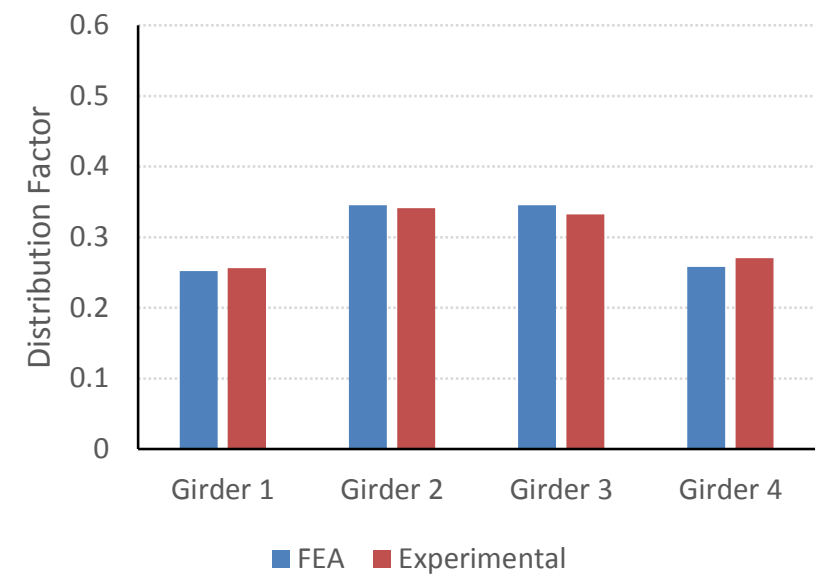

Figure 6.6: FEA vs. Experimental Average Distribution Factors for Truck Run 3

In addition to analyzing each truck run independently, further analyses were performed to calculate the stresses and distribution factors for the scenario in which two of the load trucks were simultaneously on the bridge. To simulate this scenario, data from two individual truck runs was combined. This was performed for two separate scenarios; the combination of Truck Runs 1 and 4, and the combination of Truck Runs 2 and 5. The bottom flange stresses of Girder 1 and Girder 4 for the combined loading scenario of Truck Runs 1 and 4 are shown in Figure 6.7. Since the combined loading scenarios were simulated from the same data, the finite element model still resulted in higher stresses than the field test due to the difference in boundary conditions discussed above. 
Girder 1, Truck Runs \#1 \& \#4

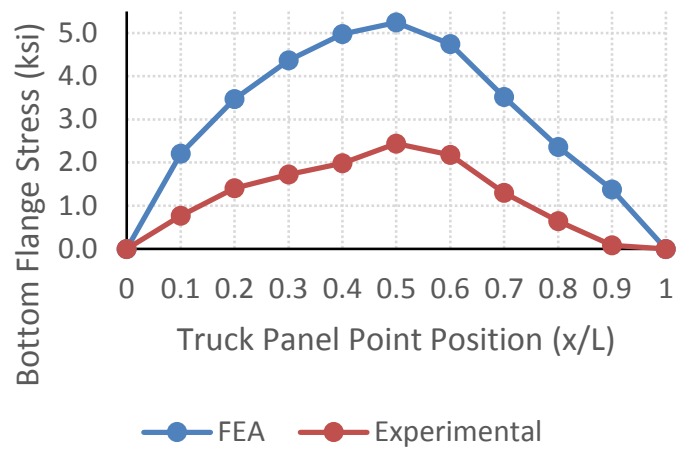

(a)
Girder 4, Truck Runs \#1 \& \#4

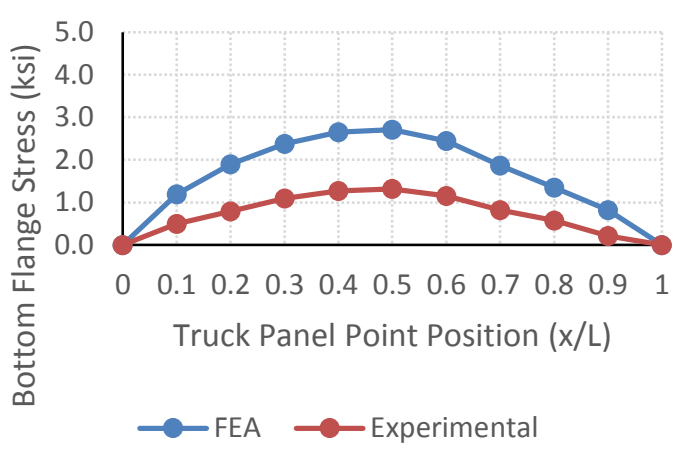

(b)

Figure 6.7: Comparison of FEA vs. Experimental Bottom Flange Bending Stress for Combined Loading Scenario of Truck Runs 1 and 4 for (a): Girder 1 and (b): Girder 4

To summarize the remaining distribution factor data between the two testing methods, Figure 6.8 displays a Q-Q plot containing all the calculated average distribution factors (with multiple presence factors applied) for each truck run, including the combined scenarios. As mentioned before, Appendix A includes a complete collection of data and graphs that summarizes the results from every truck run. 


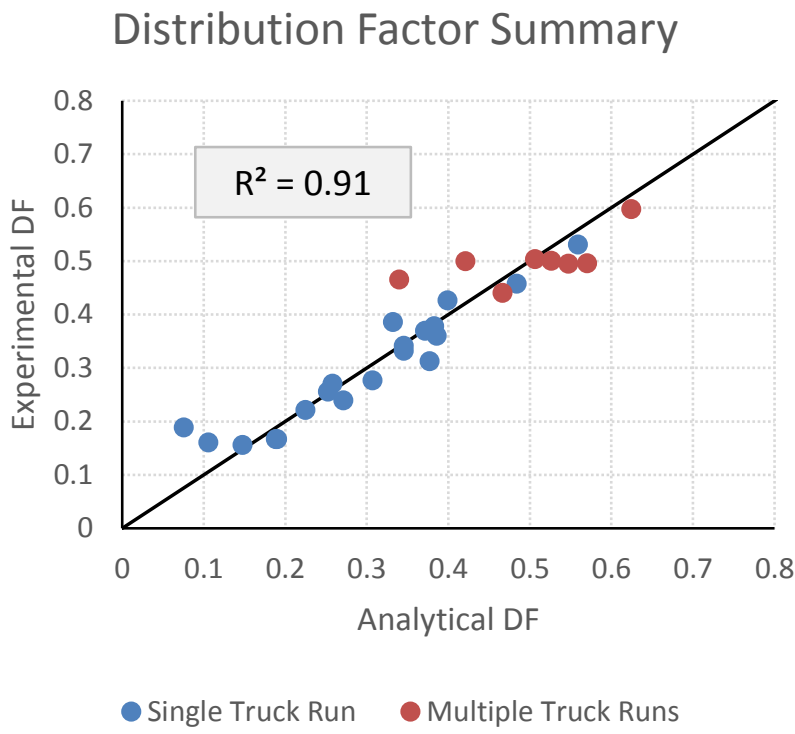

Figure 6.8: Comparison of FEA vs. Experimental Average Distribution Factors for All Single and Combined Truck Runs

\subsection{COMPARISON OF LLDFs TO AASHTO SPECIFICATIONS}

This section will compare the live load distribution factors (LLDFs) calculated from the experimental and analytical data discussed above to the LLDFs calculated using AASHTO (2014) specifications. AASHTO multiple presence factors were applied to the experimental and analytical distribution factors to accurately compare the LLDFs. Truck Run 2 will be used to compare the results between these three methods. Table 6.7 and Figure 6.9 display LLDFs calculated for Truck Run 2 for all three methods. 
Table 6.7: FEA vs. Experimental vs. AASHTO LLDFs for Truck Run 2

\begin{tabular}{|} 
Truck Run 2, Average Live Load Distribution Factors \\
\hline Girder & G1 & G2 & G3 & G4 \\
\hline FEA & 0.484 & 0.386 & 0.225 & 0.106 \\
\hline Experimental & 0.458 & 0.360 & 0.221 & 0.161 \\
\hline AASHTO & 0.688 & 0.688 & 0.688 & 0.688 \\
\hline
\end{tabular}

\section{Truck Run \#2 Average LLDFs}

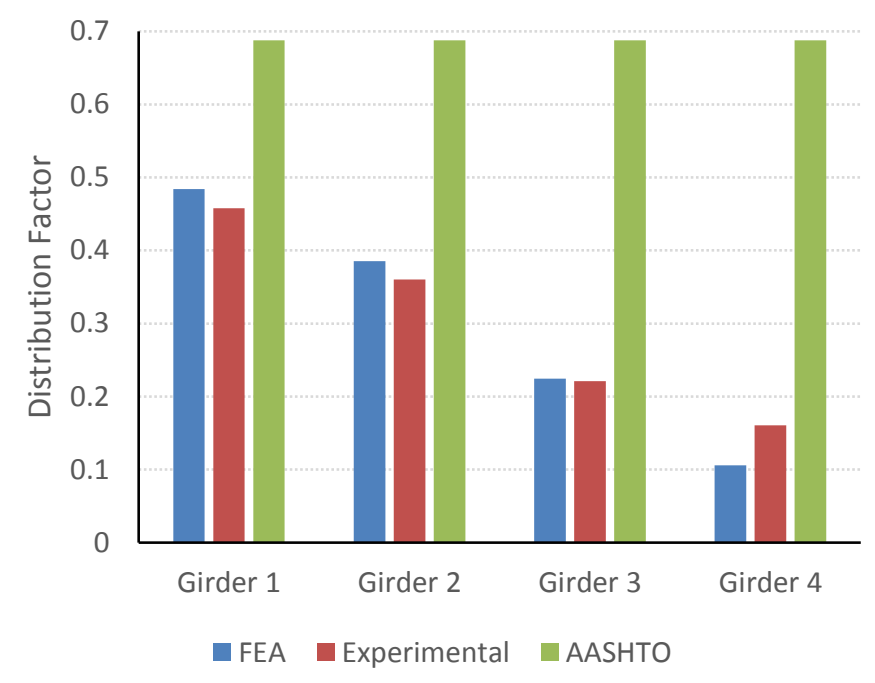

Figure 6.9: FEA vs. Experimental vs. AASHTO LLDFs for Truck Run 2

As shown in Table 6.7 and Figure 6.9, the FEA and experimental LLDFs are very similar, while the LLDFs calculated using AASHTO specifications are much higher. This data shows that the AASHTO specifications can safely be applied to press-brake-formed steel tub girders, but the AASHTO LLDFs calculated are very conservative. This conclusion is also true in scenarios with multiple lanes loaded. Table 6.8 and Figure 6.10 display LLDFs calculated for the combined loading scenario of Truck Runs 1 and 4 for all three methods. While there is less variation between FEA, experimental, and AASHTO LLDFs, the LLDFs calculated using AASHTO specifications are still conservative. 
Table 6.8: FEA vs. Experimental vs. AASHTO LLDFs for Truck Runs 1 \& 4

\begin{tabular}{|c|c|c|c|c|}
\hline \multicolumn{5}{|c|}{$\begin{array}{c}\text { Truck Runs } 1 \& 4 \text {, Average Live Load Distribution } \\
\text { Factors }\end{array}$} \\
\hline Girder & G1 & G2 & G3 & G4 \\
\hline FEA & 0.624 & 0.570 & 0.466 & 0.339 \\
\hline Experimental & 0.597 & 0.496 & 0.441 & 0.466 \\
\hline AASHTO & 0.688 & 0.688 & 0.688 & 0.688 \\
\hline
\end{tabular}

Truck Runs \#1 \& \#4 Average LLDFs

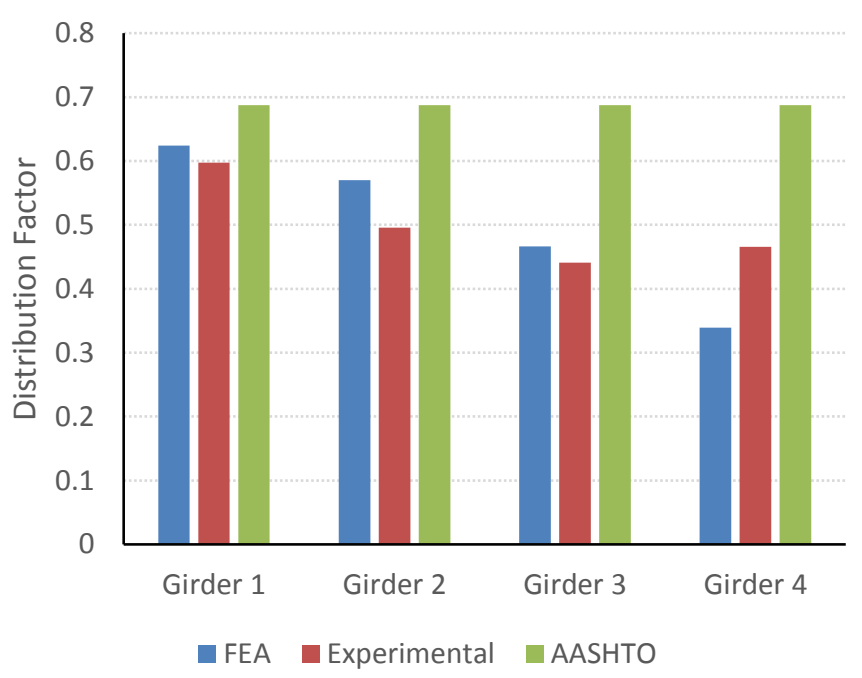

Figure 6.10: FEA vs. Experimental vs. AASHTO LLDFs for Truck Runs $1 \& 4$ 


\subsection{CONCLUSIONS}

The preceding chapter included a full discussion and comparison of the data collected from both the finite element model and field test performed on the Amish Sawmill Bridge. The data being analyzed included bottom flange stresses at midspan and distribution factors for each girder. After analyzing the data, the results from the two tests correlate very closely, apart from the minor differences in magnitude due to the varying boundary conditions represented in the two models. Additionally, LLDFs calculated from the experimental and analytical results were compared to LLDFs calculated using AASHTO specifications. AASHTO specifications for calculating LLDFs for tub girders were safely applicable to press-brake-formed tub girders, but are very conservative. 


\section{CHAPTER 7: SUMMARY AND CONCLUDING REMARKS}

\subsection{Project Summary ANd CONCLuSIONS}

The scope of this thesis was to assess the performance of press-brake-formed steel tub girders in the field, and compare it to analytical testing completed through finite element modeling. As discussed, results between the two testing methods matched very closely. Although the magnitude of bottom flange bending stress varied between the two methods due to the difference in boundary conditions between the finite element model and the field, the two sets of results exhibited corelating behavior. Live load distribution factors (LLDFs) calculated for each method

were almost identical, and displayed how the composite system transferred the various loading between the four girders. Additionally, this thesis aimed to compare LLDFs calculated from the experimental and analytical testing to LLDFs calculated using AASHTO specifications. AASHTO specifications for calculating LLDFs for tub girders can safely be applied to pressbrake-formed tub girders, but are very conservative. Based on the results and conclusions drawn from this research, press-brake-formed steel tub girders exhibit consistent performance, and are a practical option in the short span bridge industry, especially when paired with accelerated bridge construction methods.

\subsection{RECOMMENDATIONS FOR CONTINUED WORK}

The following tasks are recommended for future work:

- Present results and conclusions from this research at technical meetings and conferences to create a widespread awareness of the effectiveness of short span press-brake-formed steel tub girders.

- Using the data presented in this thesis to further analyze press-brake-formed steel tub girders in various bridge applications.

- Developing specifications to more accurately calculate live load distribution factors for press-brake-formed steel tub girders. 


\section{REFERENCES}

American Association of State Highway and Transportation Officials (2014). AASHTO LRFD Bridge Design Specifications, Seventh Edition. Washington, DC, AASHTO.

Barker, M. G., Imhoff, C. M., Mcdaniel, W. T., and Frederick, T. L. (1999). Field Testing and Load Rating Procedures for Steel Girder Bridges. University of Missouri - Columbia: Missouri Department of Transportation.

Barth, K. E., Michaelson G. K., Barker, M. G., (2015). Development and Experimental Validation of Composite Press Brake-Formed Modular Steel Tub Girders for Short-Span Bridges. ASCE Journal of Bridge Engineering, 20 (11).

Bridge Diagnostics, Inc. (n.d.). STS-WiFi Operations Manual. Boulder, CO.

Burner, K. A. (2010). Experimental Investigation of Folded Plate Girders and Slab Joints Used in Modular Construction. Department of Civil Engineering. Lincoln, NE, University of Nebraska-Lincoln. Master of Science.

Chandar, G., M. D. Hyzak, et al. (2010). Rapid Economical Bridge Replacement. Modern Steel Construction. Chicago, IL, National Steel Bridge Alliance. 2010.

Dassault-Systèmes (2012). Abaqus/CAE. Providence, RI, Dassault Systèmes Simulia Corp.

Eom, J., and Nowak, A. S. (2001). Live Load Distribution for Steel Girder Bridges. ASCE Journal of Bridge Engineering, 6 (6): 489-497

Federal Highway Administration. (2012). Innovative Bridge Research and Deployment (IBRD) Program. https://www.fhwa.dot.gov/discretionary/2012ibrd.cfm.

Federal Highway Administration. (2017). Geosynthetic Reinforced Soil-Integrated Bridge System. https://www.fhwa.dot.gov/innovation/everydaycounts/edc-3/grs-ibs.cfm.

Gallion, B. R. (2016). eSPAN140 Performance Assessment: V-65 Jesup South Bridge (Buchanan County, Iowa). Department of Civil \& Environmental Engineering. Morgantown, WV, West Virginia University. Master of Science.

Glaser, L. A. (2010). Constructability Testing of Folded Plate Girders. Department of Civil Engineering. Lincoln, NE, University of Nebraska-Lincoln. Master of Science.

Intelligent Engineering. (n.d.). SPS: Sandwich Plate System. http://www.ie-sps.com/. 
Kelly, L. T. (2014). Experimental Evaluation of Non-Composite Shallow Press-Brake-Formed Steel Tub Girders. Department of Civil \& Environmental Engineering. Morgantown, WV, West Virginia University. Master of Science.

Kozhokin, P. (2016). Evaluation of Modular Press-Brake-Formed Tub Girders with UHPC Joints. Department of Civil \& Environmental Engineering. Morgantown, WV, West Virginia University. Master of Science.

Michaelson, G. K. (2014). Development and Feasibility Assessment of Shallow Press-BrakeFormed Steel Tub Girders for Short-Span Bridge Applications. Department of Civil \& Environmental Engineering. Morgantown, WV, West Virginia University. Doctor of Philosophy.

Morgan, S. A. (2010). Towards the Development of Efficient and Economical Short Span Modular Bridges. Department of Civil \& Environmental Engineering. Morgantown, WV, West Virginia University. Master of Science.

Nakamura, S. (2002). "Bending Behavior of Composite Girders with Cold Formed Steel U Section." ASCE Journal of Structural Engineering 128 (9): 8.

Short Span Steel Bridge Alliance (2016). Amish Sawmill Bridge: An Innovative Steel Solution for Short Span Bridge Design. http://www.shortspansteelbridges.org/case-studies/casestudies-folder/amish-sawmill-bridge---an-innovative-steel-solution.aspx.

Taly, N. and H. Gangarao (1979). "Prefabricated Press-Formed Steel T-Box Girder Bridge System." AISC Engineering Journal 16 (3):9. 


\section{APPENDiX A: RESUlts FOR ALL TRUCK RUNS}

The following appendix includes the entirety of the results, tables, and graphs generated to compare the analytical and experimental results from the Amish Sawmill Bridge Test for all truck runs. It should be noted that the data from tests where two lanes were loaded does not show distribution factors with AASHTO multiple presence factors (MPFs) applied because the multiple presence factor for two lanes loaded is equal to one. 


\begin{tabular}{|c|c|c|c|c|c|c|c|c|c|}
\hline \multicolumn{2}{|c|}{ Panel Points } & \multicolumn{4}{|c|}{ Averages $(\mu \varepsilon)$} & \multicolumn{4}{|c|}{ Distribution Factors } \\
\hline$x(\mathrm{ft})$ & $\mathrm{x} / \mathrm{L}$ & G1 & $\mathrm{G} 2$ & G3 & G4 & G1 & $\mathrm{G} 2$ & G3 & G4 \\
\hline 0 & 0 & 0 & 0 & 0 & 0 & --- & --- & --- & --- \\
\hline 5.2 & 0.1 & 56.47 & 38.06 & 19.14 & 7.14 & 0.467 & 0.315 & 0.158 & 0.059 \\
\hline 10.4 & 0.2 & 88.99 & 60.82 & 29.96 & 11.83 & 0.464 & 0.317 & 0.156 & 0.062 \\
\hline 15.6 & 0.3 & 112.25 & 75.82 & 37.71 & 15.14 & 0.466 & 0.315 & 0.157 & 0.063 \\
\hline 20.8 & 0.4 & 129.30 & 86.09 & 41.79 & 16.91 & 0.472 & 0.314 & 0.152 & 0.062 \\
\hline 26 & 0.5 & 138.85 & 91.86 & 41.84 & 16.93 & 0.480 & 0.317 & 0.145 & 0.058 \\
\hline 31.2 & 0.6 & 126.04 & 83.20 & 37.67 & 15.24 & 0.481 & 0.317 & 0.144 & 0.058 \\
\hline 36.4 & 0.7 & 91.68 & 60.84 & 29.60 & 11.85 & 0.473 & 0.314 & 0.153 & 0.061 \\
\hline 41.6 & 0.8 & 59.16 & 40.69 & 22.10 & 9.16 & 0.451 & 0.310 & 0.169 & 0.070 \\
\hline 46.8 & 0.9 & 33.66 & 23.69 & 13.71 & 5.61 & 0.439 & 0.309 & 0.179 & 0.073 \\
\hline 52 & 1 & 0 & 0 & 0 & 0 & --- & --- & --- & --- \\
\hline & & & & \multicolumn{2}{|c|}{ Average } & 0.466 & 0.314 & 0.157 & 0.063 \\
\hline & & & & \multicolumn{2}{|c|}{ MPF Applied } & 0.559 & 0.377 & 0.188 & 0.075 \\
\hline & & & & \multicolumn{2}{|c|}{ St. Dev. } & 0.013 & 0.003 & 0.011 & 0.005 \\
\hline
\end{tabular}

\begin{tabular}{|c|c|c|c|c|c|c|c|c|c|}
\hline \multicolumn{10}{|c|}{ Truck Run 2, Simplified Distribution Factors (FEA) } \\
\hline \multicolumn{2}{|c|}{ Panel Points } & \multicolumn{4}{|c|}{ Averages $(\mu \varepsilon)$} & \multicolumn{4}{|c|}{ Distribution Factors } \\
\hline$x(\mathrm{ft})$ & $\mathrm{x} / \mathrm{L}$ & G1 & G2 & G3 & G4 & G1 & G2 & G3 & G4 \\
\hline 0 & 0 & 0 & 0 & 0 & 0 & --- & --- & --- & --- \\
\hline 5.2 & 0.1 & 48.54 & 38.29 & 22.94 & 10.72 & 0.403 & 0.318 & 0.190 & 0.089 \\
\hline 10.4 & 0.2 & 78.93 & 63.17 & 36.22 & 17.18 & 0.404 & 0.323 & 0.185 & 0.088 \\
\hline 15.6 & 0.3 & 97.31 & 77.30 & 44.64 & 21.16 & 0.405 & 0.322 & 0.186 & 0.088 \\
\hline 20.8 & 0.4 & 111.31 & 89.04 & 49.78 & 23.32 & 0.407 & 0.326 & 0.182 & 0.085 \\
\hline 26 & 0.5 & 118.54 & 97.30 & 50.54 & 23.22 & 0.409 & 0.336 & 0.175 & 0.080 \\
\hline 31.2 & 0.6 & 107.36 & 88.23 & 45.69 & 20.87 & 0.410 & 0.337 & 0.174 & 0.080 \\
\hline 36.4 & 0.7 & 78.44 & 62.72 & 35.74 & 16.45 & 0.406 & 0.324 & 0.185 & 0.085 \\
\hline 41.6 & 0.8 & 51.89 & 40.36 & 25.95 & 12.51 & 0.397 & 0.309 & 0.199 & 0.096 \\
\hline 46.8 & 0.9 & 29.79 & 22.77 & 16.05 & 7.84 & 0.390 & 0.298 & 0.210 & 0.103 \\
\hline 52 & 1 & 0 & 0 & 0 & 0 & --- & --- & --- & --- \\
\hline & & & & \multicolumn{2}{|c|}{ Average } & 0.403 & 0.321 & 0.187 & 0.088 \\
\hline & & & & \multicolumn{2}{|c|}{ MPF Applied } & 0.484 & 0.386 & 0.225 & 0.106 \\
\hline & & & & \multicolumn{2}{|c|}{ St. Dev. } & 0.006 & 0.012 & 0.011 & 0.007 \\
\hline
\end{tabular}




\begin{tabular}{|c|c|c|c|c|c|c|c|c|c|}
\hline \multicolumn{2}{|c|}{ Panel Points } & \multicolumn{4}{|c|}{ Averages ( $\mu \varepsilon)$} & \multicolumn{4}{|c|}{ Distribution Factors } \\
\hline$x(\mathrm{ft})$ & $x / L$ & G1 & $\mathrm{G} 2$ & G3 & G4 & G1 & $\mathrm{G} 2$ & G3 & G4 \\
\hline 0 & 0 & 0 & 0 & 0 & 0 & --- & --- & --- & --- \\
\hline 5.2 & 0.1 & 26.08 & 33.89 & 33.89 & 26.63 & 0.216 & 0.281 & 0.281 & 0.221 \\
\hline 10.4 & 0.2 & 40.53 & 55.08 & 55.08 & 41.45 & 0.211 & 0.287 & 0.287 & 0.216 \\
\hline 15.6 & 0.3 & 50.82 & 69.05 & 69.05 & 51.93 & 0.211 & 0.287 & 0.287 & 0.216 \\
\hline 20.8 & 0.4 & 56.15 & 79.96 & 79.96 & 57.36 & 0.205 & 0.292 & 0.292 & 0.210 \\
\hline 26 & 0.5 & 56.40 & 88.30 & 88.30 & 57.69 & 0.194 & 0.304 & 0.304 & 0.198 \\
\hline 31.2 & 0.6 & 50.70 & 80.26 & 80.26 & 51.85 & 0.193 & 0.305 & 0.305 & 0.197 \\
\hline 36.4 & 0.7 & 39.58 & 56.65 & 56.65 & 40.43 & 0.205 & 0.293 & 0.293 & 0.209 \\
\hline 41.6 & 0.8 & 29.02 & 35.97 & 35.97 & 29.65 & 0.222 & 0.275 & 0.275 & 0.227 \\
\hline 46.8 & 0.9 & 17.86 & 20.10 & 20.10 & 18.25 & 0.234 & 0.263 & 0.263 & 0.239 \\
\hline 52 & 1 & 0 & 0 & 0 & 0 & --- & --- & --- & --- \\
\hline & & & & \multicolumn{2}{|c|}{ Average } & 0.210 & 0.288 & 0.288 & 0.215 \\
\hline & & & & \multicolumn{2}{|c|}{ MPF Applied } & 0.252 & 0.345 & 0.345 & 0.258 \\
\hline & & & & \multicolumn{2}{|c|}{ St. Dev. } & 0.013 & 0.013 & 0.013 & 0.013 \\
\hline
\end{tabular}

\begin{tabular}{|c|c|c|c|c|c|c|c|c|c|}
\hline \multicolumn{10}{|c|}{ Truck Run 4, Simplified Distribution Factors (FEA) } \\
\hline \multicolumn{2}{|c|}{ Panel Points } & \multicolumn{4}{|c|}{ Averages $(\mu \varepsilon)$} & \multicolumn{4}{|c|}{ Distribution Factors } \\
\hline$x(\mathrm{ft})$ & $\mathrm{x} / \mathrm{L}$ & G1 & $\mathrm{G} 2$ & G3 & G4 & G1 & G2 & G3 & G4 \\
\hline 0 & 0 & 0 & 0 & 0 & 0 & --- & --- & --- & --- \\
\hline 5.2 & 0.1 & 19.65 & 30.57 & 36.35 & 34.04 & 0.163 & 0.253 & 0.301 & 0.282 \\
\hline 10.4 & 0.2 & 30.67 & 49.09 & 59.10 & 53.51 & 0.159 & 0.255 & 0.307 & 0.278 \\
\hline 15.6 & 0.3 & 38.37 & 61.53 & 74.27 & 66.98 & 0.159 & 0.255 & 0.308 & 0.278 \\
\hline 20.8 & 0.4 & 42.17 & 70.14 & 86.87 & 74.58 & 0.154 & 0.256 & 0.317 & 0.272 \\
\hline 26 & 0.5 & 41.94 & 75.31 & 97.17 & 76.52 & 0.144 & 0.259 & 0.334 & 0.263 \\
\hline 31.2 & 0.6 & 37.60 & 68.38 & 88.27 & 68.93 & 0.143 & 0.260 & 0.335 & 0.262 \\
\hline 36.4 & 0.7 & 29.58 & 50.02 & 61.42 & 52.69 & 0.153 & 0.258 & 0.317 & 0.272 \\
\hline 41.6 & 0.8 & 22.19 & 33.21 & 38.01 & 37.41 & 0.170 & 0.254 & 0.291 & 0.286 \\
\hline 46.8 & 0.9 & 13.80 & 19.24 & 20.83 & 22.52 & 0.181 & 0.252 & 0.273 & 0.295 \\
\hline 52 & 1 & 0 & 0 & 0 & 0 & --- & --- & --- & --- \\
\hline & & & & \multicolumn{2}{|c|}{ Average } & 0.158 & 0.256 & 0.309 & 0.276 \\
\hline & & & & \multicolumn{2}{|c|}{ MPF Applied } & 0.190 & 0.307 & 0.371 & 0.332 \\
\hline & & & & \multicolumn{2}{|c|}{ St. Dev. } & 0.012 & 0.003 & 0.020 & 0.011 \\
\hline
\end{tabular}




\begin{tabular}{|c|c|c|c|c|c|c|c|c|c|}
\hline \multicolumn{10}{|c|}{ Truck Run 5, Simplified Distribution Factors (FEA) } \\
\hline \multicolumn{2}{|c|}{ Panel Points } & \multicolumn{4}{|c|}{ Averages $(\mu \varepsilon)$} & \multicolumn{4}{|c|}{ Distribution Factors } \\
\hline$x(f t)$ & $\mathrm{x} / \mathrm{L}$ & G1 & $\mathrm{G} 2$ & G3 & G4 & G1 & G2 & G3 & G4 \\
\hline 0 & 0 & 0 & 0 & 0 & 0 & --- & --- & --- & --- \\
\hline 5.2 & 0.1 & 15.40 & 27.54 & 37.59 & 40.26 & 0.127 & 0.228 & 0.311 & 0.333 \\
\hline 10.4 & 0.2 & 23.83 & 43.11 & 61.04 & 64.55 & 0.124 & 0.224 & 0.317 & 0.335 \\
\hline 15.6 & 0.3 & 29.74 & 54.16 & 76.72 & 80.81 & 0.123 & 0.224 & 0.318 & 0.335 \\
\hline 20.8 & 0.4 & 32.61 & 61.02 & 89.66 & 90.99 & 0.119 & 0.222 & 0.327 & 0.332 \\
\hline 26 & 0.5 & 32.41 & 63.57 & 99.96 & 95.38 & 0.111 & 0.218 & 0.343 & 0.327 \\
\hline 31.2 & 0.6 & 29.07 & 57.67 & 90.77 & 86.11 & 0.110 & 0.219 & 0.344 & 0.327 \\
\hline 36.4 & 0.7 & 22.99 & 43.88 & 63.19 & 63.89 & 0.119 & 0.226 & 0.326 & 0.329 \\
\hline 41.6 & 0.8 & 17.33 & 30.44 & 39.26 & 44.00 & 0.132 & 0.232 & 0.300 & 0.336 \\
\hline 46.8 & 0.9 & 10.89 & 18.30 & 21.56 & 25.82 & 0.142 & 0.239 & 0.282 & 0.337 \\
\hline 52 & 1 & 0 & 0 & 0 & 0 & --- & --- & --- & --- \\
\hline & & & & \multicolumn{2}{|c|}{ Average } & 0.123 & 0.226 & 0.319 & 0.332 \\
\hline & & & & \multicolumn{2}{|c|}{ MPF Applied } & 0.148 & 0.271 & 0.382 & 0.399 \\
\hline & & & & \multicolumn{2}{|c|}{ St. Dev. } & 0.010 & 0.007 & 0.020 & 0.004 \\
\hline
\end{tabular}

\begin{tabular}{|c|c|c|c|c|c|c|c|c|c|}
\hline \multicolumn{2}{|c|}{ Panel Points } & \multicolumn{4}{|c|}{ Averages ( $\mu \varepsilon)$} & \multicolumn{4}{|c|}{ Distribution Factors } \\
\hline$x(f t)$ & $x / L$ & G1 & $\mathrm{G} 2$ & G3 & G4 & G1 & $\mathrm{G} 2$ & G3 & G4 \\
\hline 0 & 0 & 0 & 0 & 0 & 0 & --- & -- & --- & --- \\
\hline 5.2 & 0.1 & 76.12 & 68.63 & 55.49 & 41.18 & 0.631 & 0.569 & 0.460 & 0.341 \\
\hline 10.4 & 0.2 & 119.66 & 109.91 & 89.06 & 65.34 & 0.623 & 0.573 & 0.464 & 0.340 \\
\hline 15.6 & 0.3 & 150.62 & 137.35 & 111.98 & 82.12 & 0.625 & 0.570 & 0.465 & 0.341 \\
\hline 20.8 & 0.4 & 171.47 & 156.22 & 128.66 & 91.50 & 0.626 & 0.570 & 0.470 & 0.334 \\
\hline 26 & 0.5 & 180.79 & 167.17 & 139.01 & 93.45 & 0.623 & 0.576 & 0.479 & 0.322 \\
\hline 31.2 & 0.6 & 163.64 & 151.58 & 125.94 & 84.17 & 0.623 & 0.577 & 0.479 & 0.320 \\
\hline 36.4 & 0.7 & 121.26 & 110.86 & 91.01 & 64.53 & 0.626 & 0.572 & 0.470 & 0.333 \\
\hline 41.6 & 0.8 & 81.35 & 73.90 & 60.12 & 46.56 & 0.621 & 0.564 & 0.459 & 0.356 \\
\hline 46.8 & 0.9 & 47.46 & 42.93 & 34.53 & 28.13 & 0.620 & 0.561 & 0.451 & 0.368 \\
\hline 52 & 1 & 0 & 0 & 0 & 0 & --- & --- & --- & --- \\
\hline & & & & \multicolumn{2}{|c|}{ Average } & 0.624 & 0.570 & 0.466 & 0.339 \\
\hline & & & & \multicolumn{2}{|c|}{ St. Dev. } & 0.003 & 0.005 & 0.009 & 0.015 \\
\hline
\end{tabular}




\begin{tabular}{|c|c|c|c|c|c|c|c|c|c|}
\hline \multicolumn{2}{|c|}{ Panel Points } & \multicolumn{4}{|c|}{ Averages $(\mu \varepsilon)$} & \multicolumn{4}{|c|}{ Distribution Factors } \\
\hline$x(\mathrm{ft})$ & $\mathrm{x} / \mathrm{L}$ & G1 & $\mathrm{G} 2$ & G3 & G4 & G1 & $\mathrm{G} 2$ & G3 & G4 \\
\hline 0 & 0 & 0 & 0 & 0 & 0 & --- & --- & -- & --- \\
\hline 5.2 & 0.1 & 63.94 & 65.83 & 60.53 & 50.98 & 0.530 & 0.546 & 0.502 & 0.423 \\
\hline 10.4 & 0.2 & 102.77 & 106.28 & 97.27 & 81.73 & 0.530 & 0.548 & 0.501 & 0.421 \\
\hline 15.6 & 0.3 & 127.06 & 131.45 & 121.36 & 101.97 & 0.527 & 0.546 & 0.504 & 0.423 \\
\hline 20.8 & 0.4 & 143.92 & 150.05 & 139.44 & 114.31 & 0.526 & 0.548 & 0.509 & 0.417 \\
\hline 26 & 0.5 & 150.95 & 160.87 & 150.50 & 118.61 & 0.520 & 0.554 & 0.518 & 0.408 \\
\hline 31.2 & 0.6 & 136.44 & 145.91 & 136.46 & 106.98 & 0.519 & 0.555 & 0.519 & 0.407 \\
\hline 36.4 & 0.7 & 101.43 & 106.60 & 98.93 & 80.34 & 0.524 & 0.550 & 0.511 & 0.415 \\
\hline 41.6 & 0.8 & 69.22 & 70.80 & 65.21 & 56.51 & 0.529 & 0.541 & 0.498 & 0.432 \\
\hline 46.8 & 0.9 & 40.68 & 41.06 & 37.61 & 33.66 & 0.532 & 0.537 & 0.492 & 0.440 \\
\hline 52 & 1 & 0 & 0 & 0 & 0 & --- & --- & --- & --- \\
\hline & & & & \multicolumn{2}{|c|}{ Average } & 0.526 & 0.547 & 0.506 & 0.421 \\
\hline & & & & \multicolumn{2}{|c|}{ St. Dev. } & 0.005 & 0.006 & 0.009 & 0.011 \\
\hline
\end{tabular}

\begin{tabular}{|c|c|c|c|c|c|c|c|c|c|}
\hline \multirow{2}{*}{\multicolumn{2}{|c|}{ Panel Points }} & \multirow{2}{*}{\multicolumn{4}{|c|}{ Averages ( $\mu \varepsilon)$}} & \multirow{2}{*}{\multicolumn{4}{|c|}{ Distribution Factors }} \\
\hline & & & & & & & & & \\
\hline$x(f t)$ & $x / L$ & G1 & $\mathrm{G} 2$ & G3 & G4 & G1 & G2 & G3 & G4 \\
\hline 0 & 0 & 0 & 0 & 0 & 0 & --- & --- & --- & --- \\
\hline 5.2 & 0.1 & 19.78 & 13.54 & 8.45 & 5.75 & 0.416 & 0.285 & 0.178 & 0.121 \\
\hline 10.4 & 0.2 & 36.33 & 24.33 & 12.12 & 7.32 & 0.454 & 0.304 & 0.151 & 0.091 \\
\hline 15.6 & 0.3 & 42.28 & 26.90 & 14.46 & 10.24 & 0.450 & 0.287 & 0.154 & 0.109 \\
\hline 20.8 & 0.4 & 49.14 & 29.48 & 15.71 & 12.28 & 0.461 & 0.277 & 0.147 & 0.115 \\
\hline 26 & 0.5 & 65.10 & 36.80 & 16.05 & 12.70 & 0.498 & 0.282 & 0.123 & 0.097 \\
\hline 31.2 & 0.6 & 59.81 & 32.46 & 13.38 & 11.89 & 0.509 & 0.276 & 0.114 & 0.101 \\
\hline 36.4 & 0.7 & 33.12 & 18.66 & 9.63 & 9.41 & 0.468 & 0.263 & 0.136 & 0.133 \\
\hline 41.6 & 0.8 & 15.55 & 8.72 & 5.77 & 9.16 & 0.397 & 0.222 & 0.147 & 0.234 \\
\hline 46.8 & 0.9 & 3.08 & 1.41 & 0.93 & 3.87 & 0.331 & 0.152 & 0.100 & 0.417 \\
\hline 52 & 1 & 0 & 0 & 0 & 0 & --- & --- & --- & --- \\
\hline & & & & \multicolumn{2}{|c|}{ Average } & 0.443 & 0.261 & 0.139 & 0.158 \\
\hline & & & & \multicolumn{2}{|c|}{ MPF Applied } & 0.531 & 0.313 & 0.167 & 0.189 \\
\hline & & & & \multicolumn{2}{|c|}{ St. Dev. } & 0.055 & 0.047 & 0.024 & 0.106 \\
\hline
\end{tabular}




\begin{tabular}{|c|c|c|c|c|c|c|c|c|c|}
\hline \multicolumn{2}{|c|}{ Panel Points } & \multicolumn{4}{|c|}{ Averages $(\mu \varepsilon)$} & \multicolumn{4}{|c|}{ Distribution Factors } \\
\hline$x(\mathrm{ft})$ & $\mathrm{x} / \mathrm{L}$ & G1 & $\mathrm{G} 2$ & G3 & G4 & G1 & G2 & G3 & G4 \\
\hline 0 & 0 & 0 & 0 & 0 & 0 & --- & --- & --- & --- \\
\hline 5.2 & 0.1 & 16.48 & 12.99 & 9.36 & 7.27 & 0.357 & 0.282 & 0.203 & 0.158 \\
\hline 10.4 & 0.2 & 31.44 & 25.97 & 14.85 & 11.02 & 0.378 & 0.312 & 0.178 & 0.132 \\
\hline 15.6 & 0.3 & 37.33 & 29.02 & 18.12 & 12.22 & 0.386 & 0.300 & 0.187 & 0.126 \\
\hline 20.8 & 0.4 & 43.56 & 34.07 & 21.25 & 13.86 & 0.386 & 0.302 & 0.188 & 0.123 \\
\hline 26 & 0.5 & 56.68 & 45.54 & 21.16 & 13.93 & 0.413 & 0.332 & 0.154 & 0.101 \\
\hline 31.2 & 0.6 & 52.10 & 40.47 & 18.52 & 12.39 & 0.422 & 0.328 & 0.150 & 0.100 \\
\hline 36.4 & 0.7 & 30.64 & 23.08 & 13.81 & 8.56 & 0.403 & 0.303 & 0.182 & 0.113 \\
\hline 41.6 & 0.8 & 15.95 & 11.90 & 8.68 & 6.69 & 0.369 & 0.275 & 0.201 & 0.155 \\
\hline 46.8 & 0.9 & 7.06 & 5.97 & 4.81 & 4.38 & 0.318 & 0.269 & 0.216 & 0.197 \\
\hline 52 & 1 & 0 & 0 & 0 & 0 & --- & --- & --- & --- \\
\hline & & & & \multicolumn{2}{|c|}{ Average } & 0.381 & 0.300 & 0.184 & 0.134 \\
\hline & & & & \multicolumn{2}{|c|}{ MPF Applied } & 0.458 & 0.360 & 0.221 & 0.161 \\
\hline & & & & \multicolumn{2}{|c|}{ St. Dev. } & 0.031 & 0.022 & 0.022 & 0.031 \\
\hline
\end{tabular}

\begin{tabular}{|c|c|c|c|c|c|c|c|c|c|}
\hline \multicolumn{2}{|c|}{ Panel Points } & \multicolumn{4}{|c|}{ Averages ( $\mu \varepsilon)$} & \multicolumn{4}{|c|}{ Distribution Factors } \\
\hline$x(f t)$ & $x / L$ & G1 & $\mathrm{G} 2$ & G3 & G4 & G1 & $\mathrm{G} 2$ & G3 & G4 \\
\hline 0 & 0 & 0 & 0 & 0 & 0 & --- & --- & --- & --- \\
\hline 5.2 & 0.1 & 11.50 & 12.88 & 12.69 & 9.95 & 0.245 & 0.274 & 0.270 & 0.212 \\
\hline 10.4 & 0.2 & 16.95 & 24.16 & 24.59 & 15.61 & 0.208 & 0.297 & 0.302 & 0.192 \\
\hline 15.6 & 0.3 & 21.85 & 27.11 & 27.14 & 20.67 & 0.226 & 0.280 & 0.280 & 0.214 \\
\hline 20.8 & 0.4 & 25.67 & 33.46 & 32.26 & 24.15 & 0.222 & 0.290 & 0.279 & 0.209 \\
\hline 26 & 0.5 & 26.37 & 45.65 & 42.93 & 26.31 & 0.187 & 0.323 & 0.304 & 0.186 \\
\hline 31.2 & 0.6 & 22.54 & 41.11 & 37.84 & 22.85 & 0.181 & 0.331 & 0.304 & 0.184 \\
\hline 36.4 & 0.7 & 15.79 & 21.22 & 20.05 & 15.41 & 0.218 & 0.293 & 0.277 & 0.213 \\
\hline 41.6 & 0.8 & 8.81 & 9.57 & 9.43 & 10.89 & 0.228 & 0.247 & 0.244 & 0.281 \\
\hline 46.8 & 0.9 & 4.13 & 4.49 & 4.60 & 6.74 & 0.207 & 0.225 & 0.230 & 0.338 \\
\hline 52 & 1 & 0 & 0 & 0 & 0 & --- & --- & --- & --- \\
\hline & & & & \multicolumn{2}{|c|}{ Average } & 0.213 & 0.284 & 0.277 & 0.225 \\
\hline & & & & \multicolumn{2}{|c|}{ MPF Applied } & 0.256 & 0.341 & 0.332 & 0.270 \\
\hline & & & & \multicolumn{2}{|c|}{ St. Dev. } & 0.020 & 0.033 & 0.026 & 0.051 \\
\hline
\end{tabular}




\begin{tabular}{|c|c|c|c|c|c|c|c|c|c|}
\hline \multicolumn{2}{|c|}{ Panel Points } & \multicolumn{4}{|c|}{ Averages ( $\mu \varepsilon)$} & \multicolumn{4}{|c|}{ Distribution Factors } \\
\hline$x(f t)$ & $\mathrm{X} / \mathrm{L}$ & G1 & $\mathrm{G} 2$ & G3 & G4 & G1 & G2 & G3 & G4 \\
\hline 0 & 0 & 0 & 0 & 0 & 0 & --- & --- & --- & --- \\
\hline 5.2 & 0.1 & 6.88 & 9.32 & 11.47 & 11.32 & 0.176 & 0.239 & 0.294 & 0.290 \\
\hline 10.4 & 0.2 & 12.29 & 20.79 & 25.43 & 19.99 & 0.157 & 0.265 & 0.324 & 0.255 \\
\hline 15.6 & 0.3 & 17.29 & 24.62 & 29.00 & 27.59 & 0.176 & 0.250 & 0.294 & 0.280 \\
\hline 20.8 & 0.4 & 19.38 & 28.11 & 34.93 & 31.62 & 0.170 & 0.247 & 0.306 & 0.277 \\
\hline 26 & 0.5 & 19.06 & 35.56 & 49.00 & 32.68 & 0.140 & 0.261 & 0.360 & 0.240 \\
\hline 31.2 & 0.6 & 15.37 & 30.77 & 42.23 & 27.69 & 0.132 & 0.265 & 0.364 & 0.239 \\
\hline 36.4 & 0.7 & 11.69 & 18.23 & 22.24 & 18.97 & 0.164 & 0.256 & 0.313 & 0.267 \\
\hline 41.6 & 0.8 & 6.65 & 8.68 & 9.59 & 10.74 & 0.186 & 0.243 & 0.269 & 0.301 \\
\hline 46.8 & 0.9 & -0.23 & 0.24 & 1.16 & 3.45 & -0.051 & 0.052 & 0.252 & 0.747 \\
\hline 52 & 1 & 0 & 0 & 0 & 0 & --- & --- & --- & --- \\
\hline & & & & \multicolumn{2}{|c|}{ Average } & 0.139 & 0.231 & 0.308 & 0.322 \\
\hline & & & & \multicolumn{2}{|c|}{ MPF Applied } & 0.167 & 0.277 & 0.370 & 0.386 \\
\hline & & & & \multicolumn{2}{|c|}{ St. Dev. } & 0.073 & 0.068 & 0.037 & 0.161 \\
\hline
\end{tabular}

\begin{tabular}{|c|c|c|c|c|c|c|c|c|c|}
\hline \multicolumn{2}{|c|}{ Panel Points } & \multicolumn{4}{|c|}{ Averages ( $\mu \varepsilon)$} & \multicolumn{4}{|c|}{ Distribution Factors } \\
\hline$x(\mathrm{ft})$ & $\mathrm{x} / \mathrm{L}$ & G1 & $\mathrm{G} 2$ & G3 & G4 & G1 & $\mathrm{G} 2$ & G3 & G4 \\
\hline 0 & 0 & 0 & 0 & 0 & 0 & --- & --- & --- & --- \\
\hline 5.2 & 0.1 & 9.55 & 12.74 & 16.28 & 19.40 & 0.165 & 0.220 & 0.281 & 0.335 \\
\hline 10.4 & 0.2 & 7.41 & 14.20 & 26.91 & 31.41 & 0.093 & 0.178 & 0.337 & 0.393 \\
\hline 15.6 & 0.3 & 11.95 & 20.02 & 29.51 & 32.93 & 0.127 & 0.212 & 0.313 & 0.349 \\
\hline 20.8 & 0.4 & 14.23 & 24.62 & 36.73 & 37.21 & 0.126 & 0.218 & 0.326 & 0.330 \\
\hline 26 & 0.5 & 15.64 & 28.97 & 53.33 & 42.69 & 0.111 & 0.206 & 0.379 & 0.304 \\
\hline 31.2 & 0.6 & 14.93 & 26.96 & 48.64 & 40.32 & 0.114 & 0.206 & 0.372 & 0.308 \\
\hline 36.4 & 0.7 & 13.06 & 20.31 & 29.41 & 30.72 & 0.140 & 0.217 & 0.315 & 0.329 \\
\hline 41.6 & 0.8 & 7.94 & 10.15 & 14.18 & 20.08 & 0.152 & 0.194 & 0.271 & 0.384 \\
\hline 46.8 & 0.9 & 4.12 & 4.13 & 6.97 & 13.35 & 0.144 & 0.145 & 0.244 & 0.467 \\
\hline 52 & 1 & 0 & 0 & 0 & 0 & --- & --- & --- & --- \\
\hline & & & & \multicolumn{2}{|c|}{ Average } & 0.130 & 0.200 & 0.315 & 0.355 \\
\hline & & & & \multicolumn{2}{|c|}{ MPF Applied } & 0.156 & 0.239 & 0.378 & 0.426 \\
\hline & & & & \multicolumn{2}{|c|}{ St. Dev. } & 0.022 & 0.025 & 0.045 & 0.052 \\
\hline
\end{tabular}




\begin{tabular}{|c|c|c|c|c|c|c|c|c|c|}
\hline \multicolumn{2}{|c|}{ Panel Points } & \multicolumn{4}{|c|}{ Averages ( $\mu \varepsilon)$} & \multicolumn{4}{|c|}{ Distribution Factors } \\
\hline$x(f t)$ & $x / L$ & G1 & $\mathrm{G} 2$ & G3 & G4 & G1 & $\mathrm{G} 2$ & G3 & G4 \\
\hline 0 & 0 & 0 & 0 & 0 & 0 & --- & --- & --- & --- \\
\hline 5.2 & 0.1 & 26.66 & 22.86 & 19.92 & 17.07 & 0.616 & 0.529 & 0.461 & 0.395 \\
\hline 10.4 & 0.2 & 48.62 & 45.12 & 37.55 & 27.31 & 0.613 & 0.569 & 0.474 & 0.344 \\
\hline 15.6 & 0.3 & 59.58 & 51.53 & 43.46 & 37.83 & 0.619 & 0.536 & 0.452 & 0.393 \\
\hline 20.8 & 0.4 & 68.52 & 57.59 & 50.64 & 43.90 & 0.621 & 0.522 & 0.459 & 0.398 \\
\hline 26 & 0.5 & 84.16 & 72.37 & 65.05 & 45.38 & 0.630 & 0.542 & 0.487 & 0.340 \\
\hline 31.2 & 0.6 & 75.19 & 63.23 & 55.61 & 39.58 & 0.644 & 0.541 & 0.476 & 0.339 \\
\hline 36.4 & 0.7 & 44.81 & 36.88 & 31.86 & 28.37 & 0.631 & 0.520 & 0.449 & 0.400 \\
\hline 41.6 & 0.8 & 22.19 & 17.40 & 15.36 & 19.90 & 0.593 & 0.465 & 0.410 & 0.532 \\
\hline 46.8 & 0.9 & 2.84 & 1.65 & 2.09 & 7.32 & 0.409 & 0.238 & 0.301 & 1.053 \\
\hline 52 & 1 & 0 & 0 & 0 & 0 & --- & --- & --- & --- \\
\hline & & & & \multicolumn{2}{|c|}{ Average } & 0.597 & 0.496 & 0.441 & 0.466 \\
\hline & & & & \multicolumn{2}{|c|}{ St. Dev. } & 0.072 & 0.101 & 0.057 & 0.228 \\
\hline
\end{tabular}

\begin{tabular}{|c|c|c|c|c|c|c|c|c|c|}
\hline \multicolumn{2}{|c|}{ Panel Points } & \multicolumn{4}{|c|}{ Averages $(\mu \varepsilon)$} & \multicolumn{4}{|c|}{ Distribution Factors } \\
\hline$x(\mathrm{ft})$ & $x / L$ & G1 & $\mathrm{G} 2$ & G3 & G4 & G1 & G2 & G3 & G4 \\
\hline 0 & 0 & 0 & 0 & 0 & 0 & --- & --- & --- & --- \\
\hline 5.2 & 0.1 & 26.03 & 25.73 & 25.64 & 26.67 & 0.500 & 0.494 & 0.493 & 0.513 \\
\hline 10.4 & 0.2 & 38.85 & 40.17 & 41.76 & 42.42 & 0.476 & 0.492 & 0.512 & 0.520 \\
\hline 15.6 & 0.3 & 49.28 & 49.05 & 47.63 & 45.14 & 0.516 & 0.513 & 0.499 & 0.472 \\
\hline 20.8 & 0.4 & 57.78 & 58.69 & 57.98 & 51.07 & 0.512 & 0.520 & 0.514 & 0.453 \\
\hline 26 & 0.5 & 72.32 & 74.52 & 74.48 & 56.62 & 0.520 & 0.536 & 0.536 & 0.407 \\
\hline 31.2 & 0.6 & 67.03 & 67.43 & 67.16 & 52.72 & 0.527 & 0.530 & 0.528 & 0.415 \\
\hline 36.4 & 0.7 & 43.70 & 43.39 & 43.23 & 39.29 & 0.515 & 0.512 & 0.510 & 0.463 \\
\hline 41.6 & 0.8 & 23.89 & 22.05 & 22.86 & 26.77 & 0.500 & 0.461 & 0.478 & 0.560 \\
\hline 46.8 & 0.9 & 11.18 & 10.11 & 11.78 & 17.73 & 0.440 & 0.398 & 0.464 & 0.698 \\
\hline 52 & 1 & 0 & 0 & 0 & 0 & --- & --- & --- & --- \\
\hline & & & & \multicolumn{2}{|c|}{ Average } & 0.501 & 0.495 & 0.504 & 0.500 \\
\hline & & & & \multicolumn{2}{|c|}{ St. Dev. } & 0.027 & 0.043 & 0.023 & 0.089 \\
\hline
\end{tabular}




\section{Truck Run \#1 DFs}

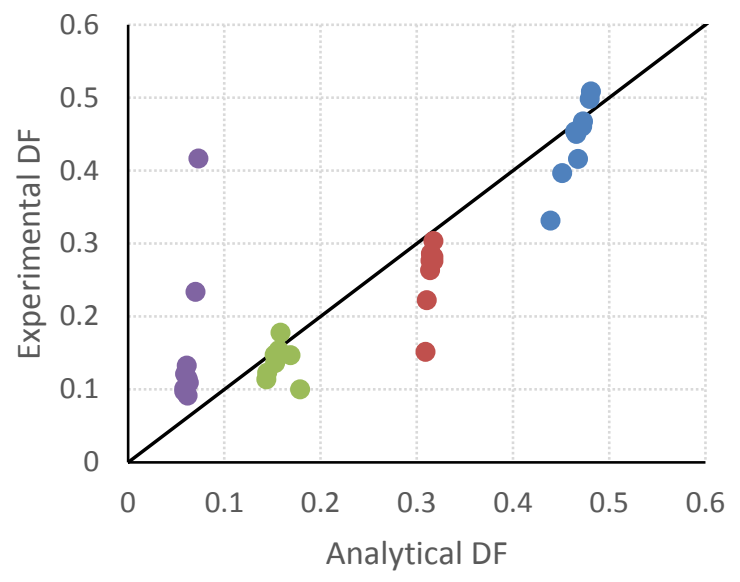

- Girder 1 - Girder 2 - Girder 3 @ Girder 4

Truck Run \#2 DFs

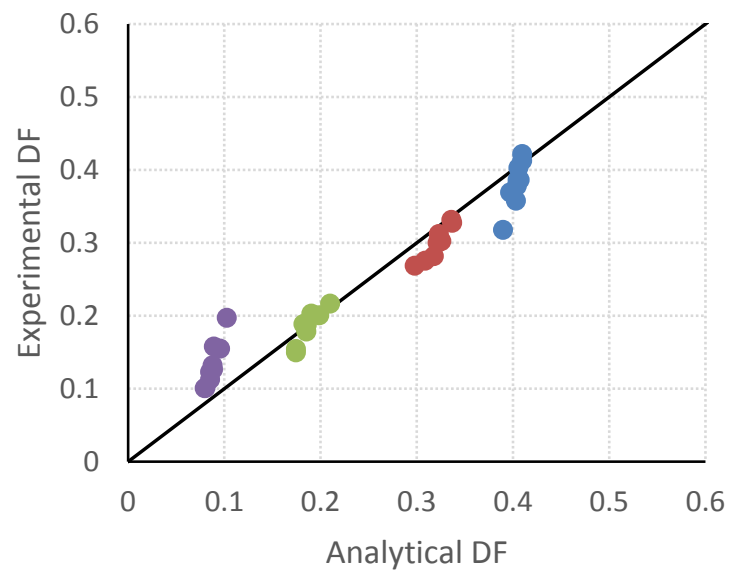

- Girder 1 -Girder 2 Girder 3 Girder 4
Truck Run \#1 Average DFs

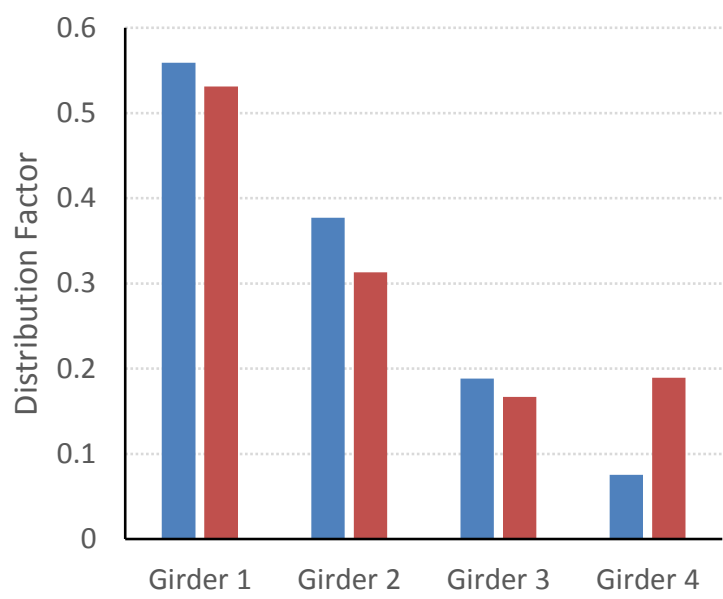

- FEA $\quad$ Experimental
Truck Run \#2 Average DFs

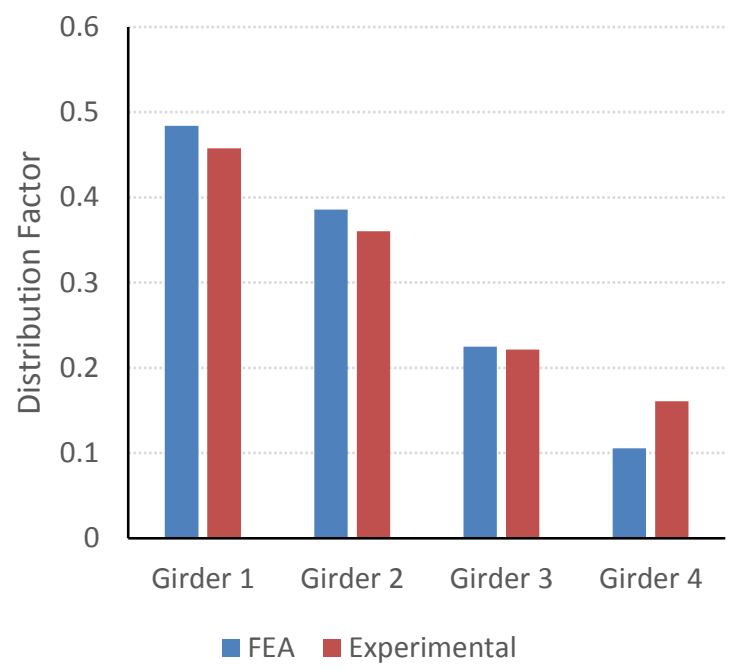


Truck Run \#3 DFs

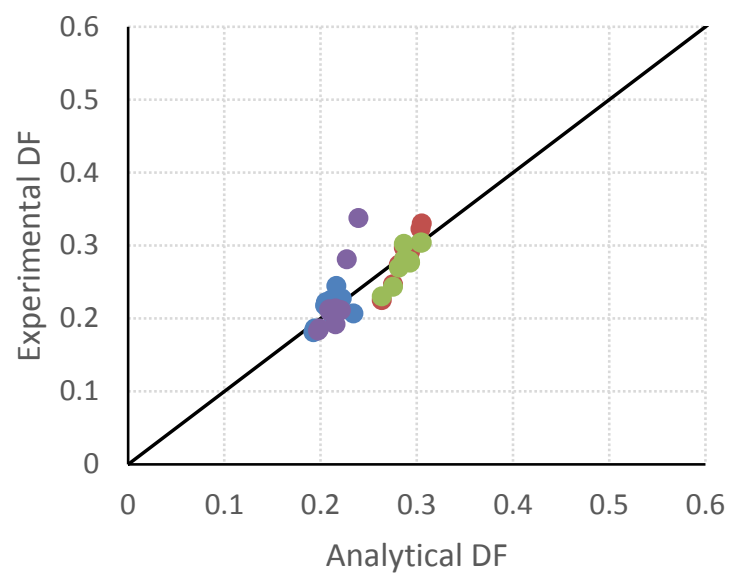

- Girder 1 • Girder 2 G Girder 3 -Girder 4

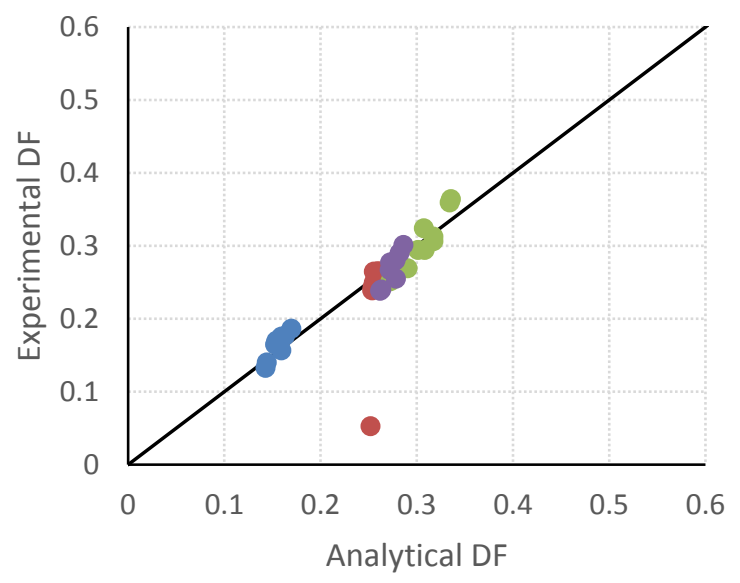

- Girder 1 -Girder 2 Girder 3 -Girder 4

Truck Run \#3 Average DFs

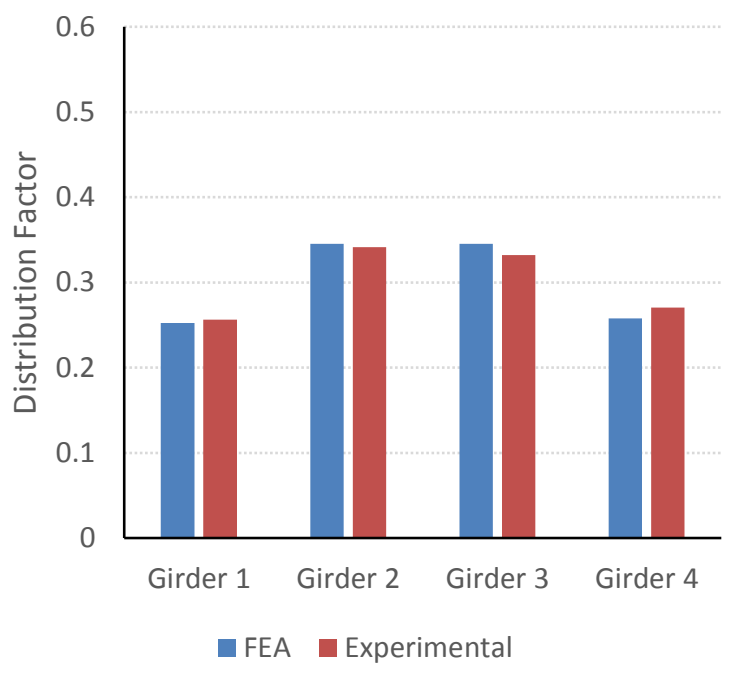

Truck Run \#4 Average DFs

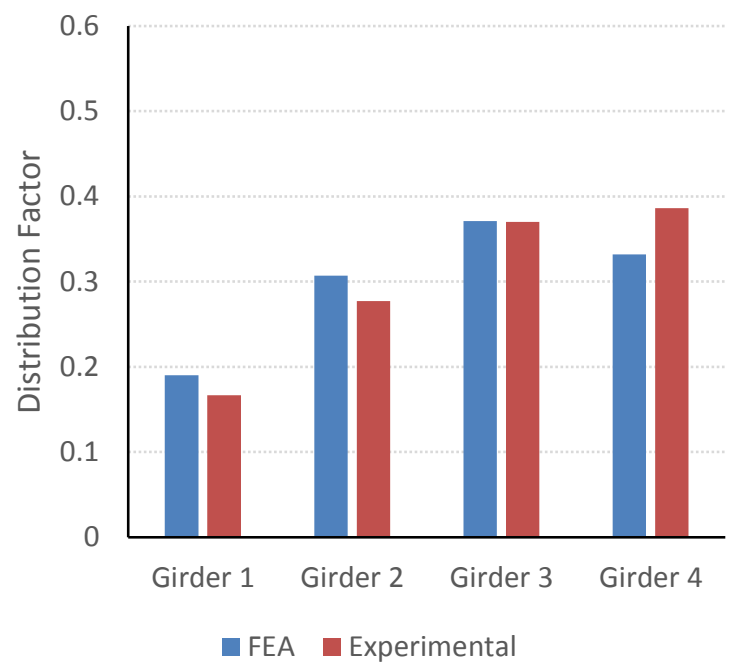


Truck Run \#5 DFs

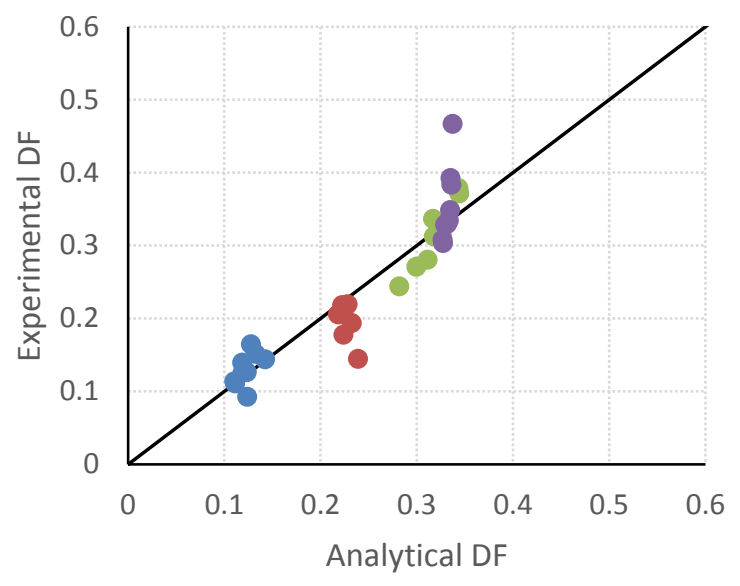

- Girder 1 @ Girder 2 -Girder 3 @Girder 4

Truck Runs \#1 \& \#4 DFs

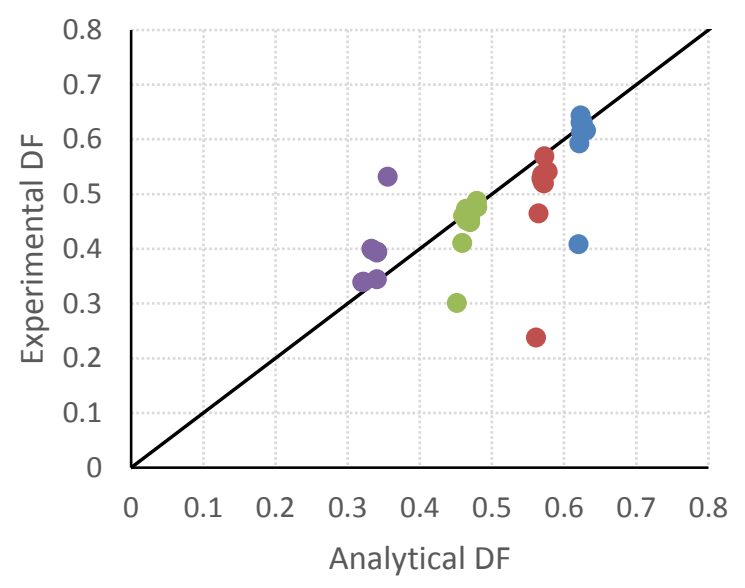

- Girder 1 - Girder 2 - Girder 3 Girder 4
Truck Run \#5 Average DFs

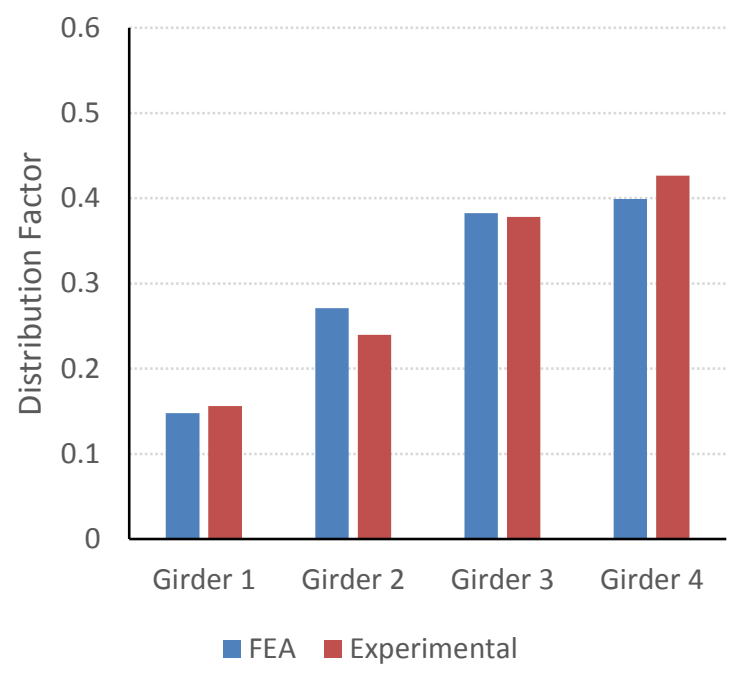

Truck Runs \#1 \& \#4 Average

DFs

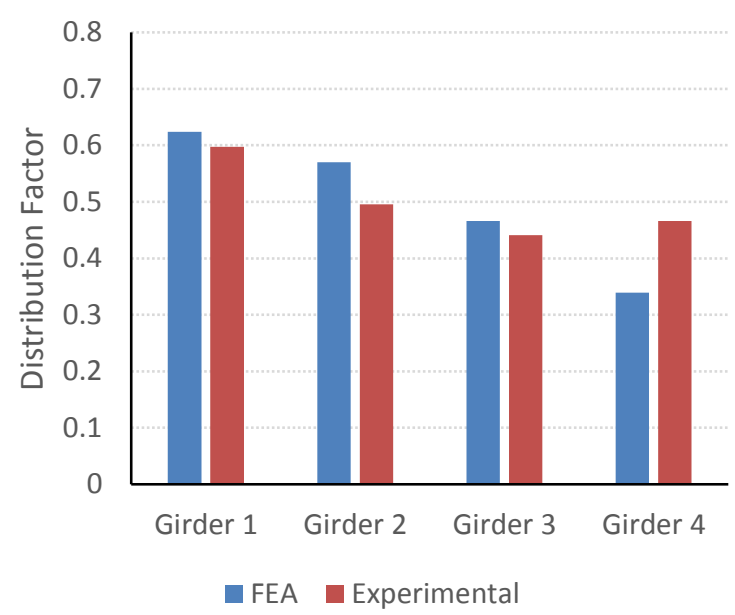


Truck Runs \#2 \& \#5 DFs

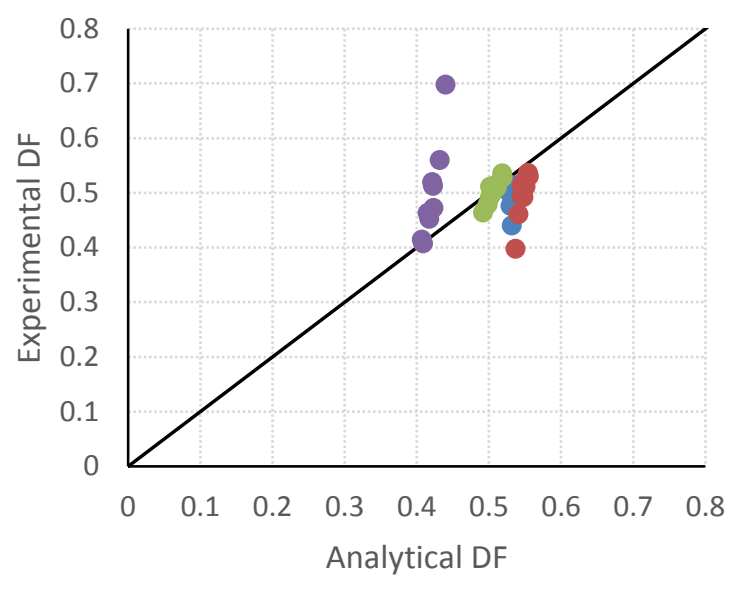

- Girder 1 - Girder 2 - Girder 3 Girder 4

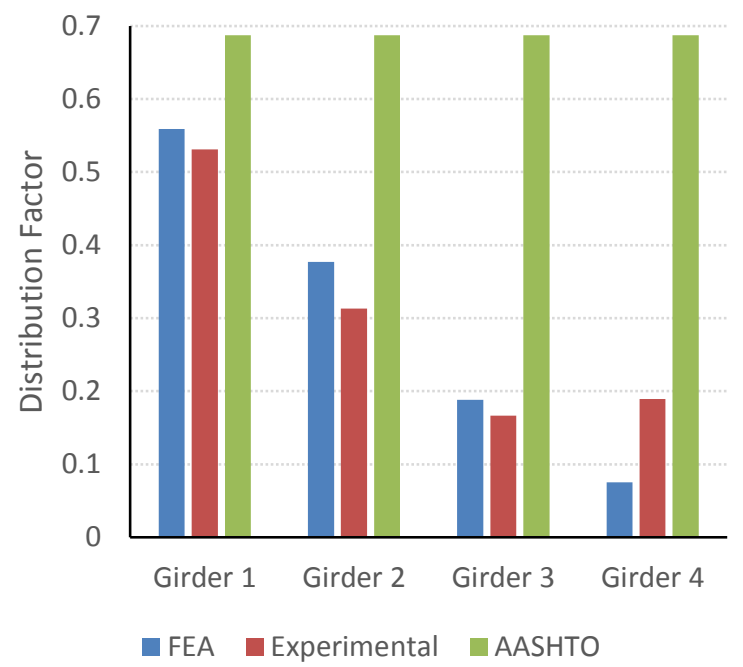

Truck Run \#2 Average LLDFs

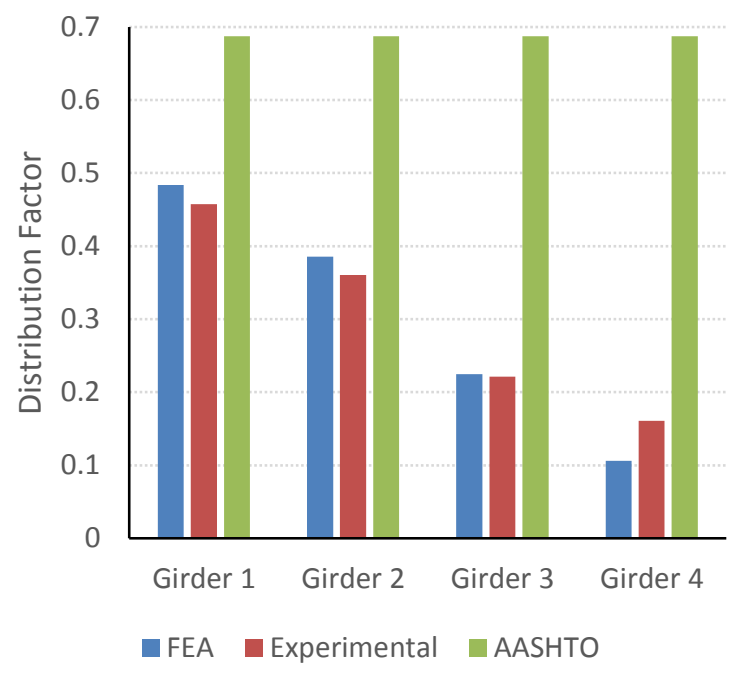


Truck Run \#3 Average LLDFs

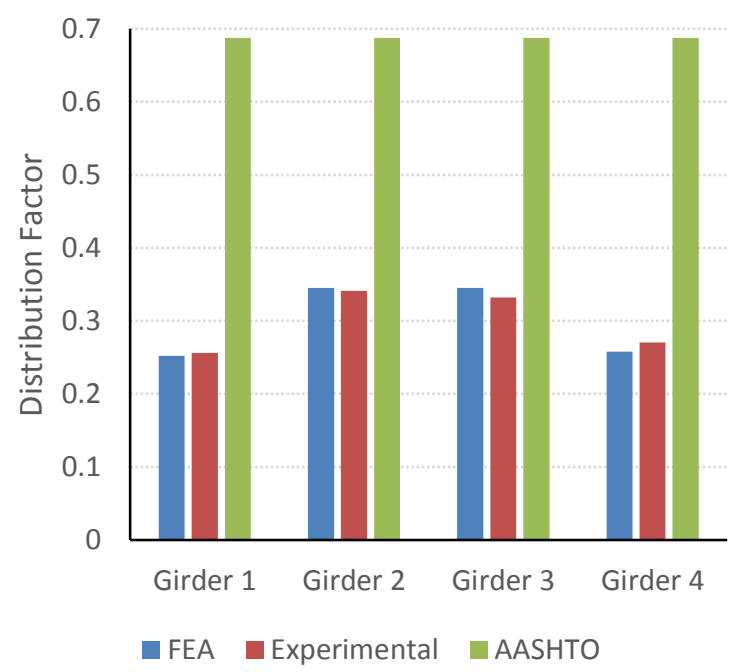

Truck Run \#5 Average LLDFs

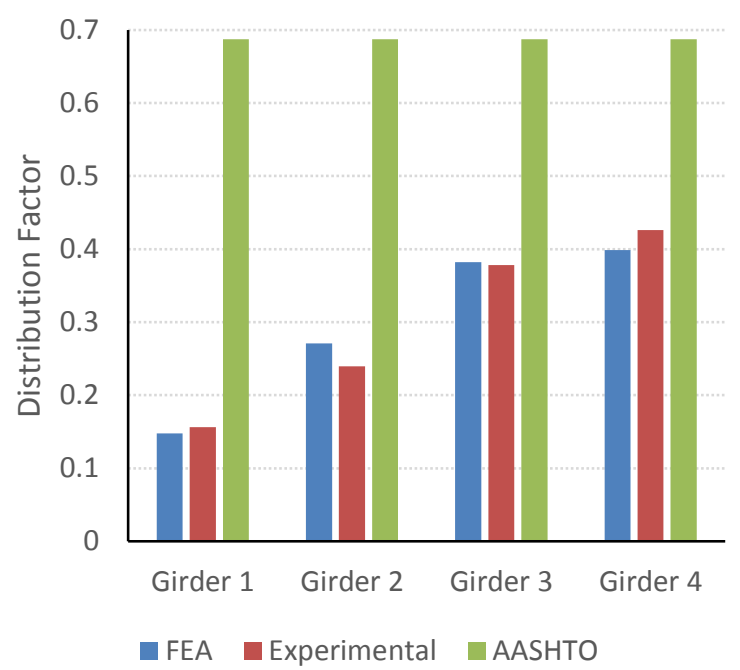

Truck Run \#4 Average LLDFs

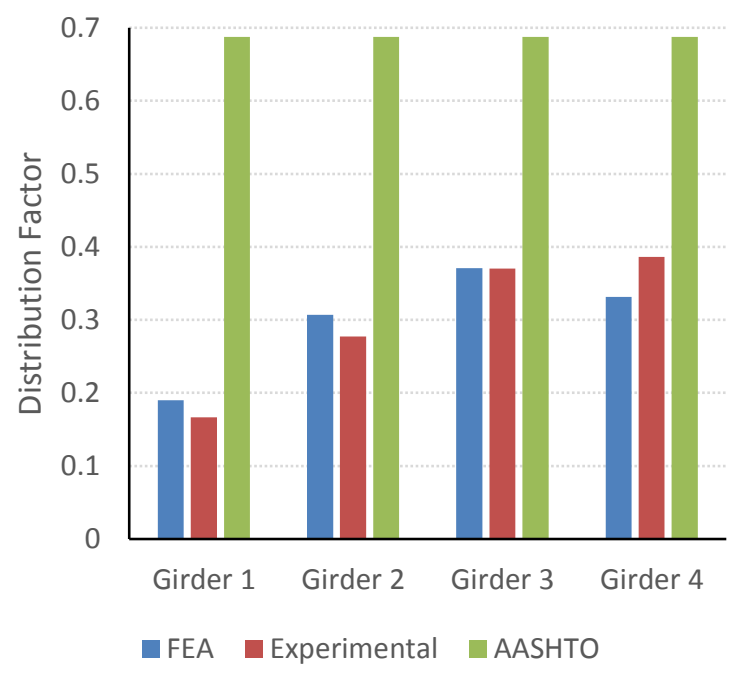

Truck Runs \#1 \& \#4 Average LLDFs

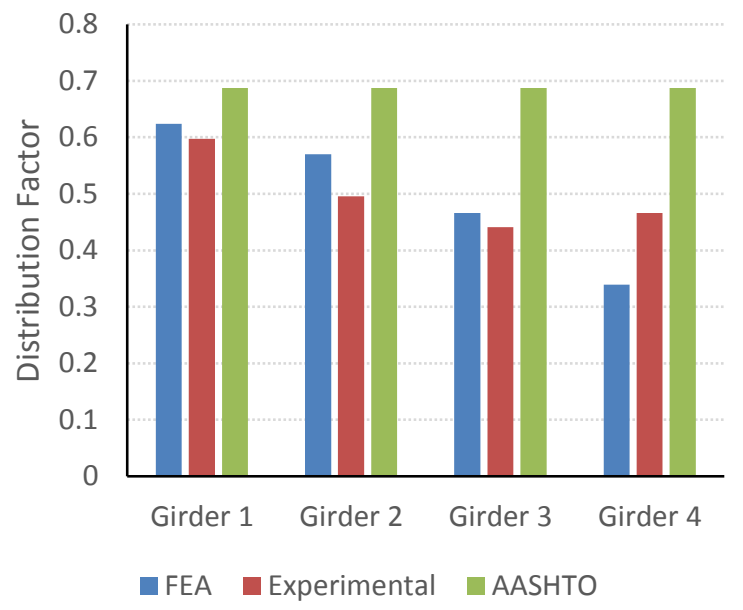


Truck Runs \#2 \& \#5 Average

LLDFs

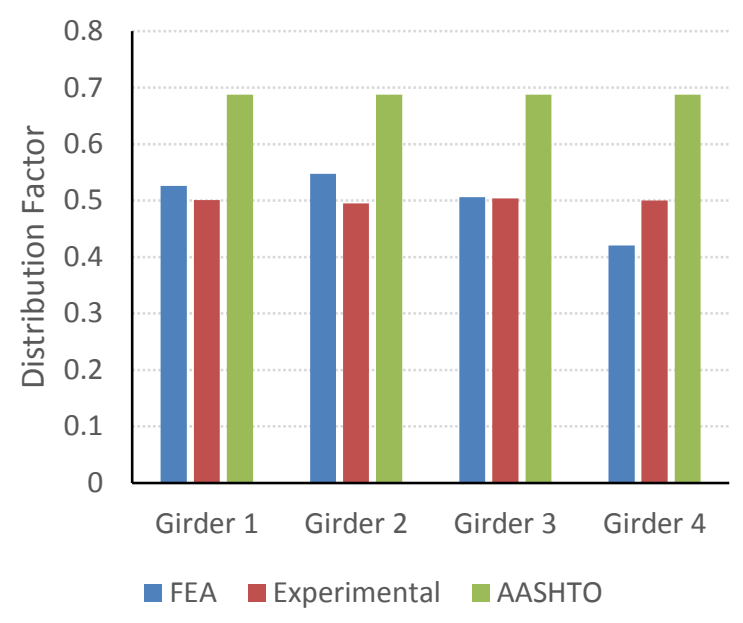

Truck Run 1, Bending Stress (ksi)

\begin{tabular}{|c|c|c|c|c|c|c|c|c|c|}
\hline \multicolumn{10}{c|}{ Truck Run 1, Bending Stress (ksi) } \\
\hline \multicolumn{1}{|c|}{ Panel Points } & \multicolumn{9}{c|}{ FEA } \\
\hline $\mathrm{x}(\mathrm{ft})$ & $\mathrm{x} / \mathrm{L}$ & $\mathrm{G} 1$ & $\mathrm{G} 2$ & $\mathrm{G} 3$ & $\mathrm{G} 4$ & $\mathrm{G} 1$ & $\mathrm{G} 2$ & $\mathrm{G} 3$ & $\mathrm{G} 4$ \\
\hline 0 & 0 & 0 & 0 & 0 & 0 & 0 & 0 & 0 & 0 \\
\hline 5.2 & 0.1 & 1.64 & 1.10 & 0.56 & 0.21 & 0.57 & 0.39 & 0.25 & 0.17 \\
\hline 10.4 & 0.2 & 2.58 & 1.76 & 0.87 & 0.34 & 1.05 & 0.71 & 0.35 & 0.21 \\
\hline 15.6 & 0.3 & 3.26 & 2.20 & 1.09 & 0.44 & 1.23 & 0.78 & 0.42 & 0.30 \\
\hline 20.8 & 0.4 & 3.75 & 2.50 & 1.21 & 0.49 & 1.43 & 0.85 & 0.46 & 0.36 \\
\hline 26 & 0.5 & 4.03 & 2.66 & 1.21 & 0.49 & 1.89 & 1.07 & 0.47 & 0.37 \\
\hline 31.2 & 0.6 & 3.66 & 2.41 & 1.09 & 0.44 & 1.73 & 0.94 & 0.39 & 0.34 \\
\hline 36.4 & 0.7 & 2.66 & 1.76 & 0.86 & 0.34 & 0.96 & 0.54 & 0.28 & 0.27 \\
\hline 41.6 & 0.8 & 1.72 & 1.18 & 0.64 & 0.27 & 0.45 & 0.25 & 0.17 & 0.27 \\
\hline 46.8 & 0.9 & 0.98 & 0.69 & 0.40 & 0.16 & 0.09 & 0.04 & 0.03 & 0.11 \\
\hline 52 & 1 & 0 & 0 & 0 & 0 & 0 & 0 & 0 & 0 \\
\hline
\end{tabular}




\begin{tabular}{|c|c|c|c|c|c|c|c|c|c|}
\hline \multicolumn{9}{|c|}{ Truck Run 2, Bending Stress (ksi) } \\
\hline \multicolumn{1}{|c|}{ Panel Points } & \multicolumn{3}{c|}{ FEA } \\
\hline $\mathrm{x}(\mathrm{ft})$ & $\mathrm{x} / \mathrm{L}$ & $\mathrm{G} 1$ & $\mathrm{G} 2$ & $\mathrm{G} 3$ & $\mathrm{G} 4$ & $\mathrm{G} 1$ & $\mathrm{G} 2$ & $\mathrm{G} 3$ & $\mathrm{G} 4$ \\
\hline 0 & 0 & 0 & 0 & 0 & 0 & 0 & 0 & 0 & 0 \\
\hline 5.2 & 0.1 & 1.41 & 1.11 & 0.67 & 0.31 & 0.48 & 0.38 & 0.27 & 0.21 \\
\hline 10.4 & 0.2 & 2.29 & 1.83 & 1.05 & 0.50 & 0.91 & 0.75 & 0.43 & 0.32 \\
\hline 15.6 & 0.3 & 2.82 & 2.24 & 1.29 & 0.61 & 1.08 & 0.84 & 0.53 & 0.35 \\
\hline 20.8 & 0.4 & 3.23 & 2.58 & 1.44 & 0.68 & 1.26 & 0.99 & 0.62 & 0.40 \\
\hline 26 & 0.5 & 3.44 & 2.82 & 1.47 & 0.67 & 1.64 & 1.32 & 0.61 & 0.40 \\
\hline 31.2 & 0.6 & 3.11 & 2.56 & 1.33 & 0.61 & 1.51 & 1.17 & 0.54 & 0.36 \\
\hline 36.4 & 0.7 & 2.27 & 1.82 & 1.04 & 0.48 & 0.89 & 0.67 & 0.40 & 0.25 \\
\hline 41.6 & 0.8 & 1.50 & 1.17 & 0.75 & 0.36 & 0.46 & 0.35 & 0.25 & 0.19 \\
\hline 46.8 & 0.9 & 0.86 & 0.66 & 0.47 & 0.23 & 0.20 & 0.17 & 0.14 & 0.13 \\
\hline 52 & 1 & 0 & 0 & 0 & 0 & 0 & 0 & 0 & 0 \\
\hline
\end{tabular}

\begin{tabular}{|c|c|c|c|c|c|c|c|c|c|}
\hline \multicolumn{9}{|c|}{ Truck Run 3, Bending Stress (ksi) } \\
\hline Panel Points & \multicolumn{9}{c|}{ FEA } \\
\hline $\mathrm{x}(\mathrm{ft})$ & $\mathrm{x} / \mathrm{L}$ & $\mathrm{G} 1$ & $\mathrm{G} 2$ & $\mathrm{G} 3$ & $\mathrm{G} 4$ & $\mathrm{G} 1$ & $\mathrm{G} 2$ & $\mathrm{G} 3$ & $\mathrm{G} 4$ \\
\hline 0 & 0 & 0 & 0 & 0 & 0 & 0 & 0 & 0 & 0 \\
\hline 5.2 & 0.1 & 0.76 & 0.98 & 0.98 & 0.77 & 0.33 & 0.37 & 0.37 & 0.29 \\
\hline 10.4 & 0.2 & 1.18 & 1.60 & 1.60 & 1.20 & 0.49 & 0.70 & 0.71 & 0.45 \\
\hline 15.6 & 0.3 & 1.47 & 2.00 & 2.00 & 1.51 & 0.63 & 0.79 & 0.79 & 0.60 \\
\hline 20.8 & 0.4 & 1.63 & 2.32 & 2.32 & 1.66 & 0.74 & 0.97 & 0.94 & 0.70 \\
\hline 26 & 0.5 & 1.64 & 2.56 & 2.56 & 1.67 & 0.76 & 1.32 & 1.25 & 0.76 \\
\hline 31.2 & 0.6 & 1.47 & 2.33 & 2.33 & 1.50 & 0.65 & 1.19 & 1.10 & 0.66 \\
\hline 36.4 & 0.7 & 1.15 & 1.64 & 1.64 & 1.17 & 0.46 & 0.62 & 0.58 & 0.45 \\
\hline 41.6 & 0.8 & 0.84 & 1.04 & 1.04 & 0.86 & 0.26 & 0.28 & 0.27 & 0.32 \\
\hline 46.8 & 0.9 & 0.52 & 0.58 & 0.58 & 0.53 & 0.12 & 0.13 & 0.13 & 0.20 \\
\hline 52 & 1 & 0 & 0 & 0 & 0 & 0 & 0 & 0 & 0 \\
\hline
\end{tabular}




\begin{tabular}{|c|c|c|c|c|c|c|c|c|c|}
\hline \multicolumn{9}{|c|}{ Truck Run 4, Bending Stress (ksi) } \\
\hline \multicolumn{1}{|c|}{ Panel Points } & \multicolumn{3}{c|}{ FEA } & \multicolumn{4}{c|}{ Experimental } \\
\hline $\mathrm{x}(\mathrm{ft})$ & $\mathrm{x} / \mathrm{L}$ & $\mathrm{G} 1$ & $\mathrm{G} 2$ & $\mathrm{G} 3$ & $\mathrm{G} 4$ & $\mathrm{G} 1$ & $\mathrm{G} 2$ & $\mathrm{G} 3$ & $\mathrm{G} 4$ \\
\hline 0 & 0 & 0 & 0 & 0 & 0 & 0 & 0 & 0 & 0 \\
\hline 5.2 & 0.1 & 0.57 & 0.89 & 1.05 & 0.99 & 0.20 & 0.27 & 0.33 & 0.33 \\
\hline 10.4 & 0.2 & 0.89 & 1.42 & 1.71 & 1.55 & 0.36 & 0.60 & 0.74 & 0.58 \\
\hline 15.6 & 0.3 & 1.11 & 1.78 & 2.15 & 1.94 & 0.50 & 0.71 & 0.84 & 0.80 \\
\hline 20.8 & 0.4 & 1.22 & 2.03 & 2.52 & 2.16 & 0.56 & 0.82 & 1.01 & 0.92 \\
\hline 26 & 0.5 & 1.22 & 2.18 & 2.82 & 2.22 & 0.55 & 1.03 & 1.42 & 0.95 \\
\hline 31.2 & 0.6 & 1.09 & 1.98 & 2.56 & 2.00 & 0.45 & 0.89 & 1.22 & 0.80 \\
\hline 36.4 & 0.7 & 0.86 & 1.45 & 1.78 & 1.53 & 0.34 & 0.53 & 0.64 & 0.55 \\
\hline 41.6 & 0.8 & 0.64 & 0.96 & 1.10 & 1.08 & 0.19 & 0.25 & 0.28 & 0.31 \\
\hline 46.8 & 0.9 & 0.40 & 0.56 & 0.60 & 0.65 & -0.01 & 0.01 & 0.03 & 0.10 \\
\hline 52 & 1 & 0 & 0 & 0 & 0 & 0 & 0 & 0 & 0 \\
\hline
\end{tabular}

\begin{tabular}{|c|c|c|c|c|c|c|c|c|c|}
\hline \multicolumn{10}{|c|}{ Truck Run 5, Bending Stress (ksi) } \\
\hline Panel Points & \multicolumn{9}{c|}{ FEA } \\
\hline $\mathrm{x}(\mathrm{ft})$ & $\mathrm{x} / \mathrm{L}$ & $\mathrm{G} 1$ & $\mathrm{G} 2$ & $\mathrm{G} 3$ & $\mathrm{G} 4$ & $\mathrm{G} 1$ & $\mathrm{G} 2$ & $\mathrm{G} 3$ & $\mathrm{G} 4$ \\
\hline 0 & 0 & 0 & 0 & 0 & 0 & 0 & 0 & 0 & 0 \\
\hline 5.2 & 0.1 & 0.45 & 0.80 & 1.09 & 1.17 & 0.28 & 0.37 & 0.47 & 0.56 \\
\hline 10.4 & 0.2 & 0.69 & 1.25 & 1.77 & 1.87 & 0.21 & 0.41 & 0.78 & 0.91 \\
\hline 15.6 & 0.3 & 0.86 & 1.57 & 2.22 & 2.34 & 0.35 & 0.58 & 0.86 & 0.95 \\
\hline 20.8 & 0.4 & 0.95 & 1.77 & 2.60 & 2.64 & 0.41 & 0.71 & 1.07 & 1.08 \\
\hline 26 & 0.5 & 0.94 & 1.84 & 2.90 & 2.77 & 0.45 & 0.84 & 1.55 & 1.24 \\
\hline 31.2 & 0.6 & 0.84 & 1.67 & 2.63 & 2.50 & 0.43 & 0.78 & 1.41 & 1.17 \\
\hline 36.4 & 0.7 & 0.67 & 1.27 & 1.83 & 1.85 & 0.38 & 0.59 & 0.85 & 0.89 \\
\hline 41.6 & 0.8 & 0.50 & 0.88 & 1.14 & 1.28 & 0.23 & 0.29 & 0.41 & 0.58 \\
\hline 46.8 & 0.9 & 0.32 & 0.53 & 0.63 & 0.75 & 0.12 & 0.12 & 0.20 & 0.39 \\
\hline 52 & 1 & 0 & 0 & 0 & 0 & 0 & 0 & 0 & 0 \\
\hline
\end{tabular}




\begin{tabular}{|c|c|c|c|c|c|c|c|c|c|}
\hline \multicolumn{9}{|c|}{ Truck Runs 1 \& 4, Bending Stress (ksi) } \\
\hline \multicolumn{1}{|c|}{ Panel Points } & \multicolumn{9}{c|}{ FEA } \\
\hline $\mathrm{x}(\mathrm{ft})$ & $\mathrm{x} / \mathrm{L}$ & $\mathrm{G} 1$ & $\mathrm{G} 2$ & $\mathrm{G} 3$ & $\mathrm{G} 4$ & $\mathrm{G} 1$ & $\mathrm{G} 2$ & $\mathrm{G} 3$ & $\mathrm{G} 4$ \\
\hline 0 & 0 & 0 & 0 & 0 & 0 & 0 & 0 & 0 & 0 \\
\hline 5.2 & 0.1 & 2.21 & 1.99 & 1.61 & 1.19 & 0.77 & 0.66 & 0.58 & 0.50 \\
\hline 10.4 & 0.2 & 3.47 & 3.19 & 2.58 & 1.89 & 1.41 & 1.31 & 1.09 & 0.79 \\
\hline 15.6 & 0.3 & 4.37 & 3.98 & 3.25 & 2.38 & 1.73 & 1.49 & 1.26 & 1.10 \\
\hline 20.8 & 0.4 & 4.97 & 4.53 & 3.73 & 2.65 & 1.99 & 1.67 & 1.47 & 1.27 \\
\hline 26 & 0.5 & 5.24 & 4.85 & 4.03 & 2.71 & 2.44 & 2.10 & 1.89 & 1.32 \\
\hline 31.2 & 0.6 & 4.75 & 4.40 & 3.65 & 2.44 & 2.18 & 1.83 & 1.61 & 1.15 \\
\hline 36.4 & 0.7 & 3.52 & 3.21 & 2.64 & 1.87 & 1.30 & 1.07 & 0.92 & 0.82 \\
\hline 41.6 & 0.8 & 2.36 & 2.14 & 1.74 & 1.35 & 0.64 & 0.50 & 0.45 & 0.58 \\
\hline 46.8 & 0.9 & 1.38 & 1.24 & 1.00 & 0.82 & 0.08 & 0.05 & 0.06 & 0.21 \\
\hline 52 & 1 & 0 & 0 & 0 & 0 & 0 & 0 & 0 & 0 \\
\hline
\end{tabular}

\begin{tabular}{|c|c|c|c|c|c|c|c|c|c|}
\hline \multicolumn{10}{|c|}{ Truck Runs 2 \& 5, Bending Stress (ksi) } \\
\hline \multicolumn{2}{|c|}{ Panel Points } & \multicolumn{4}{|c|}{ FEA } & \multicolumn{4}{|c|}{ Experimental } \\
\hline$x(\mathrm{ft})$ & $x / L$ & G1 & G2 & G3 & G4 & G1 & G2 & G3 & G4 \\
\hline 0 & 0 & 0 & 0 & 0 & 0 & 0 & 0 & 0 & 0 \\
\hline 5.2 & 0.1 & 1.85 & 1.91 & 1.76 & 1.48 & 0.75 & 0.75 & 0.74 & 0.77 \\
\hline 10.4 & 0.2 & 2.98 & 3.08 & 2.82 & 2.37 & 1.13 & 1.16 & 1.21 & 1.23 \\
\hline 15.6 & 0.3 & 3.68 & 3.81 & 3.52 & 2.96 & 1.43 & 1.42 & 1.38 & 1.31 \\
\hline 20.8 & 0.4 & 4.17 & 4.35 & 4.04 & 3.32 & 1.68 & 1.70 & 1.68 & 1.48 \\
\hline 26 & 0.5 & 4.38 & 4.67 & 4.36 & 3.44 & 2.10 & 2.16 & 2.16 & 1.64 \\
\hline 31.2 & 0.6 & 3.96 & 4.23 & 3.96 & 3.10 & 1.94 & 1.96 & 1.95 & 1.53 \\
\hline 36.4 & 0.7 & 2.94 & 3.09 & 2.87 & 2.33 & 1.27 & 1.26 & 1.25 & 1.14 \\
\hline 41.6 & 0.8 & 2.01 & 2.05 & 1.89 & 1.64 & 0.69 & 0.64 & 0.66 & 0.78 \\
\hline 46.8 & 0.9 & 1.18 & 1.19 & 1.09 & 0.98 & 0.32 & 0.29 & 0.34 & 0.51 \\
\hline 52 & 1 & 0 & 0 & 0 & 0 & 0 & 0 & 0 & 0 \\
\hline
\end{tabular}



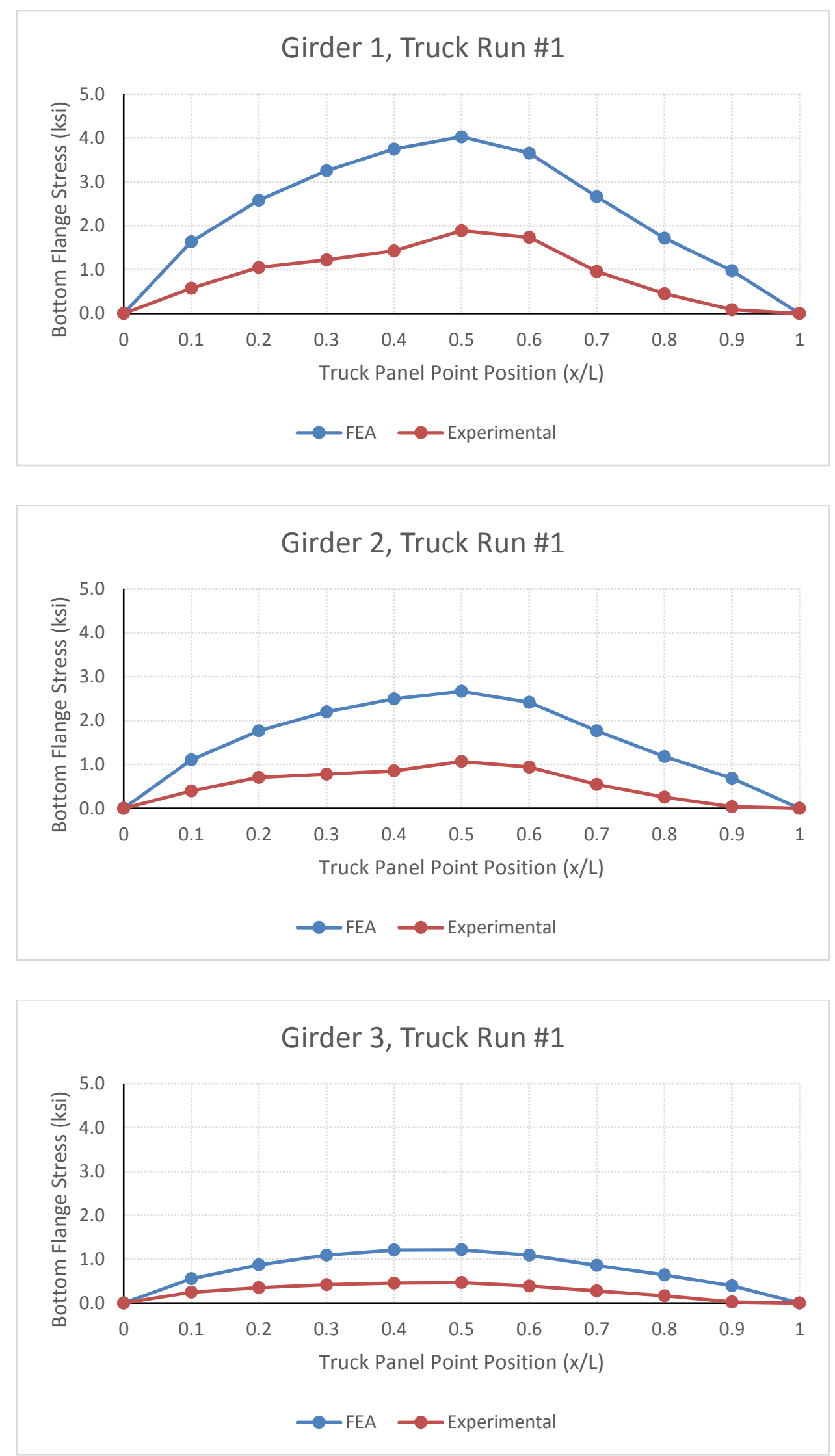

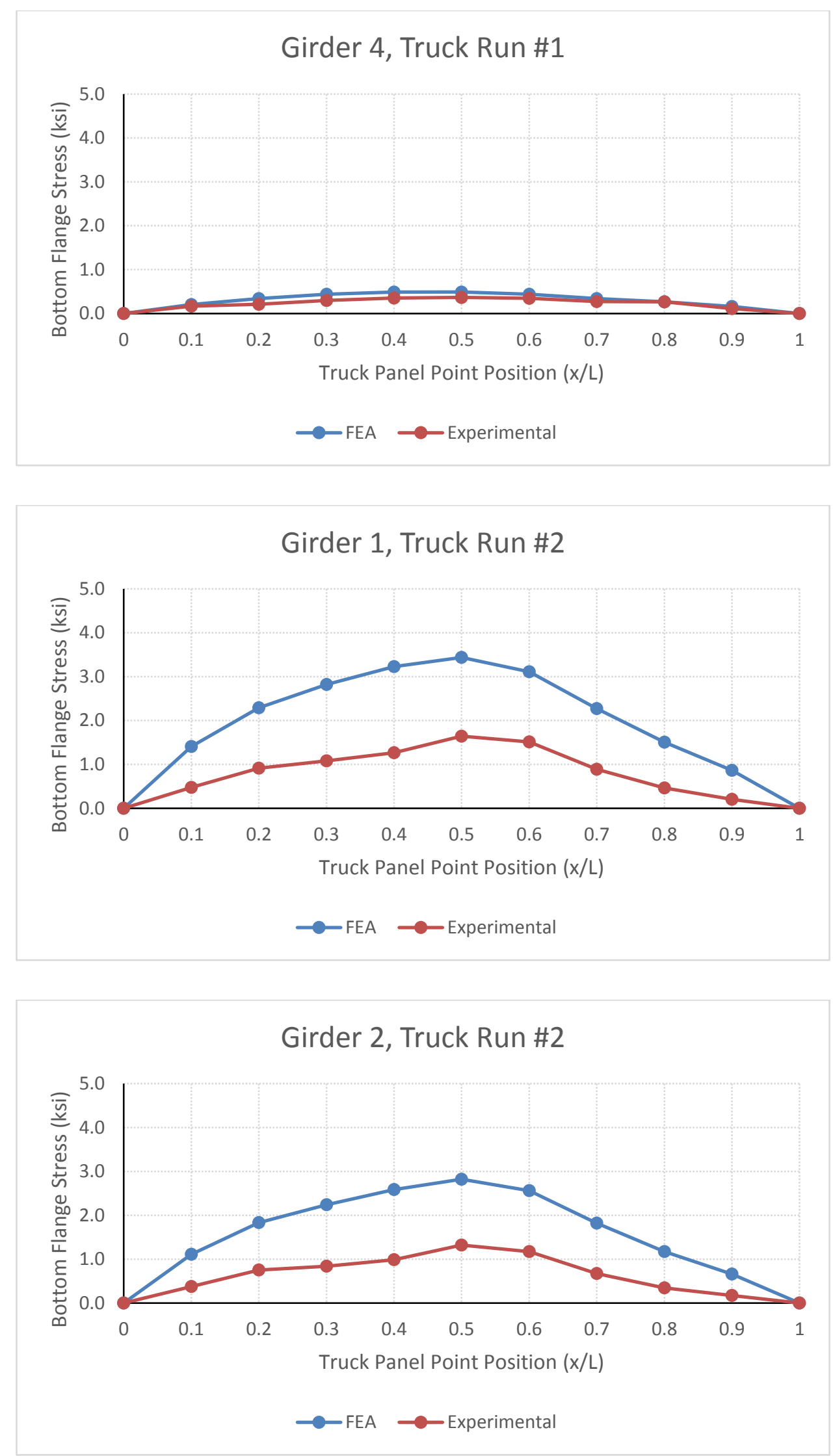

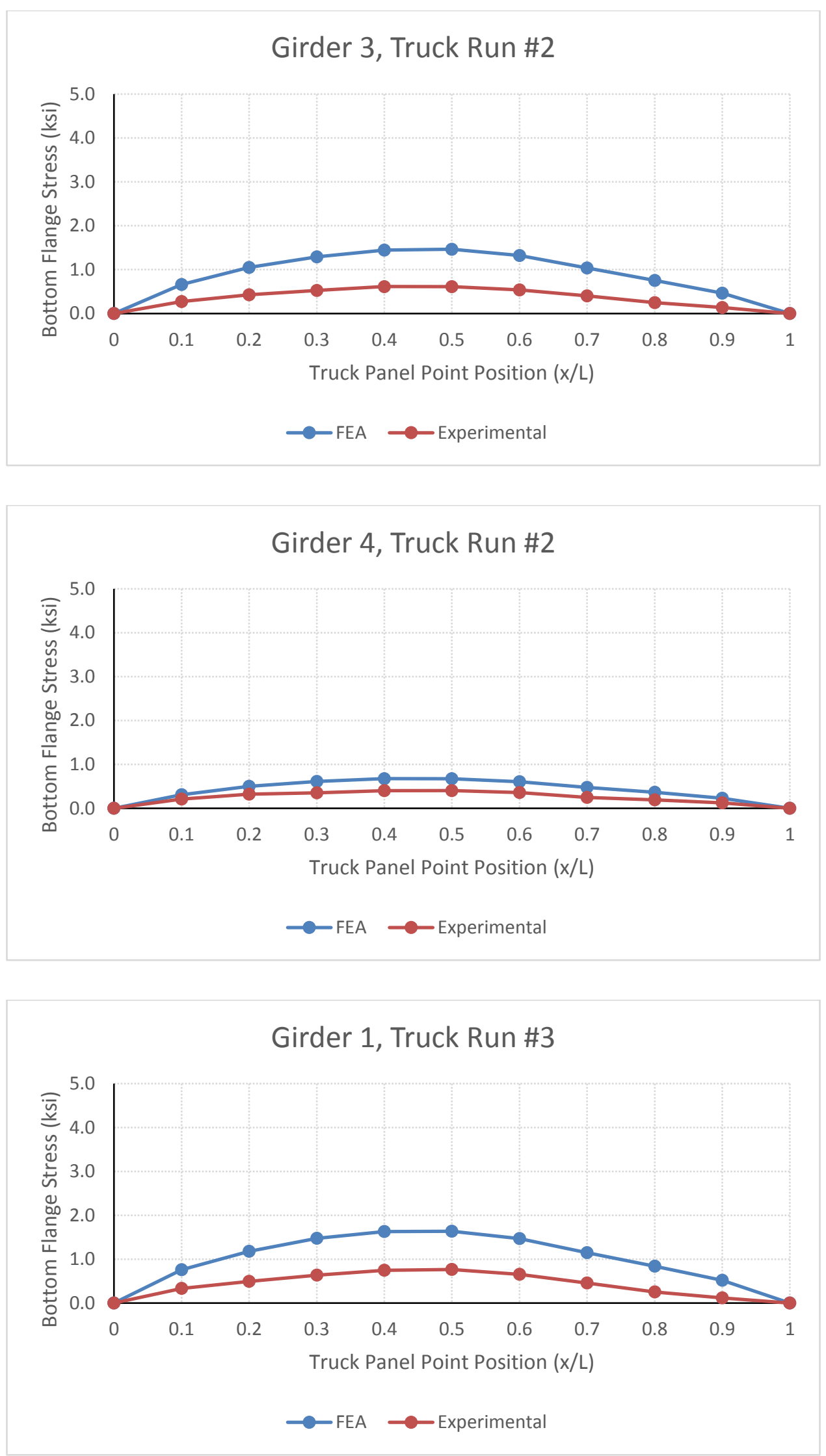

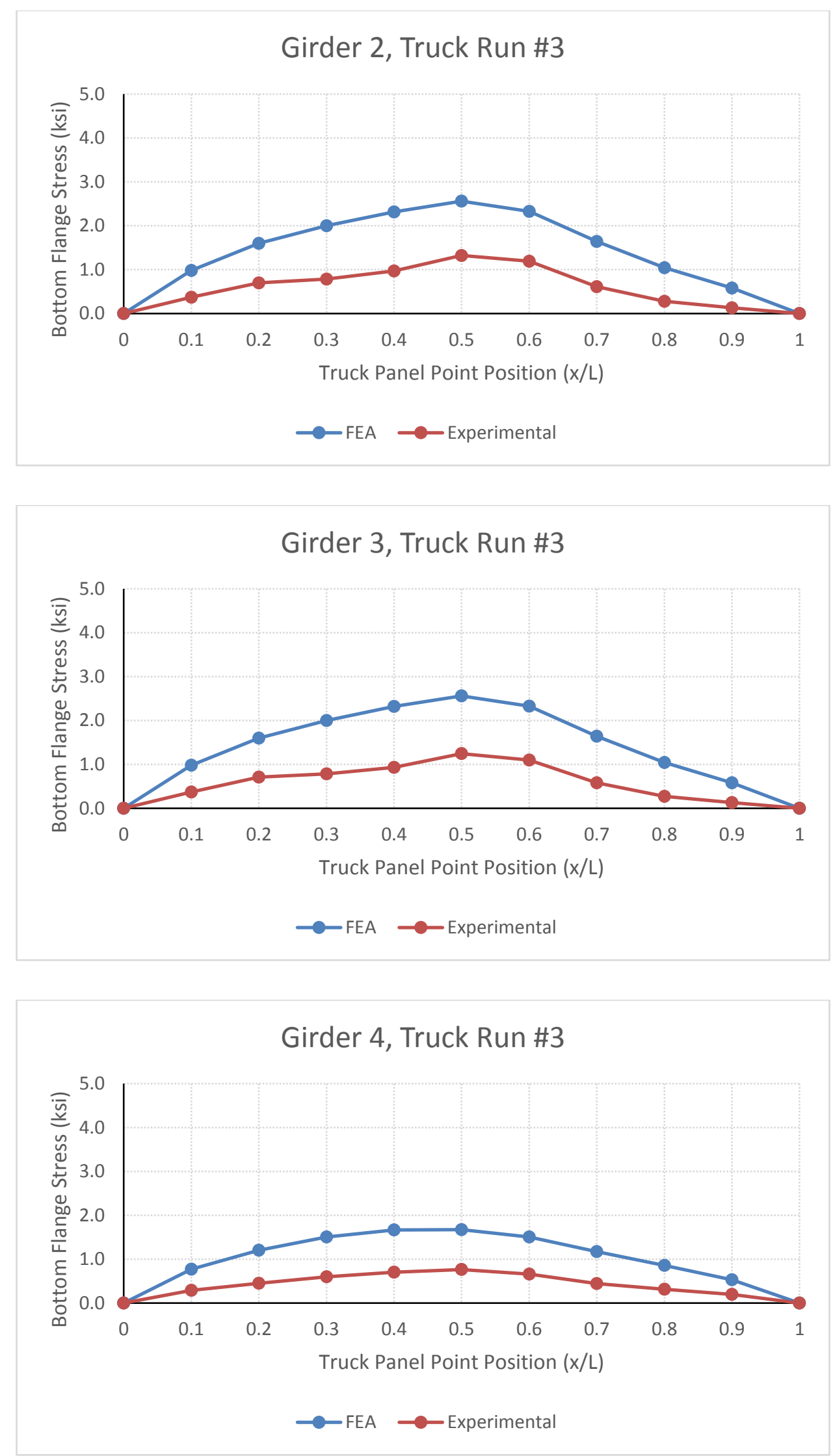

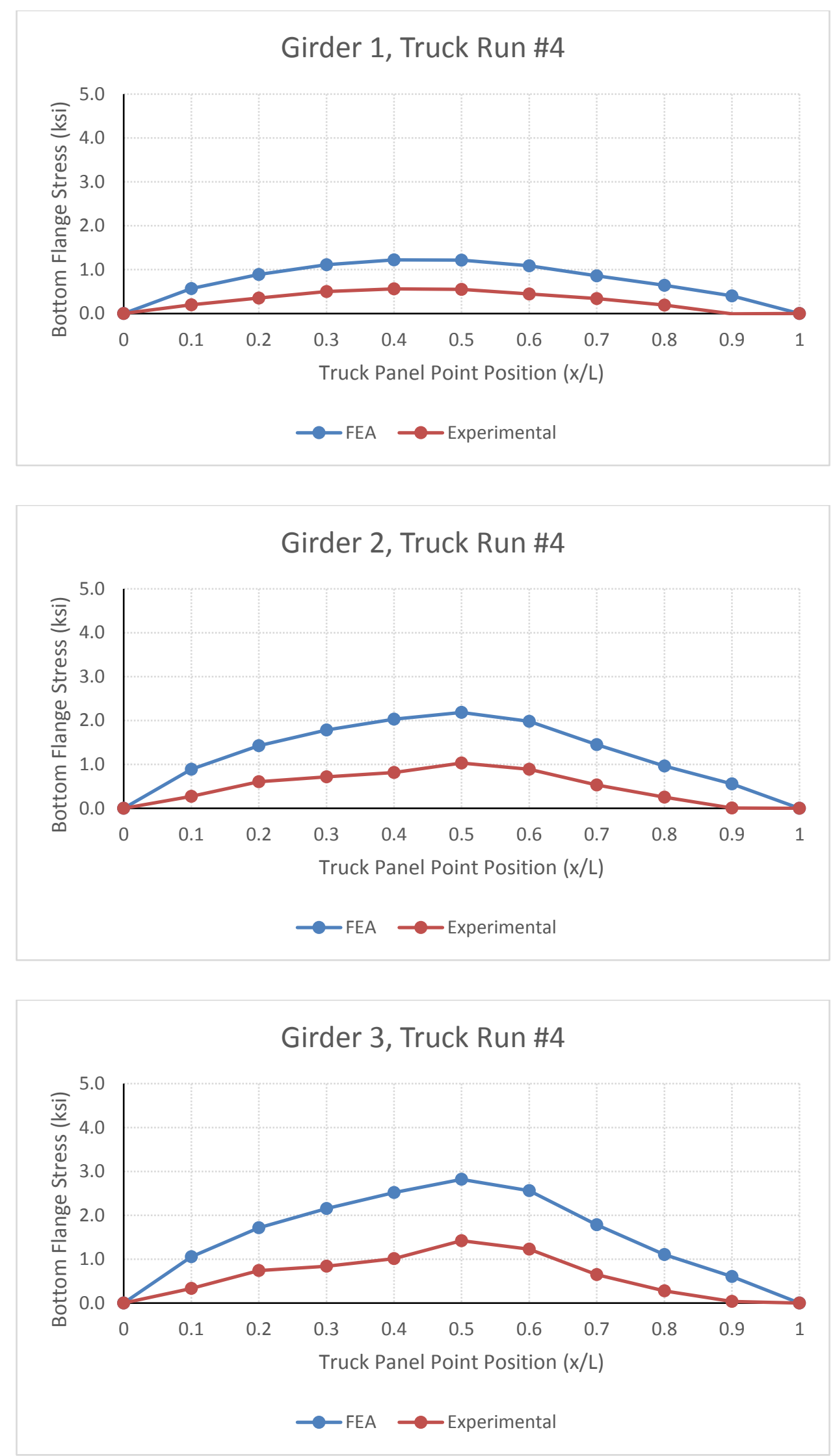

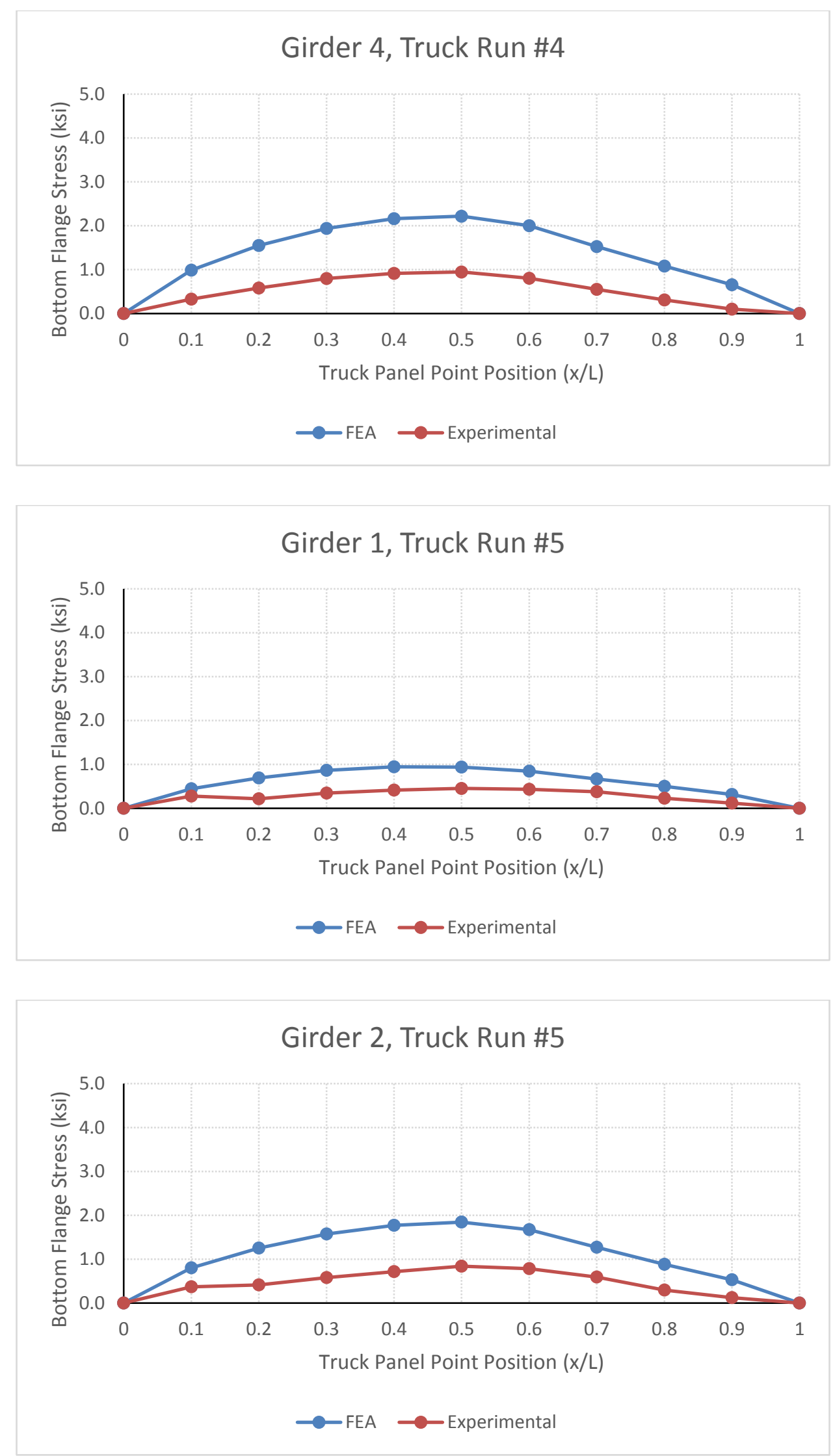

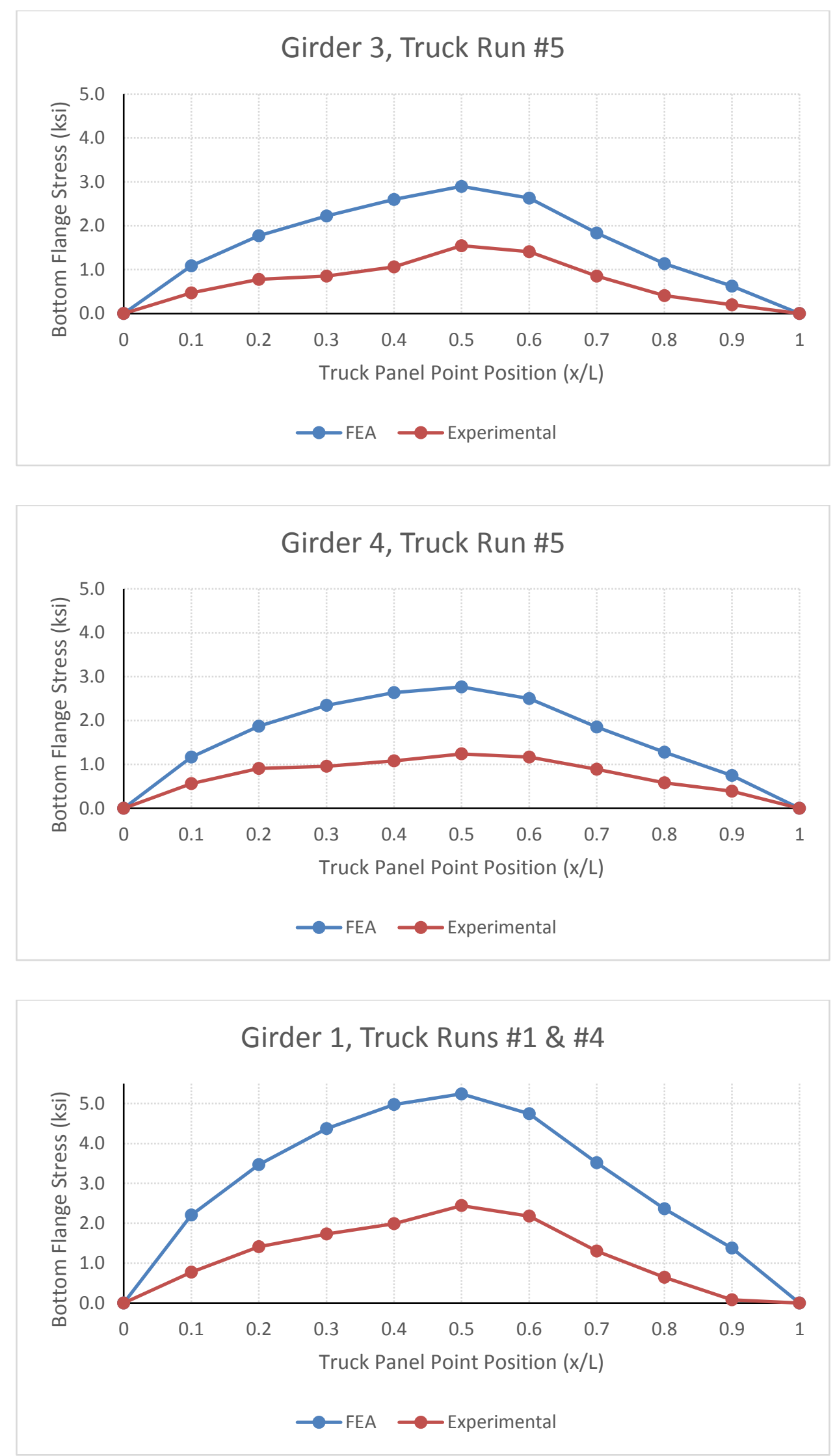

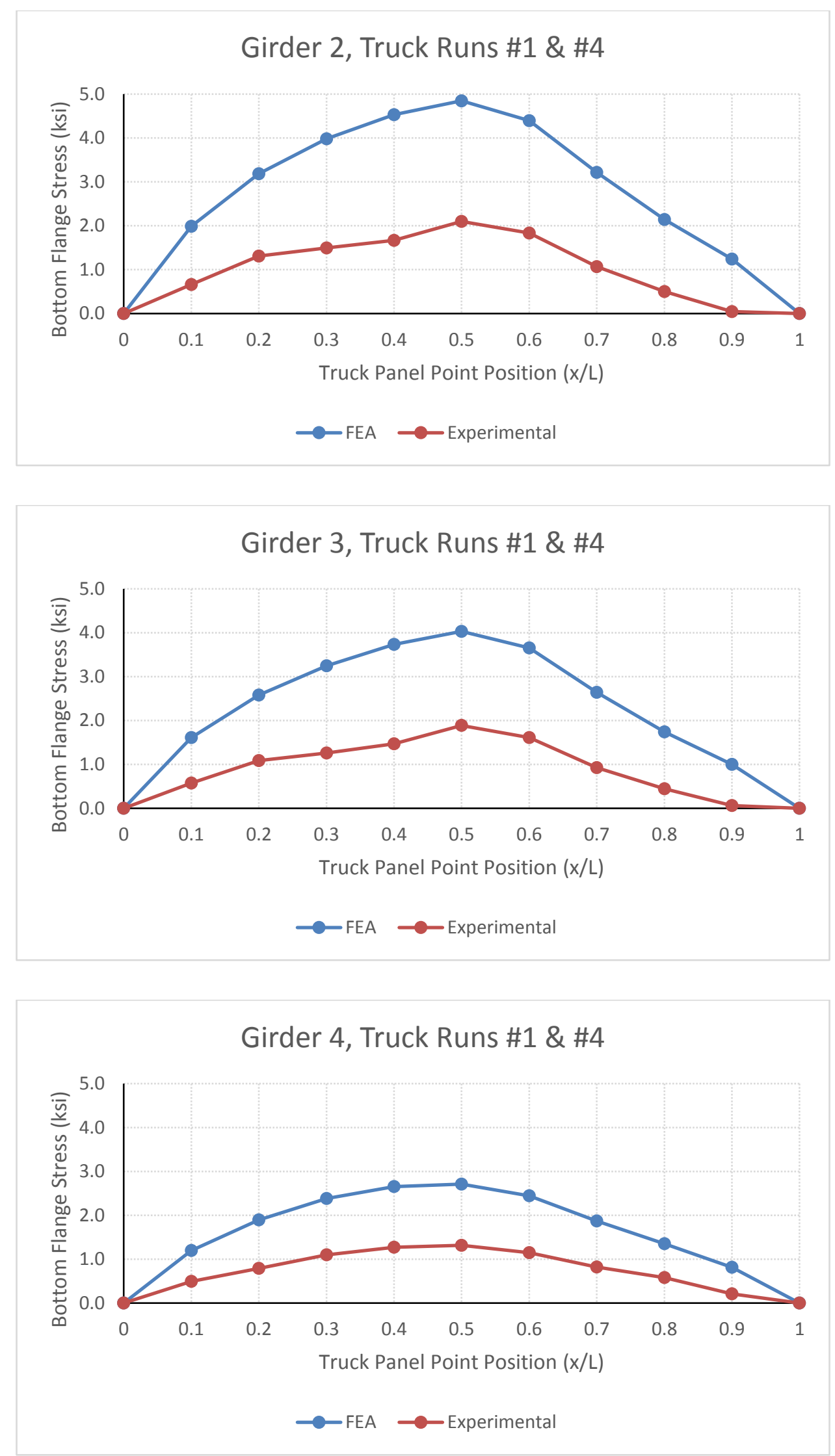

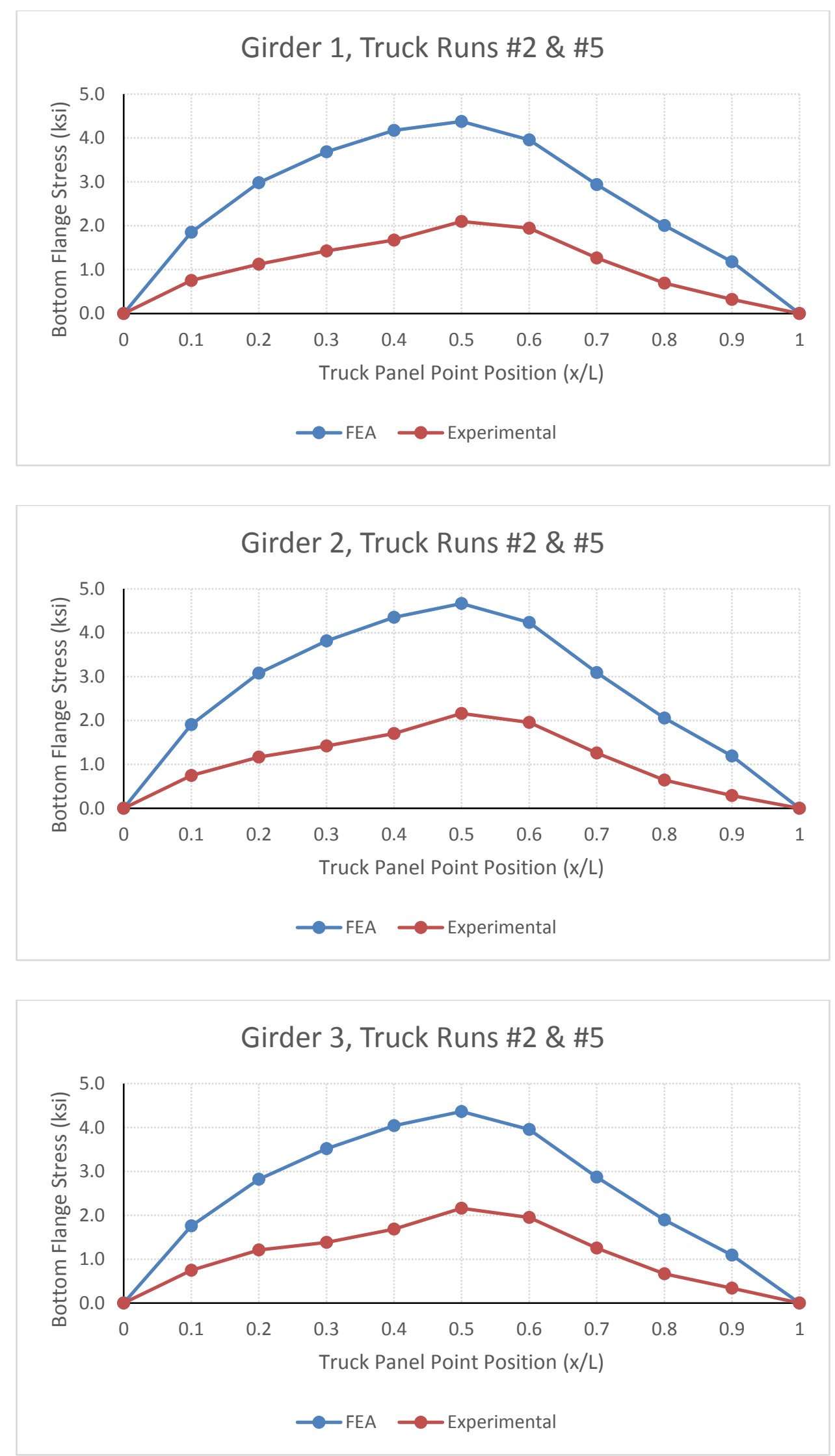


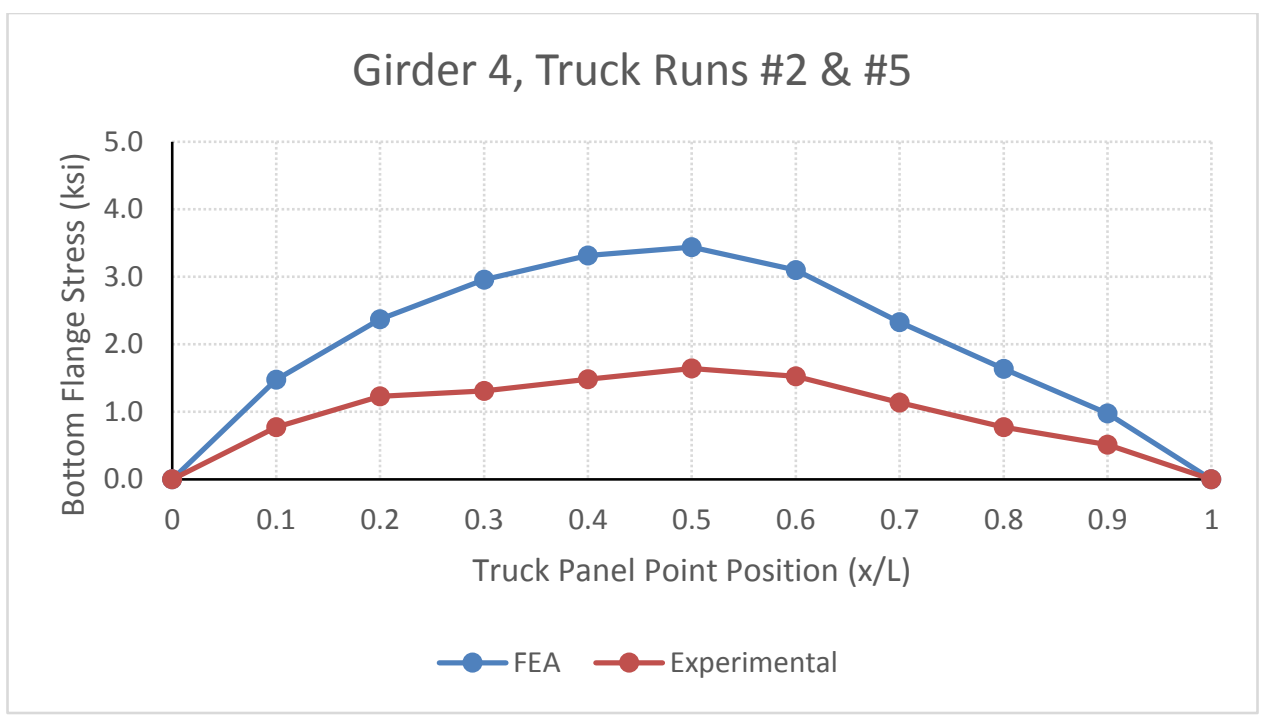




\section{APPENdix B: Amish SAWMill BRIDge PlanS}

The following appendix includes the plans for the Amish Sawmill Bridge. It should be noted that the plans have been scaled down from their original $11 \times 17$ format to $81 / 2 \times 11$. 


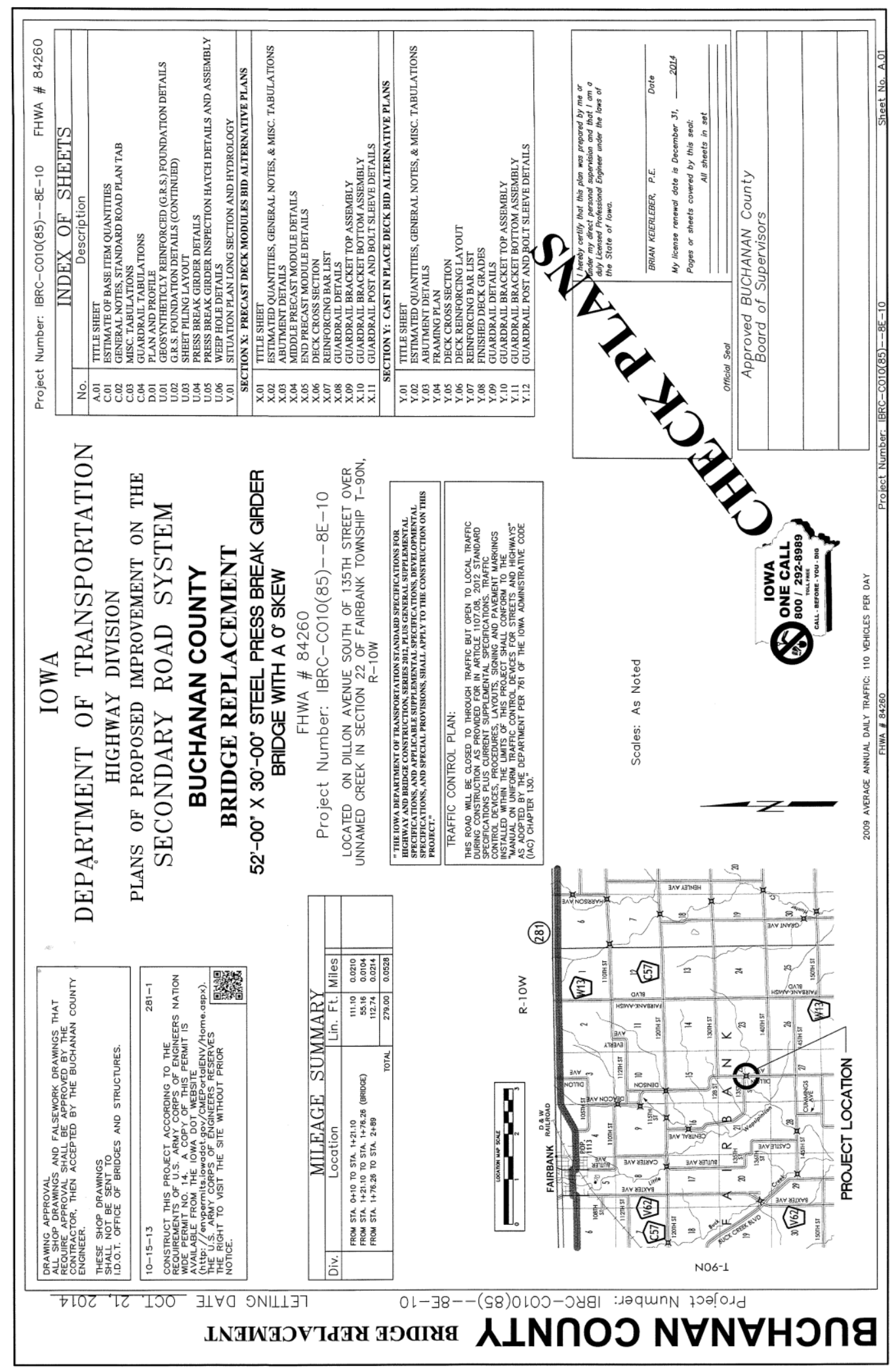




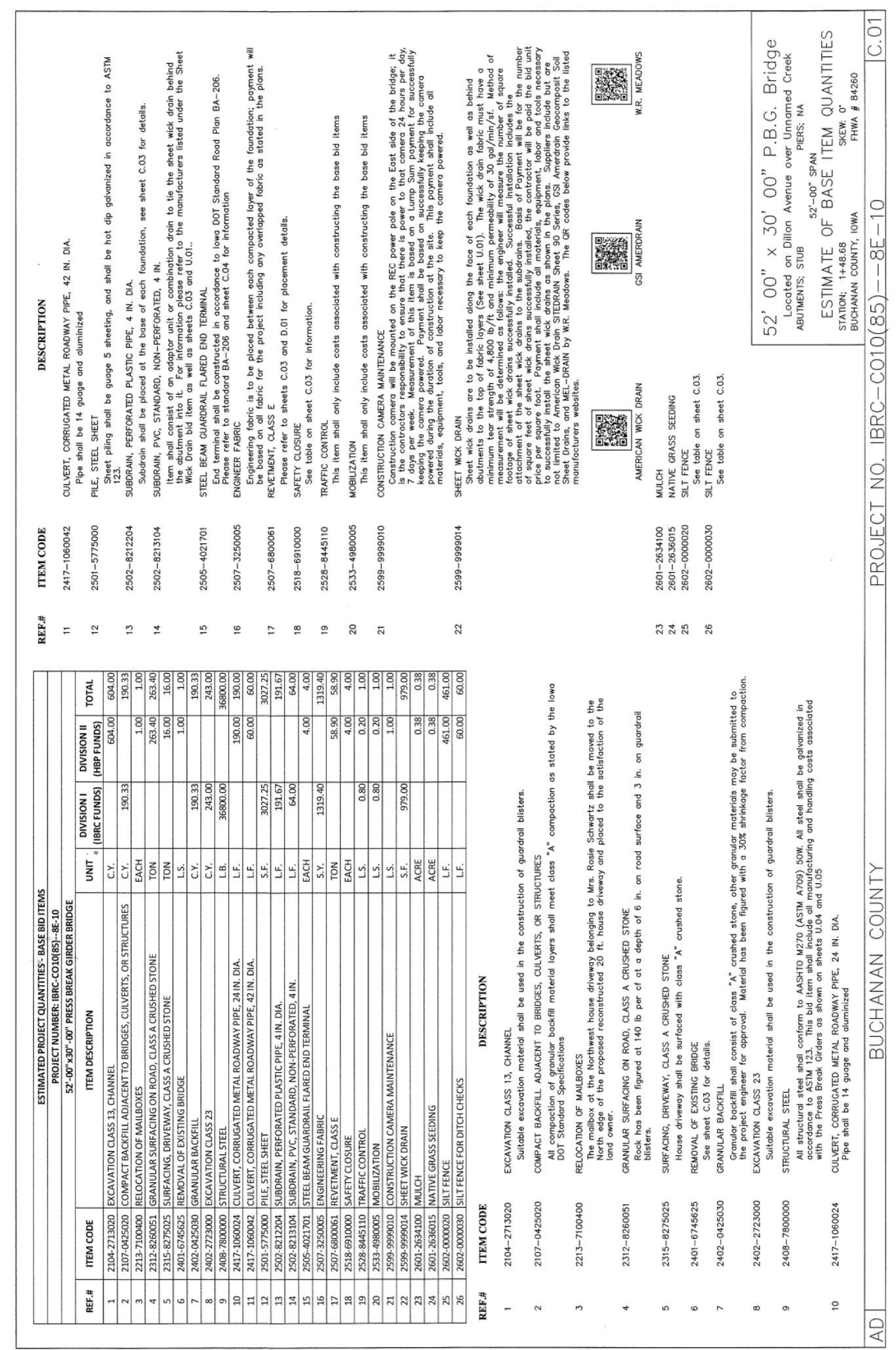




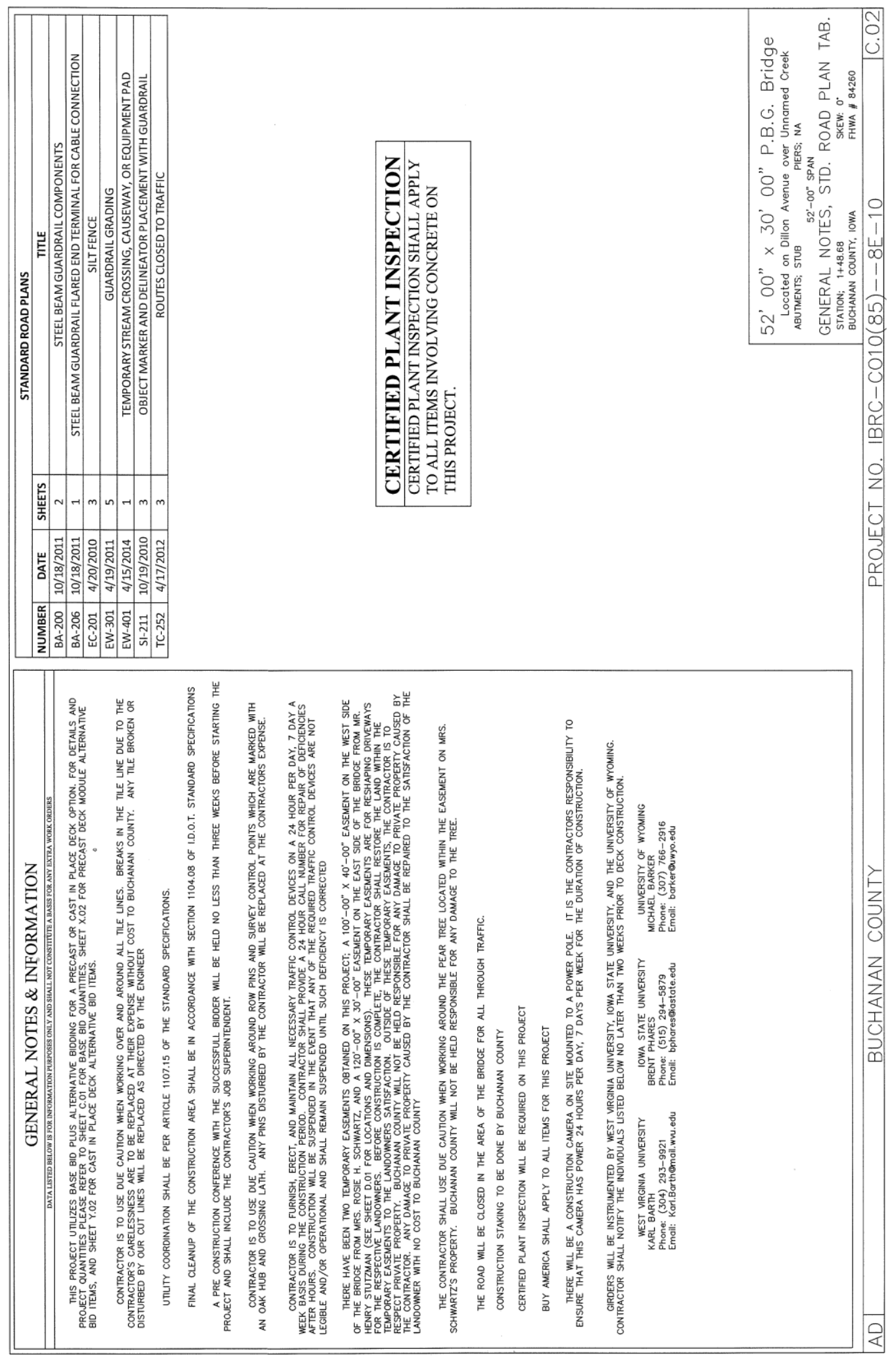




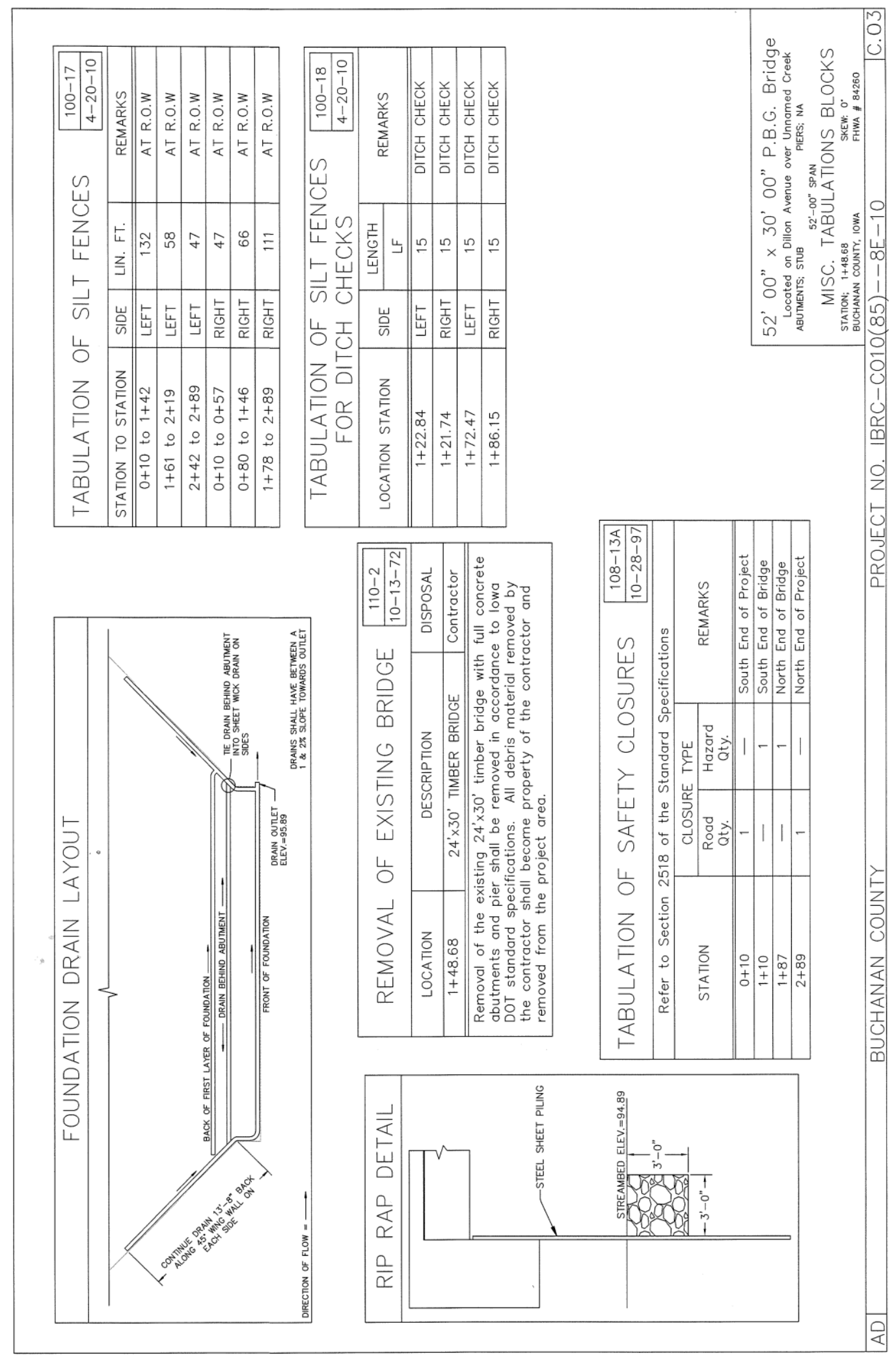




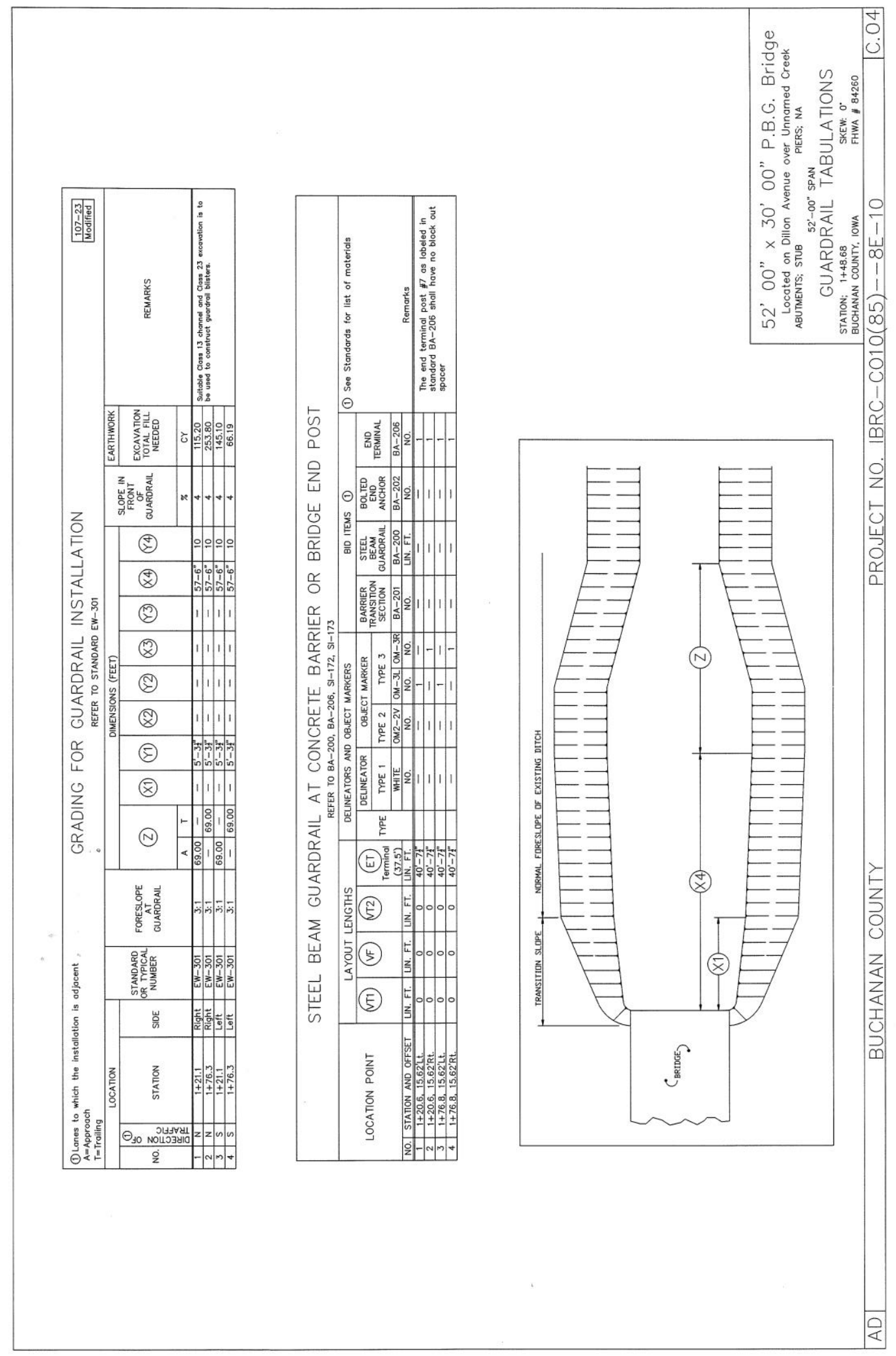




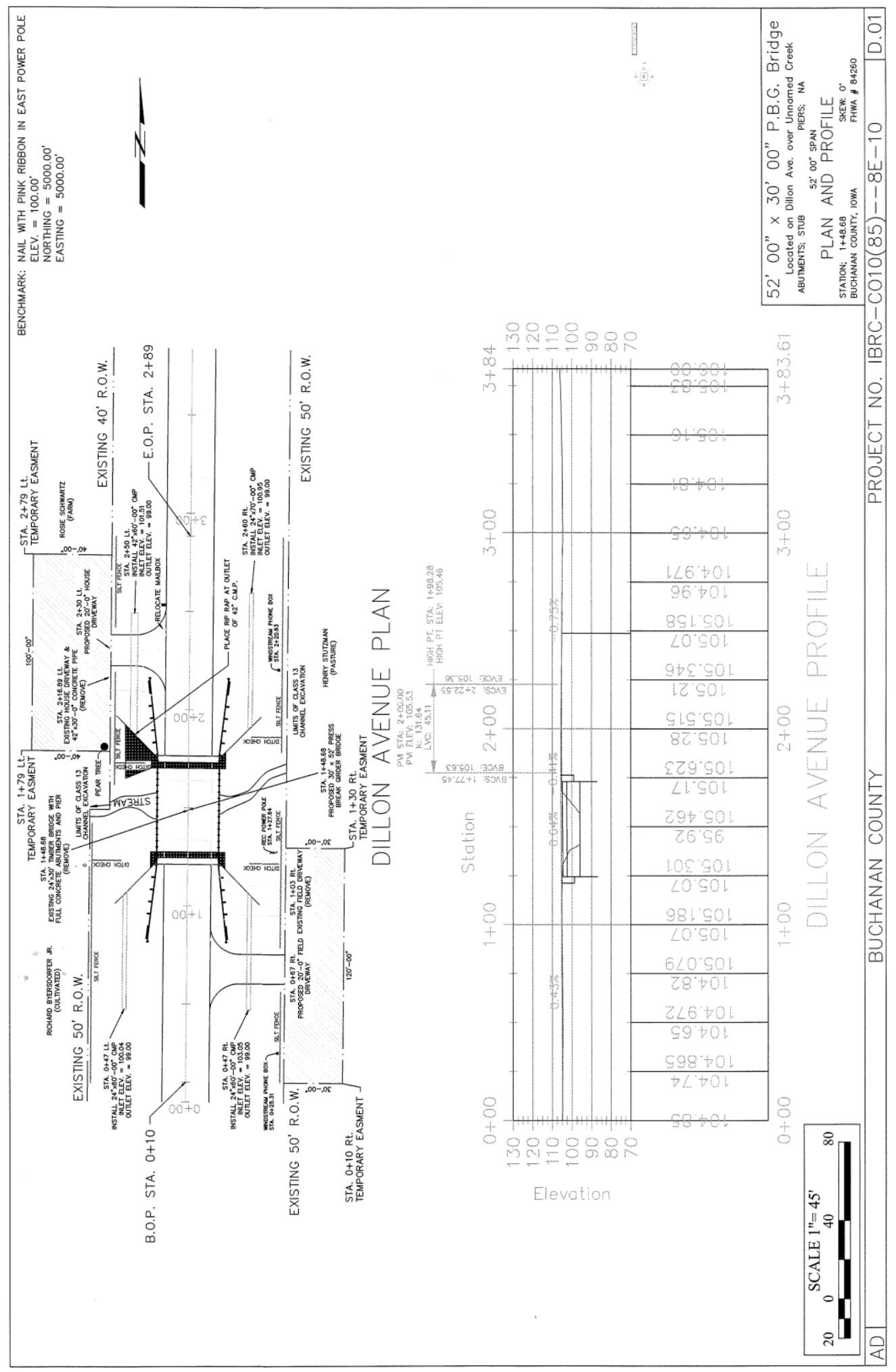




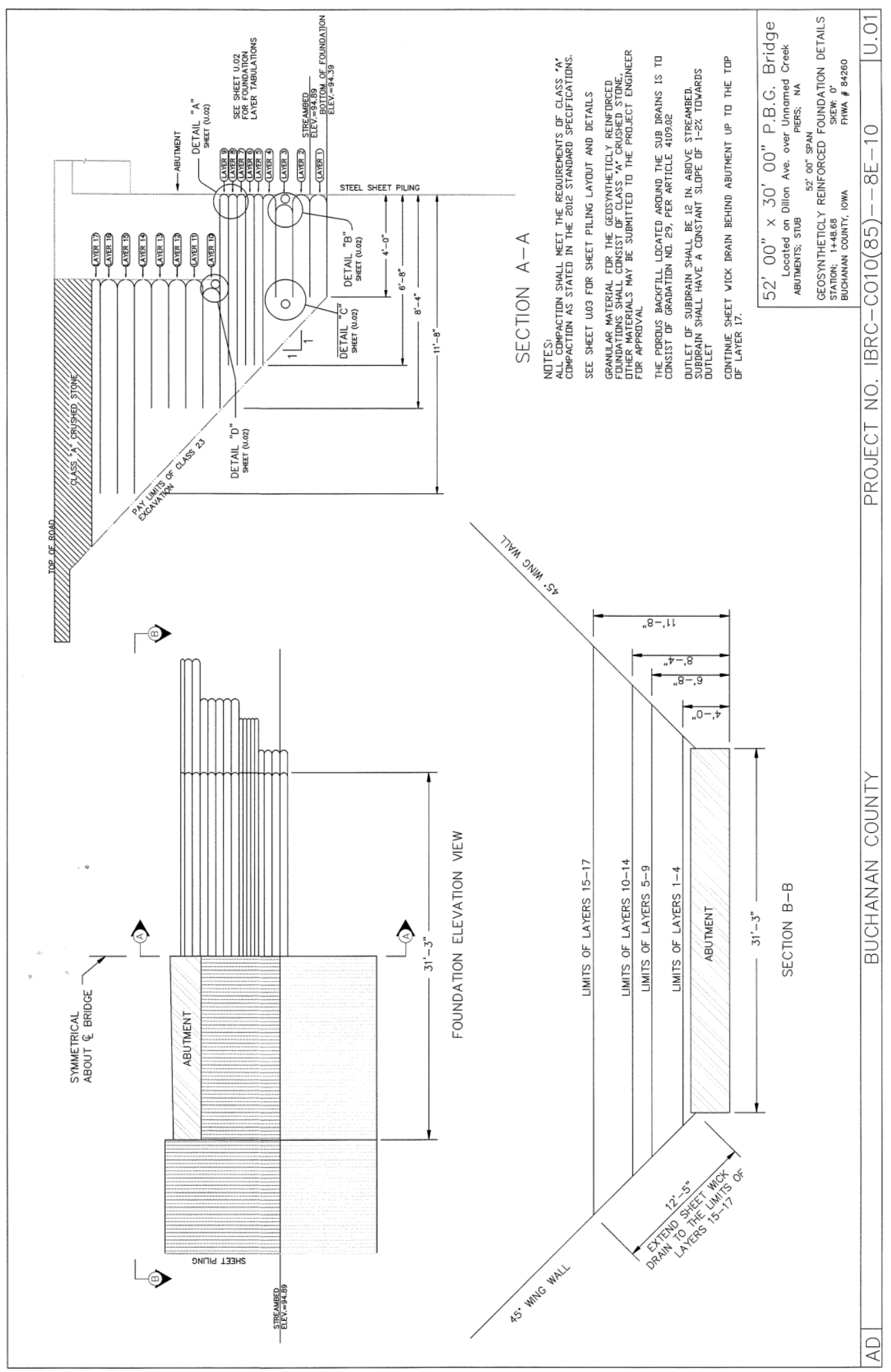




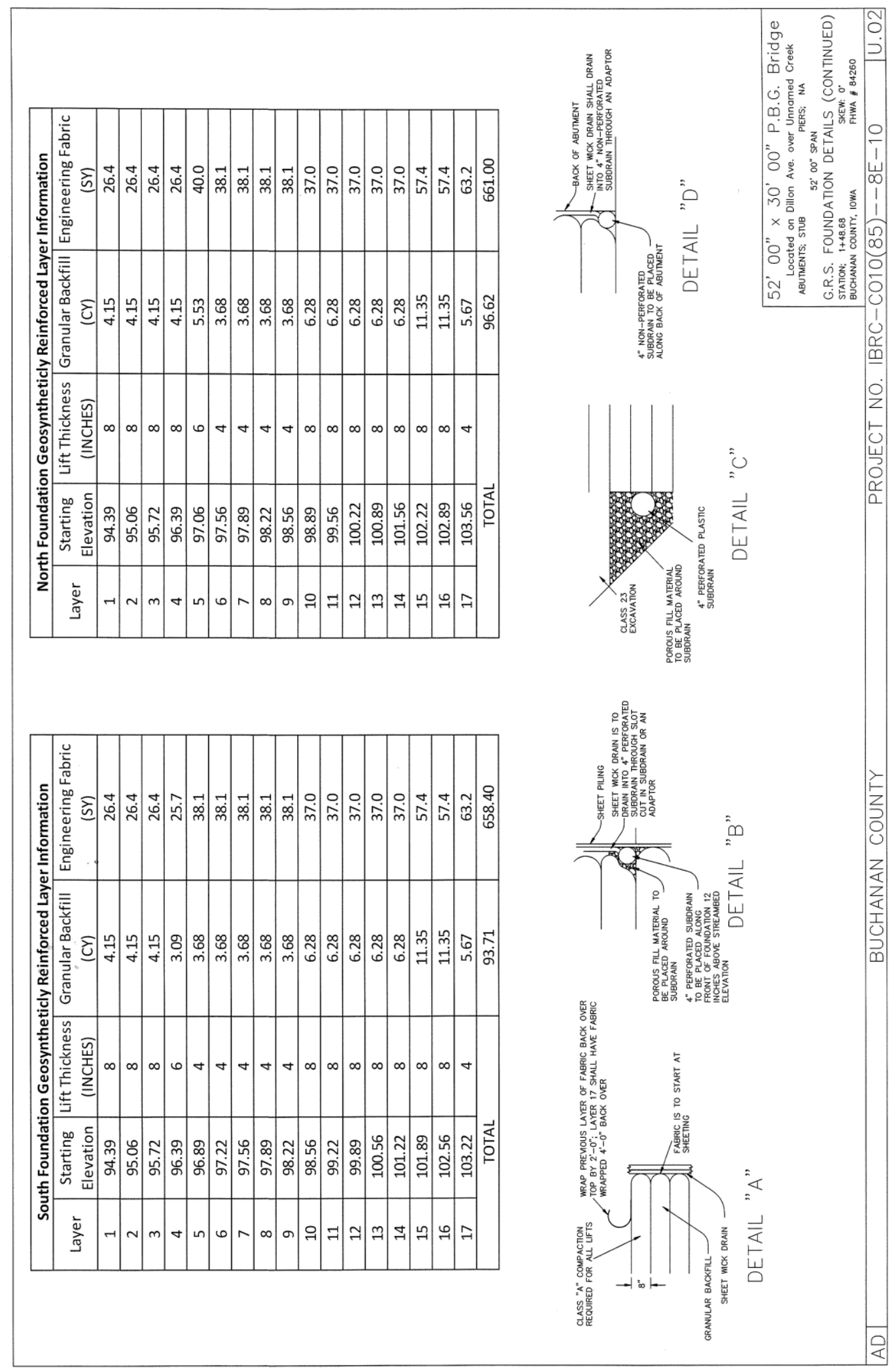




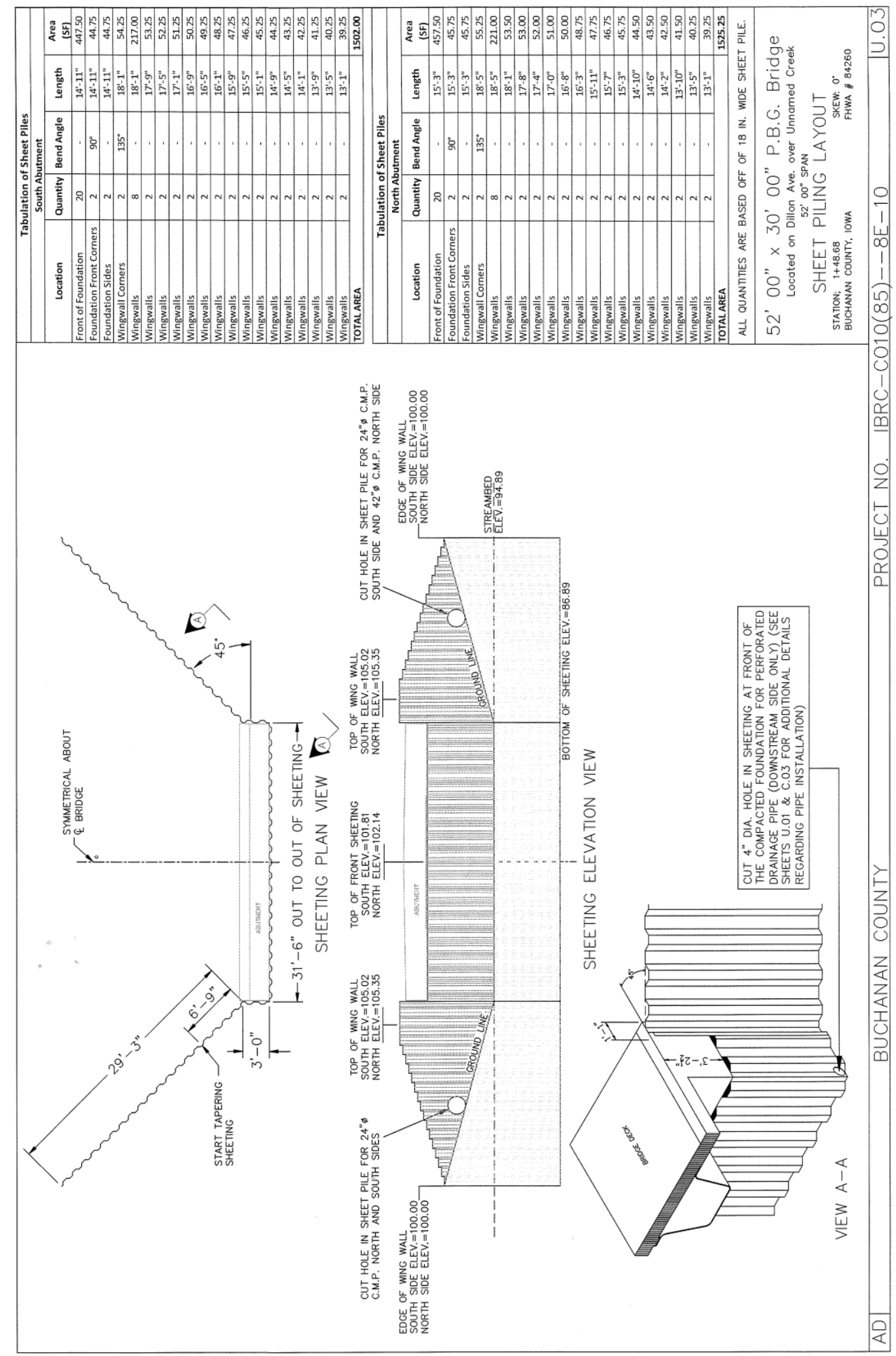




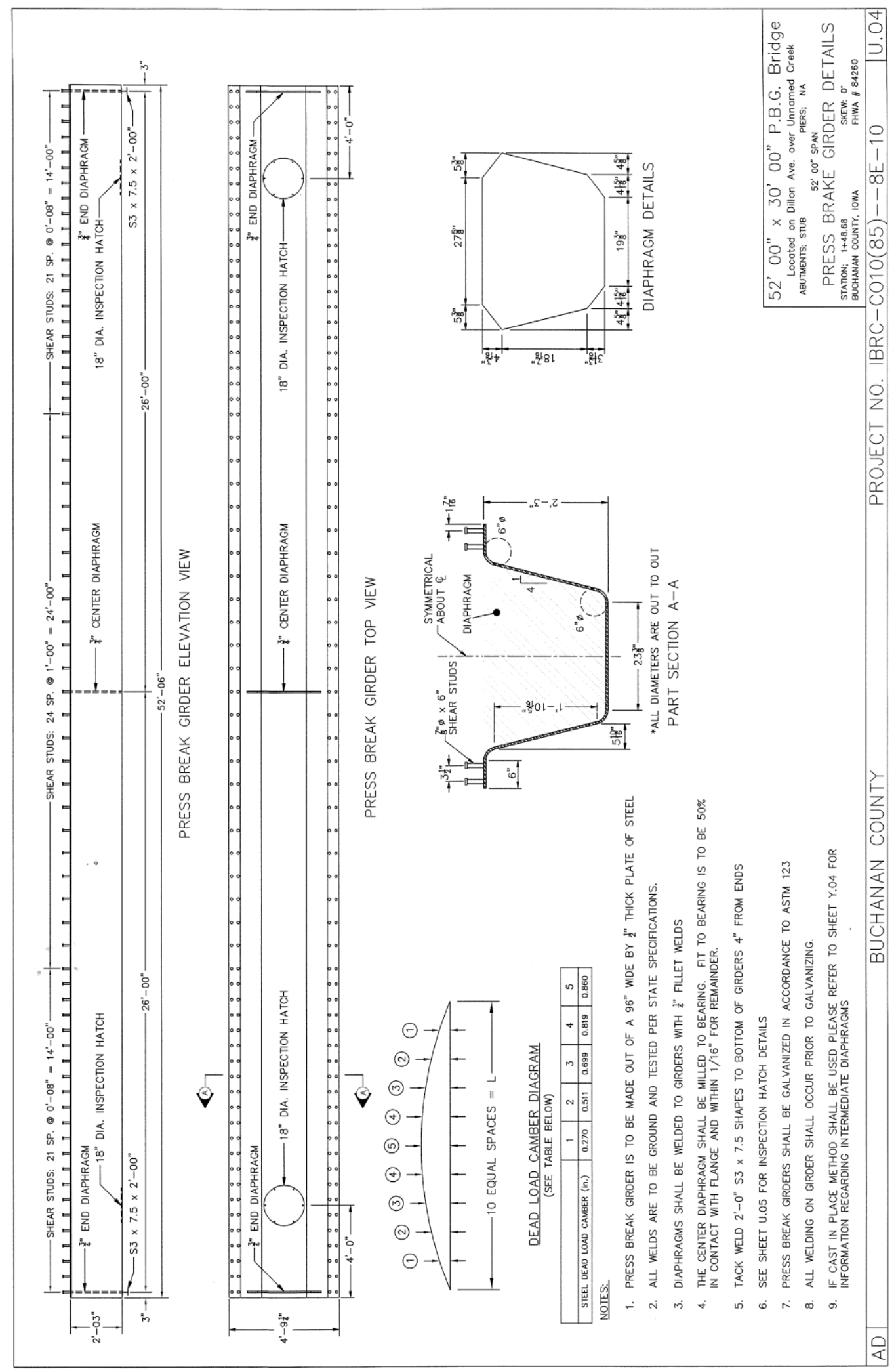




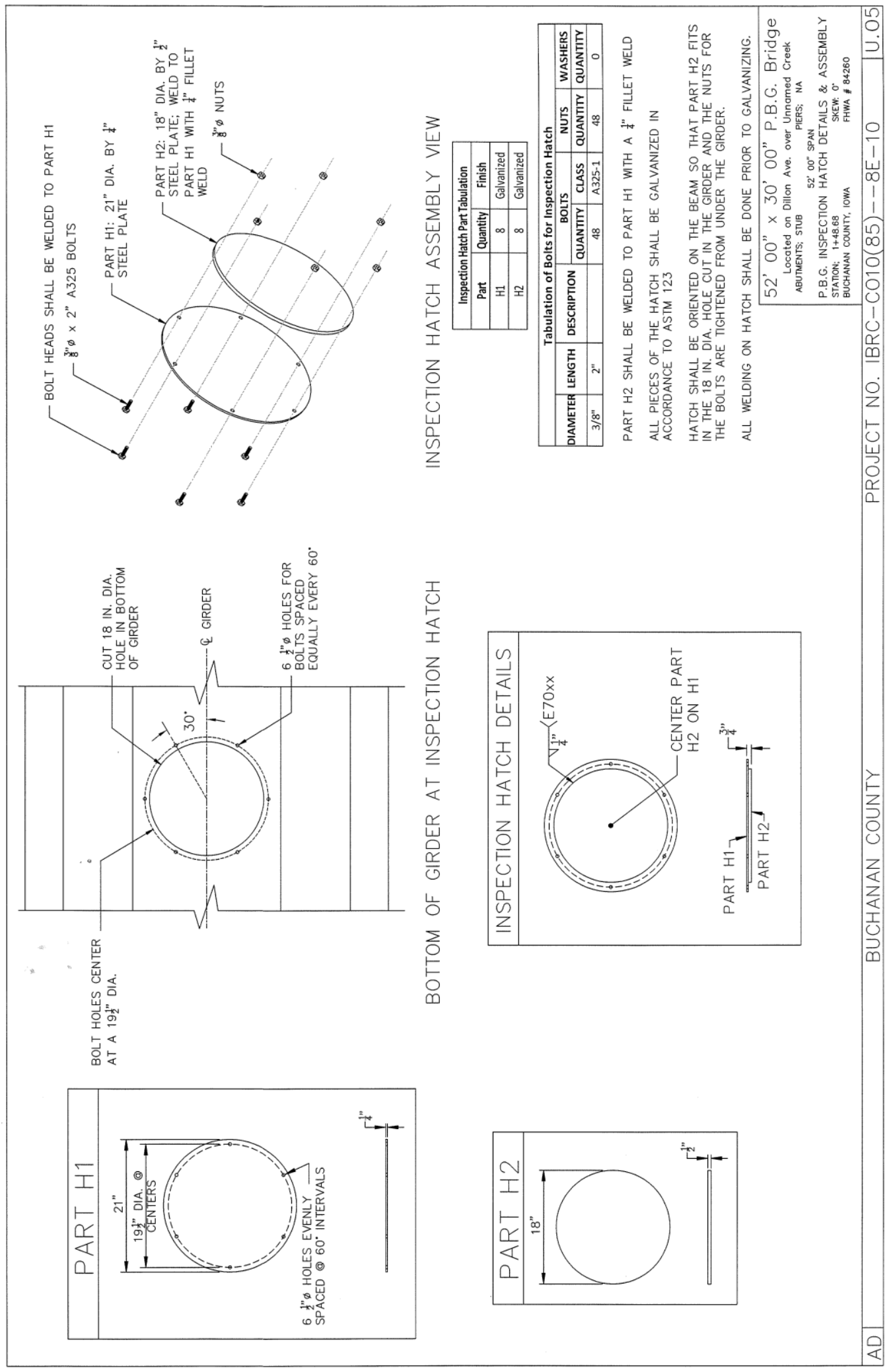




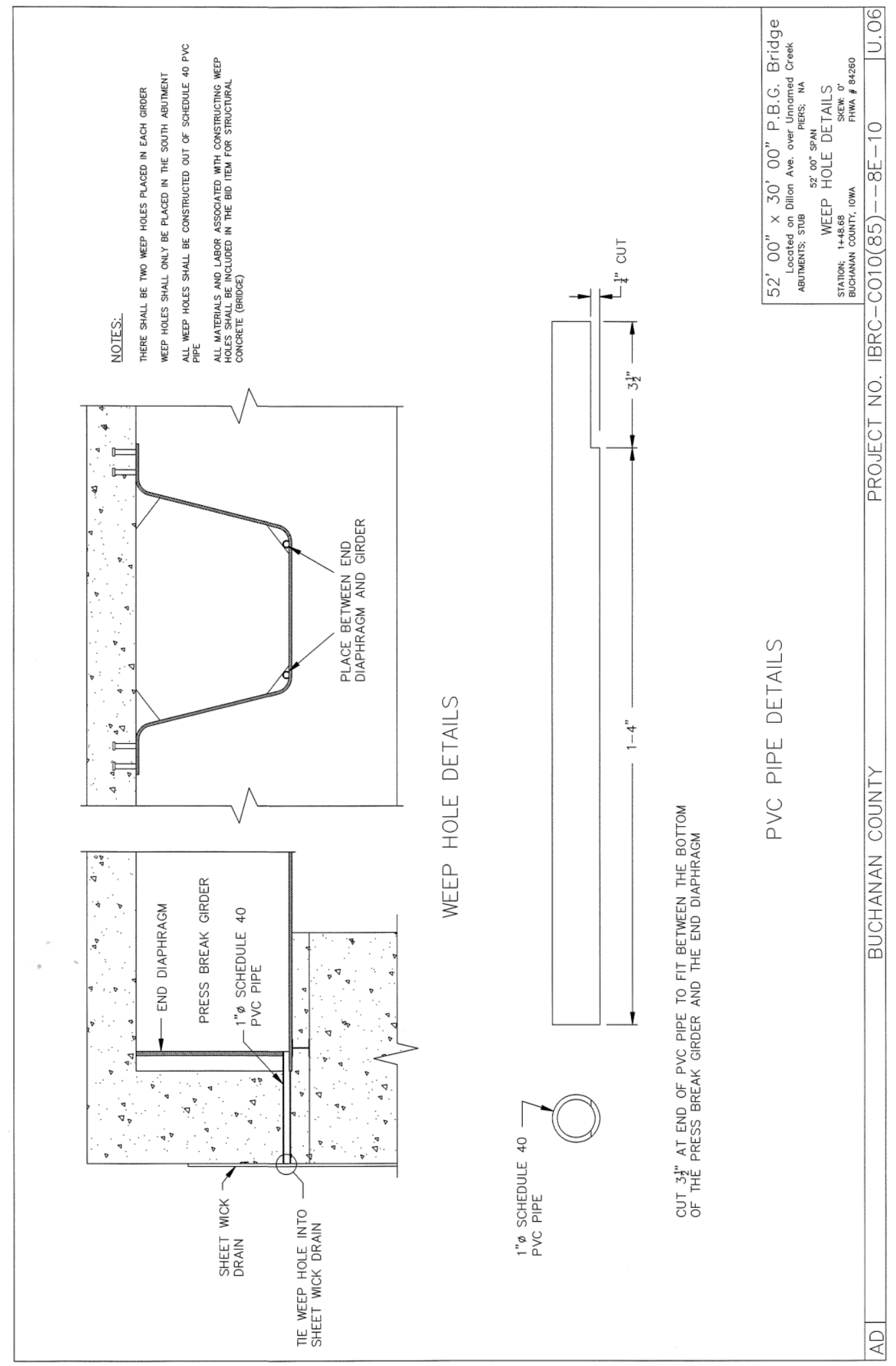




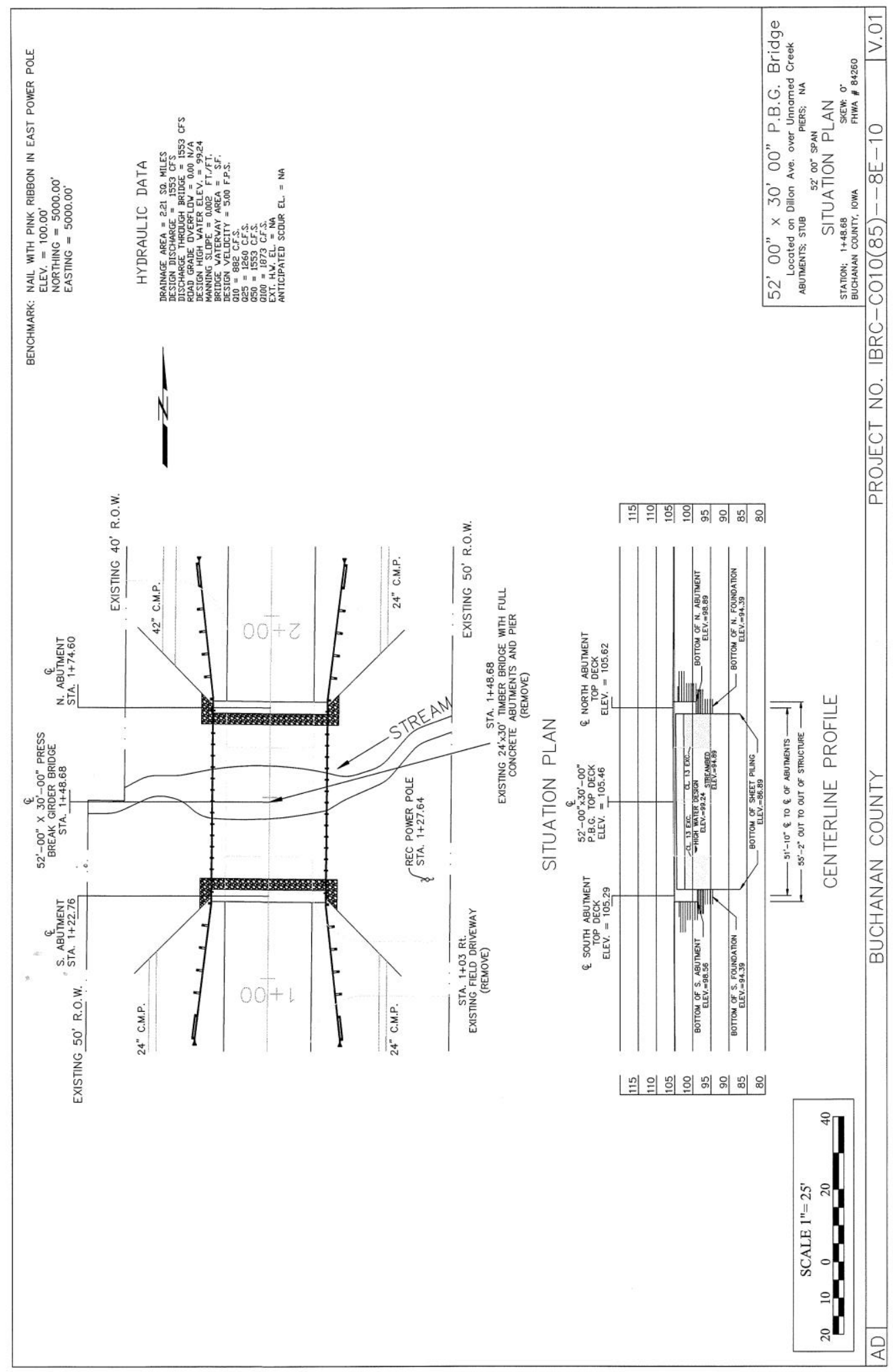




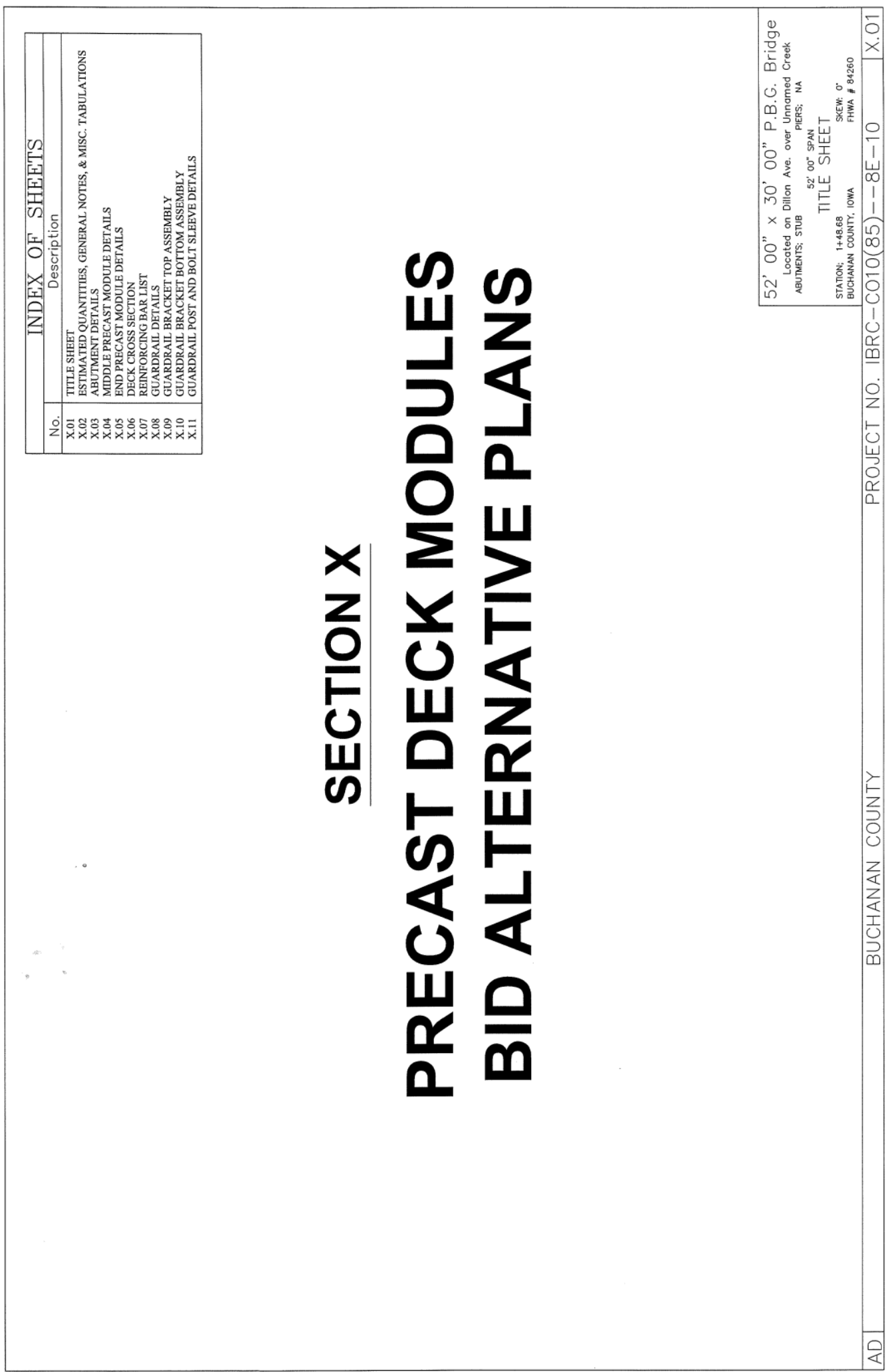




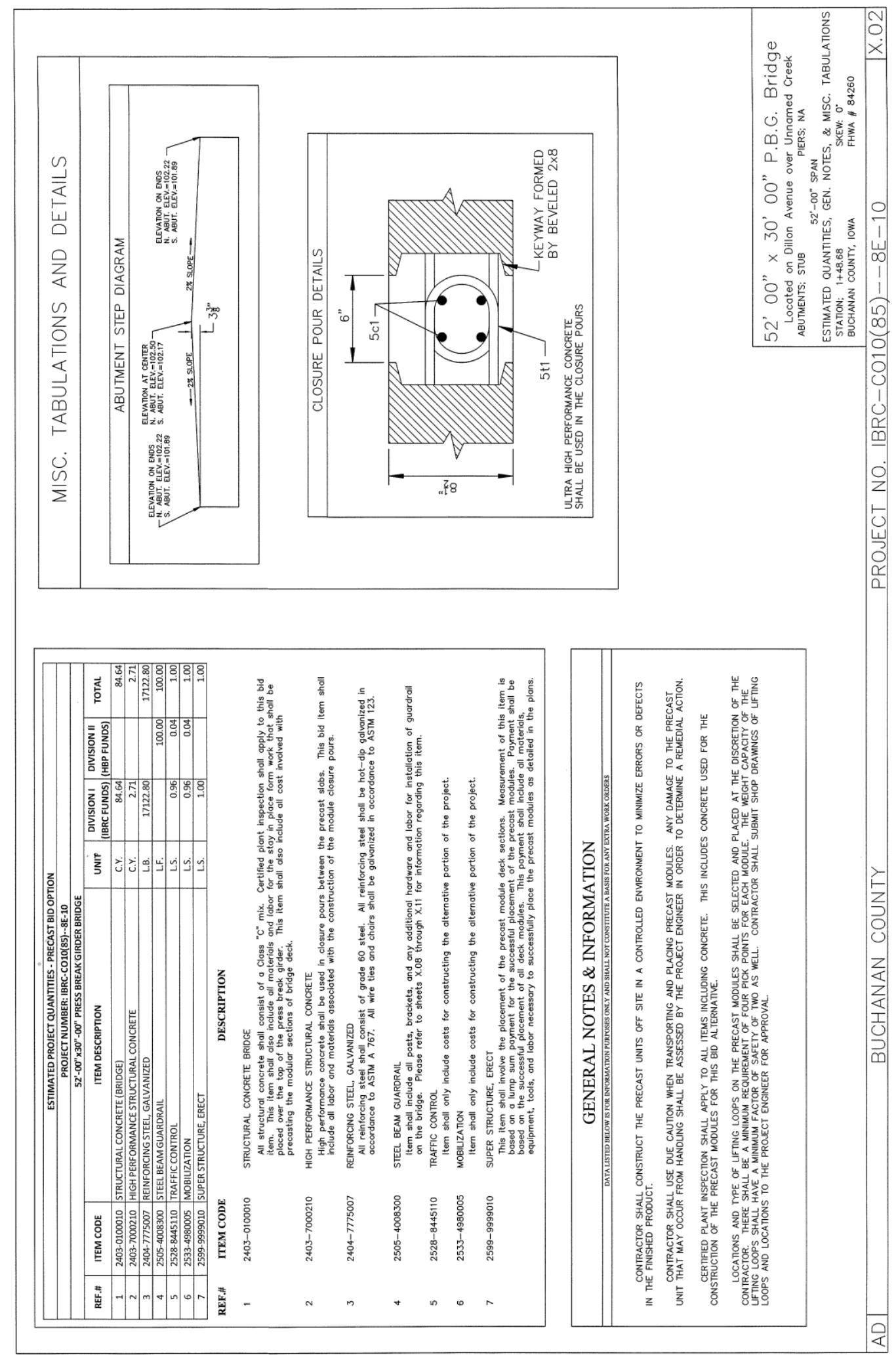




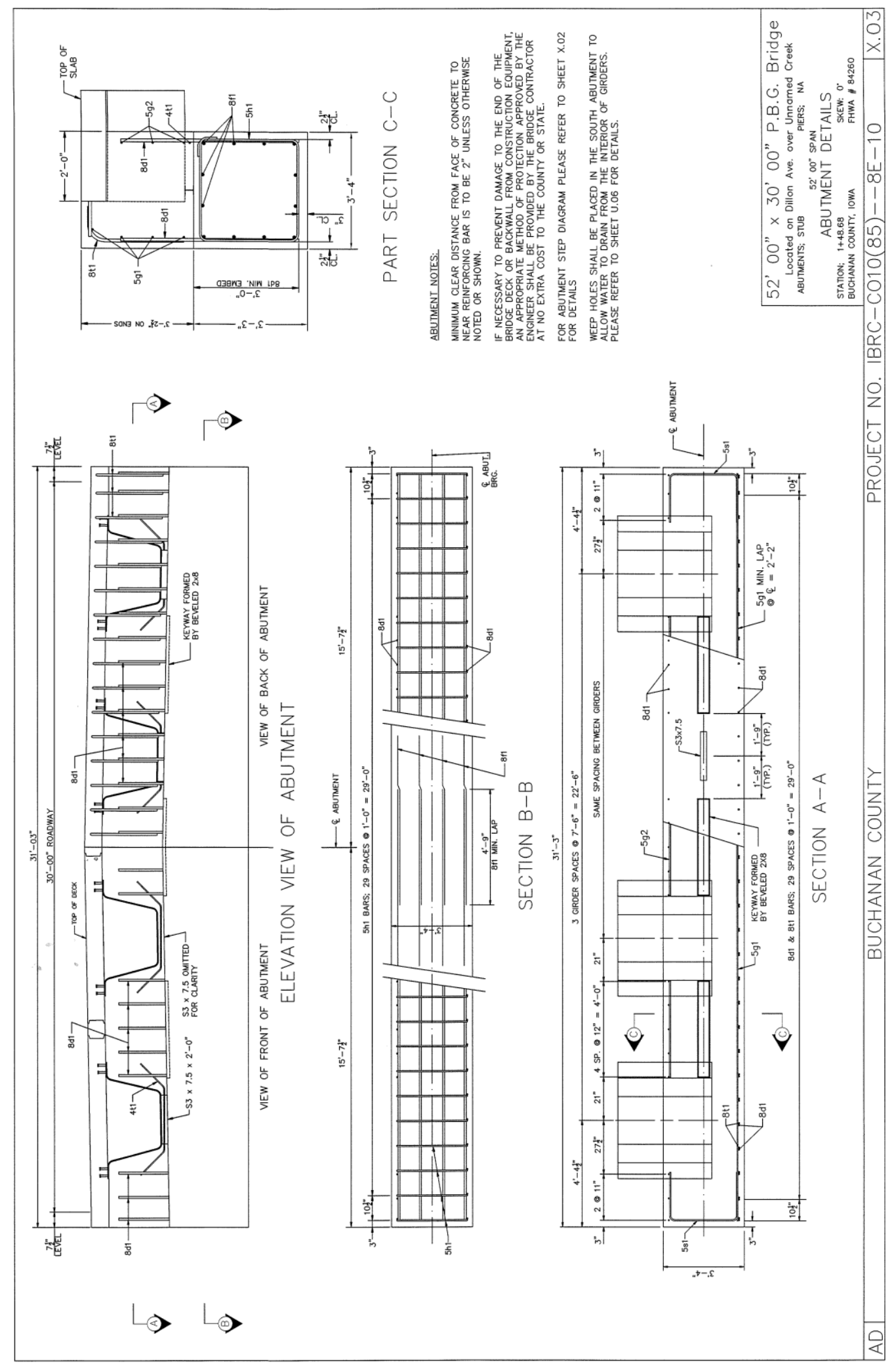




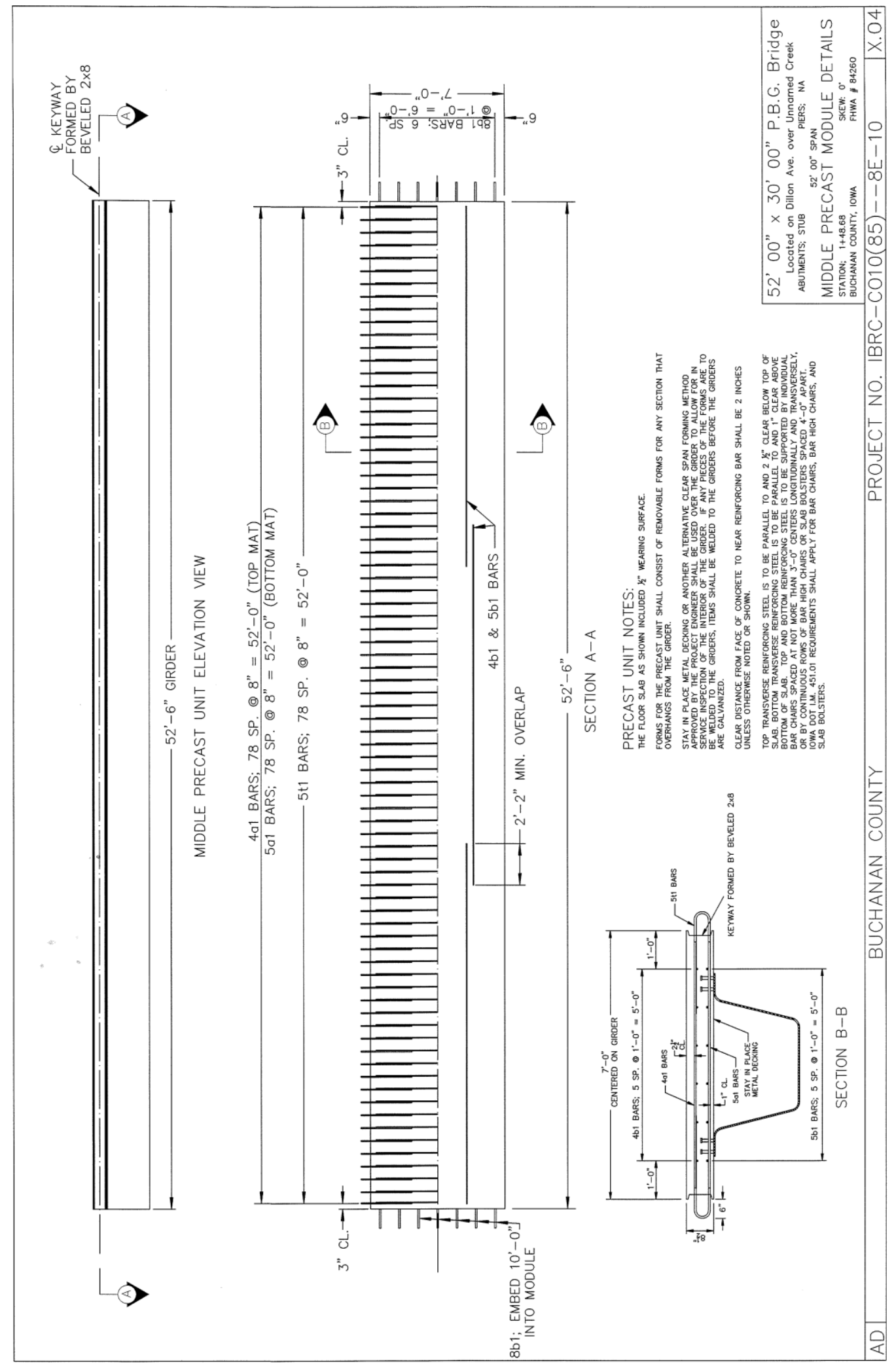




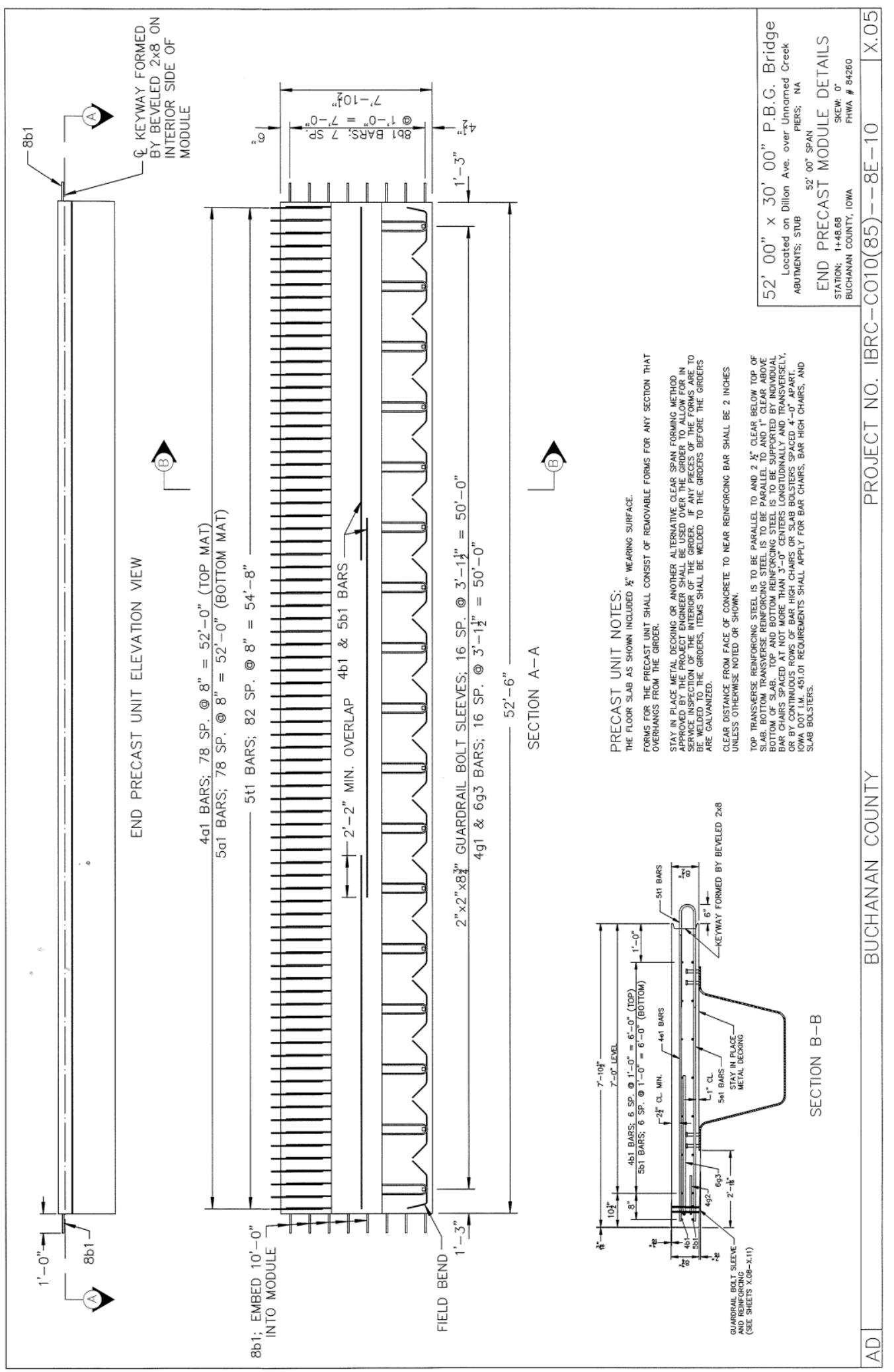




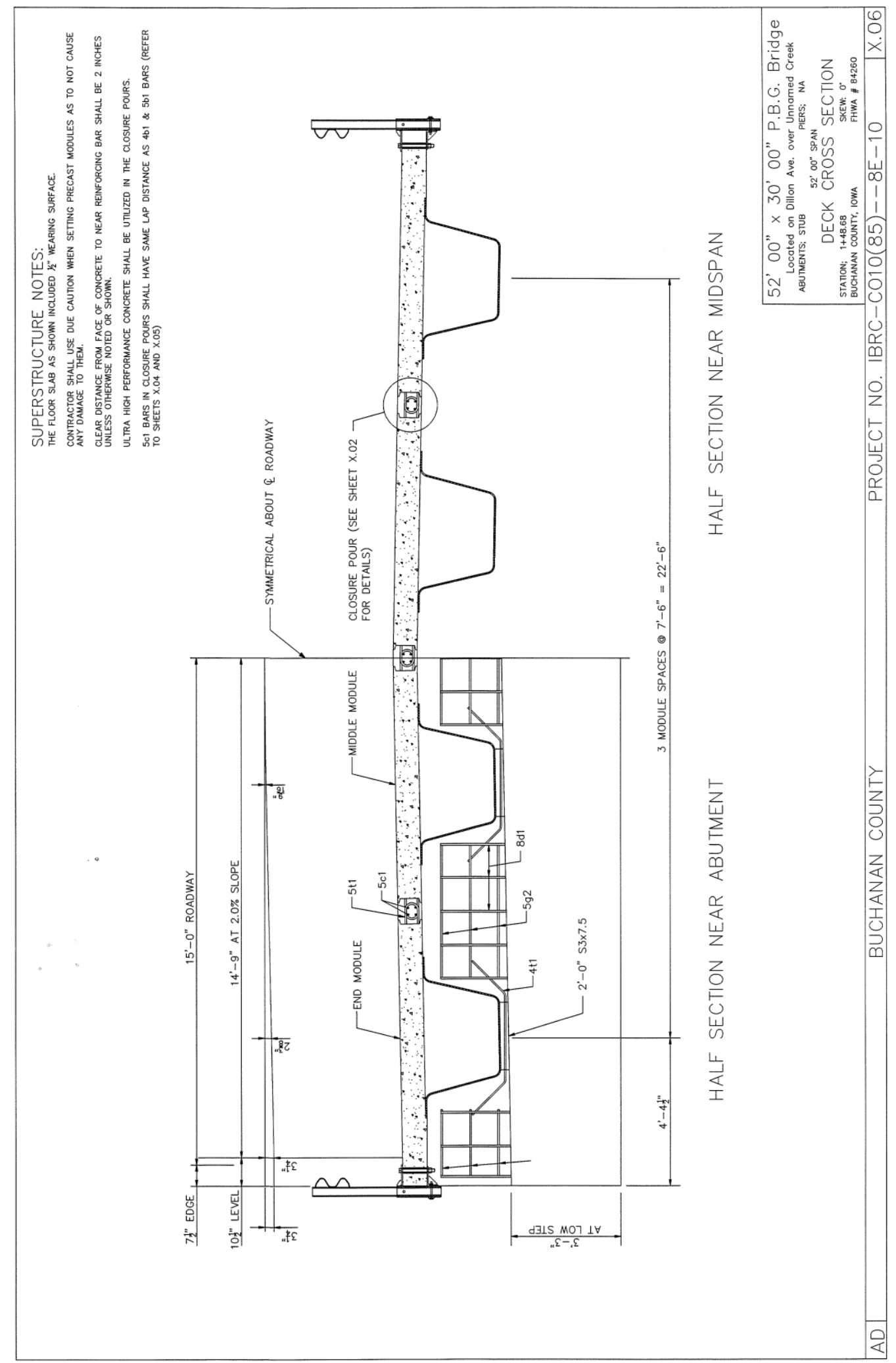




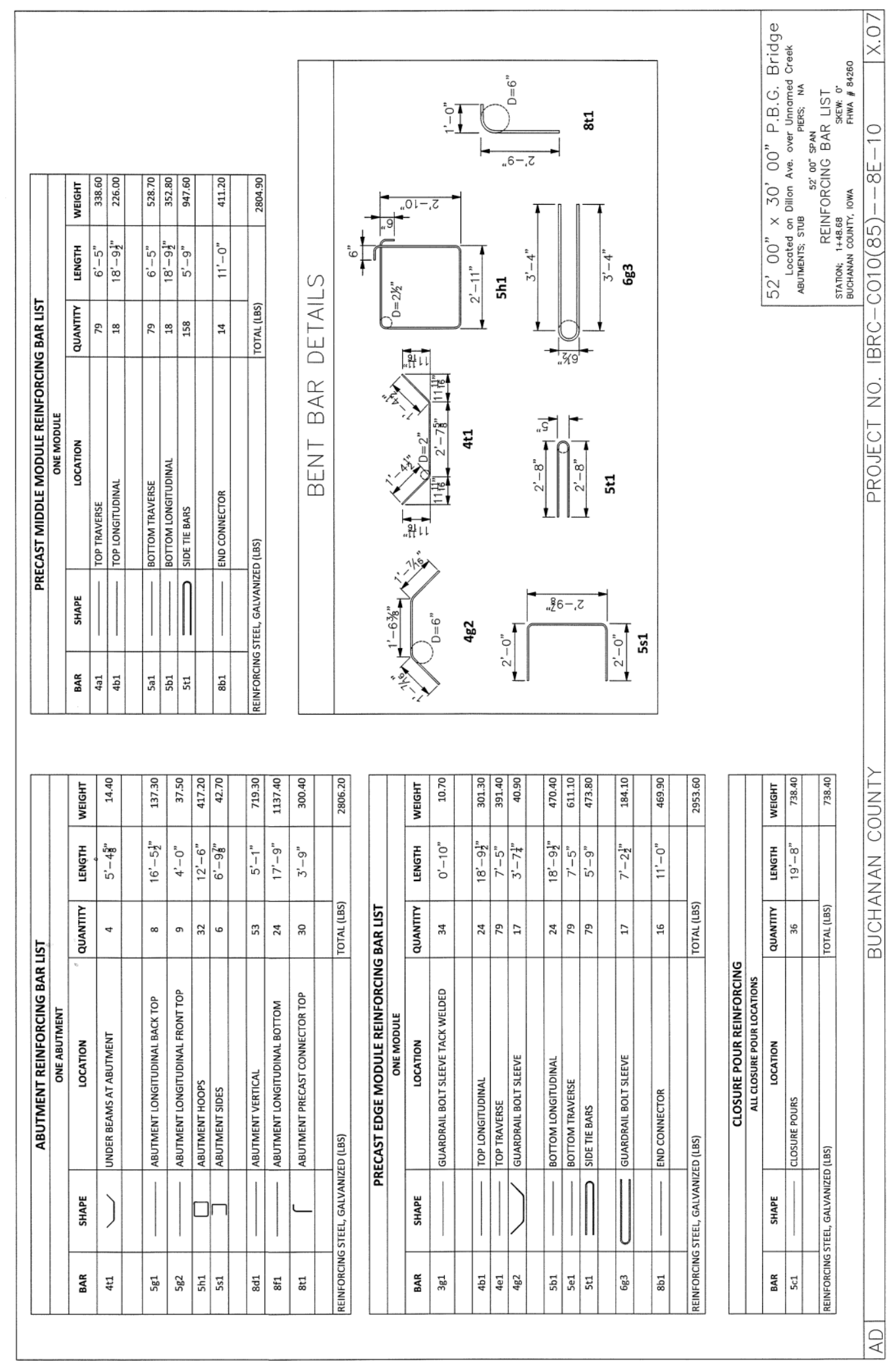




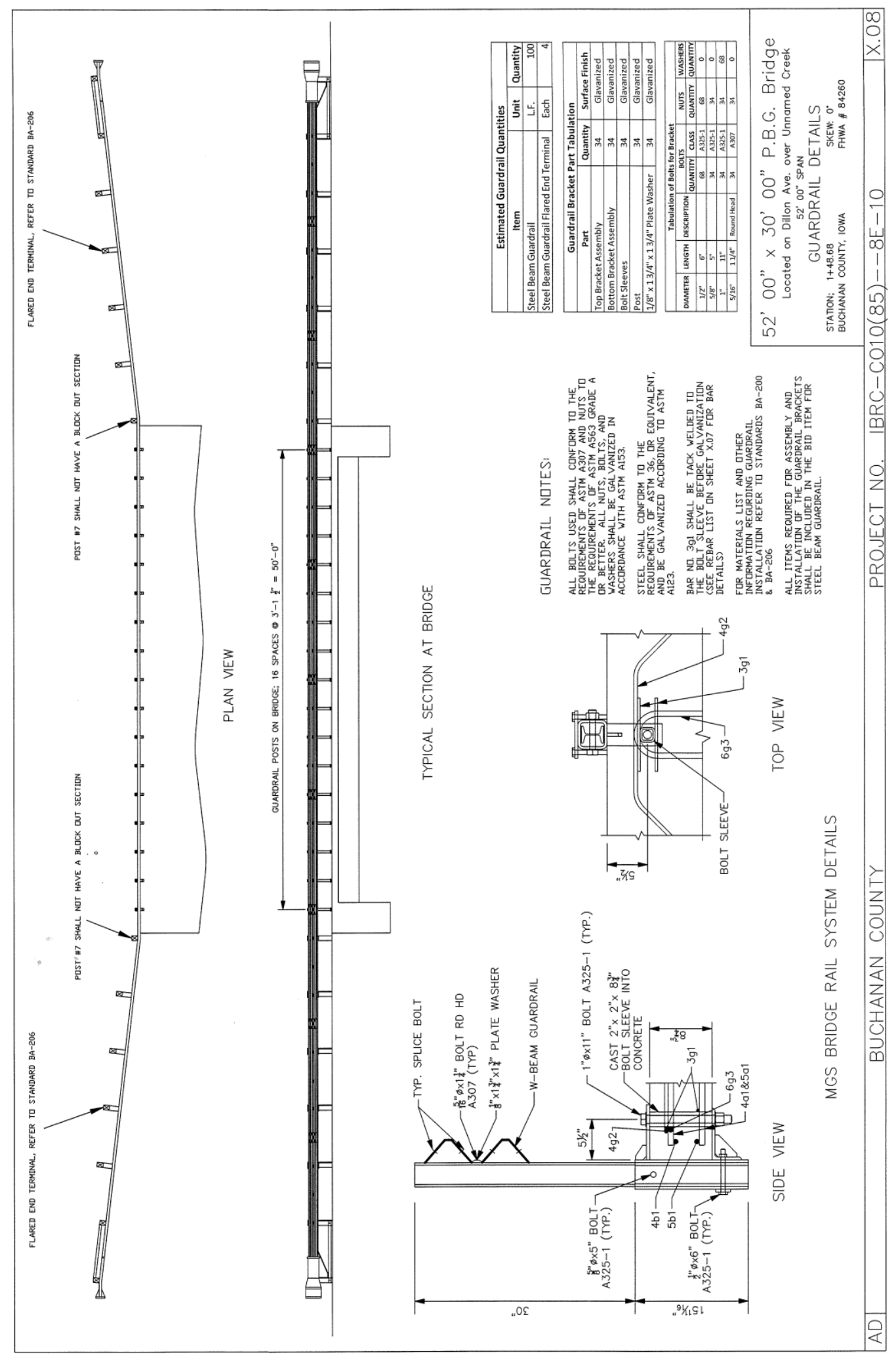




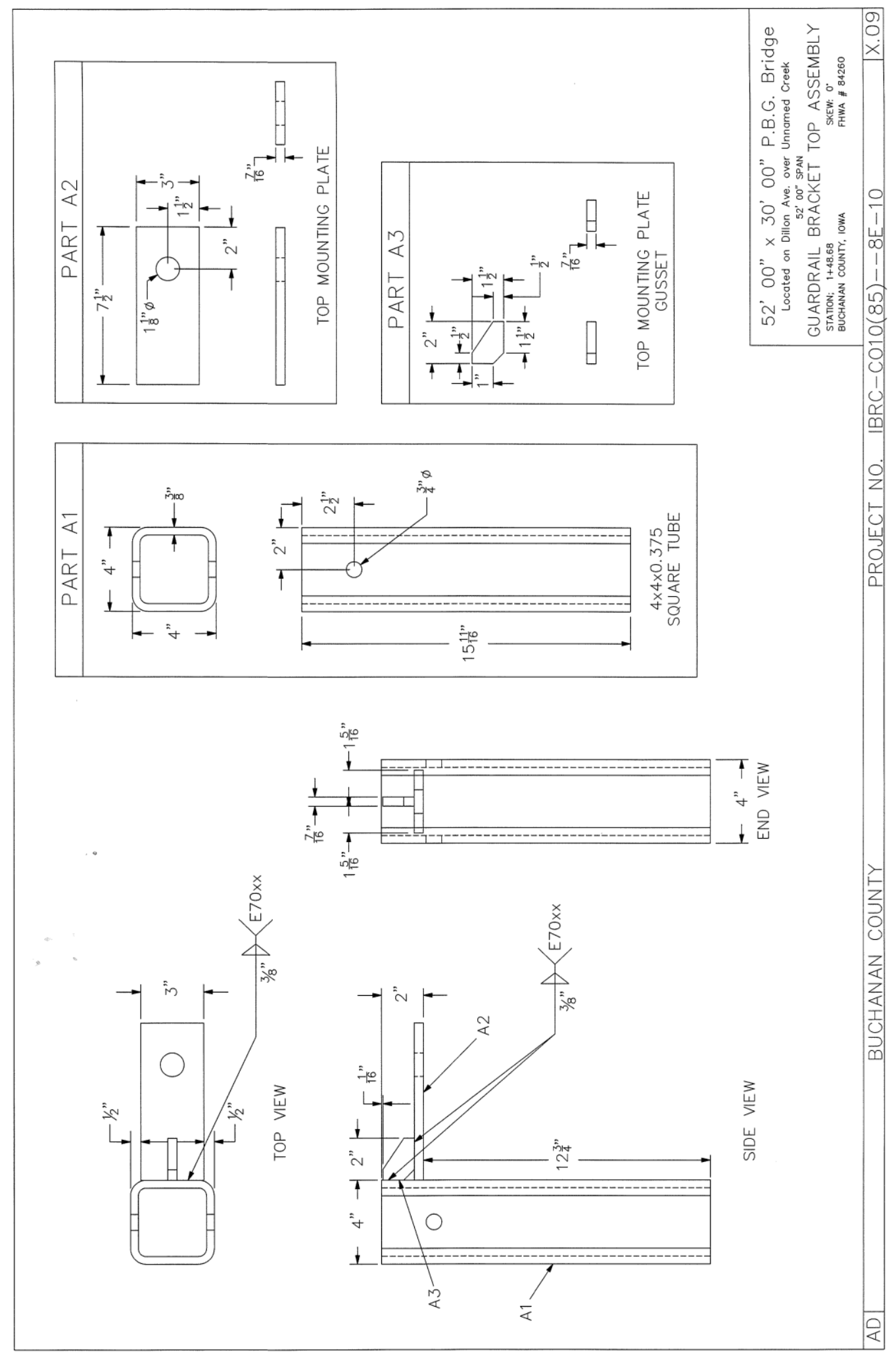




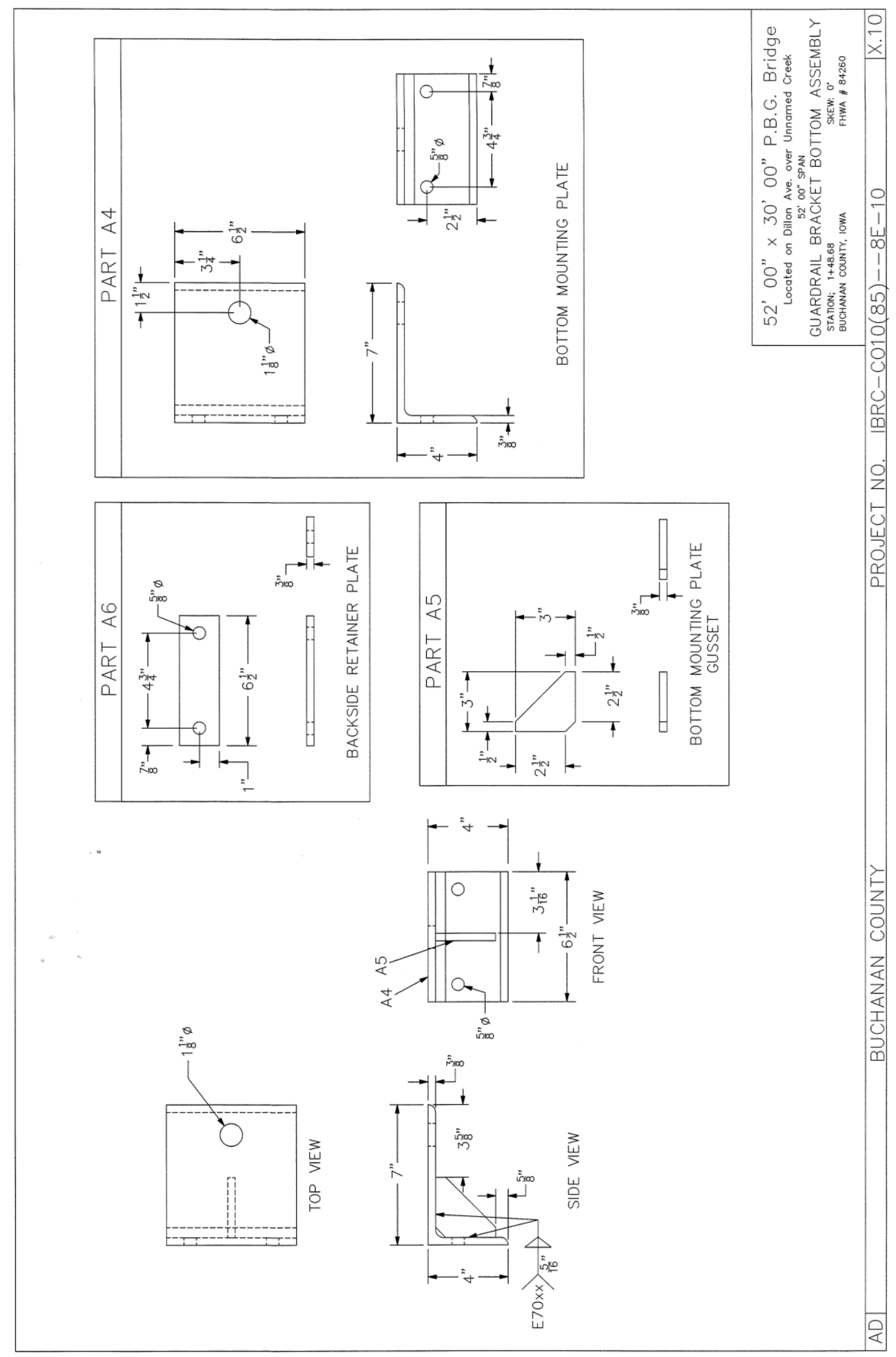




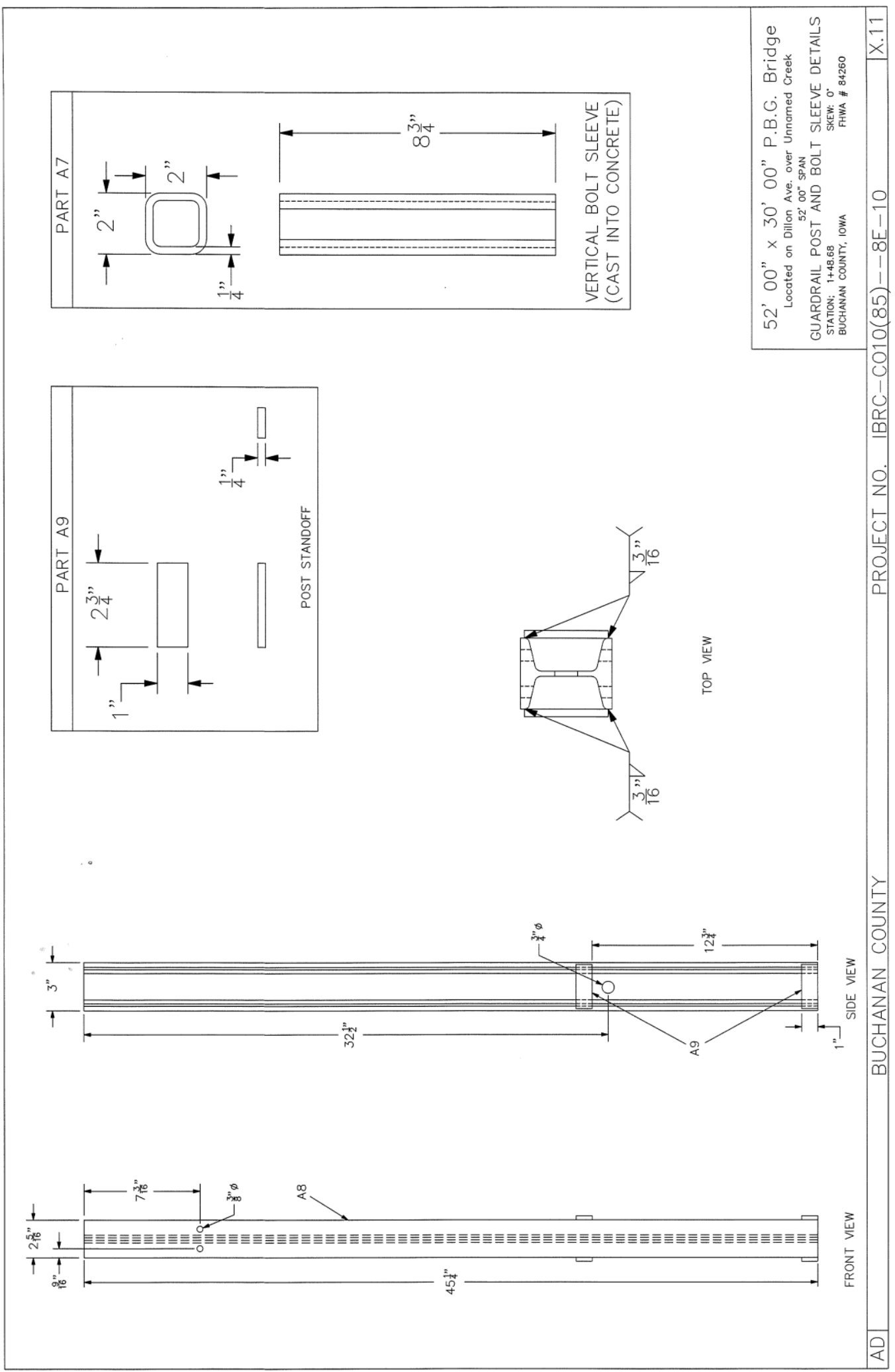




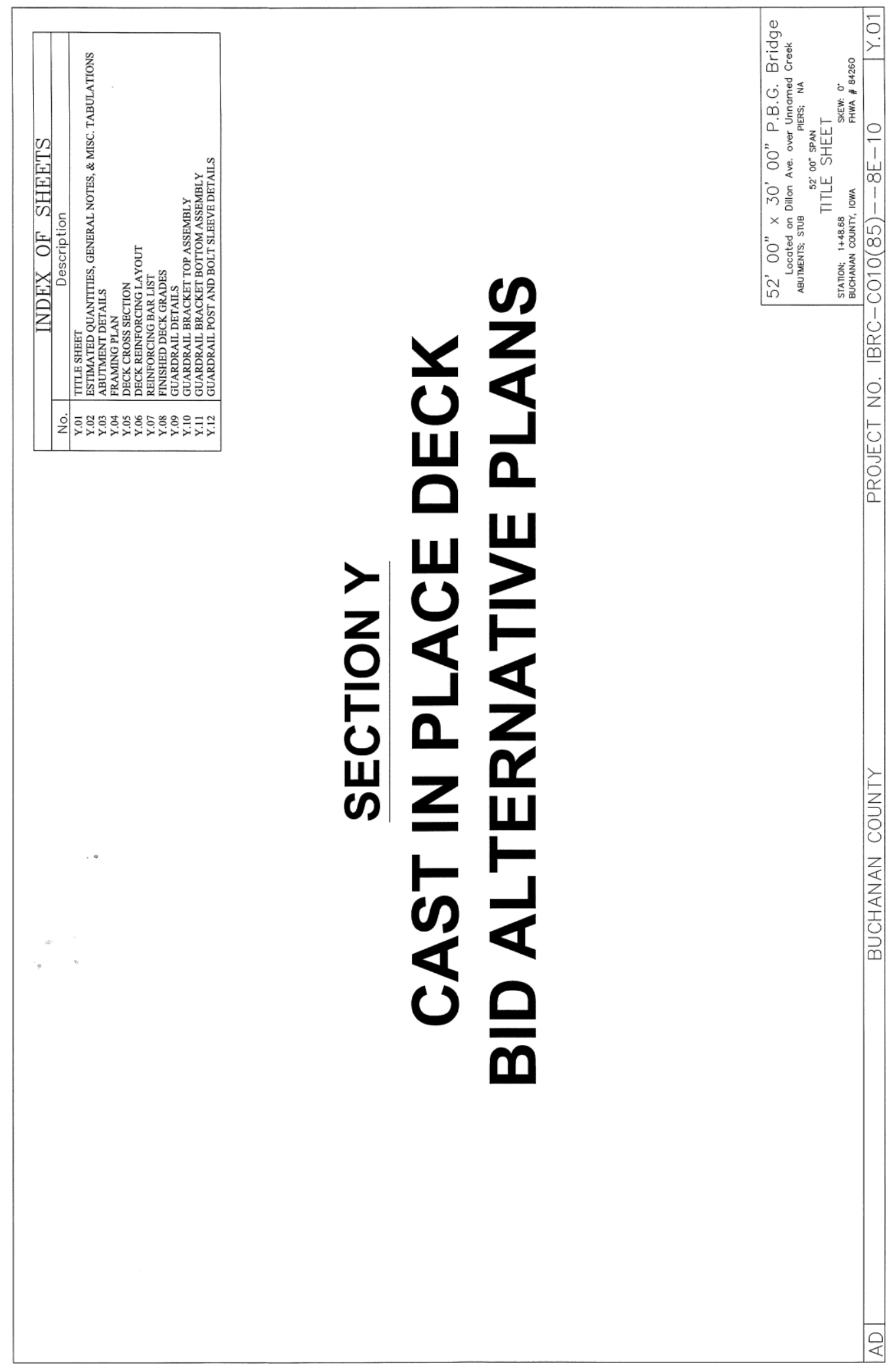




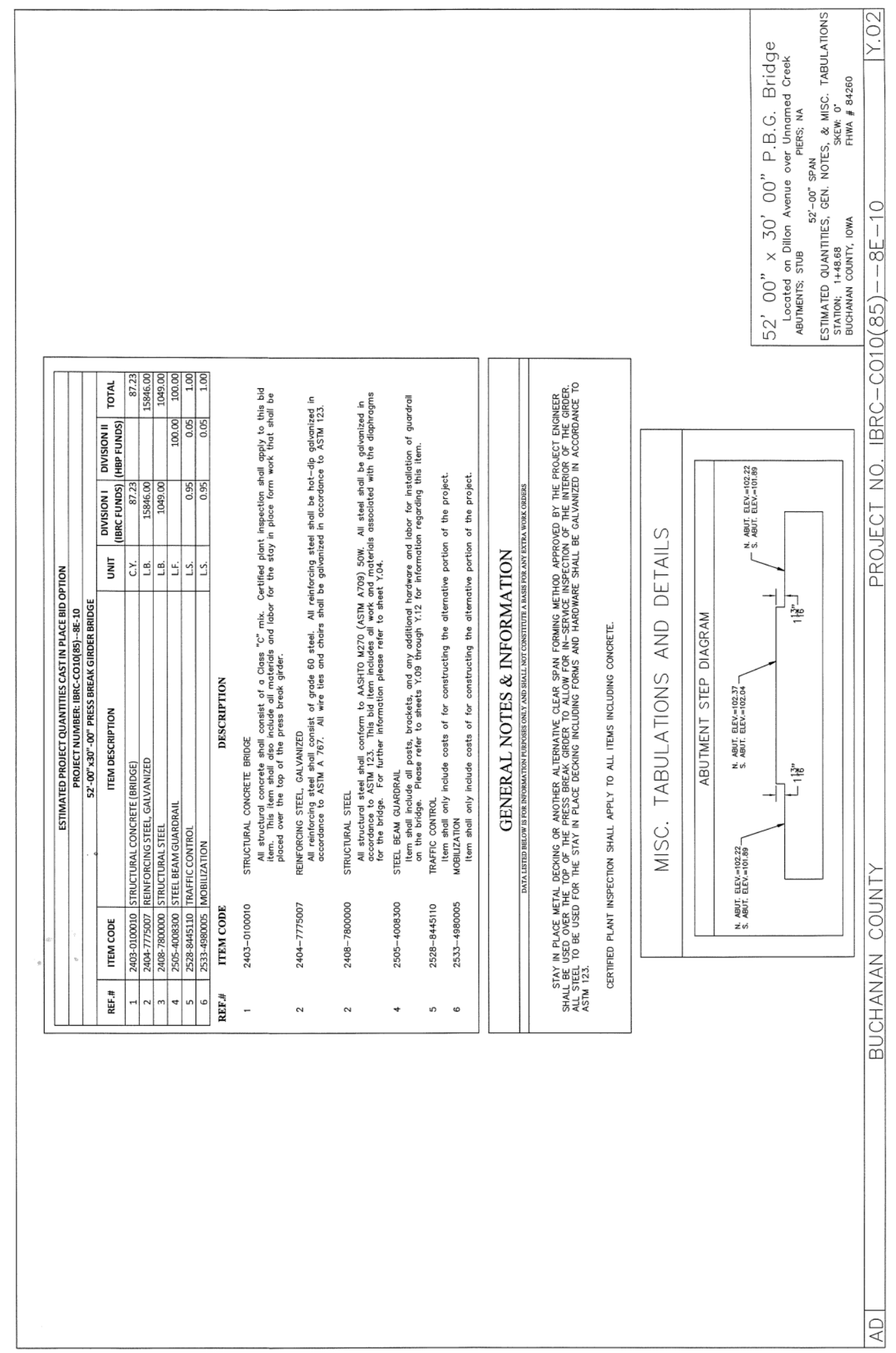




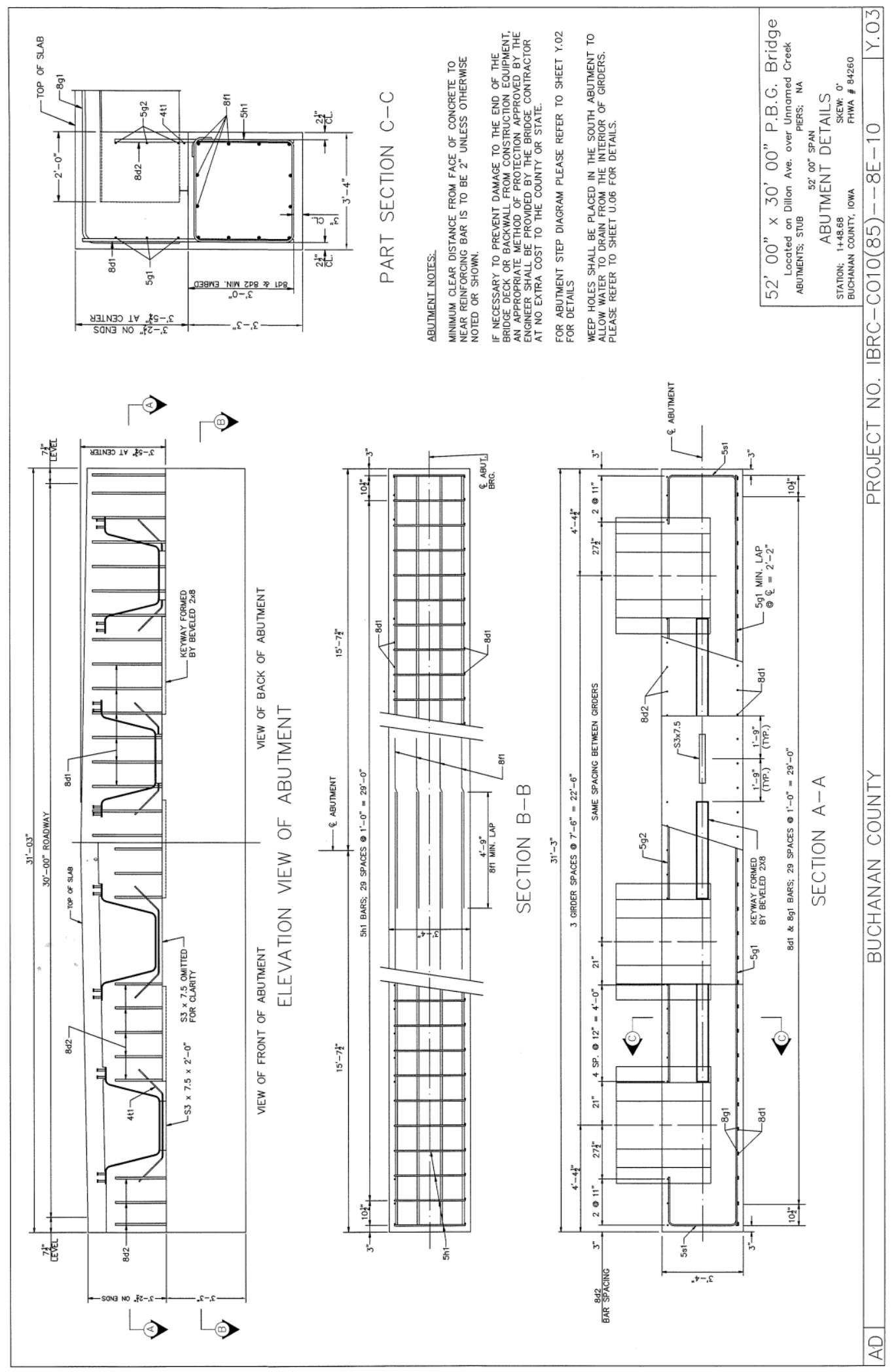




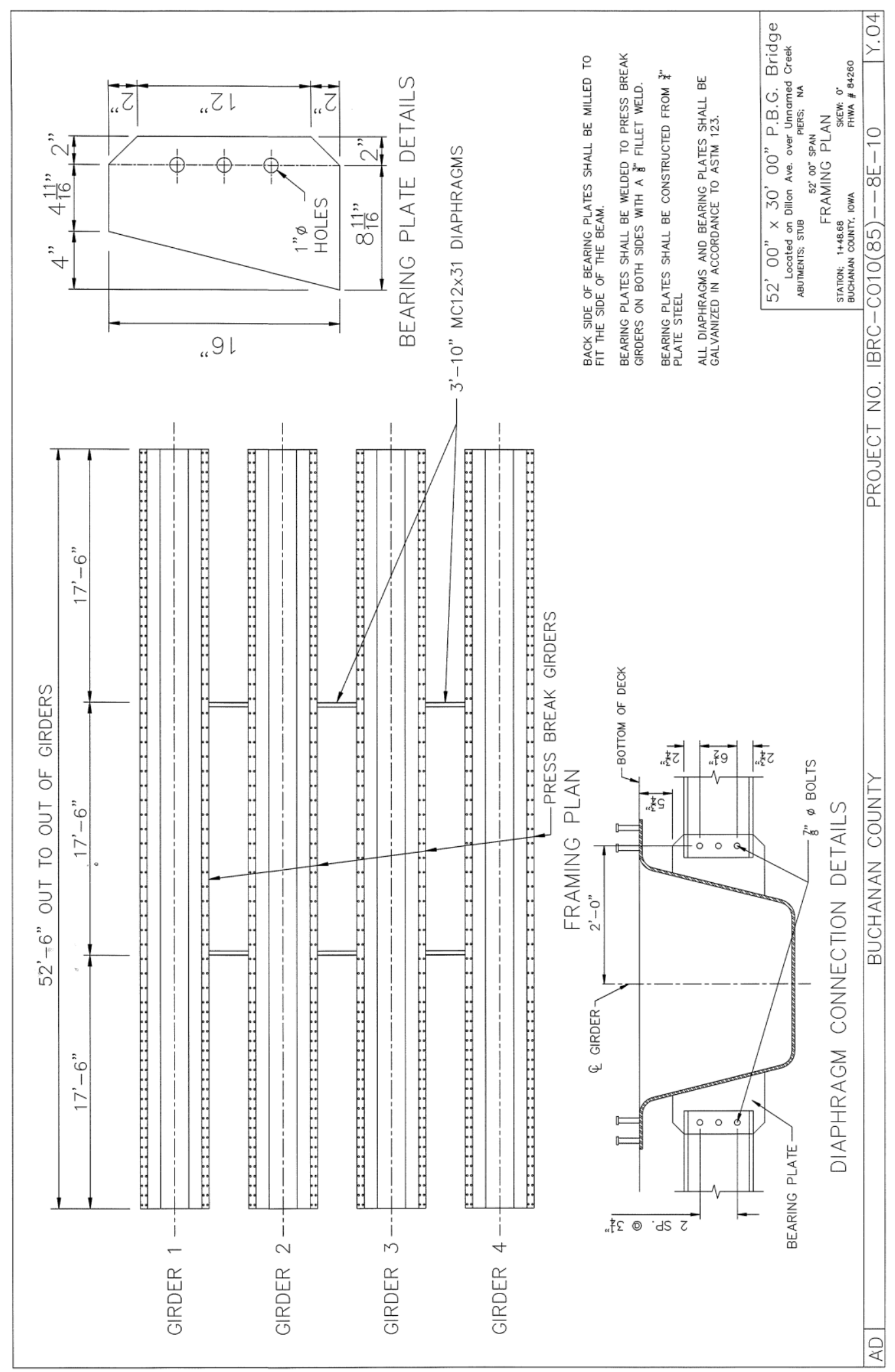




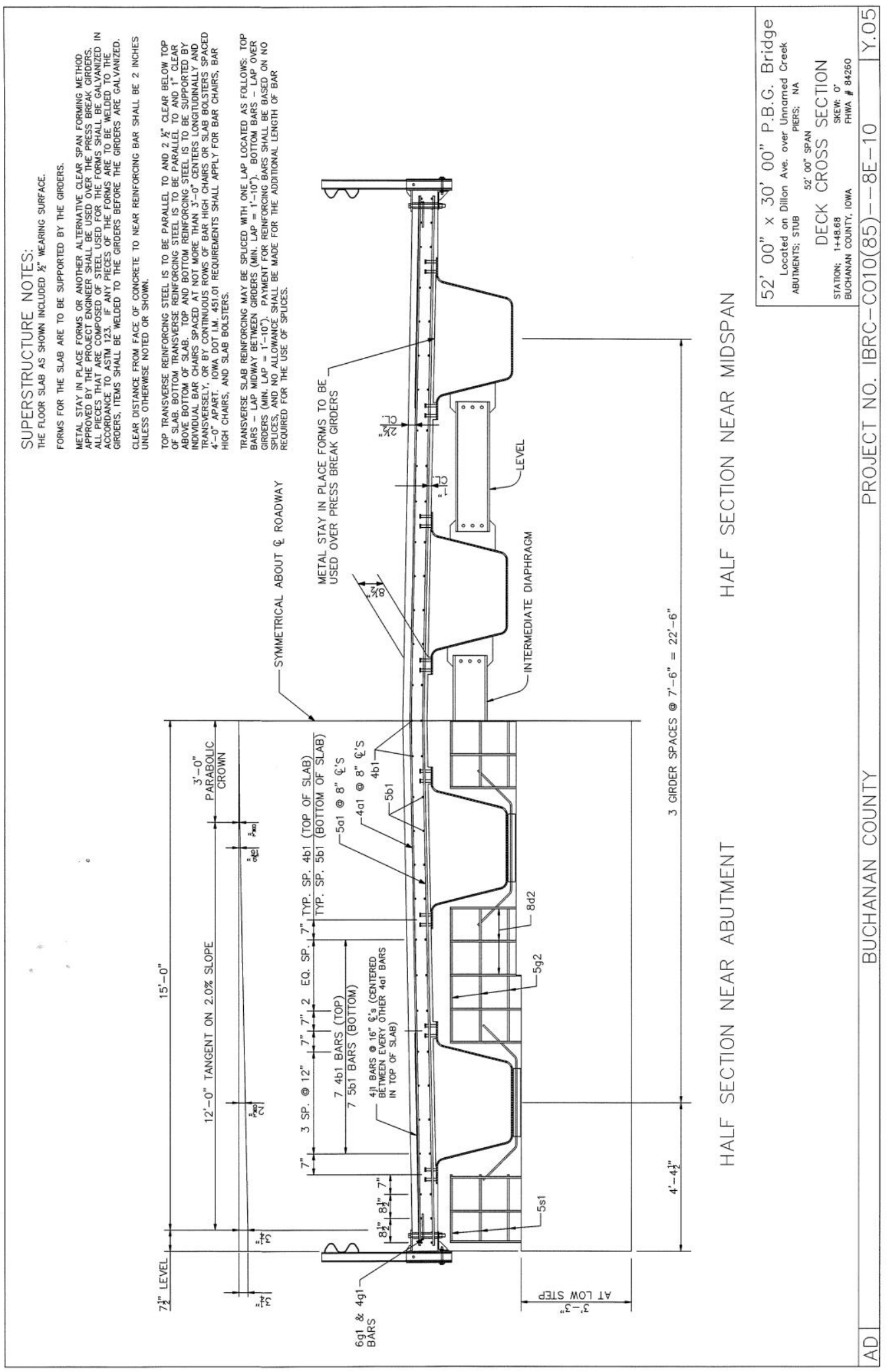




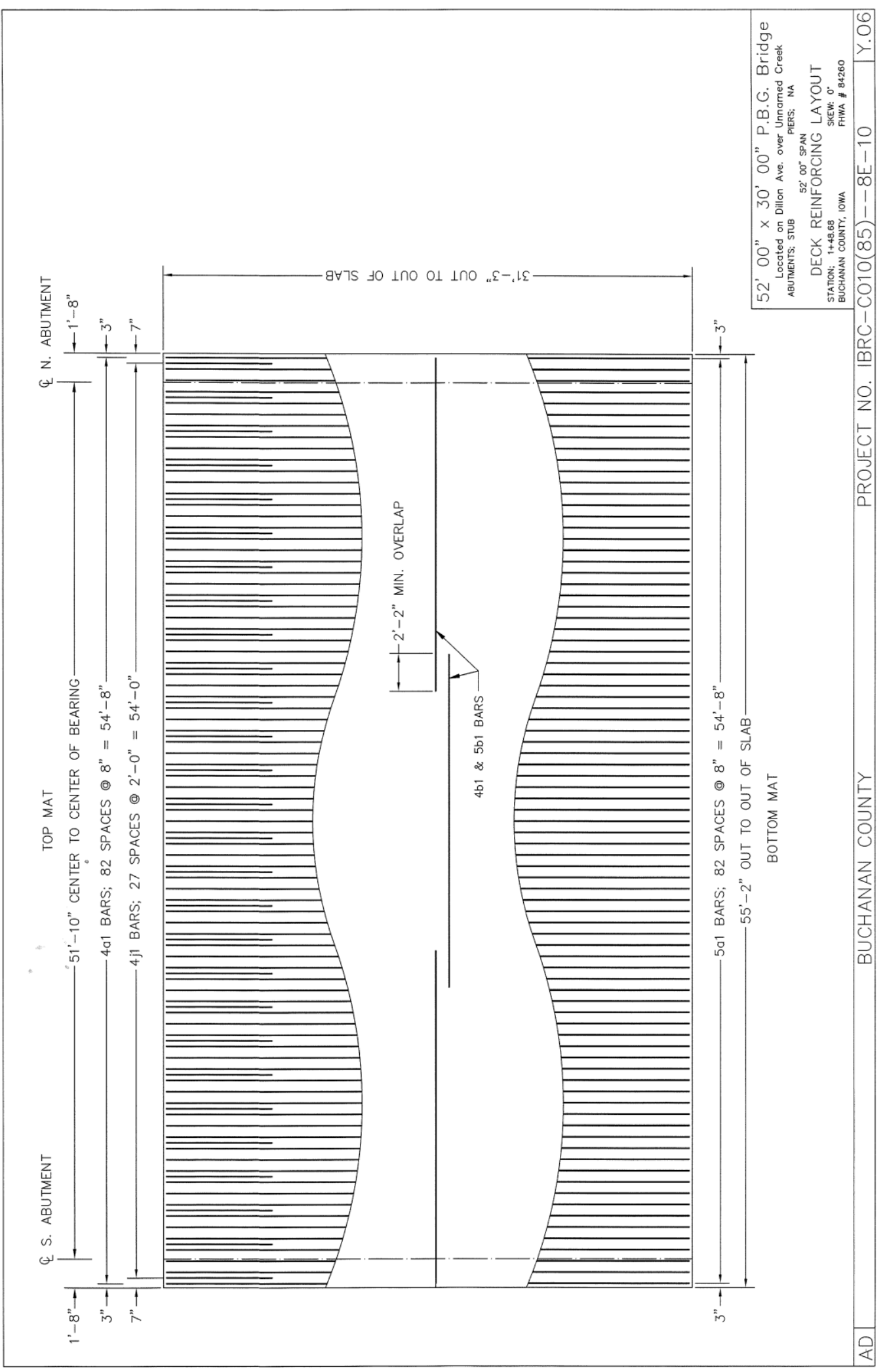




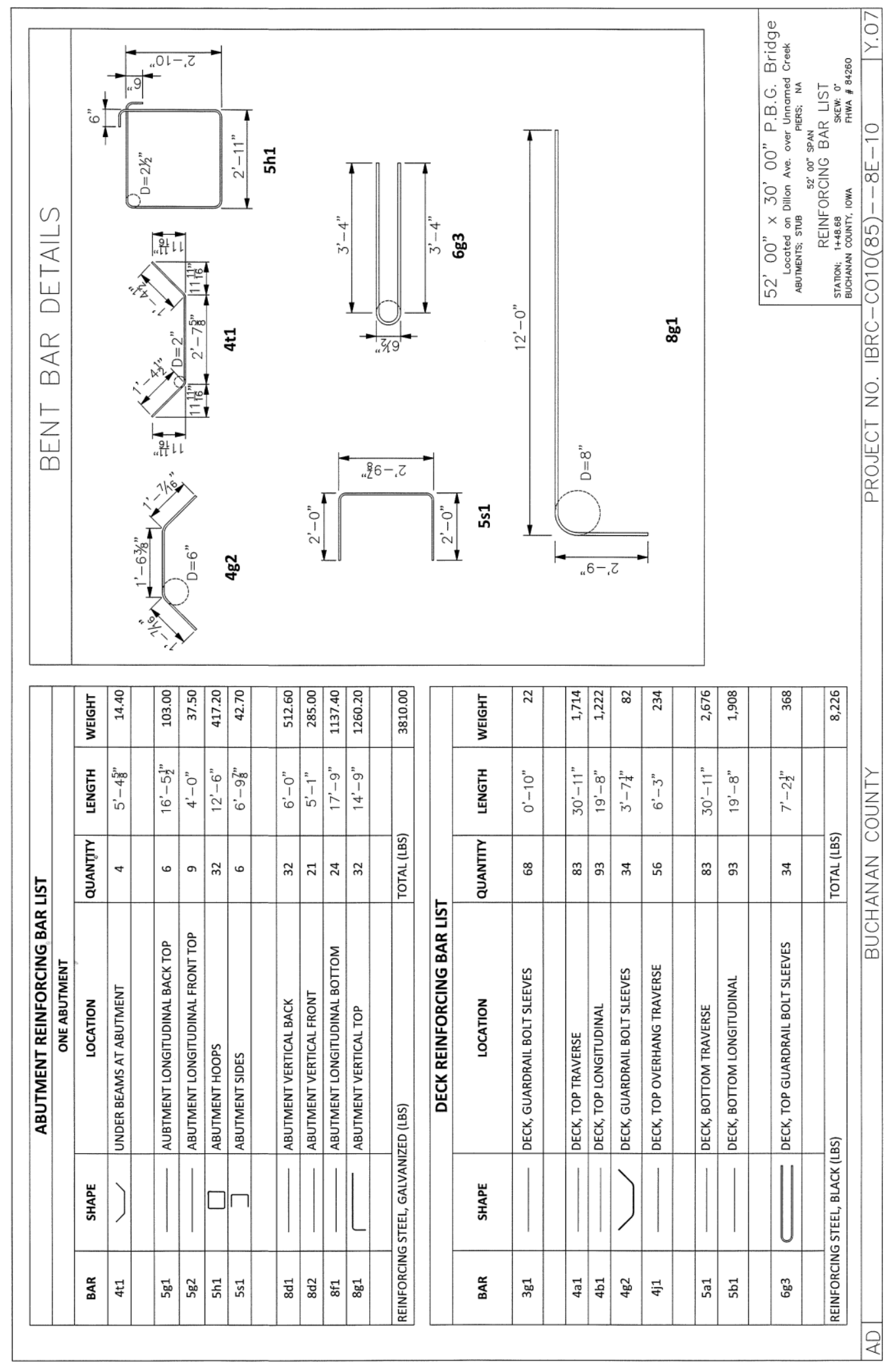




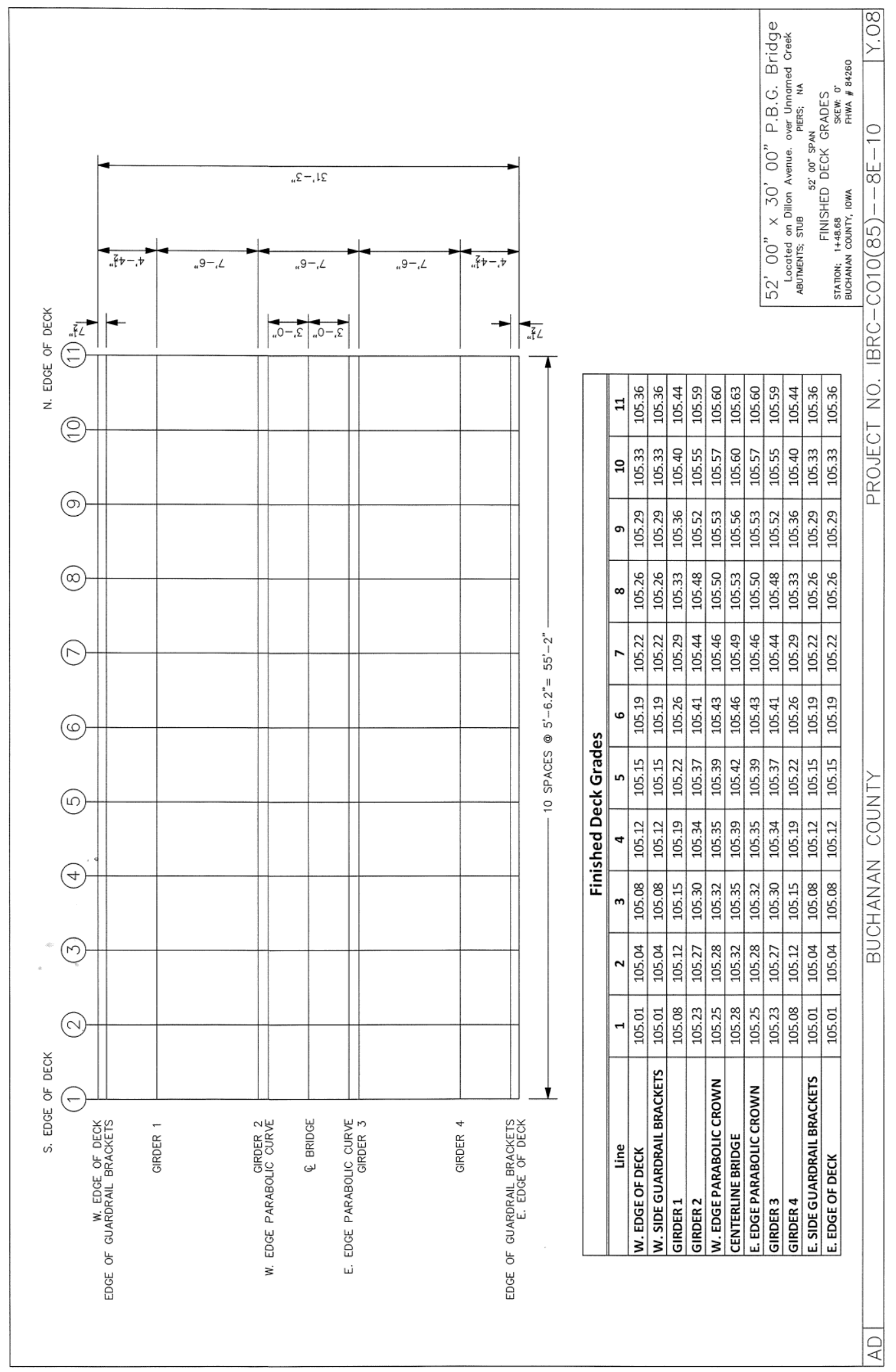




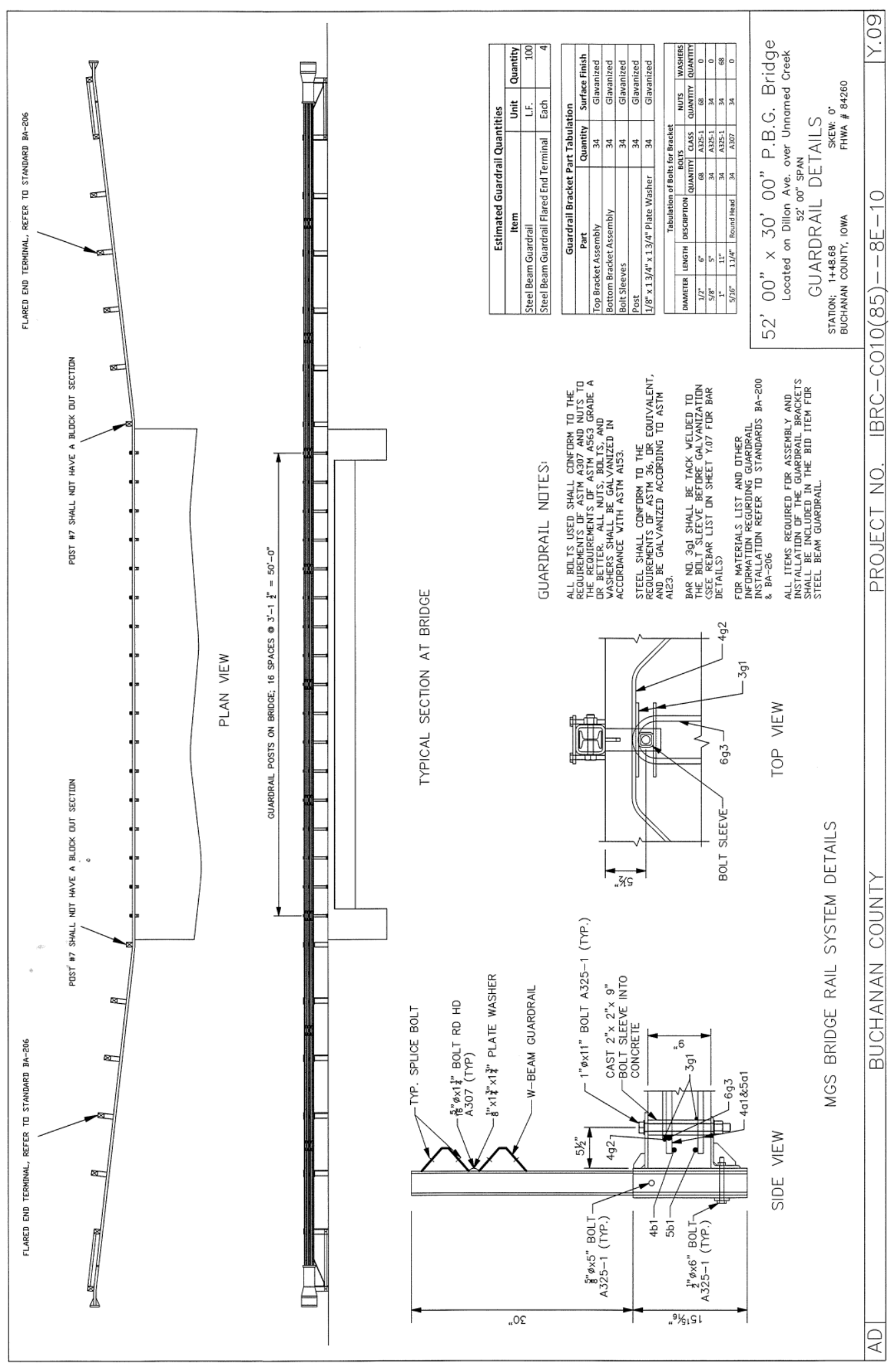




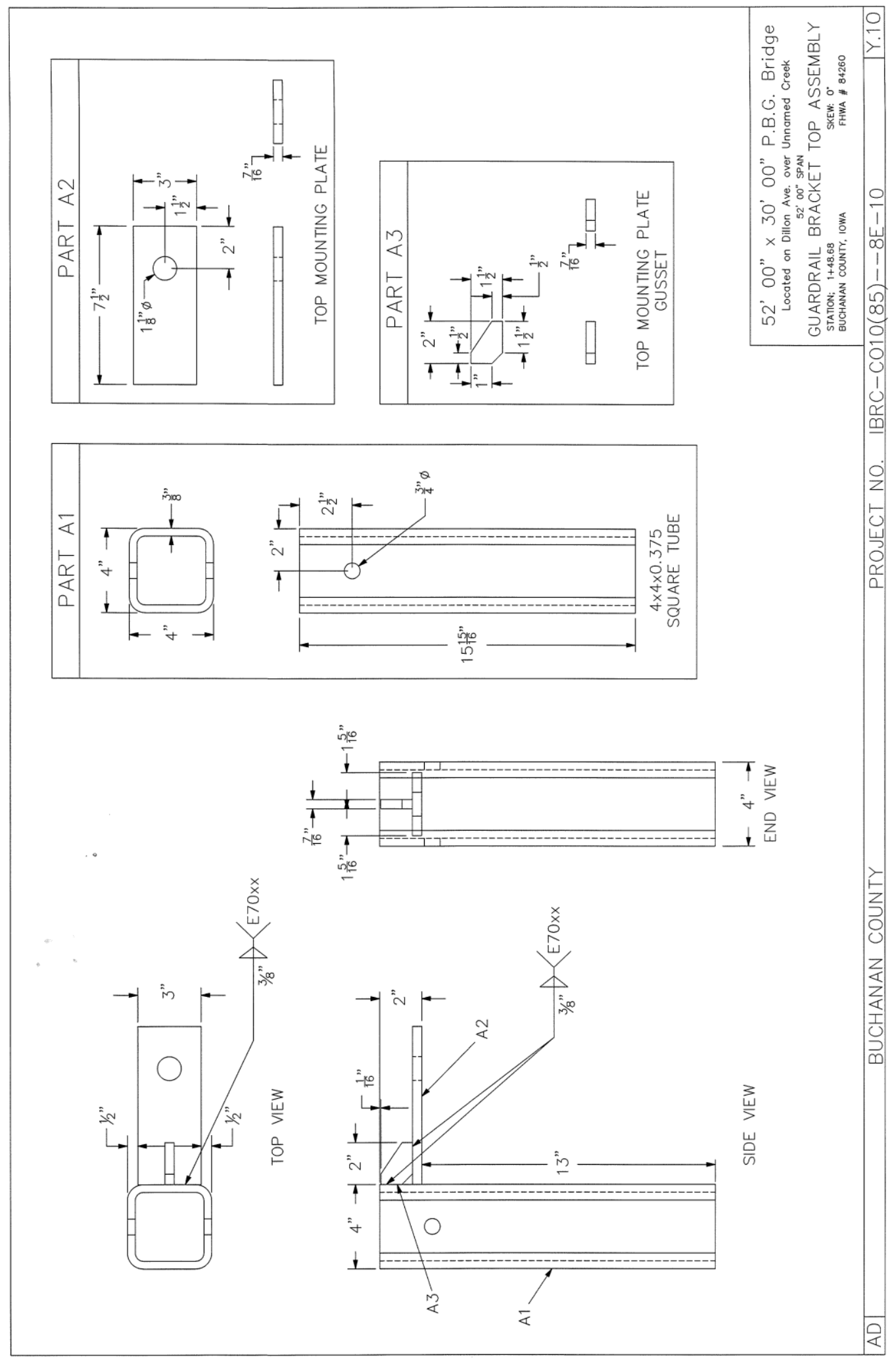




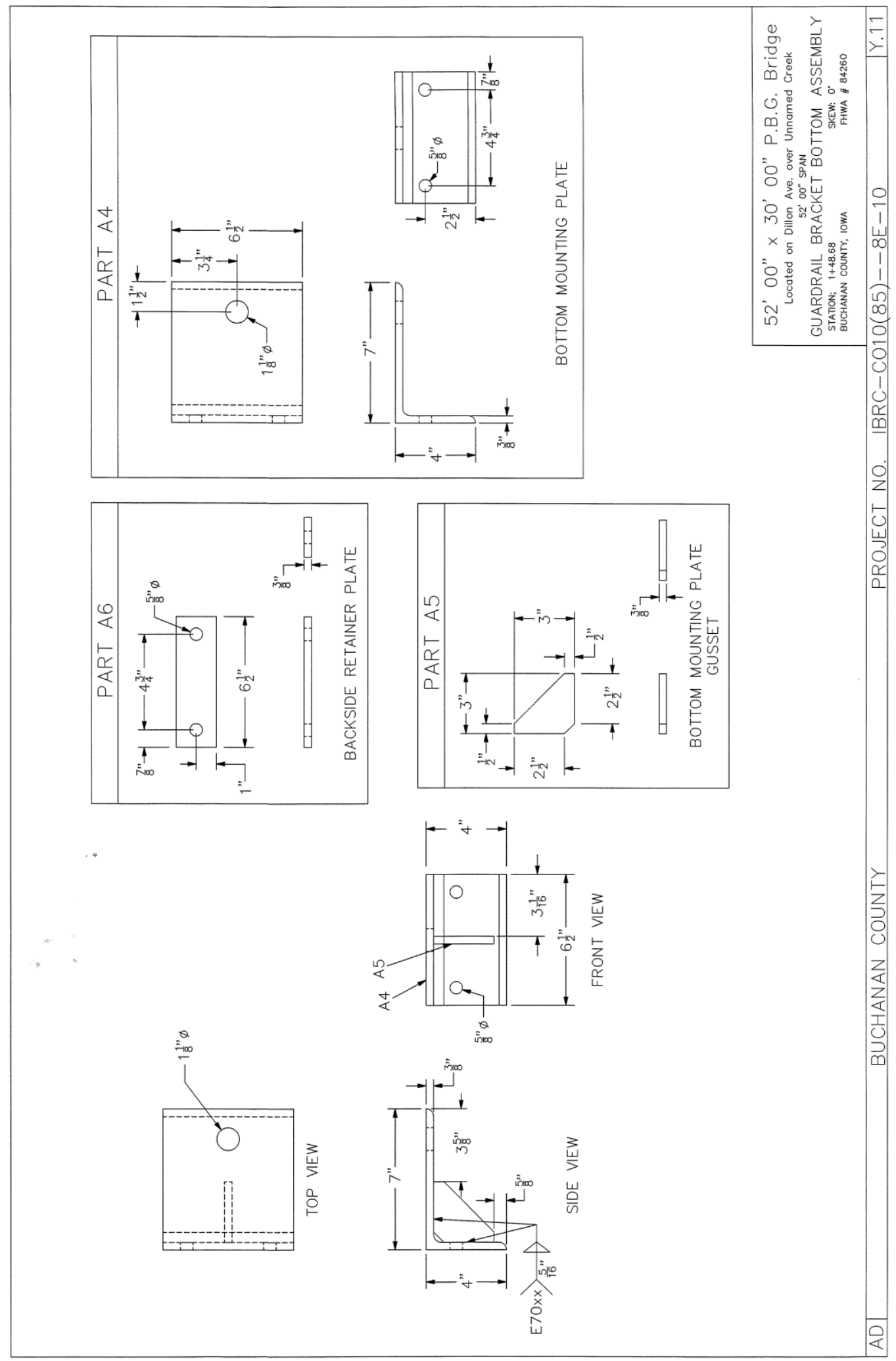




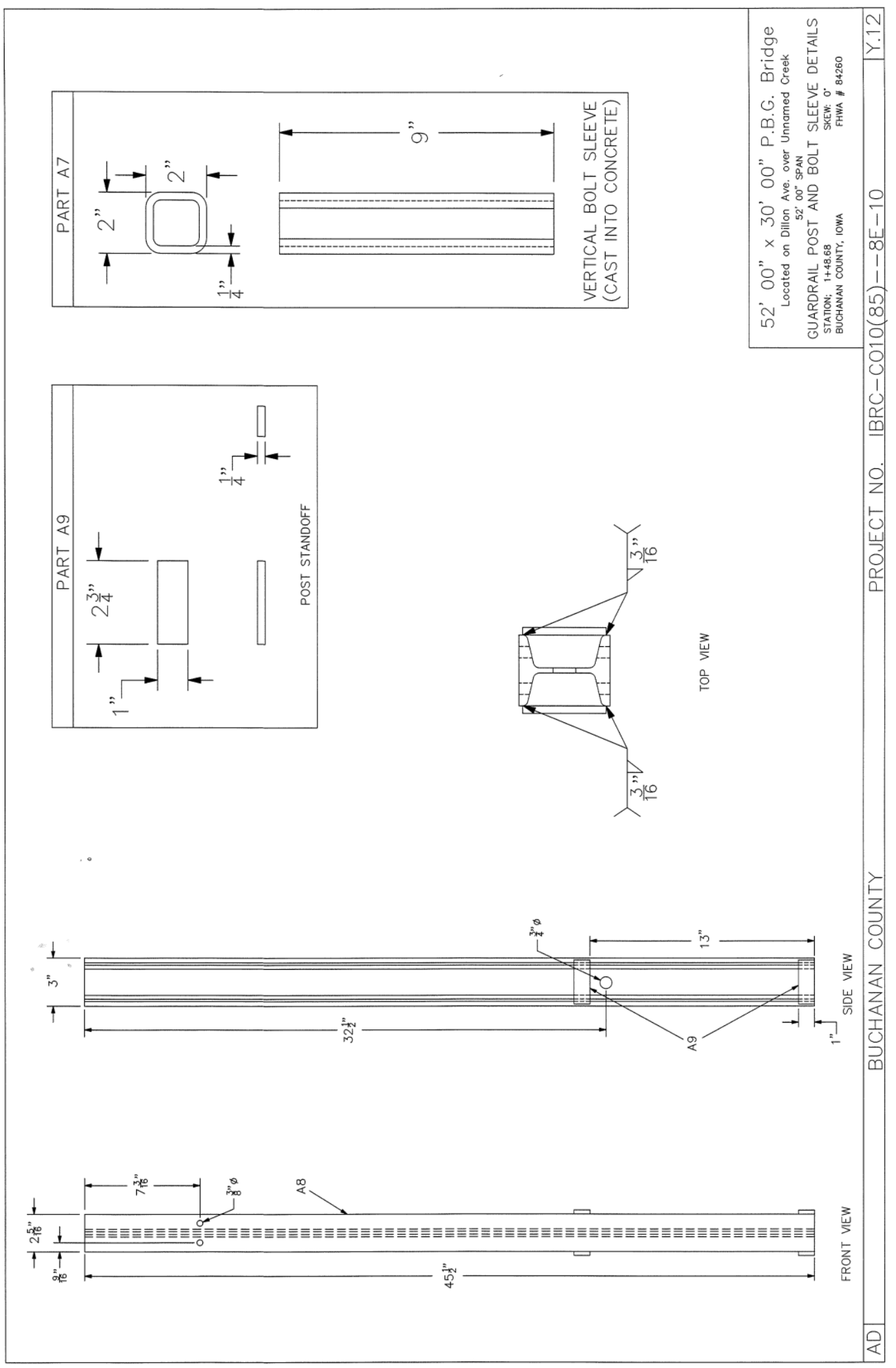

